


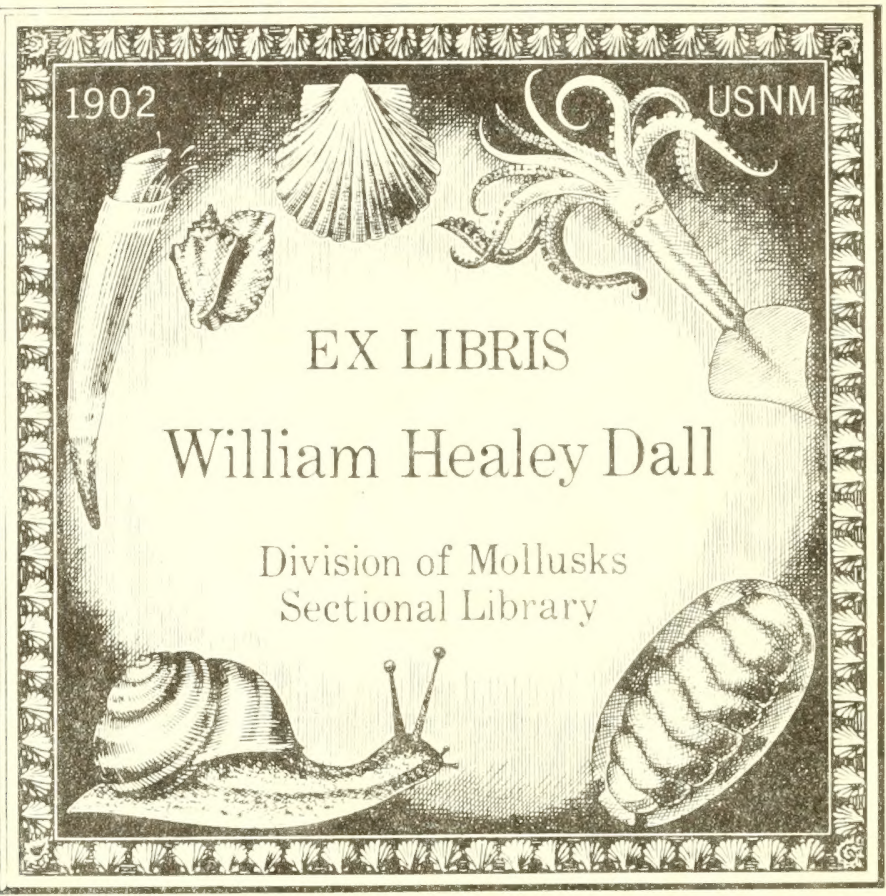

3

I LISTER 


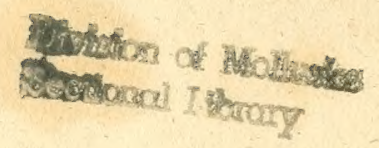




$$
\text { g }
$$




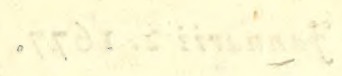

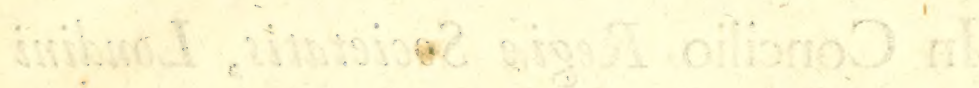

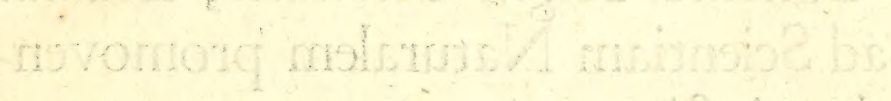

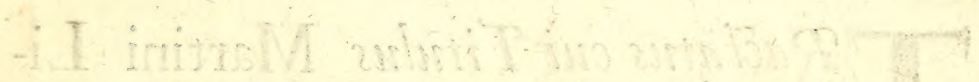

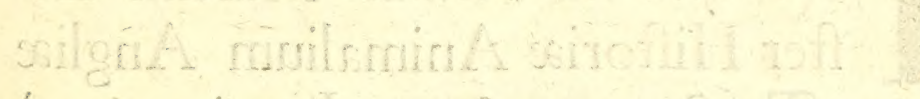

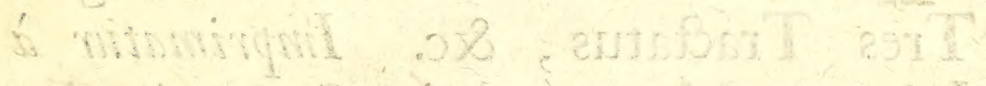

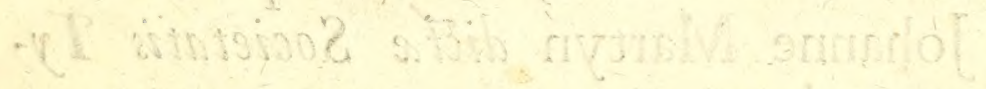

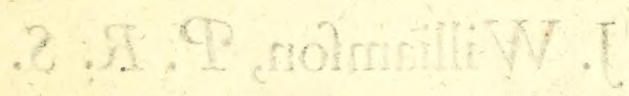


Fanuarii 2. 1677 .

In Concilio Regie Secietatis, Londini ad Scientiam Naturalem promovendam inftituta.

TRactatus cui Titulus Martini Lifter Hiftoriæ Animalium Angliæ Tres Tractatus, \&c. Imprimatur à Johanne Martyn dicte Societatis $\mathcal{T}_{\boldsymbol{y}}$ pograpbo.

J. Williamfon, P. R. $S$. 


\section{MARTINI LISTER $E$}

SOCIETATE REGIA LO $\mathcal{X} I \mathcal{X} I$

$H I S T O R I A$

A N I M A L I U M A NGLI E TRES TRACTATUS.

\section{UNUS DE}
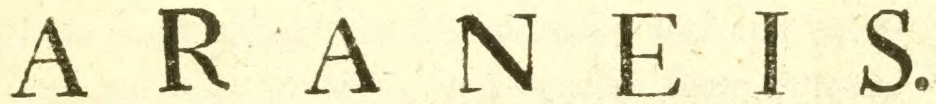

\section{A L TER DE}

$\mathrm{COCHLEIS}$

Tum Terreftribus tum Fluviatilibus。 TERTIUS DE

COCHLEIS MARINIS.

Quibus adjectus eft Quartus de Lapidibus ejufdem Infule ad cochlearum quandam imaginem figuratis.

\section{Memorice Rationi.}

\section{O NDINI,}

Apud fob. Martyn Regix Societatis Typographum, ad infigne Campanx in Commeterio D. Pauli, 1678 . 


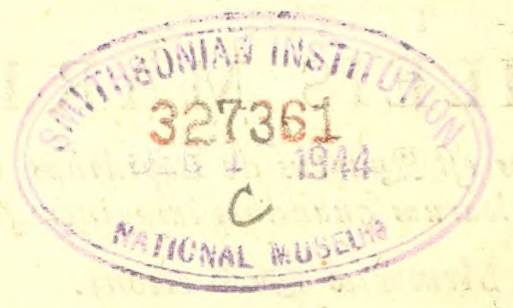




\section{LECTORI S.}

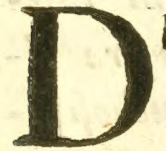

Ecenwium eft, ex quo plurima noftre In $u$. la Infecta defcripfi ; atq; ex is cume Ara neos, quấferè nunc funt metbodo, dispofuiffem, eorum fpecimen non ita din pôft publici juris feci. At nè animi quidem imperum in bas res celabo: etenim, cum olim otio idoneo fruebar, in agrum Lincolnien fem me contuli; ubi non boras tantùm, aut dies aliquot, fed $m$ nes benè multos in barum minutarum beftiolarum inveftigatione totus impendi. Harum autem defcriptiones per proximam byemem recenfui. Cйm verò Araneo. rum genus of Specierum numero, or vita ratione pra cateris infigne mibi vifum eft, illud inprimis felegi; or quantum per negotia liceret, in bunc u $q$; diem $\int u b i n d e$ aliquid novi adjiciendo adauxi. Reliquas autem Notas ferè neglexi, univerfo Cocblearum genere excepto; quod in eandem methodum fimiliter compegi, at $q$; illi fubjungendum effe putavi, ut fimul ederentur. Atq; bac quidem de Operis origine.

Illud autem in boc Opufculo pracipue infti$A$ 2

tui ; 


\section{Ad Lectorem.}

tui; nimirum fingulorum Generum Baftioles, quàm accuratiffimè in pecies diducere; cujus illa cerie fingularis utilitas effe poffet; ut, fi que in pofterum praclara experimenta de bis Animalibus aliorum induftria confecerit, ea tutò buc referri poffint, fuífq; quxq; locis rectè di/ponantur. Mibi interea illud fatis Supérg; eft, ea primum noftra Animalia feculo indicâfse rerum Naturce ftudiofiffemo. Qui verò fimile opus aggreffe fuerint, ii tandem intelligant, quantum fudavimus, réfq; adeo minutas, vel extremầ lineà ceriò cognofcere, effe aliquid.

Cùm antem pleraq;, quxe bîc babentur, ad fi$\operatorname{dem}$ ferisûs referri po flint, in id maximè incubui, nè ip $\int e$ primium deceptus, pafteros in errorem ducerem. Summam fanè diligentiam adbibui, ut veras $\int p e c i e s$ diftinguendo, non multiplicando citra neceffitatem, fingulas, minutiffrmis licèt, fidifflmis tamen Obfervationibus, qua ad animaliums mores vitámq; JpeEtarent, exornarem.

Alicui fortè in Defcriptionibus nimius effe videbor; nam reliquas Notas quod attinet, ece in fingulis fpeciebus omninò proprix er peculiares funt. At ea fateor wulto plira fuerunt, quàm nunc funt; fiquidem multa à me prasifa dor repurgata funt : que verò fuperfunt, non utiq; videntur omittenda, ant Supervacua. 


\section{Ad Lectorem}

Scribendi autem rationem quod attinet, fcire licet, eam ipfis rebus non extrinfecam effe Go arbitrariam, jed à propriis earum naturis de fumptam, iíf $q$; maximè convenientem, atq; adeò memorix rationíq; fummopere utilem.

Praterea illud de Araneis monere debemus, univer $\int a s \int c$. defcriptiones ad fominarum Exemplaria factas effe. Nam Go ba multo Sapius occur. runt, quàm mares; 0 in bis not c characterisfica, ob fummam pictura elegantiam, maximè illuftrantur.

Rurfus omnium ferè Animalium figuras coram me delineandes curavi; ut optiwns artifex, non frim tantüm conceptum, ut fieri Soler, exprimeret; fed, quò faciliks acciperet, que uniufcujufq; Jpeciei maximè depingenda eßent Nota, eas primùme digito indicavi. Nam in bis hominibus, que aliàs laudabilis, nunc nè concedenda quidem licentia eft; fiquidem non bîc quid in poftutu, aut animalis figura jucundius; fed quid ei vivo fimillimum fit, ô quo promptiòs rectiú $q$; à reliquis difcriminetur, pracipuè defideratur. Id quod ma. xima ex parte preftitum effe confido. Aliquot, $f_{a-}$ teor, ơ me malè babet, è multis PiEture defunt; quòd ipfa animalia, cùm Pictor mecum adfuit, babere non potui : at ee admodum pamce fune, $f c_{0}$ afterifcis in Tabulà notatce.

Poffremd, 


\section{Ad Lectorem.}

Poftremo, etiamfi libri Titulus Araneos Coch. leáfq: Anglice ferat, nolo tamen aliquis exiftimet, aut borum generum Beftiolas omnes noftras omnino ane conforipfiffe, ant illas effe noftras tantum, atq; buic Infule peculiares, ac fi non alibi terrarum inveniantur, Illud tamen audacter affirmo, neminem apud nos ullam novam fpeciem à me non. defcriptam temerè invenire poße: quot verò diligentiam noftram effugerint, alii videant. Item illud alierum propriis ip $\int e$ oculis aliqua ex parte didici, ex noftris $f c$. beftiolis aliquas fpecies cum tranfmarinis Europeis communes eße; imò nullus dubito, quin bonam etiam partem bujus generis animalium totius Europæ comprebendat Atq; ea Latinè evulgari idcisco volui. 


\section{ARANEORUM ANGLIE}

L I B. I.

\section{De Araneis in genere.}

\section{CAP. I.}

\section{De Araneorum paribus tum externis tum internis.}

1.

Elis, ab ipfo ore procedentibus, univerfi tol

Aranei donantur; at ea duorum, ficut ipfi aranei, generum funt: vel enim ex duobus fpiculis in modum forcipis hamatis conftant, ut omnibus Otonoculis ;

vel ex duobus brachiis forcipatis, five in binos digitos diductis, more Cancrorum marinorum, ut Binoculis : $\mathrm{ab}$ illis verò ictus venenatus \& perniciofus, quòd iis tela admodum tenuia \& angufta fint, \& quæ facillimè in corpus penetrent \& altè infideant; $a b$ his fortè innocuus morfus, quòd ea obtufa \& vix ad ictum inferendum nata.

Eorum autem, cujufcunq; generis fint, fubftantia fere cruftacea \& fragilis eft.

Maribus binoculorum Tela in acuta genicula eminent.

Utriufq; generis maribus Tela \& majora \& validiora funt, duplicemq; is ufum præftant, ad vim inferendam. ut in arripiendis \& occidendis Mufcis, aut illatam vim re. pellendam ulcifcendámve. 
corrickls.

2. Item univerfis Araneis binæ Antennæ five Cornicula funt; hæc proximè fupra Tela capiti inferta; hæc, perinde ut pedes, è quibufdam juncturis conitant.

In forminis Octonoculis \& utriuff̧; fexûs Binoculis ferè xquali craflitie funt; in maribus verò Octonoculis ea extrema velut quibufdam capitulis five nodis turgent: in maribus autem Phalangiis iidem nodi latiores \& magis depreffi.

In univerfis certè ad blandè palpandum data; an verò alius corum ufus fit, me non fatis perficere fateor. Vt uterq; Penis fit, vcl è quo penis exeritur in maribus Octonoculis, \& alternatim in coitu adhibitus, aliquando $\mathrm{cx}$ iftimavi; an recè id quidem, alii mecum videant.

3. Ipfun a. Caput nullâ incifurâ ab humeris pectoréve difcernitur; in pleriff; verò Octonoculis ipfis humeris inferitur in modum literx Romanx $\mathrm{V}$, cujus bafis frontem indicat.

bouli. 4. Oculorum, magnitudinem quod attinet, multiplex differentia eft ; at his numerus tantùm vel octonarius vel binarius, an fenarius in ullo inveniatur, multùm dubito; certè in Phalangiis id minimè verum eft.

In nonnullis omnes oculi æqualis magnitudinis funt; in aliis in tripliçem ferè diducuntur.

Eorum etiam fitus maximè diverfus eft, ut aliam atof; aliam figuram conftituant.

Item his color non unus; qui tamen ferè niger, interdum purpurafcens, rufefcens aut viridis.

Horum antem ufus non ad predam tantùm commodiùs difcernendam, fed in reticulis etiam conficiendis infignis eft.

7omiless

5. Octo pedes pectori inferuntur; horum verò longitudinem quod fpectat, multiplex varictas, neq; in hâc re cedunt oculis, Nam ex his alii priores pedes, alii noftremos, alii fecundos longifimos habent: deinde in aliis pri- 


\section{Pe Araneis in gerere.}

mi \& poftremi quatuor intermedios; in aliis quatuor primi totidem pofteriores longitudine fuperant: rurfus in nonnullis alternatim difponuntur, ut fecundi primos, \& quarti tertios excedant. Quorfum hæc inquics? refpondeo, eadem Mufcas \& reliqua infecta capiendi neceffitas pre vicuu, in varios modos Naturam coëgit.

r. mnibus araneis internodia terna in cruribus.

"6. Alvus notabili incifurâ à pectore dividitur; neq; id Alvuss

tamen perpetuum eft: nam binoculi aranei excipiendi funt; quorum corpus integrum effe videtur.

At alvi figura fupra omnia accidentia in maximam vavietatem difcriminatur; ejúfq; pictura innarrabili ele. gantiâ delineatur.

7. Ani appendices non oblivifcendx; qua an Fiftulx Ani apgexdiceres fint ad multorum filorum fimplicium fimul commodiorem emiffionem, vel ad Telarum tantum artificium, (nam huc illuc, dum ab ano deducitur, iis impulfum rectúmq; vidimus) an ad utrumg; conducant, adhuc incertus fum.

8. Alii aranei ferè glabri funt, alii pilis contecti : alii pili. cutem molliorem, alii ferè cruftaceam habent.

Atq; hæe hactenus de partibus Araneorum externis: quæ verò fit partium internarum configuratio, ut certò explicem, animalium extrema parvitas prohibet.

9. Nonnulla autem conjecturalia proponam: ut de U- Vternse tero, qui vel unicâ cellâ conftare imaginandus eft, in his f. gui femel ova fua cuncta pariunt; aut in duas pluréfve cellulas diftingui, quibus fc. partus mulkiplex \& tempore inæqualis eft; duófq́; pluréfve Folliculos ovis repletos fubinde conficientibus.

Ic. Item Inteftina non fimiliter in omnibus configurar : Intefinta nam alia exiftimanda funt in Octonoculic, quibus fc. excrementa liquida, \& aila in Binoculis, quibus eadem figurata \& dura funt; fiquidem idem litriufq; generis araneis ferè promifcuum victûs genus è mufis alinfog; infectis.

$$
\mathrm{B}_{2} \text { II. Porrè }
$$


Fili concepiso sulwm.

11. Porrò Fili conceptaculum in aliquibus deeffe videtur, ut in Binoculis: in Octonoculis verò vel duplex eft, vel datur etiam filum uterinum. Nam à multis araneis duplex filum, \& colore \& aliis accidentibus planè diftinctum, procedit; huic autem polteriori fententix illud fidem facit, quod ferè circa partum hoc alterum prodit obfervandum.

De iis autem vifceribus, qux in Pectore infunt siè furpicandi quidem locus datur.

\section{C.A P. II. \\ De generatione Araneornm:}

A Ranei omnes ovipari funt.

1 Coitu foecundas fieri nihil dubii eft; fiquidem fuus cuiq; fœeminæ mas fub partûs tempore adeft, vitámq; tum quafi conjugalem degunt; at id copulandi tantùm, neutiquam nidificandi, aut Araneolos nutriendi gratiâ fit. Etenim Coitu peracto difcedit mas, nec unquam aut certè admodum rarò poftea confpicitur cum fominâ; etfí multiplicem quidem partum ex certis \& non brevibus intervallis illa fxpiùs per æeftatem edat.

Aranei non pariunt, donec ad juftam magnitudinem perveniant; quod ferè fit intra annum aut plurimùm biennium. Illud certè in fingulis fpecicbus fub partûs tempore obfervare licet; quòd, qui nidificant, cujufcunq; fpe. ciei fint, ferè omnes ejufdem magnitudinis funt, nec majores facilè reperiantur ufpiam.

Ferè minimi aranei pauca ova pariunt; majufculis verò admodum numerofus partus; ex his certè quibufdam poflint effe ultra mille ovß in una xitate.

Ova 


\section{De Araneis in genere.}

Ova univerfis araneis fphærica \& perfecte rotunditatis funt.

Ovis cortex mollis, membranaceus, pellucidus: intùs humor unicolor in ejufdem fpeciei araneis; at diverficolos in diverfis eoram fpeciebus ; qui etiam cis corticem apparet ; eíq; ferè albidum, interdum fubluteum; aut pallidè cæruleum, aut pallidè purpurafcentem colorem dat.

Magnitudine multùn inter fe difcrepant ova; in pallcis æquant finapi femina; in pleriff; verò ferè ad papaveris albi femina accedunt.

Ova pauca aut nulla à partu nudè \& fine omni tegmine relinquuntur: fed alia membranacei five linteoformes Folliculi includunt; aliis verò laxiora fila ad modum lanæe carminatæ circuminjiciuntur: item alia inter fe cohærent in modum pilulæ, ferè ad lupini figuram depreffx; in his verò unus ovorum ordo alteri fuperinjicitur, firmitérq; inter fe tota ovorum compages conglutinatur : alia ruptis membranis diffluunt.

Aranei ovis non incubant ; neq; enim eorum tactus, ut in pennigeris animalibus, tepifactivus eft; his extreman cutem frigefcere, more ferpentum, exiitimandum eft : ex his tamen nonnulli funt, qui affiduè eorum ovis inhærent, aut aliàs fecum ea geftant; fed ea fretûs cura, non fotus aut incubatio eft.

Tempus ab ovorum partu ad araneolorum exclufionem in plerifq; ad vigefimum primum diem extenditur: id tamen non eft perpetuum : nam ex his funt, qui ad Septembrem menfem parti, per brumam ad primum ufq; ver, \& in aliis nonnullis paulo tardiùs, in ovis permanent. Verùm in his pofterioribus non fatis conftat, quot diebus or pus fit, à maturationis mome.to ad fretum edendum; an pluribus, vel totidem tantùm, quot jam numeravimus : mihi fanè durum eft exiltimare, ova per tot menfes conrinenter maturefcere. 
* mis.anitr: Ut autem ipfa Ova vermiculi fint, ut vult Ariftoteles *; the $\{, 2 \%$ aut ipfi araneoli intù aliquando fint in ovis in formâ vermiculorum, minùs verifimile eft : ex ovis certè ii integri eduntur, \& in fingulis membris fibi fimiles.

\section{A P. III. \\ De Fili nainu, ejufq; entittendi ratione.}

Raneis proprium eft, etiam ftatim ac nati, filum ab A ano emittere: at non omnibus; nam de Binoculis id ita effe nondum mihi certò conftat: id autem affirmare videtur Mouffetus nofter ; \& mihi levis furpicio eft, quòd in fætus curâ ita effe poffit: illud tamen maximè obftat, ipfos binoculos nullâ injuriâ excitari poffe, ut filum oftendant, perinde ut fit in octonoculis omnibus.

Mares quoq; non aliter quàm fœeminæ, licèt id multo rariuss, \& fila projiciunt \& interdum reticula texunt.

Fila autem emittendi ratio veteribus ferè incognita oft; \& à me, quantùm fcio, primùm obfervata, \& ante aliquot * ..65. . . 103. annos Anglicè evulgata eft in * Tranfactionibus Philofophicis dictis Clariflimi Dni oldenburgh. Illud tamen non filendum duxi, efle apud ipfum Ariftotelem non leve hujus rei indicium, quod tamen adeò obfcurum eft, ut id muitos etiam doctiffimos interpretes non parùm excrcue* Hil, Anval. rit. Verba ejus hæc funt, * "Aranei ftatim clim editi 6i. "sp. "funt, fila mittunt, non intrinfecìs tanquam excremen" tum, ut Democritus ait; fed extrinfecus de fuo corpore, "vcluti corticem, aut more corum, qux villos fuos eja-

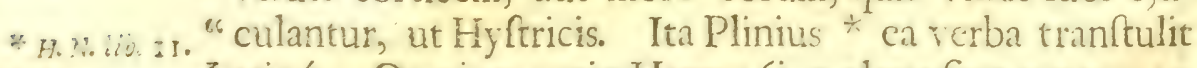
66. 24. Latiné. Operis materiæ Uterus (i. c. alsus five venter, ut rectè F. Redi) aranci fufficit: five id ira comunta alvi na- 


\section{De Argheis in genere.}

tura ftato tempore, ut Democrito placet, five eft quædam intùs lanigera fertilitas. Ut alios multos interpretes recentiores umittam, fic nuper F. Redi in hunc locum. "Erravit Ariftoteles contradicens fupientifimo Democri"to, cùm in eâ opinione fuit, Arancos telam fuam non "deducere ex partibus Uteri internis, fed extemis totius "corporis, ac fi materia fili lanugo quxdam cliet, corporis "exteriora per modum corticis ambiens.

Quicquid fit, licèt hæc verbat vald̀ obfcura fint, fi de loco aut fili materia interpretentur; in is tamen flum mittendi modum rectè explicuiffe videtur fummus Philofophus, Nam aranei quidem fila fua non aliter, quàm Hyftrica villos de fuo corpore vi quâdam ejaculantur : in co differunt, quòd cùm illi $a b$ hyltricis corpore omnino foluti è longinquo ferantur; araneorum fila, etiamfi longifinia emiffa, adhuc tamen intra ipfius beftiolx anum adhærent, lit radii ad folem. Atq; ad eundem modum non tantüm araneoli; fed omnes omnium ætatum, fpecierum, certè ex octonoculis, \& fexûs fila emittunt.

At non unum tantìm \& fimplex filum, ut ante nos expofitum eft, $a b$ ano emittunt ; fed fapiùs plurima fimplicia fila fimul ejaculantur, velut totidem micantes radios ad Cometæ caudam. An ipfius ani Appendices in aliquibus araneis, velut Tubuli, huic multiplici filo aliquid faciant, aliàs videndum eft.

Filum autem quodq; fingulare omni ferè pilo tenuius \& exilius eft : illud tamen non fimplex \& planum, fed ramofum \& carminatum effe vult P. Blancanus apud F. Redi. Fortè multiplex filum pro ramofo fumplit : mihi certè unumquodq; filum \& lreve \& terfum videtur.

Filorum una contimuitas $\in$ ft, five ea ejaculatione frontè emittant, five vi \& $x$ nolente animali manu educantur. Ea antem modò abrumpunt ipfi aranei, modò in exiguos glomerulos niveos, prioribus fc. pedibus celeriter fupra ca- 
put circumactis, recolligunc. A priore illâ ratione penè in finita illa filorum fimplicium multitudo, ubiq; per terram fparforum, oritur.

Sed quod omnem fidem fuperat; $\&$ de quo omnino nul. la mentio apud antiquos aut recentiores eft, Araneolos, aut mediæ certè ætatis \& magnitudinis, nam adultos in aëre me nunquam obfervâffe memini, fili auxilio fe committere leni auræ, afcenfúmq; in aërem pérq; fummas nubes moliri: Illud certè veriffimum eft, eas longè extra confpectum meum evectos fuiffe, etiamfi fupra celfifimam Turrem aliquoties de induftria contemplarer.

Ad Octobrem verò menfem hanc exercitationem maximè frequentant; quanvìs per totum annum,etiam mediâ brumâ, fi quando per id tempus fol clarè fplendefcat, \& tranquillus aër fit, hujus quidem ejaculationis non paucos effectus per agros pérq; fepes non rarò animadverti.

Item illud addam, in iftis longiffimis filis aëreis, jam in fines craffiores, fed inæquales implicatis, à longis fortaffe in aëre vectionibus, Muf́cas cafu an de induftriâ irretitas me frpiùs notâffe.

Eilorum a. validâ ejacuîatione jam cognitâ, facilè intelligemu s modum, quo aranei inter duas ex longo intervallodiftantes arbores, aut trans amnem aliquem reticula fufpendere poffint. Id quod antea quàm difficile erat explicatu : vide apud Mouffetum \& F. Redi.

Eft etiam alia non minùs admiranda Proprietas, nimirùm quòd Aranei, quæ emiferint fila, ea intùs reducere poffint: de quo vide Experimentum infrá. Itáqj his in pofterioribus duplicem dari poteftatem videtur, illi pulmonis in fanguineis animalibus, qui motu reciproco fpiritum aitrahunt \& emittunt, haud diffimilem. In quæltione vexò, ubi quæritur, an filorum materia intùs fit, veluti liquida vifci maffa, aut fli jam figurati conglomeratio? Huic quidem pofteriori fententix faveret ifta fili reciprocatio. 
At fili materiam cjúfq; Conceptaculum quod atcinet, equidem id fuccum corporis fingularem effe exiftimo, fuóq ; ferè proprio vafe contineri, ut in Erucis.

Filum a. ex aqua communi coctum, non liquercit; ut, ne igne quidem, fi torreatur. Flammam non concipit; fed gummi inftar glutinofam retinet naturam.

Fila quidem recenter educta vifcida effe videntur,aut certè vif́ido quodam humore infici; an verò denuò illinantur, ut vult Moufetus nofter, dubito. Fllud quidem rectè expofuit, eorum materiam effe lentam, glutinofam, fequacem; nec ficcitate nec humore ea tenacitatem fuam amittere.

Filo autem non unus color; ferè aëreus \& pellucidus, quo facilius incautæ Mufcæ fallantur; eft etiam ei fubpurpureus, fubcæruleus, fubviridis. Neq; verò fili una natura eft ; nam quod molle eft, quod afperum, quod tenue, quod craffius vidi : idq; quod magis miror, ab eodem aranco fub partûs tempore; an ideo alterum ab utero, alterum è proprio Conceptaculo exeat; aut idem humor in diverfis partibus ejufdem Ductûs alium atq; alium colorem \& naturam obtineat ?

De diversâ Textrinæ ratione aliàs infrà fufiùs acturi fumus; neq; ut hîc ea jam memorem, opus eft. Illud tantùm reprehendendum eft in Moufeto aliifq; ubi afferit, Araneolım quemq; nendi \& texendi rationem à parentibus edoccri, \& cum ætate peritiam acquirere majorem. Cùm hæc pedum fatalis fcientia, hic naturalis inftinctus fit, nihil dubii eft. Certè donec cum matre in nido permanent, nihil texunt; \& præter victum nihil curant aut animadvertunt.

Araneolos è nido defumptos fila emittere verum eft, precipuè fi quâ injuriâ laceffantur: at id non reticuli conficiendi causâ, fed ut efingiant, ficri confuevit.

Illud auten perpetumin eft, Araneolorum retia xque 
degantia atq; natu majorum five adultorum, unoq; codemq's ipfiffimo artificio \& formâ confici per fingulas omnium ætatum fpecies. In eo verò difcrimen, quod fortè Moufeto impofuit, $a b$ araneis parvis parva reticula fieri, à fenioribus \& majoribus ampliora, atq; ita fecundùm corporis incrementum, retia quibullibet proportionari. At hoc verum eft tantùm de ejufdem fpeciei araneis; nam funt ¿̀ mediocribus, quibus retia longè ampliora funt, quàrn è majufculis ulli.

\section{A P. IV. \\ De Vernationem exuendi rations.}

CEnectutem exuere araneos omnes Antiqui prodide. 1) runt, \& noftra obfervatio abundè teftatur. An verò id foli octonoculi faciant, aut etiam binoculi, mibi nondum fatis conftat.

Illam verò quotannis fxpiùs, immo fingulis menfibus, fri benè pafti fuerint, exuere, ut Moufetus nofter perhibet, minùs verifimile eft : fiquidem his eadem ratio effe videtur in fenectute exuendâ, atq; avibus in plumis aut quadrupedibusin pilis \& cornubus: illis veròcunctis ea femel in anno cadere fatis eft.

Arancoli quidem, paucos poft dies à Nativitate, cuticulam exuunt : Et fi deinde aliam atg; aliam cuticulam, fecundùm eorum incrementum, imò eò ufq; donec ad juTtam eorum magnitudinem pervenerint, fc. intra aliquot menfes aut annum exuere putemus; ut in Erucis fieri notumeit; hoc fidem Moufeto eatenus tantùm dabit: id verò in aduitis ita fieri, haud libenter concedo. 


\section{De Araneis in genere.}

Illud autem perpetuum eft ex noltrâ obfervatione; nimirùm fub initium novi victîs vernalis unicam vernationem in fingulis Telis reperire licere; \& fi per plures menfes in eâdem Telâ permaneant, quod plerifu; fpeciebus mori eft, vix \& ne vix quidem fecundam invenies.

Integram cuticulam exuunt, etiam Telis non exceptis, quæ ferè cruftacea funt, ut jam dictum eft; per pectus au. tem ea finditur, fed quo ufq, attendendum.

Omnes Cuticulas, quas per totam vitam exuturi funt, iis fubeffe à prima ftatim generatione, verifimillimum eft.

\section{A P. V.}

De Arneorum vidtu Co venandi ratione: ubietiam de vefpis Ichnenmonis araneormm boftibus.

Lerifq; araneis, retium certè \& telarum Textoribus, ferè promifcuus victus elt, ex omnigenis Mufcis; fía quidem corum venatio \& præda fortuita eft.

Attamen ex his etiam funt, quibus hæc, quàm illa ma gis grata eft Mufca : ideoq; loca telis frequentant, ubi id genus mufcæ facilè reperiantur. An verò Venatorii aranei, ut lupi \& phalangia, hoc vel illud mufcarum genus præcipuè infectentur, mihi nondum obfervare contigit.

Cibo fui generis utuntur, ut rectè Ariftoteles; atq; adeò poflint etiam Lacertas aliófve ferpentes interficere, ut Plinius perhibet: fed noftrorum araneorum quod $_{\text {Cio }_{2}}$ tantus animus non eft.

Illud veriffimum eft, cos quallibet mufcas occidere, non inermes \& imbelles tantùm; fed vefpas etiam \& prægrandes quafcunq; Apes, Tabanos, aliáq; infecta perniciofa, ut Scolopendras. 
Item ex his fint, qui araneorum ova depafcunt; ipfos quoq; arancos vel fii vel alterius generis arripiunt; etiam cìm lui juris funt, \& libere venantur, \& non cuftodiâ vexati.

Araneus quifq; fuo victitat labore; mas fuo, fuoq; foemina.

Solo mufcarum fucco, fi illarum cadavera rejceta infpicias, vefei videntur: fin autem corum excrementaquoq; probè examines, in is etiam particula corticum mufcasum non paucæ infunt: duriorq; crufta, communc.Mufcarum tcgumentum, in causâ ex parte efle pofiit, cur non ex toto id devorent, quod edunt. In Cancrorum certè marinorum \& Locuftarum ventriculo infecta marina integra devorata vidi; ipfre autem hæ beftiolæ, ex infectis funt; \& ad araneorumgenus quàm proximè accedunt.

Aranei nihil recondunt, quòd diu fine cibo vivere poffunt; per hyemem verò ex toto abftinent, \& ne victum quidem quærunt ; ipfiq; ut plurimùm per id tempus telis involuti conquiefcunt; at non torpidi interim, fed $x$ què agiles, ac cùm foràs prodeunt vcnatum.

Omni etiam anni tempore jejunium diutinum ferre poffint ; calidis quoq; regionibus etiam per æeftatem, non folùm cùm hyems eos necelfariò cogat. Araneos, inquit F. Redi, tàm mafculos quàm fơminas vafis vitreis excepi; longitudinem vitx fine alimento inter alia obfervavi; nonmullis à 15 Julii, quo die capti crant, in finem ufq; Januarii producentibus.

At Aranei non omnibus Mufcis (ut id obitèr hîc notèm) adeò terribiles funt; quin ex Mufcis aliqux funt, quæ ipfos etiam araneos interficiant; ut quædam Vefpæà veteribus Icloneumones dictæ; à Moufeto autem noftro credem Mufce tripiles appellantur; quod ex iis pleræq; ab ano perpetuò cxerto aculeo, inter duas appendices, vagimæ ufum preftantes, medio, infigniuntur. 


\section{De Araneżs in genere.}

Quòd auten id genus Mufcæ araneorum ova depafcunt, inq; ipfis eorum Folliculis ideo fuum fretum pariunt, in altero libro non uno fub Titulo demonfravimus. Quæ quidem obfervatio malè intellecta, Vefparum Ichneumenôn Fabulæ, apud veteres adeò decantatæ, benè locum dare potuit. De quâ re ita Ariftoteles * "Vcfpex 'Ichneumones nuncupatæ, minores quàm cæteræ funt, 7 Hill. Animat: 'Phalangia perimunt, occilaq; ferunt in parietinas, aut 'aliquid tale foramine pervium; deinde illinunt luto, atq' ' $\mathrm{ex}$ is incubando fuum procreant genus.

At araneorum Ova non tantìm id genus $V \in$ tpis victur funt, dùm in Verniculo; fed ipfi etiam aranci ab iiflem vefpis infectantur, ut rectè Ariftoteles: Quod egometnon fine fummâ admiratione \& delectatione obfervavi, a q; alii mecum recentiores viri, hujus rei idonei teftes.

Goedartius Batavus fic. * "Mufca hæc, cujus figuram * Hil. Infet. 'damus, inquit ille, acerrimus eft araneorum hoftis, \& p.r. r. 'fingulari antipathiâ cos perfequitur, atq; occidit; cùm 'reliquæ mulcæ araneorum reticulis ftrangulari foleant, iifq; 'pro cibo inlervire. Expertus fum mufcas predictas, dum 'aranei mufcarum capturæ ftudent, in medio reticulorum 'fuorum mufcas advolaturas expectantes, cas medias arri'pere, \& lethali vulnere afficere. Quod ubi animadver'tunt aranci, fubitò fe in terram, filo quodam appenfos 'dejiciunt; fed fequtintur mufcæ \& fingulos arancorum 'pedes ordine quodam confringunt, tandem plenâ jam a'deptâ victoriâ, cum gaudio corpus aranci ambiunt aliquo'ties, præ gaudio quafi exultantes. Id factum ter obfer'vavi,pofteáq; mufcam cum aranco jam mortuo avolantem 'vidi. Hæc Goedartius.

Illa autem obfervatio de arancis retium textoribus facta E.llonii lii... eft; at Bellonius apud Aldrovandum etiam de Phalangio $10 \cdots, c 7.2 \approx 0$ fimilem refert. 'Animalculım eft è vefparum genere, quod atul Aldis:o. "Ichneumon Vefpa appellatur: bellum internecinum ha- 
'bet cun phalangio; cùn verò corum pugnam vidimus, 'ipfam commemorare libuit. Infecti genus eft, fanguinis 'expers, formâ Apis five Verpæ, vel magnæ formicæ alatæ ' perquam fimilis, vefpâ tamen minus, in terra etiam fuum 'Iatibulum quemadmodum Phalangium faciens. Superat 'Phalangiumquandocunq; id extra fuum latibulum inveni're poteft; at fi in latibulo id adoriatur, fepenumero re ' infectâ redit. Accedit, ut Ichneumon Vefpa Phalangium 'è fuo latibulo cgreffum corriperet, atq; poft fe traheret,

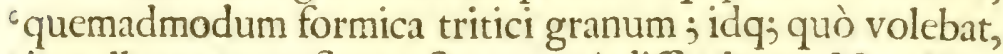
' impelleret, tametfi non fine magnâ difficultate. Nam Pha'langium pedum uncis obvia quæq; apprehendens, quan' tum poterat, renitebatur. Ichneumon verò fuo aculeo, 'quod inftar apis exerit, variis in locisipfum pungebat. De'feflus autem iftî pertractatione avolavit hàc illàc ober${ }^{6}$ rans ad baliftæfere jactum: deinde fuum phalangium re'quirens, nec quo reliquerat loco inveniens, ejus veftigia 'fequebatur, quaii illa odoraretur, non minùs quàm canes 'leporum veftigin.Deinde inventum plùs quàm quinquagies 'aculeo pupugit, urfumg; pertrahens,quo voluit,perduxit, "iftícg; planè confecit. Hxe Bellonius.

\section{A P. VI. \\ De Araneorum veneno.}

A Nglia, ut opinor, frigidioréfq́; regiones ninùs terribiles arancos edunt. At nobis noftra etiam phalangia fint ; quorum utiq; atq; univerforum quoq; cæterorum octonoculorum morfus perniciofi habendi, pertimefcerdiqg; funt.

Illude? 
Illud experimentum Clariffimo Harvæo noftro debemus. * "Ipfemet, inquit ille, aliquando experiendi cau"sâ, manum acu pupugi; mox eandem acum Aranci dente cito s. "confricans, manum alio loco perforavi, nec potui quic"quam difcriminis inter duas has panctiunculas interno" fcere: erat tamen in cute, quod difcerneret, quippe endem loco ubi venenata punctio contigerat, fubitò fefe in Tuberculum contraxit, induitq; mox ruborem, calorem, atg; inflammationem; tanquam ad pugnam \& nocentis mali expugnationem fe roboraret \& accingeret.

Aranei verò intra ftomachum recepti, five is humanus fit, de quo infigne teftimonium perhibet Moufetus *; five pe rnfic. alius cujulibet animalis, non fimiliter nocivi; ut non guftu pp.227. $23 \% \mathrm{rr}$ quidem fed in vulnere noceant. Aviculis certè plerifig; in deliciis funt; etenim hx omnigenos araneos indifcrinimatim arripiunt; cuijus rei obfervanda causâ aviculas in Caveis nutrivi. Quòd verò alvum aviculis moveant, eámve liquidiorem reddant, quantùm nos obfervavimus, minùs verum eft; fummam fanè alacritatem poft id genus victura femper demonftrârunt.

Ex parte id quoq; corum innocentiam probat, quòd ad recentia vulnera arancas i. e. eorum fila adhibuerunt antiqui. Glutinat vulnus (inquit Celfus) fi levis plaga eft, aranea: Recentiores etiam ad idem humorem ex corum corporibus ftillatitium pro fecreto habuerunt; adeò proficuus exiftimatus eft.

Item illud accedit, eorum ova etiam à delicatulis Stomachis frequentiffimè devorari innoxiè, fcil. curs cerafo fructu aut aliàs in quovis olere; infcienter tamen, ut infrà oftendam.

De morfu verò Tarantule five Phalangii Apuli, reliquorúmq; omnium araneorum exoticorum noftri non eft: inftituti aliquid fcribere. Adde quodd ifte effectus, ejufc; curandi ratio, ut merum figmentum, à doctiffimo indigen 
* philonph digena * ex toto rejicitur. At fi qua res fit, illud tan83:P. 4066 . tum quxro, an ifta nociva beftiola Phalangium fit nec ne ex noftris notis characterifticis diligenter examinatum: fi fit, hominem morfum continenter faltandi defiderio affici non adco miranda res ent, fiquidem ifte ingrediendi mos eft id genus araneis; fimiliter homines à canibus rabiofis morfos velut canes latrare proditum eft. Atq; adeò intud faltandi defiderium, fi quando torpeat, à muficâ excitari verifimile eft; \& per accidens fudorem vehementer movendo, ad curationem multùm facere poffit.

\section{A P. VII.}

¿ubi nonnulla de Araneis in genere balsentur it veteribus év recentioribus ir.dua, qux partim dubia, puring falfa fun.

I. Raneos lanis inclufos Tinearum generationem auth gere. Ariftot.

2. Averfis clunibus arancos copulari. Arift. Plin.

3. Araneos quordam unicum colore niveo Ovum parere, portaríq; fib ventre, \& per vices incubare, mare fubinde fominam invante. Mouf. N. B. prius verum eft, fi de folliculo intciligatur; polterius ommino talfum.

4. Quemq; Arancolum propriam Telam texere difcere à matre: Item aibi, nendi \& texendi rationem à parentibus edoceri: Item, omnes araneos retiarios telariofq; cum atate peritian acquirere majorcm. Mouf.

5. Ovis per triduum incubare, menféq; lumari prolem perficere. Áriftot. Plin.

6. Lacertas \& ferpentes occidere. 


\section{De Araneis in genere:}

\%. Araneos interimi à fuis liberis. Arift. Plin.

8. Ova ab initu intra feptem dies confummari \& concrefcere. Arift.

9. Vefpas Ichneumones ex Phalangiis mortuis fuum incubando procreare genus. Arift.

10. Aranei pariunt Vermiculos ovis fimiles. Arift. Plin.

II. Pedes pofteriores primis femper breviores habere. Mouf.

12. Sereno, quando volutant Mufcx, non texunt, ut aucupio vacent. Mouf.

13. Conjugio vicarias operas fubire. Mouf.

14. Phalangiorum paucos, fortè nullos, textrinam exercere. Mouf. quod eatenus falfum eft, quòd omnes ad hyberna telas conficiunt.

15. Araneum minutum coccineum fex tantùm pedes habere. Mouf.

16. Nullis filis per tranfverfum actis, ex arctiffima quadam villorum in longum continuitate fífifam Telam concinnare quofdam araneos. Mouf.

17. Araneos, ut adoleverint, matrimonia contrahere, munquam nifi morte interitura. Mouf。

18. Senectutem fingulis menfibus exuere. Mouf.

19. Generari araneos aliquot ex feminibus aëreis fitu \& corruptione putrefactis. Mouf.

20. Hiberniam \& Angliam non videre, aut non diu fuftentare Phalangia. Mouf.

21. Araneos Anglix permultos intùs devoratos nocere, morfus tamen eorum veneni expertes, \& nemini lethales, uti omnium Phalangiorum. Mouf.

22. Araneos domefticos morfus inferre inanes, titillatio oni quàm dolori propiores.

23. Gallas araneos producere. Matthiolo 


\section{A P. VIII.}

\section{De Medicamentis ex Araneis.}

3. F X quovis humore maceratos Febres arcere. 3. Aranei ex oleo vel rosât cocti ad aurem dolentem.

3. Idem ad oculorum albugines \& fluorem.

4. Ceratum ex araneis umbilico adhibitum, ad uteri fuffocationem.

5. Idem ad lienis dolorem tumoremq;. Plin.

6. Item ad Furunculos impofitum araneum.

7. Ex rosâ ad lactis coagulationem.

8. Item ad podagram \& ferpiginem ex emplaftro.

9. Araneas ftrictè alligatas vulneri, fanguinem fiftunt. Celr. Plin.

IO. Item ulcera curant, conglutinant, fanie prohibent, inflammationem arcent.

II. Item ad narium hæmorrhagiam, ad menftrua intùs forífve datæ.

I2. Quidam cinere Telarum ad eadem uti malunt.

13. Ova araneorum ex oleo nardino denti dolenti ad. hibita. Galen.

I4. Eadem ad Tertianam propinata. 


\section{De Araneis in genere:}

\section{Araneorman Anglis Tabula.}

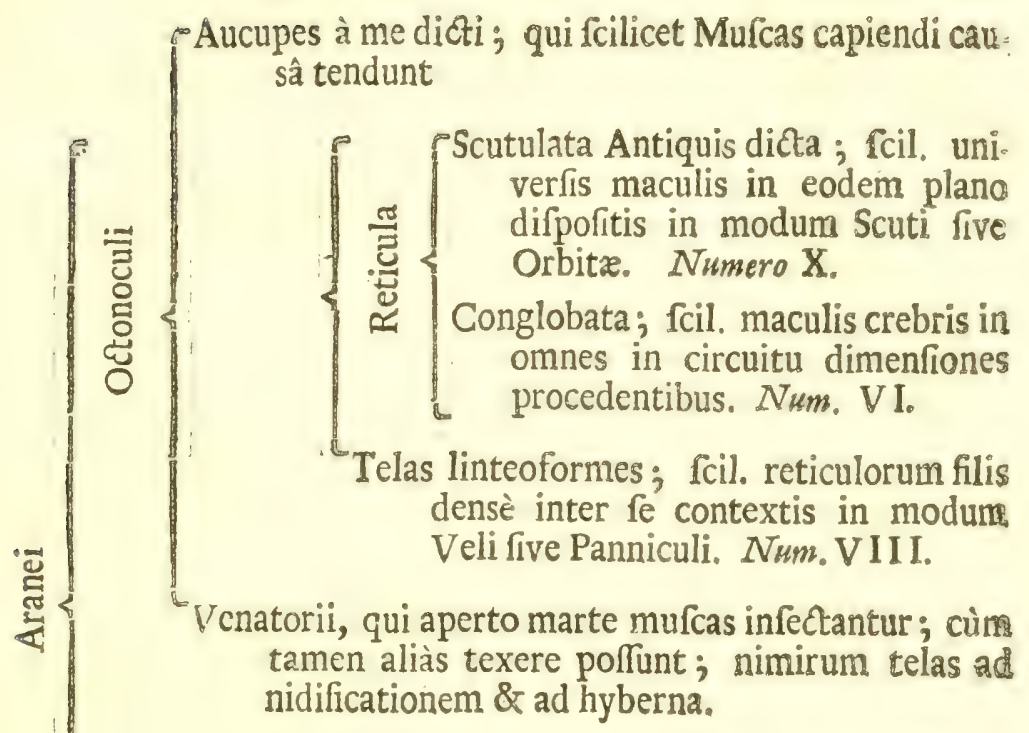
[Lupi, propriè fic dißti. Num. IV. Cancriformes. Num. II.
Phalangia, five Aranei pul ces afultim ingredientes. $N$ mm. IV.

Binoculi, ferè longipedes, Opiliones quibufdam dicti, telis digitatis five forcipatis, cancrorum marinorum more armati. Numero IV. 





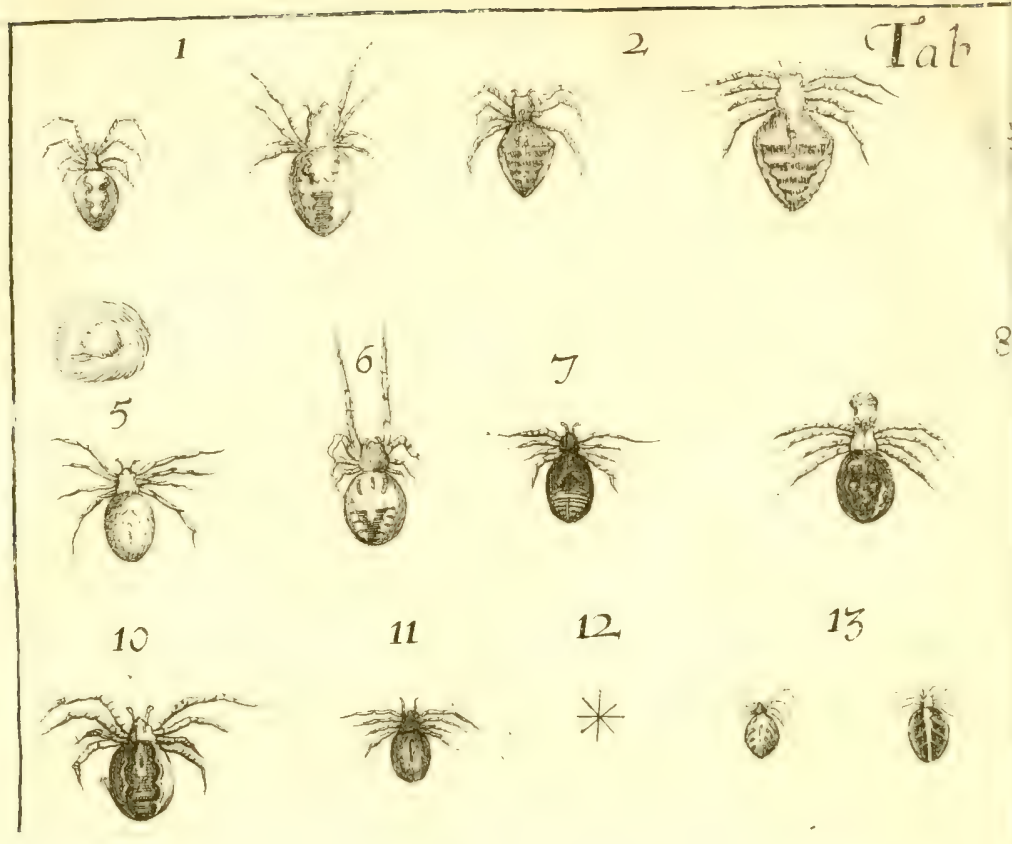




\section{ARANEORUM ANGLIE}

\section{I B. II.}

P A R S I.

De e Araneis Octonoculis.

SECTIO I.

De Araneis Mufearum predatoribus in Reticulis.

MEMBRUM I.

De Araneis seticulorum $\int$ cutulatorum Textoribus.

\section{C.A. P. I.}

De Araneis Reticula fcutulata texentibus in: genere.

TIS Araneis, qui cæteris excellunt in Retium eleganti opere, primum locum meritò dandum cxitimavi。 Quoniam autem ferè fimilis eft Textrinæ ratio in fingulis hujus generis Araneis, eam, quantum adhuc mihi obfervare contigit, paucis prefabor.

$$
\text { D } 3
$$


Itaq; fcire licet hos Araneos, vel oriente, vel occidenie fole, retia fua ordiri; quanquam eos etiam ad meridiem opus inftituiffe frè animadverti. Primùm autem ftamina aliquot circa fpatium, quod is eft in animo occupare, latè ducunt; ea verò funt ad fufpendendum rete, atq; plura fila in funes crafliufculos coalefcunt: mox itidem alia ftamina fimpliciora five radios directos in omnes in circuitu partes per medium ducunt; quod cùm exactè ceperint, in eo demittunt lanuginis cujufdam floccos velut bucceas quafdam, haudquaquam difimiles ipfis filis, nifi quòd ea fint in parvos glomerulos implicata : Tum verò è medio quoquoverfum excurrunt, alia atq; alia ftamina deducendo; donec eorum juftum numerum expleverint; atq; hactenus reticulum Carri cujufdam Orbitam quàm proximè repræfentat. Jam demum ad aliud opus fe accingunt, Maculas intelligo ; quas ferè primùm circa medium nectunt ad quatuor aut circitèr earum ordines: deinde ad extrema fe recipiunt (intermedio Reticuli fpatio aut rariffimis macularum ordinibus intertexto, aut iifdem prorfus vacuo) ubi eandem rem factitant fummâ celeritate : ut vero venerint defcendendo prope reticuli centrum, ab ifto opere tanquam fupervacaneo prorfus defiStunt, etfi totum fatium non utiq; impleverint macularum ordinibus. Poftremò floccos, quos fuprà demonftravimus in ipfo reticuli centro fub initium laborandi implicatos fuiffe, jam decerpunt, ibíq; quafi veftibulum five foramen patulum fibimet ipfis aperiunt, quo prædam fpeculentur ; quid ni ctiam hầc ratione, tanquam ultimâ manu adhibitâ, ftamina magis $x$ qualiter difponant, duriúfq; reftringant, arcténtq; ?

In ipfo autem opere conficiendo hæc preterea notavi; nimirum, quòd tùm in laborando tùm in fpeculando femper fe continent poft aut extra rete: quòd in plerifq; nec ftamina nce macularum ordines temerè excedant trigefi- 
mum mumerum, utcunq; grande aut parvum fpatium velint occupare: quòd tùm macularum fubtegmina, tùm ipfa ftamina paribus intervallis inter fe diftant; fubinde à medio ad circumferentiam crefcentibus: quòd fila circumducunt modò à dextrâ in finiftram, modò contrà : quòd dum beftiola tranfit $a b$ uno ftamine in aliud, filum per fe fequitur à ventre remiffum, nullóq; pede deductum rectúmve: quòd ubi pervenerit egregius artifex ad ftamer, cui filum adnecti debet, altero pede ultimo illud prehendit, altero fpatium fortaffe in ftamine metitur; nam illud perpetuo advertere licet, quòd ubi pes ille alter reftiterit, ibi, aut valdè propè, an citrà paululùm, etiam indiffolubilis nodus maculæe implicatur: quod an is nodus rectè dicendus fit, dubito; illud certò fcio, fubtegmen fingulis maculis ita firmiter adglutinari, ut ipfius animalis $s_{2}$ ejuff; prædx pondus, haud aliquando ita leve, aut etiam vis adhibita, id è loco dimovere non poteft citra rup. tionem: immo verò aliud obfervavi, à motu ipfius ani ; nimirùm animal fingulis ftaminibus aut ubicunq; nodo opus fit, eo uti tanquam figillo ad fili materiam veluti liquidam jamq; in aëre prodeuntem, firmandam : infuper quòd prioribus tantı̀m pedibus ad progrediendum utitur, pofterioréfq; operi expeditos habet : poftremò retia refcilfa ex aliquâ parte aliquando ad polituram refarcit.

Antiqui hujufmodi Opera Reticula Scutulata; nos verò Orbiculata à figurâ eorum circinatâ appellamus.

Horum autem artifices decem in Anglia vidimus.

Hæ verò funt notæ quædam communes Retiariorum Orbiculatorum. I. Habere ocules octo æquali magnitudine; quorum quatuor medii ponuntur in figurâ qua drangulâ, extimi per paria ferè conjunctim in parùm obliquâ lineâ. 2. Habere pedes priores omnium longiffimos, tùm fecundos, proximè his quartos, breviffimos tertios. 3. Effe ferè glabros. 4. Foliaceâ picturâ in fumniss clunibus exornari. 
De Araneis retiariis in fpecie: deq; iis imprim mis, qui in mediis reticulis predam affeduè Jpeculantur, quibus nec Domicilea nec Nidi, juxtà pofiti temerè obferventur.

\section{TITULUS'I.}

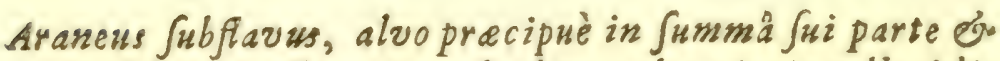
circa latera albicante, plená; oculis nigris pellucidis in capite albicante.

zeforiprio.

TS autem in mediocribus mumerandus eft; pedes præcipuè priores habet fatis longos, non nimiùm tenues, leviter maculofos, cæterùm fubflavos; in iifdem etiam pili

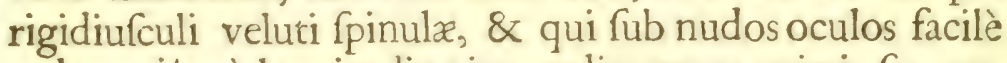
cadunt; íq; à longitudine ita ordinantur; primi fc. omnium longifinmi; tùm qui proximi ab his; tertii omnium breviffimi; nam ultimi poft fecundos numerari debent. Os humeríq; pedibus concolores funt, \& ferè pellucidi; in fronte octoni ocelli, nigri, etiam nudis noftris oculis haud difficulter confpicui, in media fc. fronte quatuor, in formâ quadrangulâ pofiti ex æquis intervallis; juxtáq; cos ad fingulos frontis fuperiores angulos alii bini, ferè conjunctim, certè valdè vicini in lineâ parùm obliquâ. Proximè ab humeris alvus five clunes admodum pleni; deinde paulatim in acumen retufius protenduntur; fuprà verò delineatur quoddam folium veftigiis admodum obfcuxis; peralvi tamen medium it recta lineola fatis confpicua, 


\section{De Araneis OEtonoculis.}

velut medius folii nervus; item proximè $a b$ humeris alvus \& ad ejus latera utrinq; ferè infignitur pæcipuo candore; cæterùm vel inaurantur vel lutefcunt, aliquando ex cinereo aut rufo variantur.

Certè hic \& reliqui, (quod freiùs dictum nolumus) pro ætate, aut anni tempore, aut cuticula noviter exutâ, colore uno haud fibi conftant; à figura tamen cæterífq; notis beftiola quæq; facilè agnofcenda eft. Medius venter nigricat, circùm luteolus. Hic autem araneus eft glaber, \& velut fquamofus mihi certè proximè per vitrum intuenti vifus eft.

Hic verò Araneus frequentiffimus eft à Calendis Maiis Lock3so ad medium Octobrem, \& aliquando tardiùs multo, inter Urticam, Geniftam, \& in filvis. Sin autem circa Octobrem tempeftas incidat valdè pluviofa, intra domos \& fub tecta fe recipiunt.

Ex his verò qui hyemant circa rivulos montofos, ferè alii videntur; adeò nigricant, illífq; qui in planitie, longè majores funt.

Mares multò ftrigofiores \& tenuiores funt; item magis rufercunt, quàm foeminæ; item iis extrema cornicula tuberculis ferè rotundis, interdum planioribus intume. fcunt; qux longè certiffima nota fexûs mafculini tùm in hoc, tùm in aliis quibufcunq; Araneorum octonoculorum generibus.

Illud autem fingulare eft in Textrinâ hujus beftiolx; Reticulats quòd ubi femel aliquot circinata fubtegmina five maculas ad medium retis adnexuerit, inde mox alia grandibus intervallis figit, quæ poftea implet, ab extimis defcendendo. Item illud alterum perpetuum eft, nec ullis aliis hujus $\mathrm{Fa}$ milix fpeciebus commune; nimirùm quòd craftrufculum filum extrà fubtérq; planum ipfíus reticuli deducit, illúdq; unâ extremitate reticuli centro, alterâ fub cavam ripam, aut alibi ufpiam, quò fe tutò recipiat, adfigere folet. Atq; 
hâc folầ notâ cùm primùm rete videris, $\&$ hunc araneum ejus authorem effe, \& ipfum araneum certò inveftigare poffis. Nam fi abfit retis centro, fub ripam juxta funiculum refedit; at nudè tamen \& fine uilo domicilio nidóve quod ufquam hactenus obfervare potuerim.

De araneâ fceminâ illud addo, eam, ineunte menfe Septembri, gravefcere: Item in multis iifdem reticulis, jam tùm marem cum formina ádfuiffe. (Etfí marem quoq; proprium rete texentem non femel vidi.) Imò duos tréfve mares eandem foeminam circumftetiffe, eam tamen fe perpetuò continuiffe in ejus centro tanquam \& folum authorem \& venatorem fui reticuli; dum illi, velut totidem proci, ad extima ftamina manerent.

Matutino tempore fortè in jucundiffimum fpectaculum incidi; nimirùm binos mares ftrenuè pugnâffe, per capita fe mutuò mordicùs tenentes, pedibúfq; inter fe miris modis implicatis: hos autem feparare volui ; utrofq; è rete, ubi unà aderant cum foemina, in manus meas recipiendo; atq; ita quidem eveniebat; at momento temporis, explicatâ manu iterùm concurrebant ad pug. nam.

A Calendis Octobribus hujus fpeciei aranearum alvos incidi ; ídq; in viginti \& ampliùs foeminis factitavi; verùm in omnino nullâ jam tum ova reperi, quòd paulò antè omnes peperiffent ; omnibúfq; adeò clunes jam detumuiffent.

Illud quoq; notandum, qui nunc mares inveniantur, exeunte $\mathrm{fc}$. OAtobri (atq; adhuc quidem multi tùm mares tùm foeminæ in reticulis fuis venantur) jam multò contraatiore alvo funt, puta, quòd à coitu celebrato, vernationem exuerant; idq; ita fưfle, etiam à teneritudine pedum conjicio.

Ex his autem araneis aliquot gravidas fub vitra non femel diligenter fervavi; at femper ante partum mortuae 


\section{De Araneis OẼonoculis.}

funt. Tandem verò aliâ ratione fxturam didici; fortè? exeunte Aprili, ad pedem grandium quercuum in plurimos ovorum folliculos, intra mufcum repofitos, incidi: hi autem folliculi erant rotundi, è laxioribus filis albidis ad magnitudinem pifi vulgaris; ex his autem aliquot in thecis ligneis fervavi, \& circa medium Maium hujus fpeciek Araneolos editos non difficulter cognovi : Poftea verò alibi in feneftris domi \& in geniftâ fpinosâ foràs eofdem folliculos frepiùs inveni, agnovíq; : fieri tamen potelt, ut aliquot ex his ovis excludantur ante brumam (nam nifi. me mea fefellit obfervatio, ex his juvenes minutiffimos vidi circa Calend. Novembres filorum ejaculatione fefe oblectantes) fed multò maxima corum pars per totam hyemen fub initium ufq; xeftatis, in ovo permanent.

Illud quoq; obfervatione dignum eft, tùm in hoc, tùm in aliis nonnullis Araneis, quòd adulti pleriq; vel pereunt per hyemem, vel eorum corpora admodum extenuantus ob diuturnam famem; nam vix unum è millenis exeunte Aprili, aut fub initium Maii invenies, qui non fit valdè exilis pro ratione molis, quam, appetente Autumno, habuerunt: huic autem pofteriori fententix libenter fidem do, quòd idem in Limacibus infrà narrabitur: hi fiquidem famem tam diu vix \& ne vix quidem fultinent penè enecati : atq; hre unica ratio Vernationis exuendæ effe videtur in fœminis; nam maribus etiam Venus poteft effe in causâ.

Tam hic quàm alii quicunq; Octonoculi aranei excrementa liquida ejiciunt.

Araneos in ipfo morfu venenum fuum demittere, ideo mihi verifimile eft ; quòd $a b$ unâ aliquâ hâc beftiolâ à me !aceffitâ, lymphæ puriffimæ fimiles guttas exiguas decies \&x amplins intra breve tempus refperfas notavi ; idq; to ties factitavit, quoties mordere voluit: in corio tamen manortuo propter fecuritatem periculum feci, de meo certè

$$
\text { E : }
$$

ludere 
ludere nolui; ut an veneficus \& quatenus fit ipfe lntex, mihi adhuc incompertum eft.

\section{TITULUS II.}

Araneus rufus, five avellaneus, cruciger, cui utring; ad Juperiorem alvi partem quafi fingula tubercala eminent.

H IC autern araneus è majoribus eft; unum cercè \& 1 alterum ex his vidi, qui nucis majufculæ è corylo magnitudinem facilè implerent.

Color ei rufus, aut qualis in avellanâ maturâ.

Pedes craffrufculi, nec nimiùm breves, maculis rufis diftincti ; idem eorum ordo quoad longitudinem, qui in fuperiore.

Atq; idem dictun volo \& de numero \& de fitu oculorum.

Porrò ei rari pili, í́q; maximè per humeros cani.

Alvum autem plenam habet; fuprà planam; atq; ad folii cujufdam imitationem depictam. Medios clunes diftinguit alba lineola recta, \& tranfversè ducitur altera ad figuram quandam Crucis; item ei proximè ab humeris alixe aliquot maculæ exigux albæ: ex utroq; alvi latere, ubi magis in latitudine patet, quafi fingula Tubercula aut anguli eminent, maculis quoq; fubalbidis diftincta; atq; ea cum extremâ alvo figuram triangularem ferè æquiangulam formant: ad verò latera multæ maculæ obliquæ, rufæ, undatx : in ventre verò binæ maculx lunatx.

nonts

In dumetis \& ad fepes non ita rarus circa Cantabrigiam : in rupibus autem, maceriis, Torrentiúmg; alveis Angliæ borealibus admodum frequens araneus.

Circinata retia tendit ampliffumr, atq́; adeò confpicua valdé. 


\section{De Araneis OElonoculis.}

Mihi autem jam abundè fatisfactum eft, mafculum araneum etiam fuum quemq; Reticulum texere; quòd ineunte Junio ex his plures mares in propriis reticulis fpeculantes vidi. Ac tum fortè, dum iple diligenter eos inlpicerem, unus \& alter Mas, mufcam, qux incidit in rete, arripuit, maculiff; coram me fufpendit; id quod antè fecerant de aliis aliquot Mufcis à fe captis.

Mediis reticulis affixi diligenter \& affiduè totas dies mufcis infidiantur; quippe Receflibus certè artificiofis carent.

De hoc autem aliifq; nonnullis araneis frpiffimè nota$v i$, quòd dum reticuli medio infidunt, illud tremulo atq; admodum citato motu aliquoties vibrant $;$ an ut pulverem è reticulis fuccutiant, aut fi quæ fortè capta fit in iis, explorent; aut quầ de aliâ causâ me latet.

$\mathrm{E}$ maximis fupradictis alteram gravidam fub vitro ultra menfem fervavi : mufcas tamen à me victui oblatas noluit, \& tandem mortua eft: adeóq; fruftrà fuit experimentum de fretura five partîs ratione.

Maio exeunte, interdum citiùs, horum fxturam innumerabilem in dumetis vidi nuper exclufam,\& inftar raceni cohærentem multis filis à fe ipfis circumductis ad defenfionem fui ; matrem autem minimè tantùm juxtao vorum cortices notavi : horum verò araneolorum tum clunes albiç, attamen aliis notis facilè cognofcibiles.

In Torrentium alveis Regiunculæ Craven dictx ex his plurimos minuciffimos incipiente Augufto obfervavi, radiculæ fernina vix æquantes; fuóq; quemq; reticulo, corporis moli pari, infidentem.

Ex his autem aliquot nuper editos thecầ ligneâ inclufí, póftq; aliquot dies eos omnes cuticulam exuiffe notavi: an fingulæ araneorum faturæ idem faciant, \& quoties, ut de plerifq; Erucis notum eft, inquirendum reftat.

$$
\text { E } 3 \text {. }
$$




\section{TITULUS III.}

Araneus ex viridi inaurates, elvolongiufculá, pretenui.

istagnhingos. I I C autem Araneus è mediocribus eft, fi corporis tantùm molem refpicias; at habitâ etiam pedum longiffimorum ratione, nullis facilè cedit; præcipuè ii, quos in fylvis invenias.

eilor. Ei verò pedes, humeri, cornicula \& tela omnia fubflava funt \& ferè pellucida : habet autem alvum ex viridi inauratam, levitérq; depictam foliatim.

ocali. Hujus octo oculi nigri facilè à quovis numerari poffunt, etiam fine confpicillo, idq; propter dilucidum caput : eorum autem ordo non æquè vifibilis; nam ex duplici ferie atq; xqualibus intervallis per mediam frontem difponi videntur; cùm reverà fuperiorum normam rectè fequuntur; quæêt, cìm quatuor medii in figurâ quadrangulâ, reliqui extimi uirinq; per paria parùm obliquè politi fint.

Pedes.

Ei verò Pedes omnium hujus generis facilè longiffumi, tenuifimiqg; funt; item leviter hirfuti: horum primi, ut in fupersoribus, reliquos longitudine fuperant, tum qui ab his proximi, tertii omnium brevifimi, poftremi ad fecundos propiùs accedunt.

Alwaso Alvus fubteres, nifi quòd ab humeris aliquantulum emineat, retufa, prxlonga; color alvi in fuperiore ejus parte ex viridi flavefcit, velut inauratus, nec nimiùm obicuris veftigiis pifturæ foliacex diftinguitur ; certè fi per vitrum fimplex cam intuearis, velut fquamulis aureis contecta effe videtur more ferpentum.

rime

Ipfe aute $\mathrm{n}$ Venter infufatur, quem extrà ambiunt luteolæ lunulæ.

3. It: Tela hujus aranei longiufculas 
Hujus autem generis araneorum qui fylvicolæ funt, ferè Sylvicole ang altero tanto majores funt campeftribus, ut videantur alia fpecies, cùm non fint. An fortè ibi tutiores ab aviculis, vitámq; adeò in plures annos prolongant, dum corpora majora interim incrementa fumant; illud certè, quod fuprà de primo araneo monticolâ narravimus, cun hâc ob. fervatione fatis bene convenit.

Retia tendit fatis ampla è rarioribus maculis ad antra 2$) \ldots$. ferè \& in foflis, \& precipuè rivulos amat, nec fylvas horret; fuis certè locis à primo vere frequens eft, ac fi quis alter.

Ad Calend. Maias cum Vernationem exuere fortè funmâ cum voluptate vidi; cujus exuendi rationem aliàs pluribus demonitravi.

Maio autcm exeunte, i. e. circa vigefimum quintum di- coittis ratiog em circa folis occafum hujus generis plurimos araneos ip. fo coïtu mihi obfervare contigit : illi verò filis fuis demiffi, fubq; reticula in aëre fufpenfi, ventre unius alterius ventri adhibito inter fe copulati funt: at mas etiam foemine. interior erat, ejúfq; alvus rectà protendebatur, dum foeminæ alvus curvabatur fupra ipfum marem: ipfe autem forminæ anus maris ventris fuperiorem partem tetigit; Atq; non alium equidem maris penem difcernere potui, quàm è corniculis unum tuberculo infignem; qux illum perpetuò fominæ ventris fuperiori parti adhibuiffe mihi vifum eft; ídq; alternatim. Interea utriufq; pedes \& tela miris modis inter feimplicati funt.

Junio medio codémq; menfe exeunte ex his aliquot ovin gravidas fub vitris fervavi; ubi brevì ova pallidè lutea pepererunt; eáq; valdè exigua. Hæc autem ova follicu. lis laxioribus involuta funt, ad magnitudinem grani pi- Fods:me peris majufculi ; ipforum autem Folliculorum quod proximè Ova filum ex viridi cæruleum, cùm in corum extima fuperficie id erat paulò obfcurius; multífó; hi minu- 
'rifq; globulis feu glomerulis inxquales \& quafi afperi. Ipfum autem idem de ovis fylveftrium prægrandium itidem expertus fum.

Porrò non femel inveni eordem Folliculos juncis aliarúmq; herbarum foliis affixos.

Reticuli centro infidendi modus huic araneo planè fingularis eft; qui fit, pedibus fc. 4. prioribus rectà protenfis conjunetíf ;

Inter mufcas ab hoc araneo captas etiam ceftros aliquoties obfervavi; tantus animus eft in hac beftiolâ. Illud præterea de natura feroci hujus animalis addam, duas majufculas Fominas in eâdem thecâ ligneâ inclufí unà; atq; una alteramillicò interfecit, eámq; fuo more depafta eft: neq; è thecâ excuffa occifam libenter amittere voluit; fed quæfitam rurfus avidè arripuit.

Illud quoq; non filendum duxi, me fortè, memorix \& obfervationis causâ circiter decem araneorum genera, recenter captorum, acubus defixiffe alteri parti feu valvæ thecx lignex; quos cùm noctu in conclavi apertâ thecâ negligenter reliquiffem, manè ad unum omnes devcratos, puta à muribus, animadverti, preter tres hujusgeneris omnino intactos integrófq;

\section{TITULUS IV.}

Aranews cinereus, fylvaticns, alvo in mucronem faftigiatâ, Jeu triquetrâ.

Eicriptio. TS autem inter minores hujus generis araneos numeranIf dus eft.

Ei color cinereus maculis nigricantibus varius; ídq; maximè in pedibus.

Iidem breves, craffiufculi; atq; hoc ipfo ordine longitudinem 


\section{De Araneis Octonoculis.}

gitudinem quod fpectat, quo in fuperioribus expofitun eft.

Humeri valdè infufcantur, fi mon planè nigricant; i i ${ }^{-}$ démq; admodum pufilli funt; quo fit, quòd oculorum magnitudo, ordo, \& numerus, non nifi confpicilli ope difcerni poffint: at omnino fe habent, ut in fuperioribus, quatuor $\mathrm{fc}$. in mediâ fronte in figurâ quadrangulâ, aliíq; ex utraq; parte bini ferè conjunctim in paululùm obliquâ lineâ.

Huic Tela ex atro rubent.

Alvi verò figura rara, planéq; fingularis eft ; nimirum refima, id eft, plenior verfus anum, fupra quem quafi rurfum reflexa eminet; ac fi in mucronem effet faftigiata, feu alvo triquetrâ ; item eadem foliaceâ quâdam picturâ perbellè exornatur.

Venter nigricat ; atq; in eo quoq; funt iftæ lunatæ macul $x$, in fingulis fuperioribus notat $x$ : item ibidem funt maculæ quædam rufæe aut miniatulæ.

Extra altas \& umbrofas Sylvas non temerè reperitur'; Locus. ubi eum tùm in agro Cantabrigienfi, tùm circa Eboracum trequentem inveni.

Ampliffima retia tendit inter ramos alicujus arboris; imò nonnunquam longè fupra contactum meum.

Junio ineunte fanè pulcherrimum clt animalculum,quòd tùm fortè noviffimè cuticulam hyemalem exuit.

Oriente fole eum texentem vidi; in hujus autem opere aliquando numeravi, (nifi me fallit memoria) fupra $40 \mathrm{ma}-$ cularum ordines: atq; hoc quidem fingulare effet in hâc beftiolâ, fi perpetuum.

Menfe Julio Tineas exiguas fylveftres inter reliqua ei victui effe notavi.

Illud autem multò rarius, \& planè mirandum, præd $x$ fc. fufpenfio, five ejus refervandi modus atq ordo; in quo certè eft quædam Venationis gloriola. Habetis enim 
ipfum araneum in Reticuli centro, velut in infidiis, affrduum fpeculatorem; ejus verò prædam directâ lineâ fuprà infráq; fe dif́pofitam; atq; illud fanè oftentationem præ fe fert, fingulas nimirùm mufcas ad fingula macularum internodia implicari. Idq; perpetuum effe hujus aranei morem, jam plurimis obfervationibus exploratum habeo.

\section{TITULUS V.}

Araneus viridis, caudầ nigris punctis utrinq; ad maq" ginem Jupernè notatâ, ipfo aso croceo.

Defcriptio.

Aits.

tosus.

Rericutution Reticulum omnium ninimum, pro corporis fui proportione texit; quod perpetuum cile, multoties obfervawi in fylvis \& alibi. 
Illud etiam non pretereundum exiftimavi; corum $\mathrm{fc}$. reticula fuper corylorum folia ferè extendi plano fitu five ad lineam horizontalem; quod huic quoq; fpeciei propriè corivenit; nam reliqui rarò retia fua difíconurnt ad eundem modum; fed plerunq; in perpendiculo aut parum obliquo fitu.

Quotquot ex his vitris parvis, fortè 5 aut 6 unciarum aquæ capacibus, citráq; quatuor digitos latis, fervavi (fervavi autem multos; nam in plerifq; experimentum feci) ii ommes reticula fibi tantis anguftiis confecerunt; corúmq; centris fedulò inhærendo mufcas omnigenas, etiam œeftros, in vitra injectas avidè ceperunt, non aliter quàm fi foràs in fylvis \& fui juris effent: huic autem rei commoditatem dat illa altera proprietas jam nunc memorata; ipfa $\mathrm{fc}$. reticula pro confuetudine animalis perexigua.

Exeunte Maio ex his unam, mihi gravidam vilam, vi- ovas tro cryftallino fervavi : ováq; ibidem non ita diu pònt peperit, vitróq; firmiter affixit. Ipfa autem ova inter fe tenaciter conglutinata funt, ad figuram \& magnitudinem pifi vulgaris ; fupráq; multum filum pro Folliculo laxiùs injectum, coloris ex viridi flavefcentis. Illud etiam in hoc filo fetoro fingulare, quòd \& craffius multo \& rigidiufcu- Filuma lum inter digitos fentitur, atq; afperum; cùm molle fit illud alterum Reticuli, tenuius \& album. Poft decimum verò \& octavum diem ab ovorum partu, nefcio quâ temeritate ductus, folliculum incîdi, ováq; adhuc integra inveni: horum autem nonnulla papyro illifa eam jam infecerunt colore purpurafcente; quod indicium erat maturefcentis Embryonis. Ipfa autem Fomina poft partum multò gracilior facta, circiter 14 dies fine cibo vixit.

Marem aliquando cum forminâ fub eodem vitro inclufi: poft biduum verò marem illa occidit exfuxitq; : deinde Reticulum ibidem confecit, diúq; à mufcis, quas dedi, vixit. 
Septembri exeunte in majufculos juvenes hujus fpeciei incidi; quos tamen facilè à punctulis nigris cognovi; nam iis color erat fubrufus.

Araneorum fpecies fingulas in spiritu vini dicto immerfas confervare foleo; neq; $a b$ illo multùm mutantur aut colore aut picturâ ; hoc uno excepto, qui viridita tem hâc ratione amifit, \& fubflavus factus eft.

\section{A. P. III.}

De Retiariis alteris Orbicularis, quibus domi. cilia five Nidi juxta reticula ponuntur.

\section{TITULUS VI.}

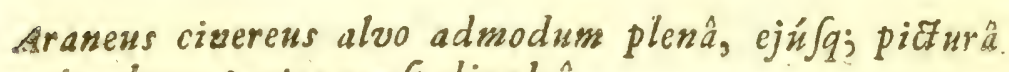
in plures partes quafe divulsâ.

Defcippio.

IC autem inter maximos ponendus eft.

Ei color cinereus: humeri quafi incani.

Pedes craffi \& non nimiùm longi, hirfuti, maculofi; eorúmq; ordo idem, qui in fuperioribus.

Item ejus oculi octoni eundem pofitum obfervant; vix nifi confpicillo difcernendi.

Alvus lata, plena, retufa; picturâ foliaceâ fupernè díftinguitur; at ea haud integra eft, fed in plures partes circitèr quinq; quafi divulfa, lineamentis $\mathrm{fc}$. five interruptis, five partim obliteratis.

Venter fufcus; duabúff; lunatis maculis fubflavis, quatoum cornua intùs fpectant, infigniturr. 


\section{De Arancis OFonoculis.}

Mari extrema cornicula tumida; \& pedes \& Tela ión- Mas. giora, \& alvus gracilior eft.

In ericetis altifimorum montium partium Angliz bo- Lochse realium, non ita rara beftiola: in auftralibus vero à primo vere inter geniftam fpinofam admodum frequens: item in herba quâlibet procerâ, puta in Acanthio, Stephalino, \&c. frepiùs etiam ad rivulos, fupra quos retia tranfverfim tendit.

Per hyemem autem latet interdum in ipfis cavis cau- Hybernas libus plantarum fuprà dictarum; nonnunquam in maceriâ; fed ubiq; per id tempus Folliculo è telầ candidâ perpetuò involutus.

Ampliffima \& valdè confpicua Retia tendit: ex unâ Reticuluhto verò parte reticuli 38 macularum ordines aliquando numeravi, ex alterâ non ultra quindecem; quod ideo fit, ut reticulum loco aptetur.

Præterea juxta reticulum Cubile five Domicilium frbi Nidus. conficit, fuprà arcuatum, infrì apertum, \& eundem $\mathrm{Ni}$ dum futurum: qux quidem nidificandi ratio longè commodior eft adverfus pluvias \& folis ardores, quàm illa quaz. in Avicularum plerarumg; nidis obfervatur.; quorum figura cùm fit eadem, tamen in his noftris beftiolis pofitus inverfus eft. Domicilii autem materia velut linea eft; è telâ fc. candidâ, mollíq;.

Mares autem in fummitatibus Graminis alicujus nidulari \&: fimplicibus maléq; difpofitis filis venari non feme! obfervavi.

Mufcis victitat parvíf; fcarabxis; ex quibus pofterio- Viaths ribus plurimos in eorum nidis inveni; item ipsâ fuâ fpecie \& fexu : nam fominam unam aliam æquè magnam interficere \& exfugere fxpiùs expertus fum. Item arancos; Opiliones dictos, de quibus infrà, libenter foràs in fuis reticulis capiunt; fiquidem hos inter mufas fufpenfos zaon femel vidimus..

$$
\text { F:3. Duss: }
$$


Duas id genus araneas gravidas cepi; atq; obfervandi causât fingulas fub fingulis vitris mox incluli: eas autem non ita diu fervaveram, quàm ova fubflava peperêre: al-

0v. tera verò id egit ad XVII, atq; altera ad XV Calendas Sextiles. Ipfa autcm ova firmiter inter fe conglutinata funt, multóq; filo Folliculorum more fuprà injecto: finguli autem Folliculi ad vitrum quifq; fum affixi funt, omnémq; propiorem ad ca aditum ctian ipfis araneis matribus fuilfe preclufum; denfis circum circa filis prætenfis, ut eas incubare, aut ova fua finu fovere non rcctè dicere polfes; etianfi primos quidem à partu aliquot dies proximè, quod poterant, aftitêre.

Fætus autem exclufus eft in ovis fuperioris aranex Nonis Sextilibus; propioris verò ad VII Idus Sextiles; ut à partu ad fxtum editum intercefferint plurimìm dies unus \& viginti. Illud addo, me de induftria hæc vitra fervâffe in conclavis mei angulo, à lumine \& fole maximè remoto; \& præterea dicam, quod resfit, alterum è vitris, ab aliis infectis priùs fub co curatis, humidum multóq; fitu fuiffe obductum. Ante dien autem primum fupra vigefimum omnia, quoad res externas immutata; tum verò primùm ovorum ordines paululum relaxari; atq; è fungulis extimis corticibus primò prorupêre finguli araneoli; atq; ita de cxteris deinceps.

Iprex autem araneæ Matres poft paucos ab exclufione dies, ambæ mortuæ funt; ea prima quæ primò peperit, mox altera; tamen mihi curæ fuiffet jam ut antè, iis victum non defuifie; quem tamen eas unquam guftâfle certò fire non potui.

Vigefimo autem fecundo Maii, ut nos computamus, mas unà cum formina in eodem Reticulo aderat; idq; de reliquis omnibus, quos illo die obfervare licuit, verum erat.

Vigefimo quarto ejufdem menfis in plcrifq; nidis ova $\because$ : 


\section{De Araneis OEionoculis.}

jam primùm vidimus; fuperiori fc. Nidi parti affixa, validáq; velut membranâ præclufia. Ipfa autem ova fubrufa funt; atq; ita firmiter inter re compaginata, uno eorum ordine alteri fuperinjecto, ut non facilè refolvi numerarive poffent. Tota autem Ovorum compages magnitudinem lupini implet, neq; diflimili figurâ deprefsầ, rariùs rotundiori ; circum circa verò fuperinducitur multum filum pallidè luteum, rigidius \& quafi afperum, cùm ipfius nidi filum planè aliud fit'; nimiùn læve, molle, \&album: an fortaffe è diverfis corporis partibus oriantur, ut ab utero illud proveniat, hoc ab inteftinis; aut fi quod aliud fit proprium fili conceptaculum, ut in Erucis, quod ore eructatum cernimus.

Undecimo Junii duos folliculos ovis repletos, magnitudinéq; æquales, in uno eodémq; Nido inveni ; at adhuc ambo integri, nullíq; araneoli exclufi. Alter autem Folliculus propriâ certè membranâ feclufus eft ab altero.

Porrò primo Augufti alterum Nidum aperui, inibíq; trinum fatum inæqualem notavi; Cc. primus ex araneolis conftabat parentum finilibus, fecundus nuper exclufus \& adhuc fubllavus, tertius adhuc in Ovo. Aliis autem annis cundem Partûs numerum vel exeunte Junio obfervare li. cet.

Maio excunte ex his aliquot gravidas in hortulum noftrum è vicinis agris tranftuli; ut obfervationi magis effent opportunx; atq; hæc preterea didici.

Hanc certè, fi non omnes hujus generis arancas, ubi femel ova peperit, ibi plures menfes fubfiftere; nee predandi aut habitandi causâ aliò migrare. Etenim hortenfes noftri inter rofx folia viridiæ primò Nidum confecerunt; deinde reticulum. De quo illud expertus fum; nempe mihi curæ fuit, ut reticulum quotidiè, quadraginta minimùm dies, defringerem, pcnitúfq; avellerem, Nido interim -integro relicto \& intacto : attamen nova indies 
indies reticula ad folis ortum refecta \& perpolita inveni: nifí tempeftas nimiùm pluviofa impediret; nec aliàs quidem operi vacabant. At non locus tantùm, fed \& perpetuus idem reticuli pofitus, non obftantibus quotidianis injuriis. Cujus rei caufa patet, quòd ibi ova, fummum amoris pignus, depofuerunt, non alibi amovenda.

Quidni huc ctiam referamus in aërem volatum Autumnalem; donec fc. partûs cura ex toto finiatur; quod fit circa menfem Septembrem.

In Nido autem altero divulfo triplicem, ut fuprà dictum eft, fætum obfervavi. Inter primum verò partum fex aderant parvæ Chryfalides five Thecæ teretes, folidæ, utráq; extremitate retufx, fublividæ, id fc. genus, è quibus Mufcx tripiles, à Moufeto noftro fic dictæ, antiquis verò Ichneumones vêpæe appellatæ, excludi folent. Ex ipfis autem Araneolis natu majoribus, qui $\mathrm{fc}$. horum vermiculorum voracitatem, dum in ovo, effugerant, quotquot à me aëri expofiti, protinùs fila ejaculando avolavêre: non injucundo fanè fpectaculo!

Ipfa autem trini fæetîs mater, priore nido fublato, ipfiffimo die alterum Nidum eodem frutice confecit ; \& poft biduum quartum partum edidit; reticulúmq; mox fibi conficiendo, diu apud nos permanfit.

\section{TIT ULUS VII.}

Araneus pullus, glaber, cruciger, alơs plènâ ovali.

Dergripitio.

A Ediæ magnitudinis êt: ci color ferè ater ; ant qui in pomi feminibus permaturis.

Pedes non nimium graciles, breves, maculot: atg; ita ordinantur, nimirùm corum primi omnium longifimi, tum qui ab his proximi, poft illos ultimi : nam tertius pedum ordo breviffimus eft.

Huncri 


\section{De Arameis Oetonoculis.}

Humeri exigui, fattigiati faftigio fc. fubrotundo, ex atro rubent refplendén' q; q quo tit ut oculos æarè difeernere licet vel optimo Microfcopio adhibito : tamen mini certò conftat de corum numero, xquali magnitudine \& pofitu, quod eadem illa omnia funt, perinde ut fuprain aliis expofuimus. Sin autem fit aliqua varietas, hre cft; quòd qui in fuperiore lineâ figuræ quadrangulæx, ferè paulo conjunctiores elle videntur, quàm qui in inferiore.

Alvus ci plenior, retufa, \& quodammodo ad fimilitudinem ovi gallinacei facta, ita tamen ut æqualem ferè dimenfionem fervet ab exortu ad infimam ejus partem, nifi media ejus pars tibi paulo plenior videatur duabus extremis: alvo color eft ex atro rubens five pullus; it ve. rò rectà per medios clunes infignis lineola alba; quam aiix circiter tres tranfverfim fecant, in modum coftarum obliquarum; item paulò infra cas verfus imum anum alix circiter tres quog; breviores lineolæ albæ itidem primariam lincolan fecant, fed magis ad angulos rectos: hinc Crucis multiplex fimilitudo. Ad alvi vero latera color fubalbidus.

Venter infufcatur, nifi ubi duabus lunatis maculis infignitúr.

Ex frequentiffimis Araneis eft; fed raro alibi inveni- Locuso tur nifi inter juncos $\&$ in pratis udis.

Prodit ex hybernis Maio incipiente; quo tempore in herbarum fummitatibus Telam pro Nido orditur albam tenuémq;

Sub idem tempus Vernationem quoq; exutam reperire licet in ipfo Nido.

Medio verò Maio, fi faveat temapeftas ferena, reticula orbiculata conficiunt prope Nidos.

In Reticulis autem multigenas Mufcas fufpenfas vidi- vicutus mus; inter quas etiam farabros quofdam exiguos obfervare licet; id precipuè in Nidis à pullorum exclufione. 
Maio autem exeunte, Folliculum ova continentem in pleriff; Nidis reperies; ovis verò ipfis exiguis color fubluteus, perfectx rotunditatis, ut reliquis univerfis araneis: ipfe autem Folliculus, qui proximè ova involvit, albus, figurâ lenticulari ; fuprà verò injicitur filum aliud laxius ex atro purpurafcens; etiam ipfus Nidi filo folito fufcius, fi illud benè attendas.

Medio verò Junio in plerifq; Nidis jam bini Folliculi funt; in nonnullis etiam Nidis eorum neuter adhuc exclufus eft; in plerifq; verò ex iis unus partus in pullo, alter adhuc in ovo; in aliis quidem paucis unicus tantùm Folliculus, qui vel exclufus vel integer.

Ad Calendas autem Quinctiles numerofum fæetum in Nidis notavi, quos neq; mater adhuc teneros deferuerat; at victurm iis ufg; providebat.

Multos id genus centenos araneos in quodam prato fylveftri nidulantes menfe Junio obfervavi; at mihi redeunti circa finem Julii vix unus è multis repertus eft; an fortè quòd Aviculis fylvæ vicinæ gratifimi fuerant?

\section{TIT ULUS: VIIT.}

Araneus fravus, quatuor infignibus maculis albis, aliif $q$; mult is exi, uis ejufdeñ coloris in picturầ cluninn foliaceâ notatus.

Defciptio. S autem precipure Magnitudinis eft, nulliqs Anglicano Aranco facilè cedit; ex his certè nonnullos vidimus magnitudinem nucum majufoularum corylorum xquantes.

Ei color vel flavus vel fubrufus.

Pedes craffi, longi, , pinofi, infigniter maculofi : quorums primum par reliquos excedit longitudine; deinde fecunlum; tum quartum; brevifimi funt terii 
Oculorum ordo hic eft; quatuor fc. medii in figura quadrangulâ æquali diftantiâ pofiti funt; juxta hos utrinq; par unum, ferè conjunctim collocatum; omnes 2 quali magnitudine funt.

Ei alvus admodum plena; fupra quam foliacea quædam pictura delineatur, in extimis oris undata; in fuperiore picturæ parte funt quatuor infignes maculæa albæ, in figura quadrangulâ, at non æquilaterâ, pofitæ; etenim quæ propiores ano duæ maculæ magis inter $\mathrm{fe}$ diftant, quàm fuperiores alteræ duæ; plures etiam aliæ exiguæ maculæ albæ, hîc \& illîc, interfperfe funt; it autem rectà per mediam picturam lineola alba.

Hic rarior eft araneus in aliquibus locis; tamen in re- Roctese pibus agri Hartfordienfis aliquoties eum inveni fub menfem Auguftum: item circa Eboracum admodum frequenter in geniftâ fpinosâ, \& in Craven regione montosâ. Eo à tempore fpectabilis magnitudinis funt.

In fummis herbis fruticibúfve domicilium five Nidum juxta ampliffimum reticulum collocat : eft etiam huic araneo commune filum à reticuli centro ad Nidum ufq; perpetuò pertenfum, per quod ítq; redítq;

Medio Augufto, ex his aliquot ventre tumidas diffecuimus; inibíq; magnam copiam fpermatis cujufdam fubflavi notavimus; quod tamen partui adhuc immaturum fuiffe, à granulorum quibus conftabat, nimiâ parvitate exiltimavi.

Nidi filum albifimum; at quod circuminjicitur ovis lutefcit.

Exeunte Septembri ex his aliquot gravidas thecâ ligneấ inclufi ; quarum una mox ova peperit, binis placentulio inter fe diftinda, at eodem folliculo ambo inclufa funt ; laxiori fc. at rigidiori \& $\mathrm{z}$ flavefcente filo confecto.

Araneorum cutis non adeò facilè difrumpitur, hinc alo vo vchementer exprefia, ipfa integra erumpit, quòd alia 
atq; alia fubfit Cutis, quâ continentur vifcera : Neq; alienum eft credere univerfas Cuticulas in toto vitæ decurfu exuendas, cum beftiolâ natas fuiffe.

In liquido \& fubalbido ftercore hujus aranei, plurimas particulas nigras obfervare licet; $f c$. Scarabæorum Mufcarúmve inutiles cortices \& difficulter concoctibiles: adeo non verifimile eft, has beftiolas merâ fuctione cibum fumere, red ejus bonam partem etiam vorare.

\section{TITULUS. IX.}

Arantus nigricans, capite quadrato fre Phaiangio-for. mi, clunibus ad fmilitudinem querni folii depictis.

W IC omnium maximus eft Araneus.

Ei color furcus aut fuligineus.

Caput \& humeri depreffi, trons lata \& quafi quadrata, eâ fc. figurầ, quâ funt Phalangia infrà defcribenda.

OEtoni oculi nigri, æquali magnitudine; eundem verò fitum obfervant, qualem in fuperioribus expofuimus.

Tela eorúmq; brachia nigricant præcipuo quodam nitore.

Præterea ei cornicula, pedé $q$; crafli, maculofi; at ubi iftis maculis non infurcantur, foli obverfi rufefcunt; hirfuti, nec nimiùm breves, maribus præcipuè; de eorum verò ordine, quo alii alios longitudine excedant, vide in fuperioribus.

Alvusingens, plana interdum ad latitudinem furè unguis digiti medii ; ea verò ubi ad majorem, quod fubitò fit, latirudinem devenerit, iterum paulatim minuitur in retufum anum; in ejus autem parte fupinâ eft quædam pictura, anbitu finuolo five undato ad quandam imitationem querni folii ; intra pictare vero ambitum infufca- 


\section{De Araneis OEtonoculis.}

tur, ubi circiter quatuor nefcio qui finus exigui, tarn in hoc quàm in aliis araneis fubfidunt; extra eandem picturam alvus paulò coloratior.

Item venter nigricat; nifi ubi duæ lunatie maculre fubflavæ ejus medium occupant; quarúmq; cornua intùs fpectant.

In auftralibus Anglize partibus frequens; nec rarus in Los:3s. feptentrione, fub cortice annofarum arborum fere latet, \& ad maceriam ruderáve maximè extra ædificia.

Per hyemem verò Folliculo è candidâ Telâ diligenter Hýyerna. involvitur.

Amplifina retia tendit; fed quibus rariores maculax : Rititio hujus aranei paulo vetuftius rete valdè inelegans eft ob nimiùm frequentem refarcinationem. Ferè prædam obfervat è fpecu five domicilio, juxtà pofito.

Rarò interdiu confpicitur hic araneus; etianfi mufcre tùm quoq; frequenter impingant in ejus rete; de nocte verò prodit \& vefcitur: id quod hujufmodi experimento didici : ex his unum \& aiterum in vitris feorfim fervavi, plures his mufcas vivas manè fubminiftrando; at per totum quidem diem mufcis huc illuc difcurrentibus, velut. torpidi ac immobiles aranei permanferunt; proximâ verò luce mufcas occifas \& exfuctas perpetuò notavi.

Ipfum autem Rete multâ oneratur prædâ, at nullo cer- riç̄ins, to ordine difpofita: hic mufcas omnigenas, fcarabaos, \& non rarò majores multipedas Falos dictas occifas fufpenfáfq; obfervare licet.

Medio menfe Septembri fortê fub non nimilim obfer. ram noctem incidi in marem pedibus prælonģis corniculifq; thirgidis infignitum cum formina in Reticulo luderrtem; hine conjecturan facio id genus animalia rem veneream ferè per noctem agere.

Ex his aliquot araneas foeminas diffecui, ineunte menfe Februario, ut viderem, an fortè jam gravefcerent, at 


\section{De Arancis Octonoculis.}

nihil alind intùs inveni, preterquam fpermatis cujufdans flavefcentis ac prorfus indifcreti copiam, in ova tandem diitinguendam : hujus certè color valdè fimilis, atq; in ovis ipfis recenter editis.

Pas

A Calend. Aprilibus multa ova fubflava pariunt; cáq; intra aut juxta Domicilium difponunt: ipfa autem ova alia aliis fuperimponuntur certis ordinibus \& firmiffimâ compage in figuram deprefsâ orbiculatam, Lupini in modum \& magnitudinem : ipfis verò Ovis fuperinjicitur FolIiculus è laxiori contexturâ; qualis Erucis nonnullis ufui eft: eft etiam aliud, è quo cura animalis erga fxtum non minùs apparet; nimirùm quòd fupra eundem folliculum, etiam multam fcobem freè obductam \& adglutinatam effe obfervavi.

Intra menfem autem ova excludi aut citiùs exiftimo; quc̀ hæc ova menfe Maio à communibus vinculis, quibus proximè à partu ea inter fe contineri jam diximus, relaxari fxpè advertimus.

Tenelli autem fxtus, primùm ut editi, fubpallidi funt: poltea verò, ut adoleverint, cundem planè colorem \& matris formam indiunt.

Septembri exeunte id genus araneolum de medio reticuli fila cjaculantem, omnium primùm animadverti: neq; fas eft amplius dubitare, quin longifima fila aerea, per Autumnum præcipuè notabilia, hunc araneum fuíq̣; fimiles authores habeant, etfi ea olim Nubium progenies credita aut aliàs oriri fabulata fint. 


\section{TITULUS.X.}

Araness cinerews, capitc leviter rotundo, picfurac cliso niuns foliaceâ, ad margines undat $\hat{a}$.

$S$ inter mediocres numerandis eft.

Ei color ex nigro cinereus.

Humeri leviter faltigiati \& fubrotundis eo atiem inomine appello quicquid eft in primâ corporis divifione, Iicèt ibi fit etiam caput; iidem leves $\&$ non pilofi. If furn autem caput videtur nigrefecre, \& per modum apicis acuti anguli aut cuneatim mediis humeris inferi.

Oculi nigricant, xquali magnitudine, ita difponnntur; quatuor $f_{c}$. medii in figurâ quadrangulâa, alii bini utring; fe. rè conjunctim.

Pedes exiles, leviter pilofi, maculori; horum primi omnium longiffimi, paulìm fupra dimidium unciæ; deinde fecundi, poft hos ultimi, tertii omnium brevifimi.

Alvus plena \& craffa; picturâ toliaceâ eleganti infigo nitur; ejus verò picturæ margines undatim defignantur; extrema lineamenta nigricant, at media ejus pars præcipuè verfus humeros albefcit notabiliter; verfus anum verò intra undas funt aliquot nigra lineolæ rectæ tranfverfim ductæ. Alvi latera maculofa; venter medius nigricat; nec defunt flavæ maculx ibidem.

Hic à proximè fuperiori in his differt; $\mathrm{I}$. Huic caput ${ }^{N \cdot B \cdot}$ fubrotundum, cìm illi fit compreffius \& velut fronte quadratâ. 2. Huic alvus plenior \& crafilor. 3. Hutc mediaalvi pictura albicat, cum illi tota nigricet. 4. Hic multominor eft. 5. Eft etiam aliquid fingulare in hujus reti, mox decribendum.

Admodum frequens eft in 'Tectis \& donibus circa Ebor Lows. racum; \& alibi. 
Rete amplum \& elegantiffmum tendit: illud autem in en perpetuum \& fingulare eft, nimirùm è radiis unicum maculis utring; andari, idq; è centro reticuli ad ejus ufg; circumferentiam; quod ferè ad aliquam in paricte rimulam aut alibi, ubi animal tutò totum diem latet, porrigitur : atg; hic radius ci velut fcala eft, per quem afecndat defcendátq;

Raro nifi fub Crepufculo in reticulo obfervatur; noctúq; adeò venatur.

oss. Exeunte Angufto ova majufcula parit juxta reticulum; ea filo laxiori Havicante involvuntur. Oćtoginta $\&$ amplius in uno Nido numeravi, iis color ex fufco lubalbidus.

MEMBRUM II.

De Araneis Reticula conglobata texentibus.

\section{A P. I.}

De Araneis reticula conglobata texentibus in genere.

1. TActenus excellentifimos Nature Artifices expofuiII mus; quorum opera erudita apud Antiquós merito appellantur: Genus deinde aliud eft Arancorum, reticula quidem diverfa texentium; at non multùm diffimili artificio. Etenim in fuperioribus univerfas maculas in codem flano fitu difpofitas effe dixinzus; hî̀ vero innumeræ maculæx, æquè patentes, in omnes dimenfiones quaquaverfum porriguntur; hic, inquam, multiplex eft macularum ordo five conglobatio fub varium fitum ex omnibus in circuitu partibus in orbem ferè projectarum. 


\section{De Araneis OEtonoculis.}

Eft fanè fua pulchritudo etiam rudi aut fortuitx contex. turæ; ctenim hæ Plagx è fimplicibus filis conftant, huc illuc temerè, credas, deductis; at in fpeciem ufúmq; oriuntur egregia Reticula. Illud equidem dubito, an non Antiquorum diligentiam fugerit, inter hos fuperioréfa; differentiam annotâffe; horum certè nullum adhuc evulgatum indicium in Scriptis invenio.

Hujus autem generis araneorum notæ characteriftica funt: $\mathbf{r}$. Habere pedes priores omnium longiffimos; deinde ultimos, tum fecundos; tertios breviffimos. 2. Effe ferè aut minimæ inter araneos, aut certè minoris magnitudinis.

Horum autem fex fpecies in Anglia invenimus, quas mox aggrediar.

\section{CA P. II.}

De Araneis Reticula conglobata texentibus in fpecie; quorum alii, Folliculi loco, flum laxiss, velut lanams carptam, Ovis Superinjiciunt.

\section{TITULUS XI.}

Araneus pullus, giaber, domefticus.

II IC eft omnium hujus Familixe maximus Araneus; Difriptrice 1 etiamfi, refpectu ad univerfum genus araneorum habito, mediocris magnitudinis fit.

Ei color pullus, ad nigredinem proximè accedens, glaber, lucidus.

Humeri mirrimè depreffi, fed in faftigium elevati.

Oculi octoni, requali magnitudine; quorum medii in $\mathrm{H}$ 
figurâ quadrangulâ díponuntur, reliqui extimi per paria conjuncim fere: neq; id licet difcernere, nili optimo Microfcopio adhibito; adco in tenebris eft caput propter fummam ejus nigredinem relucentem; illćdq; ipfum velut afperum \& inæequale.

Pedes nimitim nec breves nec tenues; quorum primi \&r poftermi intermedios longitudine facile funcrant.

Alvus plena, latiufcula, compacilis; coloi is pulli, rclucentis; ad ejus verù latera albet; ipfeg; venter fubalbidus; item per medios clunes rectà ducitur lineola albida.

Mas extrcmis cornictilis tumidis infignitur.

Iock\%

Is autem in adiblis noftris ad fencitrantum cancellos vallè frequens: ubictiam per hyemem latct, fi qua propè fit rimula.

Ineunte Aprili, intcrdum multò citiùs, reticula globata orditur; quo tempore cjus etiam alvus multo fpermate intumefcit. Reticuli filum folito fufcius eft; quod tum maxime apparet, fi plura reticula in unurn filorum fafcicuium colligas.

0:k. I6 Junif fortì animadverti; quod ex his quadam Aranea iam tim ova fua fenctræx cancello ferreo affixerat. Circiter 50 ova numeravi, quibus color pallide carneus, nec tamen charte illifa, illam inficerent.

Filum autem albidum circa ova laxius injutum Folliculi loco: quo fublato, ova protinisc diffufa funt; quod minime inter $\mathrm{re}$, ut in nonmullis fuperioribus fieri folet: conglutinarentur. 


\section{TITULUS XII.}

Arancus albicans, coronâ coccineâin alvo ovalì.

S autem eft medix magnitudinis, generis ratione ei color fubalbidus.

Pedes longiufculi, tenues.

Alvus plena figurâ ferè ovali; cujus pars fuperior exornatur coronâ quâdam coccineâ, fanè eleganti.

Hunc araneum in hortulo meo Eboraci femel tantùm notavi : at circa Cantabrigiam \& alibi in auftralibus Angliæ partibus fæpiús.

Ineunte Augufto in fuffrutice quodam hujus ova unà cum matre animadverti : ficco autem \& deciduo folio nidulata eft: plurima erant Ova alba; quibus multum filum ova. laxius fuperinducebatur, colore pulchrè cæruleo.

Filum corulea. un.

\section{A P. III.}

De Araneis peticula conglobata texentibus; gropme ova Folliculis membranaceis includuntur.

\section{TIT ULUS XIII.}

Araneus ferè fubfufcus, interdum variè coloratus, alvo

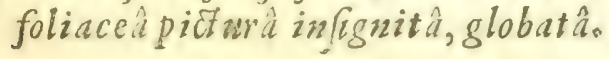

7 Nter minores numerandus eft.

Ei color ferè fubfufcus, ab hyeme maximè : at ncơ; hxe neq; alix, quod hoc loco femel monuiffe fat cft, ara- 


\section{De Araneis OEtonoculis.}

neorum fpecics, præcipuè à cuticulâ exutâ, unum atq; eundem colorem perpetuò obfervant.

Oculi xgrè difcernendi, nifi boni Microfcopii auxilio: at idem iis \& numerus, \& xqualis magnitudo, \& fitus, qui in univeris fuperioribus, i. c. quatuor modii figuram quadratam defignant, reliqui extimi utrinq; per paria ferè conjunctim difpofiti.

Pedes tenues, nec nimiùm longi, maculori; ex is antem primi omnium longiffimi, tùm poftremi, deinde fecundi, poft hos tertii onmium breviffimi.

Alvus ferè fphærica, nifi venter, paulo planior, id prohibcret; fuprà verò depingitur quádam folii timilitudine, cujus nervi venulæve dealbantur; intervalla ex fulco quafi purpurafcunt, idq; maximè fi animal foli obvertas: at ex utraq; parte folii veluti coftulæ aliquot, quæ obtufos angulos efficiunt cum medio nervo.

Venter infufcatur.

Loess. Ubiq; per Angliam frequentifimum Animal; prodire incipit circa Maium menfem.

Retia. Ineunte Junio, interdum multò citiùs inter geniftam fpinofam, in Acanthio, \& quibulibet proceris plantis retia ampliffima conglobata tendit \& juxtà nidificat.

Hujus autem aliorúmg; araneorum reticula tùm fpeciofiffima, maximéq; notabilia funt, cùm nox admodum rorida præceflerit.

mindus. Domicilium five Nidus è candidâ ac fífsâ Telâ confrcitur: fuprà autem arcuatus eft; fed quá terram fpectat, apertus.

coitizs. $\quad x$ Junii vefperi in Coitu id genus araneos vidi: mas foxminam aggreffus eft, fxpiùs reticulum tremulo motu concutiendo:quantìm autem difcernere licuit (maximámg; cá de causá dilingentiam adhibui) non alio Pene ufus eft, quàm Antcinns, foemineo ventri fuperiori alternatim applicitis, ut fuprà quog; in primo membro expofitum efe. 
Medio Junio, in fingulis Nidis fingulos Folliculos repe- Folizils. rire licet; quorum \& figura \& magnitudo eft in modum grani Piperis. Ipfa autem Ova exigua, candida, fphrerica, $2 \%:$. circiter 40 Folliculo linteo-formi, five menbranicio fabcaruleo frèc, interdun fed raro fubrufo inclufia, ut ex alio filigenere conftare videatur.

Illud magnopere miratus fum; aliquando me obfervâfe Folliculum extra Nidum fufpenfum.

Ineunte Julio in nomnulis Nidis binos Folliculos non rarò reperies.

Sub initium Augufti innumerum fatum in plerifa; nidis obfervare licet; $a b$ arancấ matre, ut opinor, uf̣; nutritum; cum quibus certè diutrì manct praedandi caufs, nè victus adhuc tenellis defit. Cui rei abunde fidem facit ingens copia cadaverum Mufcarum cxfuctarum in iplis nidis, tùm maximè obfervandarun.

Illud quoq; rurfus monendum duxi, humc araneum $\mathrm{Cu}$ tículam exuere folere à Calend. Quinctilibus, ut alius atq; alius clíe videatur: nam modò candidum, modò fubviridem, modo miniatis aut purpureis maculis interftivctum, aut aliis denig; formis notabilen frepiùs obfervavi: adeò parum eft, araneorum colores fcire, nifi nobis ctiam ipfa corporis figura, aliaz; difcriminantes notx, à victûs, partîs, \& morum ratione petendx, probə̀ fint cognitx.

\section{TITULUS XIV.}

Araneus rufus, clunium globatorum faftigio, in modust fella radiato, fylvicola. Roximè fuperiori xqualis, i.c. inter mizores nume- $n$ iftio.
randuseft. Ei color ruñs, aut ferè rubeus. 
Ex analogia conjecturam facio de Oculorum numero, magnitudine \&x pofitu; nam Capitis humerorumq: mira paryitas pro alvi ratione, \& ipfits alvi figura infolita, ca reddunt nimiùm vifu difficilia.

Pedestenues, rufi, non maculati; horum par primum longilinum, deinde ultinum, tùm fecundum, tertium omnium brevifimum.

Alvus in gibbum feu verticen orbiculatum admodum erinet; à cuo in anum acuminatum fubitò fit declivis: à fummo vero clunium faftigio five vertice radiatim procurrunt ex omni parte plures lineolx candidx in modun ftellx.

Venter planior.

Eft preterea animal glabrum, relucens, ut pleriq; hujus generis aranei.

Locuss. Rarifima Beftiola; at mihi centies vifa in Pomariis circa Cantabrigiam; itum in fyivis agri Lincolnienfis, \& in fylvis oppiduli Afcome dicti prope Bboracum.

R.ti...

Ipfis prexgrandit m Qucrcum Truncis ampliffima retia affigere amat; \&cinter majores alicujus arboris ramos: eft fane inextricabilis \& plune mirificus macularum contextus, five conglobatio.

Nidus. Ineme Janio niditicat; ídg; interdun perinde ut de proxime fuperiore cypofitum eft, fe. Nidum lintcofornem lipras arcuatum, infla aperum, ad Cafidis fimilitudinem conficit: interdum vero nido extemporaneo contentus ett ; fc è folio aligno deciduo \& marecfecmte confecto; inf autem Nidi for in medies reticulis collocantur.

In fingulis autem hujufmodi Nidis, fub initium Augufti plures arancolos inswuali partu reperi : fin vero citius in nidum incidas, plerung; duos, modo tres, quatuorve, \& Folliculi. interdum quing; folliculos, ovis repletos numerabis: unufquifq; antem Folliculus \& magnitudine \& figurâ lenticulari eft, \& colore fubrufo. 
Aliquando in quodam id genus nido, (fed femel id tantìm) à me unicus repertus eft follicutlis piri minoris magnitudine; in quro etium multo major ovoram conu inclufa eft, quàm pro confuetudine animalis.

\section{TITULUS XV.}

Arancus cinereus ì minimis, macula nigra in fomats clunibus infrgnitus.

T. I IC eft in minimis vel fui vel alterius generis neme- noinge. randus ; ita ut perdifficile efteun cxacte deferibere. Ei color cinereus ad nigredinem vergens: pilofus.

Quis fit oculorum \& numerus \& ordo bono micro-

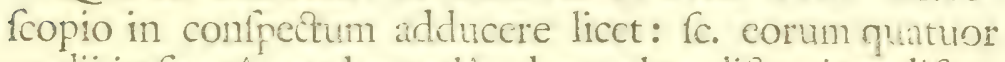
medii in figurầ quadrangalà ad xqualem diftantian diponuntur, \& utring; alii bini propius collocati.

Pedes crafli, breves, fubrufi, maculoin; quomin primi \& ultimi medios longitudine excedunt.

Alvus à pcetore plenior, paulatímq; fit acumination s fuprà in fummâ alvo pragrandem maculams nigeam confpicere licet: it'mgs pavioinfa illan verfus anum funt: aliquot lincolz, fufcr, obliqux, relut totidem coftulas.

In funmis Genifte frinole furculis; item in Eruretis u- Toouso big; frequens à Maio menfe.

Reticula exigua pro proportione anmalis ì phurimio wath. conglobatis maculis tendunt.

Item Mufce in iis capte funt perexiguæ.

Ferè juxta Reticula nidificant, Junio mene, interdum citiús.

Albila Ova pariunt ; circiter quings in Folliculo is is a.

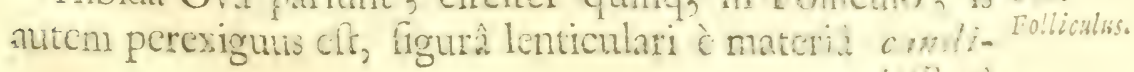
dilgimit 


\section{De Araneis OEtonoculis.}

diffimấ membranaceâ five linteoformi. Horum verò folliculorun plures fimul in codem nido, more aliorum fiui generis, fexpiis notavi.

Diverfimode nidificant; interdum fupra alicujus arboris aut herbse folium, in Reticulo venantur, dum Ovorum folliculi infra idem folium affixi fint: interdum in Ericetis montium noftrorum altifimorum in partibus Anglixe borealibustoplures hujus aranei (an, alius valdè fimilis) Folliculos intra aliam Thecam è laxiori contexturâ inclufos, fxpius obfervavi : interdum, quod notabile eft, folliculum hujus aranci alteræ cerafi fructîs maturi \& edulis extremitati, ubi fc. commodiffimus huic rei finus oft, affixum centies vidi; tu verò illam facilè credas candidam maculam effe vel fquannalam nefcio quam, vel quamlibet aliam rem, quàm quæ eft: adcò ftomachi maximè delicatuli quoties hanc innocuam buccam non minùs ignoranter, quàm avidè devorârunt!

\section{T IT ULUS XVI.}

Arancus pufllus, lividus, piçurâ clunium nigrâ dú veluti denticulatà.

r.t.initim.

S proximè fuperiorem magnitudine xquat; pufilla admodum beftiola.

Ei color fublividus.

Ejus octoni oculi non, nifi optimo Microfcopio, in confpectum adduci pollint; etiam ipfum caput pritus trans flammam, huc illuc aliquotics celeritérq; dimovendum eft; ita cnim, capite à pilis albidisnudato, apparent oculi, fuccini inftar fplendentes; cand 'mq; difpofitionem fervant, qualem in univerfis fuperioribus expofuimus.

Pedes tenues nigricant; corum prini, deinde ultimi, tùm 


\section{De Araneis OEtonoculis.}

tùm fecundi, poftremò tertii, alii alios longitudine fupc rant.

Alvus figurâ plenâ \& compactili; fuprà exornatur nigerrimâ quâdam picturâ foliaceâ, quafi denticulatầ; fíquidem verfus anum funt quædam lunatæ lineolæ, quarum quæ fuperior proximè inferiori gradatim minuitur.

Maio exeunte, id genus araneos aliquammultos inter Locuss geniftam fpinofam inveni: mares quoq; unà cum foeminis etiamnum aderant, tumidis corniculis infigniti.

Circa fummos Geniftæ fpinofx furculos reticula conglo- Retia. bata tendit.

Ibidémq; quoq; nidificat: 4 die Junii aliquot folliculos paucis ovis repletos in fingulis nidis inveni : iidem auten? Folliculi funt exigui, figurâ lenticulari, ex materia linteo- Folliculà. formi five membranaceâ confecti ; is color ex viridi fubcæruleus.

\section{MEMBRUM III.}

De Araneis Telas linteoformes texemtibss; nimirme reticulorum filis densè inter fe contextis in geodum Veli free Panniculi.

\section{CAP. I.}

De Araneis Telarum authoribus in genere.

A Ranei lintearii Telas ad noftrum artificium haudA quaquam componunt; quamvìs corum opera ejus fpeciem quandam præ fe ferant. Antiqui quidem voluerunt nos ab hifce animalibus fimilia opificia edoctos fuiffe, 
"a arinoftros ufus per imitationem tranftuliffe; $f e d h x \mathrm{Fa}$ buis funt : hic certe nulla efe filorum elegans \& ordinata contextura, nifi quam cafus dederit; fiquidem in horum araneorum operibus nihil minus notctur, quam ftamen tramáq; : red illud quog; à veritate nimium aliemum eft, guod fint confecta fine filis tranfverfim actis, ex artriflima quadam villorum in longum continuitate, ut Mon! fetus credidit.

Alii autem fpiffam, alii tenuiorem Telam pro cujufg: natura \& ufu conficiunt : omnes tamicn cam in hunc fere modum, quantum nobis adhuc obfervare licuit. Primim ab his fila horfum atg; illorfum temerè deducuntur, idem fpatium femel atq; iterum omni ex parte percurrendo, imum anum fubinde admovendo, figilli velut ufu ad $\mathrm{ea}$ firmanda intérq; fe adglutinanda; donec à fimplicium filorum in codem fere plano deductorum multitudine, illnd plene occupârunt, ac fi quoddam velum efict expanfum.

Eft ctiam in quo hi commune artificium ad venationem cum proxim fupcrioribus oftentant: nam prater $T e$ lam five Velam expanfum, funt etiam plurima fimplicia fila defuper prectenfa, ings qualdam grafi maculas difpofita: ut funt in Navibus ab antenna malif́q; Funes: and hec fer primo mufex impingunt, deinde in ipfas Telas precipitantur.

Hujus vero generis araneorum hæ funt notæe characterifrices. 3. Habere quafdam circiter quatuor Appendices, ab ano prodcuntes, mobilos \& flexibiles Textrinx apprim: accommodatas; quarum quod duæe fupcriores fere reliquis longiores funt \& valde confpicuæ, bifurcatá coudá infigniri videntur. 2. Ex quatuor mediis ocults, qui duo ori propiores, minuts inter fe diftant, quàm aleeri bini fuperiores. 3. Duo poftremi pedes totidem anteriores longitudinge vel fuperant vel xquant. 4. Plerofís cffe pilofos. 
De Araneis OEconoculis.

\section{A.P. II.}

De Araneis Linteariis in fpecie.

Hujus autem generis funt alii, qui den fam or Jpiffars Telam conficiunt; ip sífq; Telis, prope infundibslum, nidificant.

\section{TITULUS XVII.}

Arancus fubflavus, birfutus, prelongis pedibus, donsefticuss.

$S$ ferè inter mediocres eft.

Ei color fubllavus, aut pallidè fufcus, maculofus, hirfutus.

Humeri latiufculi, at paulo anguftiores verfus frontem.

Ejus octoni oculi nigricant, \& valdè confpicui funt; quatuor medii in figurầ quadrangulâ inæqualiter inter $\mathrm{fe}$ diftant; fiquidem qui ori propiores funt, magis appro* pinquantur; reliqui verò per paria utring; difponuntur, \& conjunctiores inter fe funt.

Ex pedibus ultimi longiffimi; polt hos primi; tùm fecundi; breviffimi tertii.

Alvus ei plena, ferè æquali craffitie; fuprà duplici fuba flavarum macularum ferie infignitur, item huic ibidem quædam obfcuræ lineolæ ad angulos acutos concurrunt.

Appendices $a b$ ano confpicux, more hujus generis fingulorum.

Vetuftate fiunt facilè omnium multò grandiores; ut arancorum monftra videantur; at id non ab alvi incre- 
Co D. Araneis OEtonosulis.

mento, quæ ferè etiam in his modicæ aut minoris magnitudinis eft; fed in fummâ pedum \& craffitie \& longitudine \& hirfutie. Hi verò rariffimè occurrunt. In fuperioribus aliquibus (vide T. T. I. 3.) fimilis obfervatio expofita eft.

tosks. Is autem araneus in $x$ dificiis fqualidis nimiùm frequens eft; in fylvis quoq; à me aliquoties inventus eft.

Sub initium Junii in iifdem Telis marem unà cum foeminâ adfuiffe notavi; his animi causâ nufcas injeci ; è quibus una à foeminâ, altera à mare arrepta eft.

Julio exeunte, nidificat in medio linteo prope infundibulum; quo loco perpetuò fe continet ad prædandum;

2u.s. ipfis autem ovis fuperinjicitur altera tela nivea, ac fi ea intra Telas intertexta fuiffent.

Ipfa autem ova albida funt ; miniméq; inter fe cohæsent; fed, aperto folliculo, diffluunt.

\section{TITULUS XVIII.}

siraneus cinereus, maximus, ani appendicibus infigniter prominentilus.

Denisitis)

In maximis araneis numerandus eft.

Ei color cinereus aut fublividus.

Humeri fufci, craffi, in medio paululùm faltigiati.

Oculi ita ordinantur; nimirùm quatuor in figurâ quadrangulâ, reliqui verò quatuor utrinq; per paria ; ad corum fc. angulos ex quatuor mediis, qui ori propiores funt $\&$ minùs inter fè diftant.

Ei pedes crafifi, longiufculi, fpinulis hirfuti, maculofi; idémq; de corniculis dictum fit. Ex pedibus primi \& ulvimi ferè æguali funt inter fe longitudine; tùm fecundi ; tertii breviflimi.

Tela ex atro rubent.

Alrus 


\section{De Araneis OEtonoculis.}

Alvus fublivida plena admodum, productior; à pecto. re paululùm declivis five acuminatior verfus anum; fuprà utrinq; circiter fenæ lineolæ fubalbidæ, ad obtufos angulos coëuntes.

Venter fufcus, planus.

$\mathrm{Ab}$ ano eminent ex appendicibus maximè duæ velut altera cornicula; quas dum ingreditur, perpetuò motitat.

Menfe Maio, caput humeriqg; corum, qui modicx mags nitudinis funt, aut nondum adulti, colore fubrufo in modum mali aurantii infigniurtur; item his alvus fublivida; neq; tamen reliqua ejus lineamenta-nizaiùm obfenra funt, quin facilè difcerni pofinnt:

Julio exeunte, mas unà cum furmina in ixidem Telis re. atas. peritur : huic pedes multò longiores, extremáq; cornicula velut quibufdam capitibus five nodis turgent.

In Auftralibus Anglix partibus hx befriola admodnm Loens. frequentes. $;$. at in Septentrionalibus rariès occurrunt; in. ter geniftam tamen fpinofam etiam circa Eboracum \& ali. bi cos multoties vidi.

Per hyemem $\mathrm{fe}$ abfondunt, in parietum fiffuris, ant ayjernn fub cortice alicujus annofx arboris, Telis fpiffis involuti.

A folftitio autem xftivo hos in vepribus \& dunetis invenire licet: ubi Telas onnium ampliffimas pandit; illud tera. verò perpetuò curat, ut fit retrò cellula, five patulum foramen in fundo Telæ, quà fe celeriter recipiat, aut ubi tutò habitet, præaxg; capiendæe invigilet. lliud infuper in his Telis maximè notabile eft, multa fim plicia fila, velut navis apparatus, funes quod fpectat, ab incredibili aliquando altitudine (modo id propter loca opportunum fit) rectà deorfum fuper linteum cadunt, \& tranfverfim etiam deducuntur; in hæe vero fi mufcx of fendant, in lintei finum fubter pofiti precipitantur.

His vel maximæ Apes predxe funt; at Formicis majori-viatuse bus vehementer delectantur; adcóq; juxta carum colli- 
culos ferè telias præpandunt: an fortè ideò aciditatis id genus animalium participent, aut aliầ quavis proprietate exccllant. In infundibulis certè ingens copia nufcarum aliorúmg; infectorum occiforum.

A Calendis Sextilibus, non longè ab infundibudo, Folliculum obfervavi, ipfis Telis intertextum; in hoc verò

Qva plurima Ova albida (fexaginta ipfe numeravi;) fed on!nium cujufcunq; fpecies araneorum, hactenus mihi viforum, maxima.

Ex his forminam gravidam, vitro inclufam diu fervavi; fubindè mufcas, fcarabæos, aliquando ctiam fui generis araneos aliórq; majufculos victui fubminiftrando; quos omnes illa mox acriter aggreffa eft, ac fuo more fugendo, artúfq; diripiendo depafta eft. Poft menfem verò exactunz ova peperit, eáq; in medio vitro fufpenfa miris telis involvit; ipfe autem Folliculus ftell $e_{e}$ in modum formatus eft; ipfúmq; præterea vitrum fatis amplum aliis filis, velut fumo implevit; inquo tamen vias, \& itinera, plurimáfq; quafi concamerationes reliquiffet, quibus liberum fibi aditum ad folliculum aperuiffet. Poft diem verò à partu vigefinum, circiter Cal. Septembres, quòd ne adhuc quidem ullam mutationem trans vitrum in ovis obfervare potuiffem, ut in aliis fimilibus experimentis didiceram, folliculum è vitro eximere \& aperire volui ; ut fi fortè ipfe telæx aut quid aliud Araneolorum nafcentium exitum impedirent, notarem. Ecce autem ova jam tùm integra inveni ; imo ita ut planè nihil inerat in illifis ovis \& microfcopio examinatis, preter fui fimilem materiam prorfus immutatam, \& talem qualem ab initio corum partûs. Propter affiduam verò fovendi curam, atq; ipfius matris $\&$ multo ante partum \& polt eum fumman alacritatena, quòd omnes mufcas victui oblatas nunc ut ante partum acriter interficeret, ac liguriret, in animum inducere vix poffem, illa Ova irrita aut fubventanea fuiffe: fufpicor 
tamen, ut in ufu eft quarundam Papilionum ovis, diu, imò per totam hyemem integra manere, antequam ex iis fretus edendus fit. Quævero ex his reliqua fuerunt ova, nam omnia non illifi, iterum vitro indidi, eáq; ftatim folitâ fuâ curâ amplexa eft mater, alíf̣́; novis telis diligentififimè involvit.

Medio autem Septembri plurimos bujufmodi folliculos, quos in vepribus inveni, aperire \& excutere volui: in quibus fingulis Ova fimiliter integra notavi.

Proximum vero experimentum iteravi ; aliémq; gravidam fub idem tempus anni vitro inclufi; $a b$ illa vero idem folliculus ftellatus itidem confectus eft; in quo Ova etiam trans vitrum mihi fatis vifibilia, \& à me diligenter obfervata funt per totam hyemem: at eadem rerum facies ufq; ad Februarium menfem; quo tempore è folliculo egreffi funt Araneoli, verfúfq; vitri os afcendere ceperunt; in hoc autem ftatu eos ad medium ufq; Aprilem fine ullo victu fervavi; tandémq; è vitro excuffos, fui juris feci.

ÆEftate autem admodum calidâ anni 1676 exeunte Augufto, horum folliculos aliquot aperui, in aliis ova integra reperi; in aliis verò araneolos exclufos \& coloris fubrufi; at Folliculi tunicx adhuc integræ fuerunt. 


\section{A P. III.}

De Araneis rariori ể tenui Texturâ Telan conficientibus; or qui extra quidem, fed tamen juxta eame Nidificant.

\section{TITULUS XIX.}

Arcneus niger aut caftaneus, glaber, clunibus fummo candore infterftinctis.

Dyforiptión IS verò modicx magnitudinis eft.

Ei color nigricans.

Oculi ita ordinantur, ut quini tantùm videri poffint; fied if quis eos diligentiùs microfcopio examinaverit, ex quatuor mediis, qui propius Tela five animalis os, unicus videtur; cùm tamen planè duo fint : qui verò retrò fupra frontem ponuntur, manifeftò fingulares funt, \& ex longiori intervallo fitum habent; item reliqui quatuor extrà poriti, utrinq; ad ąngulos ipfius frontis ordinantur, parúmq; diftant, quin potius proximè conjungantur.

Pedes longi, tenues, maculofi; primi an ultimi longiores? Poft quos fecundi; tìm tertii breviffimi funt.

Alvus ei plenior, orbiculatior, paulo declivior \& acuminatior verfus anum; huic color caftaneus ad nigredinem accedens, maximè in ventre \& fuper clunes; tamen ad alvi latera è candido variatur, idq; præcipuè in gravidis confpicitur; in quâ etiam pars alvi fuperior lineolis quiburdam candidis tùm maximè notabilibus diftinguitur.

$\mathrm{Ab}$ ano appendices quædam extant.

Fœminis 


\section{De Arane is OEtonoculis.}

Fœminis paulò ante partum alvus magis intumefcit, a. deóq; inflectitur, candidóq; nitore etian foliaceo pulchrè difinguitur. Mfaribus vero gracilior \& aliquanto pro- Mass dudior alvus, retufa, haud ullo candore diftincta; pedes rufefcentes; tela eorúmq; brachia valida; extrema cornicula tuberculis infignita.

Hic autem Arancus à primo Vere in fylvis frequens, ac zockso fi quis alter: item libiq; per prata, \& in foflis ficcis herbidífq;.

Omnium longè tenuifimam telam pandit; at latam; Tela. eámq; æqualiter expanfam fuṇa fummam herbam, aut ad. quercuun truncos: item hæc pertenuis Tela ex fuperiore parte inftructa eft innumeris flis fimplicibus, in modum teticuli conglobati intertextis; in qux cùm offenderint nec opinantes Mufæx, in linteum præcipitantur.

Ipfius autem Telæ conficiendæ ratio, quod fxpiùs vidi, hæc eft : nimirùm $\mathrm{ab}$ ano fila continenter remittit beftiola; eáq; quoquoverfum temerè at ferè in eodem plano deducit; fubinde fila priùs remiffa ani apice leviter tangendo; quod ubicunq; fecerit, hæc noviffima fila aliis firmiter adhærent. A medio Martio ad orientem folem hæc tu quoq; quotidie obfervare poffis.

A primo Vere in pratis pafcuifq; funt innumeræ quædam exiguæ telæ five linteola, ita tenues raræq; ut de die penè vifum, certè minùs diligentem effugiant: at fummo manè ob nocturnum rorem valdè confpicux fiunt: hujus verò generis araneolorum Opera ca maximam partem fuiffe exploratum habeo.

In his autem Telis nullum infundibulum aut Tubulus eft: fed perpetuò fe continet araneus fubter telam, cœlun fpectans; Mufcas verò, qux in telam incidunt, trans ipfam telam, quam fuprà diximus effe rariffimam, fibi attrahit.

In fylvis fqualidis vetuftífq; uti funt, quæ prope $A$ fcoree agri Eboracenfis, ad quercuum Truncos innumeri id ge- 
nus aranci telas fuas pandunt. Junii verò medio juxta fingulas telas fingulos folliculos reperire licet.

Folliculhss, Folliculus autem è laxioris \& folute texturæe filis fit; Ova ipfius autem folliculi filis demptis, Ova, quòd ninimè inter fe cohærent, diffluunt; ipfa autem intùs comprehenfa non pauca funt, ex flavorufefcentia.

Item in aliquibus duplicem partum notavi; unum fc. folliculum juxta alterum afixum; at eos inæquales; nempe ex uno araneoli editi, in altero ova nupèr parta. Ex his alias infuper forminas, etiam ineunte menfe Septembri gravefcere, frepenumerò vidi; maréf́; tùm unà adfuiffe in iifdem Telis. Item earundem folliculos autumnales, ut opinor, per totam hyemem reconditas effe in mufco ad radices annofarum arborum.

Ad Cal. Novembres hujus fpeciei penè infinitam prolem paffim notavi, precipuè filiorum ejaculatione \& volatu mirè fe exercentem. Illud quoq; addendum de his putavi; me animi causâ ex his, qui ex aëre defcendebant, aliquot cepiffe; qui quidem ftatim ac è manibus meis dimitterentur, altero protinus ejaculato filo, intrepidè afcenfum rurfus in aërem moliti funt, atg; è confpectu meo longè evolavêre.

Horum verò Araneolorum forma ab adultis eorúmq; parentibus mirè abludit: his enim fumma nigredo refplendens, exceptis pedibus, qui, uti diximus fuprà in maribus, crocei. At ea fuligo, ut adoleverint, in caftaneum tranfit, multóq; candore diftinguitur. Item à comiculis tumidis etiam nunc mares minutili facilè dignofcendi. Rurfus exeunte Marcio ex iifdem Araneolis pufillos admodum, haudquaquam auciores quàm longè ante brumam, obfervavi ; tùm hos etiam colorem ex atro refplendentem fervare, \& pedes fubcroceos habere. 
De Araneis OEronoculis:

\section{TITULUS XX.}

Araneus fuligineus, \& bumerorum faftigio, ob clwnitis picturấ candidâ, ad margines denticalatâ.

I Di color fuligineus.

Humeri parùm elevati, faftigio candido.

Oculi ob infignem capitis nigredinem difficilè difcernendi ; eorum veró medii quatuor inæquali diftantiâ difponuntur; ut qui fuperiores dno magis, qui verò duo ori propiores minùs inter fe diftent; reliqui quatuor con. junctim ferè ex utraq; parte bini.

Pedes non nimiùm breves, hìrfuti, maculofi, fic ordinati; ultimi omnium longiffimi, deinde primi, tùm fecundi, tertii brevifimimi.

Alvus productior, ferè æqualiter craffa, an paulo plenior verfus anum, fubteres, fuprà candidâ picturâ admodum infignitur; cujus picturæ latiufculæ margines lineolis nigricantibus denticulantur.

$\mathrm{Ab}$ ano appendices confpicuæ.

In regione montosâ agri Eboracenfis Craven dicti, nuf- Losia. quam non inter maceriam reperitur; item in agro Lincolnienfi, \& non rarò circa hanc urbem in locis fimilibus illum inveni fatis frequentem.

Telam non nimiı̀m amplam, rariffimâ pertenuiq; tex- Tila: turâ, pandit : hujus autem medio eft quoddam infundibulum five Tubulus, è quo prædæ capiendæ causâ dilio genter invigilat.

Maio exeunte, mares, corniculis tumidis alvo ftrigofiore confpicui, unà cum forminis adfunt in iifdem telis.

Fœminis paulò ante partum, cùm iis alvus nimiùm diftenditur, pictura clunium minùs pulchra eft.

$$
\text { K. } 2
$$


Junio menfe ejus ova pallidula alicui lapidi affixa pone infundibulum facilè reperies; ea autem candido Folliculo diligenter involvuntur.

\section{CA P. IV.}

De Araneis minùs propriè dictis Telarum authoribus.

\section{PR I VA T I M}

De Araneo, qui inira Jpeluncam Telam quidem five infundibulum linteum conficit; cui for às adnectit Reticulum è maculis in plano quidem difpofitis, at inordinatis ou rudibus.

\section{TITULUS XXI.}

Araneus nigricans pragrandi macula nigrâ in fummis clunibus, cetcrim iifdem imis oblique virgatis: an Speluncarius Monfeti?

Defcriptio.

\section{I IC majoribus annumerandus eft.}

Ei color nigricans five fufcus. Tela ex atro rubent.

Humeri craffi \& in quoddam faftiginm fubrotundum eminent; ipfum caput paulò planius êt.

Oculi, è microfcopio vifi, coloris fuccini apparent: ita ordinantur, ex quatuor mediis qui duo fupra frontem retrò pofiti, parvo intervallo inter fe diftant; ori verò, qui duo propiores, multò magis; alteri quatuor per conjugationes lutrinq; difponuntur. 


\section{De Aruneis OEnonoulis.}

Pedes craffi, maculofi, nec nimiùm longi, quorum u?timi longifini, an primi, tim fecundi, tertis brevifimi.

Alvus admodum plena, ad anum paulo crafilor, quàm à pectore : fuprà proximè à pectore eft nigra mactih pregrandis ferè parallelogrammoides, circa quam maculans obfcurè flavefcit, infra candem ex utraq; parte aliques obliquæ virgulæ coëunt ad angulos obtufos.

Venter creberrimis maculis nigris infufcatur.

$\mathrm{Ab}$ ano breviores aliquot appendices.

Tota ferè beftiola molli lanugine contegitur.

Maribus verò pedes altero ferè tanto longiores lunt, Mras. quàm fominis.

In parietum fifuris per hyemem latet, candidis Telís involutus: item id genus Aranei fumma altifimorum Ten? plorum tecta, Turriúmve faftigia libenter fandunt; in ædificiis ubiq; frequens \& alibi in rupium fiffuris.

Eft autem dubii aut mixti Operis auctor: etenim in- Telho fundibulum linteoforme primò texit; deinde huic reticulum adnectit, circumcirca ad parietes prepanfum; itlud verò è maculis inordinatis, in eodem tamen plano terè difpofitis.

Ipfa autem reticuli fila inxqualiter craffa funt; folito candidiora, ac li opaca effent ; texturâ folutâ, inftar $\mathrm{Ce}_{\mathrm{e}}$ rici nondum in filum torti.

I8 die Junii ex his plurimos in maceria inveni, candidis Folliculzs. Telis fpiffis involutos; intra quos tamen unà femper aderat Folliculus rariori texturâ, ova continems. Inf a atem ova inter fe foluta, albida, numero pauca; ciiguâ cos. magnitudine citra animalis proportionem : an plura edant partitis vicibus?

Item in aliquibus nidis Aranenli jam cditi.

Ex his foeminam gravidam unà cum foolopendrí ma iore rufâ, infeetíf;; telis armatâ, fub codem vitro incluft : illam verò aggreffa eft aranea, cémg; pluribus in locis morden-- 
do confecit; vulneribúfq; adharens fuctu eam depafta eft.

Huic aranco, dum in Reticuli veftibulo pradæe capiendæ invigilabat, majufculam mufcam conjeci; quam celeriter quidem arripuit, atq; unico morfu, quantum notare potui, occîdit, ita ut temporis momento ex toto immobilis atq; emortua eft.

Per hyemem maximè in tempeftate pluviofâ prorepune hi fimiléfq; aranei domeftici: illud verò in caufầ effe poffit, eorum cavernulas ruinofas, ubi eos latere diximus,contra vim tempeftatis non fatis tutas effe: ipfi autem ejus favitiam ex parte patiuntur, priùs quàm ex hybernis migrant: aut cùm huic fimile aliquid incidit, potiùs quàm nefcio cui animalis præfcientix referendum effe exiftimo.

\section{A P. V.}

De Araneis linteariis, qui parvâ admodum Tela ad predandum contenti funt; intráq; illam quoq; $\mathrm{Ni}$ dificant.

\section{TITULUS XXII.}

Arancus cincreus mollis five lanuginofus, cui in alvo ob.

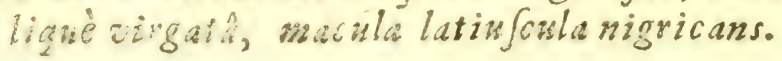

N Ner maliocres numerari debet: ei color cinereus; totus mollibus pilis lanuginéve contegitur : tela rubent. Humeri eminent faftigiati.

Oculonum hac eft ratio; nempe quatuor in mediâ fronte, quomm duo fuperiores fatis longo intervallo diftant; 


\section{De Araneis OCtonoculis.}

ftant; duo verò inferiores ferè conjunguntưr, an etian paulo majores hi? deinde alii bini ex utraq; parte etiam. conjundtim pofiti; at obliqué.

Pedes tenues, breves, non maculofi ; quorum primi reliquos longitudine multùm excedunt, deinde ultimi, tùm. fecundi, tertii breviffimi.

Alvus plena, productior, ejúfq; media paulò tumidior; infuperiore parte macula latiufcula è nigro rubens; at infra maculam aliquot obliqux virgulæx ad obtufos angulos coëunt.

Longiores $\mathrm{ab}$ ano appendices tantifper oftendit beftiola, dum fila libenter ducit.

In fylvis \& in vicinis pratis, alibígio præcipuè aufteali- Lockso bus Anglix partibus, non nimiùm rarus.

Per hyemem verò latitat fubter annofarum arborum corticem.

Mediâ æftate \& circa autumnum ex his foeminás plữ mas inveni, in candidis Telis vel folliculo inclufas unà cum fretu, aut jam edito, aut adhuc in ovis. Hui fmodi antem Folliculi ferè in fummis herbis proceris inveuiumtur. Atq; eadem ratio \& nidificandi \& prædandi, quiw cum fcio, eft.

\section{TIT UL, US XXII.}

sraneus plerung; lividus, non rarò tamen fibplavas, fine ullấpicturâ.

TS autem ferè modicx magnitudinis eft; ctî́ ex îs fint, Defcriptrio. I qui inter majores numerari debent.

Ei color fublividus, qualis in muribus domefticis; mo* dò fubllavus, aut fubrufus; ejus tamen color, quicung; fit, nullâ picturâ aut maculâs variatur, fed ex toto fui finmilis eft.

Breyifimis. 
Brevifimis denfiftmifq; pilis mollibus contegitur, non fine quodam fplendore.

Ej:s Tulangerrima, admodum craffa validéq; adeóq; ejus mortis pertmefcendus, quod vehementer noxius effe pofite.

Humeri lati \&x paululum gibbi.

Octoni oculi xquali magnitadine funt, sícq; ordinantur; quatuor medii inaqualiter diftant; ut fuperiores propiores inter fe fint, infertores ex intervallo majori: reliqui quatuor utrinq; bini difponuntur conjunctim feré.

Pedes longe omnium craffiffini funt, nec nimiùm breves; eorum primi, fecundi, ultimíq; longitudinom quod fpectat, non multùm inter fe differunt: neqj verò tcitii adeò breves funt, ut in reliquis arancis. Illud fcmel notavi, è primis pedibus dextrum \& multo tenuiorem \& fuo compari breviorem; an id fortè per accidens?

Alvus productior, paululum acuminata, unicolor; $a b$ ano appendices quidem, fed non nimiùm extantes.

Locks.

in ruderibus \& dumetis frequens; iten in 2 dificiorum parietibus non rarus.

Candidis $T$ clis inclufi per hyemem latent, maxime ubi alicujus annofx arboris cortex malè adharet.

Ex his aliquot thecâ ftanneâ incluferam, eófq̣; fingulos poftridic fingulis folliculis involatos notavi.

Humor, qui ab acîs puncturí ex corum corpore profluit, pellucidus eft, \& dilutus admodum videtur; tamen paucis momentis exficcatur, \& fit fragilis velut quoddan gluten.

Exeunte Junio ex his foeminam inveni fubter coryli corticem latentem, amplifiq; telis inclufam: quibus demptis, in aliis interioribus telis Folliculum adverti, multis Ova. ovis ferè candidis five niveis refertum.

Ipra autem Ova majufcula \& numerofa fuerunt; aperto folliculo, quòd minimè inter fe cohærebant, diffiluxerunt. 


\section{De Arane is Odronoculis.}

Sub idem tempus eundem Folliculum fubter alicujus ar. boris folii partem pronam affxum obfervavi; alifíq; telis coopertum; intra quas ipfe etiam araneus latuit.

Item ad Calendas Quintiles in fummis herbis proceri- Venatio. oribus plures hujus generis araneos fueminas intra fuas telas inveni : ubi etiam numerofus fæetus: præter linteum verò alia etiam fila fimplicia in quafdam quafi maculas circumcirca difponere folet. Ut \& venandi \& nidificandi eadem ferè ratio fit.

Hunc Araneum in ædibus noftris fæpè Erronem vidi; illúdq; adeò non filendum duxi, me alterius cujufdam aranei ova fortè in menfâ negligenter reliquiffe: qux mox ex his erronibus aliquis avidè corripuit, dimidiúmq; folliculum in paucis horis depaftus eft ; imò verò poftea, ut rem certiùs explorarem, folliculi femiefi reliquum in eandem menfam de induftria remifi, eundémq; helluonem fub noctem reverfum, \& folliculum rurfus ligurientem deprehendi 
De Araneo linteario anomalo, five fui generis, an feu noculo?

\section{TI TULUS XXIV.}

Araneus fubflavus, alvo qualı cylindraceâ maculis quadratis infignitấ; item cui ad alvi latera fingula oblique virgule flavefcentes.

T S T animal lanuginofum; \& è majoribus araneis. 1- Ei color fubflavus aut paulò fufcior.

Humeri fubfufci.

Tela nigricant.

Illud planè fingulare, fi verum, huic non ampliùs fex Oculos datos effe; fed me vitrum meum fortaffe fefellit. Ita autem, quos difcernere liceret, difponuntur; nempe in mediâ fronte bini ex intervallo, \& ex utraq; parte alii bini ferè conjunctim: atq; $i i$, qui in mediâ fronte, paululùm minutiores mihi vifi funt, quàm reliqui extimi. Sed hæc curiofiùs exploranda.

Pedes crafii, non nimiùm longi, maculofi.

Alvus productior, ferè cylindracea five teres, obtufa, plena; in fuperiore alvi parte eft quedam quadratarum macularum feries, catenæ in modum difpofitarum; exdémq; nigricant, at fi foli obvertantui, purpurafcunt; tota preterea alvus crebris punctulis fufcis confpergitur; item ad alvi latera utring; funt fingulæ obliquæ lincolæ Gavefcentes.

Mares corniculis tumidis infigniuntur. 


\section{De Araneis Octonoculis.}

In auftralibus Anglix partibus fubter annofarum arbo- Eocuss

rum corticem, item in parietibus admodum frequens: apud nos verd in feptentrione rariffimè occurrunt; tamen ex iis paucos inveni in maceriis regiunculæ montofe $\mathrm{Cr}$ ven dictx.

Per hyemem in candidis Telis latent.

Ad Calendas Junias ex his forminam in maceriâ inveni, Telis inclufam unà cum fæu numerofo.

\section{SECTIO II.}

De Araneis Venatoriis, fc. qui aperto Marie mufcas ino fectantur, nullo artificio vel reticuli vel Tele adbibito.

\section{A P. I. \\ De Araneis Venatoriis in genere.}

- Actenus araneos retium textores, cujufcunq; illi ge 1 neris fuerint, expofuimus: in alterâ verò fectione ea araneorum genera proponam, qui, cùm aliàs poffint, neutiquam tamen prædandi causâ texunt. Etenim, duñ ova Folliculis diligenter includunt, ea fxtûs cura eft: deinde ex iis plerofg; per hyemem in elegantiffimis fui artificii telis latitâffe ipfe deprehendi; adde quòd iidem laceffiti, de ventre fila remittunt; atq; ea fui cura eft, ut injurias evadant. Ipfumg; idem deniq; tùm libentiffimè factitant, ubi fereniffimis illis diebus autumnalibus mirificâ filorum ejaculatione, \& in aëre vectione vehementer oblectantur; quam tamen exercitationem, mufcas capien- 


\section{De Araneis OEtonoculis.}

di causâ fieri fufpicari fas eft. Hi autem omnes Veratorii à me appellantur, quòd prædam infectantur, non expectant. Ut autem in genera inferiora eos diducerem, fingulorum notas communes \& convenientias primò percurram.

\section{A P. II.}

\section{De Araneis Lupi dictis in genere.}

E Luporum autem nomine minùs contendo, an proximè defcribendis folis conveniat, aut etiam aIis quibulibet araneis acriter prædam infectantibus, quæ forte hujus appellationis ratio fuit apud antiquos. Ut verò aliquibus noftris beftiolis illud nomen aptetur, earum notas characterifticas breviter enarrabo.

I. Oculis quatuor magnis \& totidem exiguis donari. 2. Habere pedes poftremos omnium longiffimos. 3. Idq; ob fingularem partîs vecturam, qui, dum in ovis, ano adhæret Folliculo inclufus; ubi autem araneoli edantur, ii matris dorfum afcendunt, à quâ fic circumferuntur univerfi. 4. Per terram venantur, raróq; vel arbufcu'os fandunt, nifi id fortè inter volandum accidat. 
De Araneis OEtonoculis.

C A P. III.

De Araneis Lupis in Specie.

\section{TITULUS XXV。}

Araneus niger.

Nter mediocres numerandus eft.

Tàm mari quàm foeminæ color nigerrimus.

Ei caput exiguum, acuminatum.

Oculi ita ordinantur; ori quatuor propiores, exigui funt, pérq; paria ferè conjunctim pofiti ; paulò retrò in ipsâ fronte alii duo, longè omnium maximi, magífq; inter fe diftantes; adhuc magis retrò verfus humeros alii duo etiam majufculi, ex longiore intervallo.

Pedes pulchrè maculofi; ídq; maximè confpicuum, fi aquâ demittantur; eorum a. hæc eft menfura, ultimi reliquis multò longiores, tùm primi, deinde fecundi, poftremò tertii; fed inter hos vix aliquis notabilis exceffus eft.

Alvus plena, fubteres, verfus anum paulò craflior; ejus pars fuperior maculis nigris in duplici ferie exornatur.

In fylvis admodum trequens eft, \& alibi in dumetis \& Loosso pafcuis.

Ad rivulorum ripas fub initium Maii mares vidi forninas ad venerem excitantes; illas infectando, fuáfq; anten: nas tremulo quodam motu vibrando; contrà foeminæ mares propellebant.

Ipfos etiam rivulos haud invitè tranfnatant, certè vel leviter propulfi.

$$
\text { L } 3 \text { Exeunre }
$$




\section{De Araneis OEtonoculis.}

Exeunte Maio, fingulorum araneorum ano adhærent finguli folliculi; fc. eorum unufquifq; ad magnitudinem piperis grani ; parùm depreflus; ferè fubcyaneus, aliquando fubflavus; membranaceus five texturæ denfæe telæ inftar lintex.

ov. Ipfa autem ova fubrufa; numero circiter viginti in fingulis folliculis.

Dum ova circumvehit mater, valdè ftrigofa eft.

7 Junii fortè tùm primùm è millenis unum araneolos fuos fupra dorfum vehentem vidi; reliqui autem in folliculo fuos adhuc fub ano fovebant circumferebántq;.

Inter approbata remedia D. Mathei Liffer Equitis aurati, proavi mei plurimùm honorandi, illud invenio, quod fine invidia communicandum putavi ; nimirùm aquam ftillatitiam ex araneis nigris optimè vulnera fanare; idq; fuiffe ex fecretis D. Gualteri Razoley, fortiffimi viri.

\section{TITULUS XXVI.}

Araneus fufcus, alvo obliquè virgatâ.

Defriptito. Ediocribus annumerandus eft; at interdum reperiuntur ex his quidam fubcinerei, qui vulgarem magnitudinem facilè excedunt.

Ei color fufcus; tela capútq; nigra, \& incanâ lanugine confperfa.

Prope os quatuor exigui ocelli, fine microfcopio vix dificernendi : fuper hos alii duo prægrandes; poft illos paulò retrò ad humerorum faftigium alii duo majufculi.

Pedes luci objecti crebris maculis diftinguuntur; hirfuti ; quorum ultimi, ob commodam partûs vecturam, omnium facilè longiffimi; reliqui à primis incipiens, fuo quiq; ordine fequuntur tam longitudine quàm numero. 


\section{De Araneis OEtonoculis.}

Alvus plena, productior, fubteres, paululùm acuminata.

Hujus generis araneorum eft infinita paffim vis, per ter- Locisso ram in campis currentes $\& x$ alibi.

Per hyemem verò fub terram in dumetis latent.

Exeunte Maio fingulis araneis fingulos Folliculos, ano Fo:lislit. fubter appenfos, obfervare licet. Ejus verò color ferè fubcæruleus, interdùm fubflavus; orbiculatus, aliquantulum depreffus; ad magnitudinem grani piperis; membranaceus.

Sub initium aut medium Julii Folliculus per medium dehifcit, exeúntq; araneoli ; ipfi mox matris dorum afcendunt, eófq; ipfa fuper clunes humerófq; fecum gettare gaudet, fovet, nutrit, i. de fuâ prædâ alit; jucundiffimum planè fpectaculum!

Folliculum, ovorum involucrum, fi fubter adimere tentabis, eum beftiolx ventri fili ope ab ano remiffi firmiter adligatum invenies, at quo nodo inquies? refpondeo ubicunq; araneus anum demiferit, ibi filum neceffariò figit, ac fi cui digitus vifco inficeretur; quippe ea vel ipfius fili recenter emiffi, vel cujufdam humoris unà cum filo exeuntis natura eft.

Folliculum ab ano duce leviter fic, ut ex facili fubfequatur; cave rumpas; ita in miram longitudinem filum protrahes: protinus verò ac manum dimiferis, illud rurfus intùs reducere potens eft ipfa mater. Quæ fanè interna velut Glomeratio five fuctio eft æquè admirabilis proprietas, atq; illa altera fila ejaculandi; in quo certè hæc fpecies magnopere delectatur.

Etenim ad medium Octobrem in agro Cantabrigienfi, Filovum ejscas cùm Croci flores colligunt, fummâ ferenitate, ut ibidem illis diebus aliquando accidit, fupra fidem eft quantam multitudinem horum preter alia araneorum genera adverti in aëre velificantium. Hæc interim mihi de hâc re maximè notabilia ocsurrebant; eos interdum fingulari a- 


\section{De Araneis OEtsnoculis.}

liquo filo contentos, interdum plurima fimplicia fila, velut totidem micantes radios ad cometæ caudam ejaculatos fuiffe: deinde hæc eadem fila proximè ab ejaculatione purpureo quodam fplendore mirum in modum micâffe: neq; illud filendum putavi, hos araneos, cùm fingularibus filis ejaculandis fefe exerceant, ea modò abrumpere; mođò in exiguos glomerulos niveos recolligere, prioribus fc. pedibus fuper capita celeriter circumactis; modò fe committere leni auræ, afcenfúmq; in aërem pérq; fummas nubes moliri. Illud verifimum eft, eos, etian fuper celfiffimam Turrem aliquoties de induftria à me contemplatos, longè tamen extra confpectum meum evectos fuiffe. Poftremò in iftis longiffimis filis aëreis, jam in funes craffiores, fed inæquales implicatis, ídq; à longis in aëre veCtionibus, mufcas cafu an de induftria irretitas me non femel notâffe memini.

\section{TITULUS XXVII.}

Araneus flavus unicolor, alvo productiori acuminata.

Defcriptio.

1. $\mathrm{E} \mathrm{C}$ ingens beftiola eft, certè maximus fui generis araneus.

Ei color fubflavus, idémq; per omnia membra.

Humeri ampli, in faftigium eminentes; quod lineola fubalbida ex pilis five lanugine grifeâ per longitudinem diftinguit.

Oculi octoni ita ordinantur; quatuor exigui ori propiores; paulò retrò duo maximi ex intervallo; adhuc paulo ob ore remotius verfus humeros alii duo, proximis duobus paulò minores, at ex longiore intervallo diftantes.

Pedes ingentes, craffi, productiores; horum ultimi omnium longiffumi, tùm primi, dein fecundi, tertii brevifimi. 
Alvus pralonga, fubteres, à pectore aliquantufùm píe-. nior, deinceps paulatim in acumen definens; unicolor, nulláq'; picturâ, aut certè valde obfcurâ, diftincta. bus.

Tota beftiola pilis contegitur brevibus, denfis, molli.

Mari extrema cornicula quafi nodis five capitulis qui- niss, bufdam turgent : item ei fuper alvum ex duplici ferie circiter fex haud exiguæ maculæx nigerrimæ; cæterùm ei idem fubflavus color, qui in foeminâ fuprà dictus eft.

Ex his unam, Maio exeunte, cepi, quæ facilè omnes noftros araneos magnitudine excederet. In dumetis \& ve- Lochice pribus venatur. In auftralibus Anglix partibus frequens; at multo rarior apud nos circa Eboracum; neq; ufpiam in montofis regionibus illius agri vel femel. à me inventus eft.

Junio menfe Folliculum, pectori affixum, fecum geftat ; eam Nidificare nondum obfervavi. Folliculi figura (ph $x$ - Folliculta rica; piperis quovis grano duplo major; color fubalbidus; velamentum five tunica, quâ ova, haud parva, includuntur, membranacea eft.

Ex his marem ingentem beftiolam, at nullis maculis, ut fuprà notavimus, diftinctam, foffas quafdam in paludibus juxta Doncafter trajicientem vidi: in alterầ verò rip̣̂̀ eum expectavi ; at ipfe mihi propior factus libenter fe intra aquam profundè demifit ; juncum amplexus, ut difficulter fanè eum expircari potui, adeò de junco in juncum per aquæ fundum celeriter tranfiliit. 


\section{TITULUS XXVIII.}

Araneus fublividus, alvo undatin pictâ, productioris, acuminatâ.

riptio.

I I I inter majores araneos numerandus eft.

Ei color fublividus, qualis in mure domeftico.

Oculos, humeros, pedes quod fpectat per omnia fimiles

Thabet, atq; in proximè fuperiori pofitum eft. Eadem e. tiam alvi figura; at color diverfus, ut fuprà in Titulo diximus. Item fupra clunes eft quxdam pictura foliacea, ad margines undatim circumferipta.

Atq; eadem pilorum ratio.

Mari eædem notæ atq; foeminæ : illi præterea extrema cornicula turgent, magífi; rufefcunt; at eadem clunium pictura.

6. In auftralibus Anglix partibus frequens, at multo rarior verfus feptentrionem.

s. Circa initium Junii in dumetis \& pratis nidificat : huic Nidus linteoformis ex telâ $\mathrm{fc}$. tenuiori, in modum caffidis aut campanulæ: ferè intra hunc fe continet mater, fub pectore Folliculum continuò geftans.

inlus. Folliculo color fubalbidus; membranaceus; ferè fphrericus; duplo major piperis grano. Cùm exit mater ad venandum, folliculum fuum in nido minimè relinquit, fed fecum affiduè cum circumfert : at rarò longè à nidi veftibulo progreditur.

Ex his pulli tempore autumnali, aut luteo, aut fubcroceo colore, interdum etiam flammeo ad alvi latera illuftrantur : hi verò fub idem tempus inprimis volucres funt, \& ingentium filorum aëreorum authores.

i3. In collibus arenofis ad oftum Fluminis Tees unam \& alteram 


\section{De Araneis OẼonoculis:}

alteram fortaffe fpeciem Luporum à me nondum defcriptorum vidi : nec nunc per otium eos rurfus inveftigare licebit.

\section{A P. IV.}

De Araneis Cancriformibus, minùs propriè Lupi dicendis.

Illorum autem be Juni not characteriftice. 1. Habere pedes pofteriores omnium breviflimos, aut certè qui pedes tertios longitudine non multùm excedant.

\section{TITULUS XXIX.}

Araneus fubfufcus, minutifร̌mis oculis è violâ purpura-

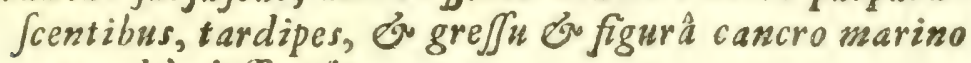
non adeò diffrmilis.

GS T medix magnitudinis beftiola.

Ei color ferè fubfufcus; nam aliàs ex his rufefcenDefription tes obfervavi, \& albidos, interdum pallidè luteos aut fubvirides in modum corticis pomi citri ; illáq; ommis varietas à cuticulâ fortaffe noviter exutâ orta eft.

Humeri breves, plani five depreffi.

Oculi perexigui, ita ordinantur; nimirum in mediâ fronte funt duo, quibus alii duo, paulò retrò verfus humeros pofiti, refiondent: ad frontis latera quatuor tubercula eminent, in quibus fingulis funt finguli ocelli; hi verò onnes diligenter intuenti è flammâ five quâdam purpurâ micant. 


\section{4 \\ De Araneis OElonoculis.}

Pedes craffrufculi, præcipuè priores quatuor, totidémgs pofterioribus hi ferè altero tanto longiores: Et quemad. modum hì ità \& illi inter fe propè æquali longitudine funt.

Alvus depreffa, lata, à pectore gracilis, fubinde plurimùm increfcente ad inftar ampullix, at eâ ferè figurâ quâ cancer marinus vulgaris, aut maximè quâ plantæ, burfæ paftoris dictre, filiquxe funt; tamen alvus non adeò obtufa cit, quin ipfe anus in quoddam acumen fubitò premineat.

In ventre crebre rugæ, in modum circuli implicate; velut cuticule plicx in extremis noftris digitis.

Preterea eft beftiola ex toto glabra.

Rependi autem modus cancro marino vulgari fimilis eft; nan etf rectà aliquando progreditur, tamen libenter vel dextrorfum vel finiftrorfum, aut etiam retrorfum repit.

in In autralibus Anglix partibus eft frequentifima beftola; certè à Cal. Marriis illos paffim in aggeribus apticis \& dumetis reperire licet. At rarò apud nos in Septentrione occurrit.

Junio monle alvus Ovis multim diftenditur; atq; ipfis arancis tim precipuè color fubfufcus, ut fuprà dictum eft.

Sexto Junii ex his unam Folliculo fuo tenaciter adhærentem adverti ; ipfe autern folliculus fummo $G$ enifte $\int_{p}$ i"o $\int_{x}$ furculo intertextus eff; hunc furculum decerpfi, illómg; unà cum araneo thecâ ligneâ inclufi; neq; tamen abicedere voluit arancus, fed folliculum pectore ufq velavit.

Folliculi aatem figura rotunda, deprefrat adnodum, haFollicalus. ta; ipfa autem ejus tunica velut membranacea, è telà fc. 0va. clensâ, niveç̂. Ova benè multa continct, exigua, pallidè camnea. Tunicâ refciftâ, ova, garòd minimè inter fe cohrent, diffluunt. 
Sui verò artificii præter folliculum vel telas vel alius alterius generis reticula mihi nunquam adhuc videre contigit : tamen fummas arbores facilè fcandit, filóq; è ventre remiffo rurfus fe in terram demittit. Certè egregius funambulus eft, \& mirificè filorum ejaculatione delectatur: neq; folùm in ac̈re, uti fuperiores, vehitur; fed ip. fe etiam afcenfum velificationémq; molitur, pedibus fc. arctiv̀s ad fe invicem applicitis fele quodammodo librat. curfum promovet regítq; nihilo feciùs quàm fi illi effent. à naturâ conceffxe alæx vel remorum ordines.

Operæ pretium effet de ejus morfu periculum facere in fanguineis animalibus; nam mihi perniciofiffima beftiola videtur; certè animus meus abhorret $a b$ infolenti. ejus greffu $\&$ figurâ, utpote nova ac prorfus aliena à cxteris araneis. At centies in manus meas receptus, femper. catenus illum innocuum expertus fum.

\section{T I T ULUS. XXX.}

Araneus parvus, fubrufus velut inasratres, ipsấ: alyg: apice infufcat a, levipes.

$\mathrm{N}$ minimis numerandus $\mathrm{eft}$.

Ei color fubfufcus, fi tamen eum foli aut flammx obs. vertas, velut inauratus.

Humeri parvi, rotundi, paululùm gibbi.

Octoni oculi nigri, fic ordinantur; nimirùm, in ipsà fronte quatuor, velut circuli curvaturâ pofiti ; tùm pau. lò retrò alii duo ex intervallo; poft eos totidem alii,omnium longè maximi. Hæc autem oculorum ratio eft, quxe tamen fine Microfcopio non benè difcernitur.

Pedes perpallidi, hirfuti, maculofi, fatis craffi, non nimiùm longi ; quod verò ad longitudinis exceffum attinet, $\mathrm{M} 3$.

Defcriptio. 
fic concipiendum eft; $f_{c}$. fecundos effe longiffimos; tùm qui primi funt, poft illos tertii, ultimi omnium breviffimi funt.

Tela exigua rufefcunt.

Alvi figura valdè depreffa, latiufcula, proximè à pectore paulò anguftior, dein multo plenior; ferè fubrotunda, nifi quod ipfe anus in acutum paululùm promineat: alvi fuperior pars foliaceâ quâdam picturầ velut auro interftinctâ adumbratur; ipfe verò ani apex infufcatur.

Per hyemem in veteribus avicularum nidis, aut ubi arida folia fimiliáq; in fepibus congefta fint, frequens latitat: per æftatem verò in dumetis \& vepribus prædam infectatur. In feptentrione Angliæ rarior eft.

Sub initium Junii ex his aliquot, folliculis niveis adhærentes, obfervavi; ipfi autem folliculi erant angulares, ftellæ in modum, valde depreffi, Geniftæ fpinofxe furculis intertexti \& affixi.

Citiffimè currit, \& è ventre inter currendum filum remittit; item circa autumnum eum fila ejaculantem fxpiùs notavi.

In reticulis Orbiculatis fuprà defcriptis hos araneos inter cæteram prædam fufpenfos aliquoties vidi.

\section{CA P. V.}

De Araneis Phalangia ditis in genere.

T. Ujus autem generis Araneorum nota charncieriftica II una eft, affultim ingredi, Pulicum more; quie fola nota evincere fatis eft, noftras beftiolas effe de Plalangiorum genere il Plinio alífq; antiquis feriptoribus commemoratorum; an verò horum fint noxii morfus fimiliter atq; illorim, 


\section{De Araneis OEtonoculis.}

illorum, nondum mihi certò exploratum eft. 2. Altera eft habere frontem veluti quadratam; 3 . Octonos Oculos inæquali magnitudine, \& in dimidii velut circuli curvaturâ difpofitos. 4. Pedes priores \& longiores \& validiores cæteris, ad affidui faltûs commoditatem.

A proximè fuperioribus Lupis in his præter alia differunt. I. Quòd his frons lata eft. 2. Quòd Oculi majufculi in his Ori propiores funt, minoréff; verfus humeros; cùm in illis contrarium pofitum obfervent.

\section{A P. VI.}

De Araneis Phalangiis in Jpecie.

\section{TITULUS XXXI.}

Araneus cinereus, alvo circirer fenis fafciis tranfverfis, in angulos acuios in medio erectis, argenteis oun. gris alternatim difpofitis infignitâ.

Nter mediocres numerandus eft.

Ei color niger argenteo interftinctus. Humeri plani five depreffi, ferè quadrati ; ipfa frons lata.

Octoni oculi nigri, ex dimidio ferè circulo fecundum frontem humerófq; fic ordinantur : duo fc. medii cxteros magnitudine multum fuperant; juxta eos alii duo minutiores funt ; paulò retrò alii duo perexigui ex intervallo longiore; poft hos ultimum par oculorum fecundis ferè $x_{0}$ quales; at ii omnium maximè inter fe diftant. Neq; id microfcopio quidem facilè difcernendum eft, antequam beftiolx 
beftiolæ caput humerófq; ad totalem pilorun confumptionem flammâ uftulaveris.

Pedes breves, hirfuti, maculofi; quorum priores reliquis paulo \& longiores \& craffiores funt, ad commodiorem faltum puta.

Alvus fubteres, acuninata; fuperiore ejus parte funt circiter tres lineolæ five fafcix argentex, latiufculæ, ad angulos obtufos coëuntes : iftæ autem fafciæ interftitiis nigris diftinguuntur, nifi ubi argentei pili id variant; quibus etiam brevioribus \& mollibus beftiola ex toto contegitur.

Huic quædam Varietas fecundùm ætatem aut cuticulam proxime exutam: idq; fummopere monere volui; ne incauti has varietates pro diftinctis fpeciebus aliquando habeant.

In veteribus ædificiorum noftrorum parietibus; item in fylvis frequentiffimus eft ubiq; per Angliam.

In poftremis pedibus fe erigere folet ; capútq; attollendo, loca, in quæ mox infiliat, undiq; refpicit: affultim ingreditur, pauciffimífį; paffibus interpofitis, haud fecùs quàm Pulices faliunt.

Laceffitus è ventre fila remittit; atq; adverfus hyemis frevitiam fibi involucrum è fpiffầ telâ linteoformi contexit ; in quâ ad medium Februarium latet inclufus; fubq; id tempus venatum prodit.

Inter cæteras mufcas omnigeni culices maximè ei arrident : ejus autem venationis modum elegantiffimis veriffimífq; verbis enarravit $C$ l. Evelinus nofter apud Doctiffimum Hookium, Micrographix dictæ Obferv. 48.

Quòd verò idem Clar. Hookizs affirmare videtur, huic tantùm fenos effe Oculos, aliíf; araneis dari plures octo, alii diligentiùs videant. Equidem fateor me in omninò nullos araneos adhuc incidiffe, quibus darentur plures aut pauciores octo, modò qui fint fecunde Part is inferiùs defribendi, eo numero excipiantur. Illud veriffi- 


\section{De Araneis OEtoroculis.}

mum eft, quòd in aliis alium pofitum, atq; ordinem ha. bent oculi ; imò verò \& $\mathrm{x}$ in nuitis inxquali funt magnitudine; fed de his rcliquífí oculorum accidentibus aliàs egimus.

Circa Aprilem prime fetionis aliquos arancolos $\mathrm{ex}$ his unum cepiffe deprehendi : quo munifum fit, araneos libenter. \& cum fui juris funt ipfos araneos infectari; \& non tancim iracundixe vindidure caufu, cim fimul curtodiantur colem vitro, ut fuprà expofitume ef.

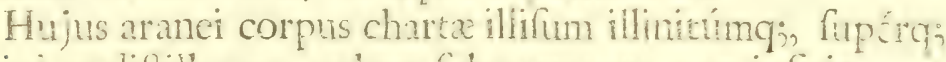
lisivium diftillatum, colore fubpupurce cam inficit.

Hujus generis Arancolos, papaveris femina non mul tùm fuperantes, circa Auguftum menfem obfervavi.

\section{TIT ULUS XXXII.}

Arancus cx rufo fubfufous, fuper cluzes preter duas maculas albis, foliaceil quâdanz pizturì, ob curè licèt delineaia infignitus.

I. I IC autem araneus proximè fuperiori paulò nuinor Dícriptio. eft.

Ei color fufcus ad nigredinem accedens; at ni cum, vitro adhibito, in clarâ luce curiofuis eximines, fubrufum videbis.

Ocuioum idem \& numerus \& poftus, \&s magnitudo, qui in fuperiore.

Iten! eaden capitis \& alvi figura, eadem pedim ratro Ex ingrediendi modus Supra alvum vero funt dux infignes, licit minores, macule allore; aliág; veftigia obfura foliacere cujufdam picturx; fiquidem paululum infra maculas delineantur quxdam virguie tranfverfe anguftiffmis: ad oblicguos angulos coëuntes, velut folii cujufdam norvuli. 
Ad parietes noftros rariùs occurrit; etfi inter fuperioresmultos ex his unum vel alterum multotics obfervavi Eboraci.

\section{TITULUS XXXII.}

Aranens fubflavus, oculis fmaragdinis, ilem cai fecun。 dùm clunes tres virgule crocer.

Deffoription.

1 Edix magnitudinis eft.

Ei color maximam partem fubflavus.

Humeri lati, ferè quadrati, admodum plani; latiffima frons.

Ejus octo Ocuil, velus totidem fmaragìi virefcunt, atq: inauratis radiis micant; $\mathrm{ex}$ his qui duo in media fronte pregrandes funt, adeóq; vel nudis octilis facile difernendi ; juxta cos alii duo paulò minutiores; port illos alii duo perexigui, poftrono alios magis retrortun duos invenies, totâ humerorum latitudine diflufos, fecundis mag. nitudine fubpares.

Pedes primi (in maribus) craff, hirfuti, cxteris longiores; thim vel ultimi vel fecundi; tertii omnium breviffimi.

Alvus fubteres, acuminata; fecundùm clunium longitudinem, tres virgule crocex, confpicux admodum.

Venter albidus.

Non aliter quàm Pulex in grefin faltat; \& laceffitus è ventre filum emittit.

Mail autem corniculia extrema turgent, \& dilatantur : relágs atro-rubentia abfcondunt.

A Cal. Sextilibirs hune primò obfervavi ad parietem Interitum Viridarii collcgii D. Gohanmis Evangeliftx Cantabrigix repentem: poftea Londini in fimilibus locis aliquoties 


\section{De Araneis OEfonoculis.}

quoties à me repcrtus cft : at è rarioribus quidem araneis eft.

Eum vitro inclufi cum altero è majoribus arneis, cui multi aranei antea predx fuifient; at hic nofter per pillres menfes unà vixit, an fortè quòd alterius vim mirâ faltandi agilitate evafit, aut quòd æquè in morfu perniciofus.

\section{TITULUIS XXXIV.}

Aranews fubrufus, Ericetis, five in rupibus degens.

Uperioribus fui generis magnitudine par eft.

D Ei color fubrufus, ad caftaneum feu pullum vergens. Deforipitio.

Humeri plani ferè quadrati; frons lata.

In mediâ fronte bini majufculi Oculi ; prope hos bini alii paulò minutiores; retrò alii duo minutiffimi ; poft hos in mediis humeris alii diı fecundis ferè æquales: oculi omnes nigricant.

Pedes breves, ex his quatuor priores (certè in maribus) reliquis multò craftiores funt.

Alvus acuminata; cui color iden, ac quem videmus in maturo pomi femine; funt etiam quedam nigricantes venulx, five lineamenta foliacea: praterea ad alvi latera candidam quandam picturam, nigro eleganter diftinctam, notes velim.

Ipfe venter cinereus.

In Ericetis tantùm agri Eboracenfís \& in nudis rupibus, eâ precipuè regiunculâ, quam Craven vocant, eum inweni. Rariffima fanè bettiola! 



\section{PARS II.}

De Araneis Binoculis.

\section{CAP. I. \\ De Araneis binoculis in genere.}

TN fuperiore parte Araneos Octonoculos, quantí maximâ potui diligentiâ exccutus fum: hâc verò alterâ parte Araneos Binoculos explicare aggrediar : Atg; horum certè plurimx, preter jam dictam, notie characteriftice funt. I. Effe plerofg; longipedes, 2. Habere cutem ferè cruftaceam. 3. Fila non mittere, aut ullum. opus textorium, quod fio, exercere; quanquan adhuc quidem de corum hibernis, aut fietûs curandi ratione, nihil exploratum habeam. 4. Binis tantùm Oculis, ut diximus, donari. 5. Caput è mediis quafi humeris eminerc. 6. Pectus ab alvo difterminari nullâ certè ad nudum oculum notabili incifurâ. 7. Tela forcipata, velut cancri marini brachia, in binos digitos diduci. 8. Adeóq; etiam vulgò innocuos credi; certè morfum quod fpectat. 9. Pedes, longitudinis rationem quod fpectat, alternatim effe difpofitos. His excrementa figurata cffe; cùm fuperiores omnes Octonoculi illa liquida reddint. 


\section{De Araneis binoculis.in Specie.}

\section{TITLILUS XXXV.}

Araneus cinercus, criftatus.

Dor.i. TS maximus eft hujus greneris araneus; $\&$ inter majores 1. omnium fuperiorum recie numcrari poteft.

Ei color pallidè fufcus aut fubcinereus.

Pcdes longiflimi tenuifimiq: quortm fecundi, ultimíq; cæteris paulò longiores funt.

Paulò retrò à fronte exiguum Capitulum inftar vcrruculæ eminet; cu; us apex duplici velut criftâ, è répinis conflatâ, armatur. Iídémq; ferè fpinulis at minoribus etiam tota frons confperfa eft.

In capitulo ex utrag, parte finguli Oculi nigricantes. Atq; the fere fimplici vitro difcemenda fiunt.

In medio dorfi Pietura fufca velut rhomboeides.

Venter albidus.

Maribus cornicula pralonga : item Tela geniculata; at forcipata, ficut in forminis: pedes magis infufcantur : idem capitulum criftatum five finulis hifutum : eidem infuper Penis in medio ventre, de quo vide plura in proxime écquenti Titulo.

A Calcnd. Anrilibus in fylvis frequens beftiola; item circa folftitum wivum in campis apertis; \& præcipuè inter fegctes numerofi; unde apud noftrates à mefle beti

Augufto menfe plerafq; fominas gravidas obfervare licet: 
licet: in his autem tùm Ova infunt alba, perfectex rotun- ava. ditatis; tamen ubi \& quo modo ova fua pariant,curéntq; nihil adhuc deprehendi.

Sub idem tempus ex his aliquot gravidas, fingulas fingulis vitris feorfum inclufi; an fortè hoc modo part's rationem explorarem. At fruftra; quippe omnes mortua funt fine ovorum partu; an propterea quòd illis neceffaria ad nidificandum defuerunt.

Sub medium Maii hujus generis Arancolos, papaveris femina non multùm excedentes adverti; his etiam pedes ecneri, tenuéfq:, albiduli, velut noviffimè editis.

Illud non omittendum duxi, hos araneos coccineis $\mathrm{Ci}_{\text {- }}$ micibus, minutifimis animalculis infertari; quippe quz corum corporibus adhærent, indéq; viçum quæritant.

\section{TITULUS XXXVI.}

\section{Aranews rufus, noncriftatus.}

1) Roxime fuperiori paulí minor eft: adeóq; inter me- D.soriptico 1 diocres numerandus eft.

Ei color rufus.

It rectà per medium dorfum fafcia nigricans, leviter finuofa, nec multum ulira mediam alvum horfum, quanquam illorfum ad ipfam frontem porrecta fit.

Item in hâc ipfá picturâ, paulo retrò ̀े fronte exigumins Tuberculum nigrum, fire Capitulum attollitur.

Duo nigerrimi oculi majuculi, in divero parte capi. tuli pofiti difcerni poffint.

Capitulum in utrog; fexu leve, mullifip frinulis an criftâ armatum.

Pedes omnium araneorum facilè longilinit, fiquidemex: his qui longiores duas uncias minimùm implent; font ctians admodun : 


\section{De Arancis Biroculis.}

adnohm temues; in tominis verò ad juncuras candidis machis difinguuntur, caterim nigri: iidena longiwhlne alternation fic ordinantur 's nimirum $\mathrm{c}$ his qui funt primi, breviores; poft cos fecundi longifini; poft hos tutii, rurfus brevifimi, tim viltimi ad fecundos pioxinè accedunt.

The forcinati, velut cancronum brachia in binos digi. tos divula.

Iten comicala longiuf́culi, atgs hre fue fmila funt in utrog; texu.

Venter albefeit, nifi ubi in imâ rarte $\mathrm{cx}$ croco leviter tinctus fit.

Mres fornina multò minor; ei pedes paulo longiorcs, extoto nigri; item fufca fucin in indem non ita notabils, Rut nulla aut cutè pen: obliterta ; dortum in fomiDîs paulo pallidiùs, in maribus intensè rufefcit.

Eosis:

In fuptentrione Anglix, raw aut nunquam oceurunt; at in antraibus Anglix partibus frequentintmi Gregatim vivunt in dumetis \& unticí $;$ itig in unâ grege circitce viguti tim mares tim fominas fepins numeravi.

Loca concamerata, ant alics texta ad phuvias quarunt.

Hujus genexis atancorum Cutis minus mollis, ac quodammolocrulacea videtur; itcm rafa, ant certè perin. 4: leviter piloni, ut funt pleriq; cimices ant farabxi.

In imo vontre antis confficindus eft, vduk circulari

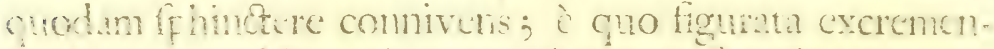
an pheng: rukit ; chm contra onnes liperiors arand avum liqualam habent, candideq materia execrnitur ve. Iut abaviculis.

Iltud crum in his armcis mabus experivilicet; fi digto chat holium ventrem furfum premas, inde tibi premenci crumpet Penis; raligud intedeni fimile, $f$ id in foeminis tentaveris.

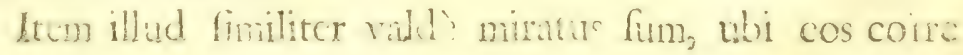
primùn 


\section{De Araneis Binoculis.}

primùm viderem; id non ita peragi, utì priùs $\mathrm{ex}$ Arifto. tele didiceram de cxteris araneis; fc. non clunibus averfis, fed os ori adjungendo.

Ad Calcnd. Sextiles ex his plerafg; forminas Ovis tùm candidis fphæricífq; graveícentes ex diffectione inveni.

Item hos Araneos majufculos Culices cepiffe non femel vidi, aliáfq; mufcas diverfas ; eáfq;, more cæeterarum id genus beftiolarum, avidè fuxiffe.

De Araneo hoc noftro Longipede hæc habet $\mathrm{Cl}$. Hookius nofter, Micrographiæ Anglice fcriptæ Obferv. 47.

'Hujus, inquit ille, Figuram optimo Microfcopio am'plificatam damus: illa autem lingularia funt: Unum, 'Micrefcopio folo difcernendum eft; ei fc. effe duos tan'tìm Oculos, fecùs ac in aliis araneis, in exiguo Tuber' culo è medio dorfo clato, vel potiùs fummo capite col"locatos; hi verò ex adverfo difponuntur, eorúmq; par' tes lucidæ dextrorfum \& finiftrorfum fpectant; ; paululùm 'tamen magis antrorfum quàm retrorfum. Ipfi autem $\mathrm{O}$ 'culi eafdem partes cum oculis maximorum animalium bi' noculorum habere mihi vifi funt; iisfiquidem cornea ad'modum lævis, multúmq; protuberans; cujus etiam me' dio ineft pupilla nigerrima, velut corneâ iride cincta. 'An verò Oculos huc vel illuc movere poffit, nondum ob'fervavi. At id minùs credibile eft, quòd ei cervix cru'ftacen, adeóq; rigidiufcula; hunc verò defectum abun'dè fupplevit ipfa Natura, \& fumma corneæ protuberan'tia, \& quòd fuprà omnem corporis umbram, quæ ejus 'profpectum ullo modo obfcurct, elati fint; adeóq; fin'guli oculi ferè hemilphæriam, licèt minùs diftinctam oc'cupent ; certè cùm ei fit corpufculum tam exiguum ro'tundúmq;, ínq; pedes admodum longos pofitum, celeri"ter fe movere \& circumvertere poffit, fic ut ei quam. 'cunq; rem facile fit diftinguere.

'Hujus autem, uti cxterorum quorunalibet Arancoruns 


\section{De Araneis Binoculis.}

- à me hactenus examinatorum, Oculorum figura, à plerilq; 'Infectis multùm differt : fiquidem Araneis Oculi læves \& 'non crebris tuberculis velut exafperati, perinde ut funt soculi aliorum infectorum.

'Alterum æquè, at nudo Oculo, notabile; Crurum. ${ }^{:} \mathrm{fc}$. corporis exigui ratione, infignis longitudo; hujus 'certè Aranei, quem delineavi, frriguli pedes totius cor${ }^{6}$ poris longitudinem fexdecies \& ampliùs fuperabant. At 'ex his funt, quibus iidem longiores, \& aliis multo brevi'ores funt. Hujus autem finguli octoni pedes in modum ${ }^{3}$ Cancri marini articulantur; at huic, ratione animalis, fin'guli articuli multo productiores. Singuli verò pedes ani'malis pectori medio elatiori inferuntur, \&z velut exiguâ 'conchâ in modum Muf́culi terminantur. Alia plura qux de mechanicâ pedum ratione addit Author, apudillum vide.

Illa infuper tranfcribenda exiftimavi.

'Hujus beftiolæ mos eft, quod aliquocies cum volup'tate obfervavi, in prædam ipfum fuum corpus, velut ma'nuum loco, injicere; neq; aliter quàm araneus lupus in 'mufcam, aut Catus in murem tranfilire.

' Totum ejus corpus admodum elegans eft; \& fillud "diffecare potuiffem, nihil dubii eft, quin intùsæquè rara, 'atq; extrà inveniffem; fortè maximầ ex parte Cancrima'rini vifceribus haud difinilia; quem quidem hoc ani'malculum in plerifq; maximì repræfentat.

'Omitto Cornicula \& Os, cancro marino fimilia; item 'Teftan velut maculofam, quod à lanugine ortum eft; 'item pedes lanuginofos; pectus largum,ventrem parvum, '\&c. de quibus confule figuram elegantem.

'Item illud noto, tres corporis preciplas partes, Caput 'fc. Pectus, 8z Ventrem in hoc animali efie mirè confufos; 'ut haud facilè quis dicere pofitt, quid fit hoc vel illud; "atg; identidem fe habent exdem partes in Cancro marino. 


\section{De Arane is Binoculis.}

-Adeò hic araneus, non alius videtur, quàm Cancer ač'reus, \&c. Vide apud $\mathrm{Cl}$. Authorem.

\section{TITULUS XXXVII.}

Araneus exiguns è candido nigróg; varius five macula tus, infigniter criftatus, fylvicola.

N minimis \& fui \& alterius generis numerari debet.

Ei color ex argenteo nigróq; varius, five maculatus. Capitulum exiguum velut è mediis humeris eminet; duplici criftâ fpinosâ five duplici ferie pilorum rigidiufculorum exornatum.

In capite exutraq; parte finguli oculi majufculi.

Pedes longi, tenues, ad articulos maximè hirfuti ; eadem iis proportio, quæ in proximè fuperioribus pofita eft; albis maculis crebris diftinguuntur.

Alvus à pectore indifcreta, ut de fuperioribus dictum eft, plena, retufa, crebris maculis argenteis infignita. In medio dorfi figura rhomboeides, ut in Titul. 35 declaras vimus.

Venter albefcit; zugis tranfverfis inæqualis.

Cornicula albefcunt.

A Calend. Martiis hunc araneum fatìs frequentem inveni in fylvis agri Lincolnienfis; item in iifdem locis circa Eboracum. 


\section{A P. III.}

De Araneis bujus partis anomalis; quibus $\int c$. pedes breves; item cutis pilofa.

\section{TITULUS XXXVIII.}

Araneus exiguns, coccineus, vulgò Anglicè a Tant dictus.

Defiristio. Inimis Araneis annumerandus eft.

1 Ei color ex toto pulchrè coccinus, aut qualis in flore papaveris erratici; nif́ quòd venter è cocco candefcit.

Ei pedes breviores, octoni, quorum quatuor priores fummo pectori, reliqui quatuor propius ventrem inferuntur. Item exigua punctula nigerrima circa priorum pedum radices obfervare licet.

Os corniculis armatur, quibus etiam fui unguiculi.

Alvus plcna fuprà rugofa, $a b$ humeris indiftincta, $a b$ iifdem latior, deinde paulatim fit acuminatior, retufa.

Pilis mollibus brevibúfq; inftar holoferici totus contegitur; inde fortè caufa quare oculi adeò difficulter difcernendi; ut de iis adhuc nihil certi habean?, quod affrmem.

Lxc:sso

A primo vere in pratis $8 z$ pafcuis præcipuè arenofis eft valde frequens; item menfe Julio plurimos ad oram maritimam circa scarborougb obfervavi.

Formidabilis fane beftiola apud noftros bubulcos; IIquidem boh̀m certa pernicies exiftimatur, fi fortè $a b$ in in bierbn devoretur. Vide Cl.D. Bromn. 
COCHLEARUIM A N G L I AE E T

$T E R R \underset{E T}{T} \mathbb{R} \operatorname{IUM}$

FLUVIATILIUM

L I B E R.

Quácunq; ingredimur in aliquam biftoriam veftiginm ponimus. Cic。

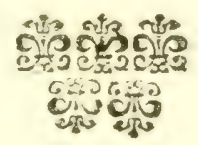

LONDINI,

Impenfis F. Martyn, R. Soc. Typographi. MDC LXXVIII. 



\section{I B R I}

\section{COCHLEARUM ANGLI露}

P A R S I.

\section{De Cockleis in genere.}

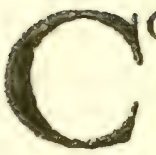

Ochleis pleriff; Teftæ funt; quæ etiam Nudæ ha- Tefte. bentur, quodam tamen Tegumento in humeros fuperinjecto \& fubter illud Officulo, propugnaculi loco, donantur.

Teftarum autem alia atq; alia figura elt.

Terreftribus verò Cochleis univerfis ea turbinata eft. Item inter Fluviatiles multi Turbines funt: at hîc etiam quibus illa in binas valvas diducitur; neq; ibidem defunt: univalves Teftæ.

Quibus autem Turbinatis five in terrâ five in aquis degentibus Operculum :eftaceum datur (quæ admodum paucre funt) iis illud eft quafi altera valva.

Operculumi, fi quod fit, ipfius animalis calci adnafcitur; ut hoc poftremun fit, quod intùs ducatur, teftámq; claudat.

Teftarum verò turbinatarum plures circumvolutiones funt; nullis duabus pauciores; ut neq; in noltris quidem ullis ampliùs decem numerare licet.

Teftarum turbinatarum circumvolutiones non ex una parte perpetuò procedunt, ferè ex finiftrâ in dextram ad. folis motum; funt tamen \& inter terreftres \& $x$ inter fluviatiles, quæ contrarium motum obfervant.

Circumvolucionum verò frequentium in Cochleis turbi- 
natis ea poteft effe ratio; quòd hæ ferè liberæ funt nec teftis fuis adfixx, (fecus quàm fit in bivalvis) hinc earum corpus, nè excidat, multiplici gyro intorquetur. Neq; tamen ideo credibile ent, quod nonnulli perhibent, eas aljquando è teftis fuis exire.

Vere cxeunte Teftæ pars fupcrior fit mollis; $f c$ an aliquâ parte veteris teftæ deciduâ, aut tantundem annuatim ancta, donec ad juftam magnitudinem perveniat.

Ipłx autem Teftæ membranulâ five pelliculâ admodùm tenui conteguntur; in quâ ferè ineft ifta colorum varietas, in fingulis fpeciebus adeò notabilis; eadem verò, fi lixivio forti demittantur, exeditur.

Bivalvium autem fluviatilium noftrorum utraq; valva æquè cava eft.

Præterea in teftis bivalvibus infunt quædam vitia, Margaritæ dictæ; cjufdem quidem cum illâ fubftantiæ, proprietatifq;. Atq; hæc hactenus de Teftis.

Plastot.

Ipfa autem Animalia pedibus carent : at is cft quædam veluti Planta, in ingreflu corum pedum vicem præftans. Terreftribus quidem Cochleis ejus figura longa, \& acuminata eft; \& qux totum quafi ventrem occupat; cjus calx in acutum producitur. In his plantæ pars meciia, mollior; extrema circumcirca ad marginem magis ad callum quendamaccedere videtur. Fluviatilibus astem turbinatis illa paulo latior \&z tenuior eft: fcilicet natationi magis accommodata.

Item ante os in aliquibus Cochlcis fuviatilibus funt ampla quæedam Labra, pimiarum al:quomodo munus preftan-tia.

Univalvi verò ifta Planta rotunda eft, inftar oris cujufdam; fcilicet ad commodiorem adhæfionem, qux quodammodo fuctione fit.

Bivalvibus autem eadem duriufcula cit, acuta, \& in aciem longam producta; ad progreflum in limo aut arenâ ficiendum.

Cochlcis 


\section{De Cocbleis in genere.}

Cochleis terreftribus \& teftaceis \& nudis \& fluviatilibus capst. Turbinatis Caput in ingreffu confpicuum à reliquo corpore exeritur. Illud verò in Bivalvibus perpetuò, quantum obfervare licet, occultatur. In nullâ autem Cochleâ æquè diftinctè in confpectum venit caput, atq; eâ ex fluviatilibus, quam fafciatam operculo donatam appellavimus; cui quidem caput figurâ velut bubulinum oft.

Cochleis terreftribus \& teftaceis \& nudis Cornicula qua- cernicuia. tuor cxeruntur è fronte : his quoq; omnibus extrema cornicula velut quibufdam capitulis turgent. Ex his duo fuperiora, multo majora \& productiona; anteriora verò. minora \& breviora funt. Item illis extremis fingula exigua puncta nigra, his non item: ut verò his iter prætentent, illis videant, credibile eft.

Cochleis verò Fluviatilibus turbinatis bina tantùm cornicula funt, eáq; mucronata, \& in aliquibus fpeciebus in modum pili tenuia ; in alis, quafi auriculx, admodum latæ \& tenues; in aliis velut in ramos diducta, pinnarúmqi vicem fupplent. At hi oculi quidem non dicendi funt.

At iifdem infuper Cochleis Fluviatilibus funt fingula oculis punctula nigra utrinq; ad radices corniculorum: neq; multum dubii eft, quin hi rectè exiftimentur Ocelli. In eo verò difcrimen; quòd ut his Oculi ad radices corniculorum collocantur, minimćq; è fede protruduntur; ; illis iidem per ipfa Cornicula penetrant, more Tuborum Confpicillis accommodatorum.

Os habent dentibus armatum; hi verò in aliquibus fal- Dintis. temfpecicbus, ut $\mathrm{Cl}$. Hookius nofter perhibet, ex uno folidóq; offe conftant, ad figuram tamen dentium nefcio quibus difcerniculis in co impreffis confecto.

Cochleis terreftribus circa imas cervices, palliolum futum reflectitur: eáq; veluti pinna five membranula quadam femicircularis eft, retrò Tuttxaperture fuperinjecta. 
Anus.

Turbinatis Cochleis urriufq; loci, atq; etiam terreftribus nudis anus ad dextram partem cervicis aperitur : quod * De pat.Ani- olim rectè obfervavit Ariftoteles*, ejúfq; rei rationem mal. 6.40 .909 pluribus verbis demontravit. "Turbinatorum, inquit ille, c.finis ad principium flectitur, \&c. Rurfus, 'extrema co' ëunt. Alibi, 'iis excrementum per meatum ori vicinum. 'emittitur.

At bivalvibus, ut in fanguineis animalibus, ex adverfo Oriea fita eft.

Fime, In illo autem foranine, quod ad dextram partem cervicis effe notavimus, non folùm anus ponitur, nam ex eo. excrementa certò exeunt : fed etiam f́piritui ingreffus patet, pulmoníq; infervit; nam, nifi illo aperto, progredi aut moveri non folent; deinde Fluviatilibus iftud foramen amplum patet, \& cùm per fummam aquam natant, illud paululùm extra aquam aëri hauriendo extollunt ; porrò fpecillum fetámve facilè admittit; quæ per mediam Plantam permeare videtur; \& in Limace nigro emergit ex ipfius caudx apice; qux fir non in omnibus, certè in eo a. nimali naturaliter ibidem aperiri videtur.

Nonnulla autem conjecturalia de partibus Cochlearum internis fubnectam.

Ventriculus. Gulam excipic Ventriculus, fatis ampius: à quo contiaitefina.

vifeus fufcurat nuatur intertinum fimplex, longum, atq; aliquot anfractibus revolutum.

Vena lactere.

Inteftinis implicatur vifcus quoddam coloris fubfufcis innumeris venis lacteis interftinctum, pro magnitudine quidem beftiolæ admodum amplis \& capacibus. Нæautem venæ lacteo quodam humore repletæ perpetuò apparent. Fortè ex his nutrimentum fuppeditatur in icjunium hybernum; ut hujufmodi animalibus fint eædem venæ etiam Promptuario, five chyli affervaculo cuidam.

Praterea, ex excrementorum differentia, certum eft inteftinorum figuram aliam atq; aliam efic in diverfis fpesicbus; faltem ex iis recum \& colon.

De 


\section{De Cocbleis in genere.}

De partibus autem Cochlearum genitalibus illud pre- Penis. cipuè miramur, alterum alteri adeò fimile effe, ut vix \& ne vix quidem difcernere licet, in quo fit fexûs differentia. Penis autem earum exertus, fetæ longæ crifpatæ, aut in modum claviculæ vitis torquetur; altera verò ejus pars multo plenior eft, vaginæq; loco infervit ipfi claviculæ.

Sunt etiam in coitu aliquibus Cochleis notanda quædam spicenta at?ater. veluti (picula tertacea, eleganter admodum figurata, ipfis earum cervicibus penitus infixa; at ab utroq; animali foluta : ubi autem illa ante coitum in corpore condantur ${ }_{2}$ aut quo modo caufáve fub id tempus ejaculentur, me latet; illud extra dubium eft, utrumq; animal ab iftis aculeis vulnerari.

Humor autem è vulneratis Cochleis ferè dilutè fubcx- Humor rubsace ruleus; atq; alius effe videtur à faliva fponte eructatâ. At Cochleis non unicolor faliva; nam aliquibus fluviatilibus saliva cosciea coccinea eft.

rea.

Cochlearum verò terreftrium ingreffus eft quædam ve- Ingref $\int 4$. luti natatio in proprio humore; illud inprimis teftatur, eas non multùm egredi è latebris umbrofis, nifi diebus pluviis; quo quidem tempore benè madent intùs $\&$ extráo Huic accedit ipfrus falivæ natura, quæ ferè temporis momento in aëre coagulatur; ut fi non continuò illam inter eundum eructarent, propriâ falivâ implicitæ, loco adfigerentur.

Cochleas autem ex coitu generari, nihil dubii eft; quod coitune ipfi in multis earum fpeciebus tùm terreftribus tùm fluviatilibus fepiùs obfervavimus.

Illis verò Ova fphærica funt ; quibus fc. mollis \& mem- $g^{2} x_{0}$ branea tefta five cortex eft.

Terreftrium Cochlearum ova ferè racematim inter fe cohærent, imperceptibili quodam glutine. At Fluviatilium ova quâdam geniturâ limpida, inftar ranarum fpermatis implicantur. Hầc etiam maturefcunt, donec ad formam $\mathrm{P}_{2} \quad$ fingulx 
frngulæ fpeciei propriam \& perfectam pervenerint; ipsâ fc. geniturâ adhuc integrâ \& non refolutâ.

Futus Cochlex tam Terreftres, quàm Fluviatiles herbis vefcuntur; illeetiam, quovis pipere magis mordacibus, fungis delectantur. Simili victu gaudent Mufculi, etiam Patellæ; qux licèt faxis, velut immobiles, adhæreant, tamen de loco in locum moventur, victûs ratione.

Cochlearum ufus multiplex eft: Teftarum pulvis ad omnia medicamenta æquè utilis \& proficuus eft, atq ipfxe margaritæ, aut oculi cancrorum dićti, aut corallia.

Item ipfa animalia in deliciis olim apud Romanos fuerunt : etiam nunc dierum in Gallia \& Italia in cibis funt 3 exe certè, quæ Pomatiæ dicuntur, fc. ex noftris terreftribus primæ.

Univerfis quoq; Europxis ad medicinam adverfus febrem hecticam. C. Celf. eas boni fucci \& ftomacho gratas effe ait. Petr. Arbiter, carum cervices ad venerem provocandarn affumptas fuiffe memorat.

Item alius ufus hodiernus noftrorum hominum, ad ceram fc. dealbandam. An coccineus quarundam humor ad picturam adhiberi poffit?

De: minic. De Cochlearum autem faginâ, ita Varro. Quæ etians à

liv. 3 .

Kitz. Nat. liu.g. Plinio \&r Macrobio fidem habent.

Idoneus fub dio fumendus eft locus Cochleariis, quem c. 5 . c. 13 . totum circùm aquâ clandas, nè quas ibi pofueris ad partum, non liberos carum, fed ipfas quæras. Aquâ, inquam, claudendie, ne fugitivarius fit parandus lockis, Is melior eft, quem \& non coquit fol, \& tangit ros. Qui fi naturalis non eit, ut ferè non funt in aprico loco, neq; habeas in opaco, ubi facias, ut funt fub rupibus, ac montibis, quorum alluant radices lacus ac fluvii, manu facere oportet rofidum; qui fit, li adduxcris fiftulam \& in cam papillas impofueris tenues, que eructent aquam, ita ut in aliquem lapidem incidat, \& late difipetur. Parvus his cibus opus eft? 


\section{De Cochleis in genere.}

eft, \& is fine adminiftratore. Et hunc, dum ferpit, non folum in areâ reperit, fed etiam, fi rivus non prohibet, in parietes ftantes invenit. Deniq; ipfe exgruminantes ad propalam vitam diu producunt, cum ad eam rem pauça laurea folia interjiciant, \& afpergant furfures non multos. Itaq; Cocus has vivas an mortuas coquat, plerung; nefcit.

Genera Cochlearum funt plura, ut minutx albulæ, quæ afferuntur è Reatino: \& maximæ quæ de Illirico apporrantur: \& mediocres qux ex Africâ afferuntur. Non quòd in his regionibus quibufdam locis, ex magnitudinibus non fint difpariles; nam \& valdè amplæ funt, quædam ex Africa, quæe vocantur Solitanæ, ita ut earum Calices quadeantes octoginta capere poffint; \& fic in aliis regionibus eædem inter fe collatæ, \& minores funt \& majores.

Hæ in fæeturâ pariunt innumerabilia ; earum femen minutum, \& teftâ molli, diuturnitate obdurefcit.

Magnis infulis in areis factis, magnum obulum deferunt æris.

Has quoq; faginare folent ita, ut Ollam cum foraminibus incruftent fapâ \& farre, ubi pafcantur, quæ foramina habeat, ut intrare aër polfit. Vivax enim hæc natura. Hæc autcm Varro. Jam fingulas fpecies exequar. 


\section{Cocblearsm Anglide Tabula.}

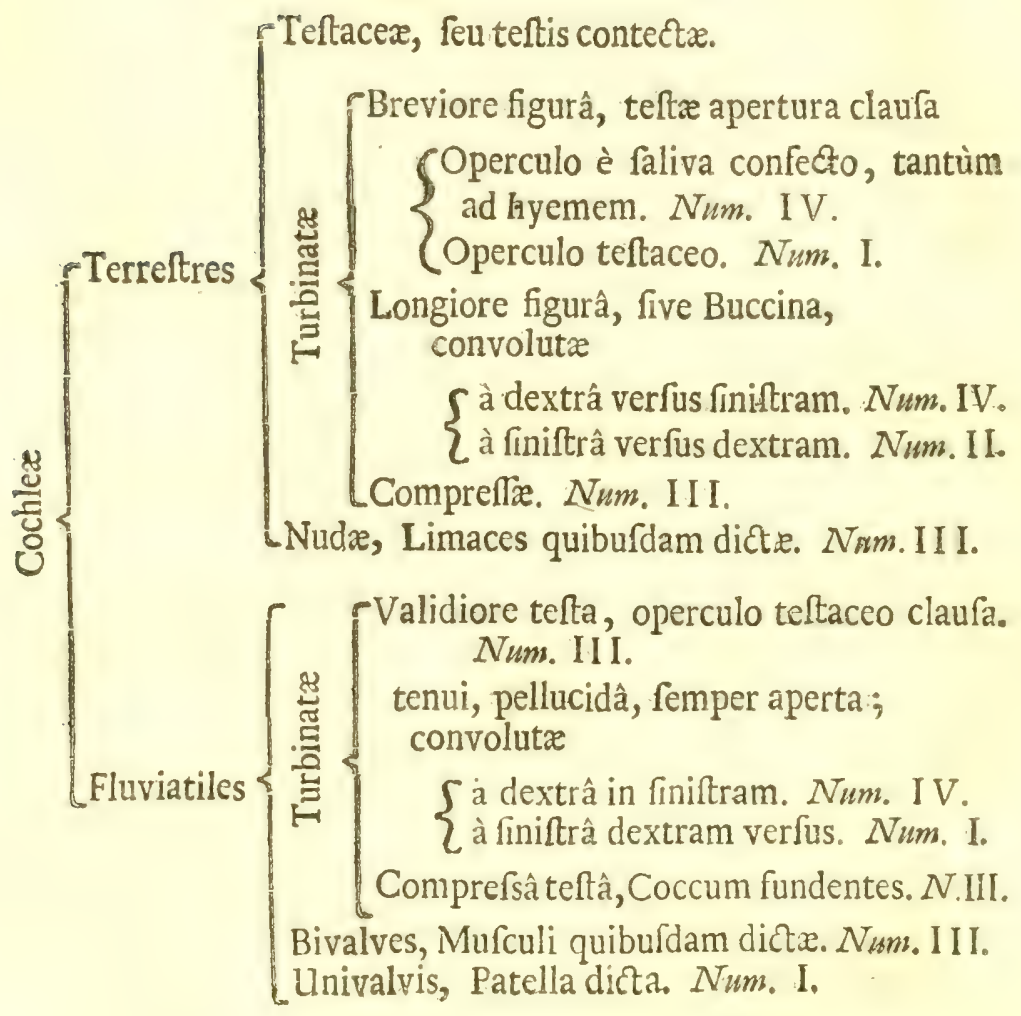


Ipla 



\section{EIBRI}

\section{COCHLEARUM ANGL}

\section{PARS II.}

\section{De Cocbleis Terreftribus.}

Terreftrium Cochlearum Note characterifice funt.

1. Habere extrema Cornicula capitulis quibufdans five nodis infignita. 2. Quatuórq; numero.

\section{S E C T I O, I.}

De Cocbleis terreftrilus, Teftis contedis.

\section{ME MBR UM I.}

De Cocbleis terreftribus Teftis contectis, turbinatis, breviore figurâ.

In bis autem not is communibus conveniunt harum Cocho learum tefze. I. Intra quinq; anfractus finiri. 2. EJse magis compactili er breviore figurâ, ut ipfins tefte a. pex parùm aut nibil emineat. 3. Aperture extremas oras effe leviter reflexas. 4. Fafciis infigniri.

\section{A P. I.}

De Cochleis fuprà diftindtis in specie.

\section{T IT ULUS I.}

Cocblea cinerea, maxima, edulis, cujus os opercalo crafso velut gypleo per hyemem clauditur. Pomatice Gefneri, De Aquatilibus, pp. 644.255.

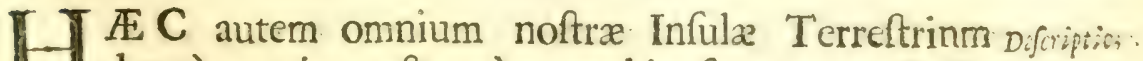
longè maxima eft; cùm ex his funt, quæ Gallinacei ovi mediocris magnitudinem ferè impleant. 
Ipra tefta cinerea, five fubalbida eft.

Ei infuper non nimiùm obfcura veftigia quarundam $\mathrm{Fa}$ fciarum latarum, fubrufarúmg;, fecundùm anfraçuum ductus circumvolutarum.

A teftre apertura ad cjus apicem non amplius quinq; anfractus five orbes numerare licet.

Aperture extremæ oræ leviter reflectuntur; item ad iman oræ finiftræ reflexæ parten, ubi reliqux teftæ jungitur, eft quidem fin us anguftus; intra quem tamen fpecillum demittere licet ad dimidiam unciam; is antem finus Teftrexterior eft, neq; ad ejus cavitatem pertingit.

Teftx aperturam adverfus hyemem diligenter obturat ipfe animal; ei fc. Operculum album, craffum, fragile, velut gypfeum, è propriâ falivâ confectum, ex omni parte firmiter adglutinando.

Cochlex omnes, inquit Wottonus nofter apud Gefnerum, leviore quodam tegnine fibi fuperimpofito hyeme latent; fed Pomatix ab hâc re peculiare fibi nomen fortitæ funt.

Aprili verò ineunte id circa oras refolvitur, atq; integrum protuditur. Illud mihi, ex his unam circa initium Martii menfis in finu fervanti aliquando contigit, quòd teporem fentiens animal intra paucas horas Operculum amoverat erepsitq;.

Eft autem ipfe animal bene carnofum, nec palato nimiùm ingratum.

Lockso Agro Hardfordienfi \& alibi in Angliâ "meridionali abundint, in Septentrionali nufquam mihi faltem occurrit.

In vepribus per hyemem figillatim conduntur.

In Gallia Narbonenfi admodum vulgò eduntur.Item Parifiis tempore quadragefimali magnâ quantitate væneunt.

Coquuntur ex aqua fluviatili, \&z adjectis oleo, fale \& pipere lautum ferculum præparant. 


\section{De Cocbleis Terreftribus.}

\section{TITULUS II.}

Cocblea vulgaris major, pulla, maculata dir fafciata, borterniss.

\# Æ , magnitudinem quod fpectat, proximum lo- Defriptrian cum obtinet; fuperioris tamen vix dimidium attingit.

Ei color pullus, aut caftaneus, fafciis aliquot latis cingitur; maculíq; crebris fubllavis, aut fubcinereis in modum marmoris interftinguitur.

Aperturæ margines leviter reflexi ; idq; iis præcipuè qux vel ad juftam magnitudinem pervenerunt, vel quibus ea Teftx pars fatis obduruit.

Eft præterea tefta è quinq; anfractibus revoluta, formâ rotundâ, brevi \& compactili, ejus quippe apex omnium minimè exftat, fed aliis volutis fuperinjectis penè occultatur.

Ipfi animali funt quatuor cornicula; ex his duo fuperiora, quæ longè majora funt, fingula puncta nigra habent; quæ in inferioribus non funt. Illa à quibufdam Oculi haud malè exiftimantur.

Ei labra fuperiora valdè angufta.

In dumetis \& fepibus nimium frequens; item hortos in - zocuse feftat.

Per hyemem in arborum annofarum fiffuris, aur cavis earum truncis latent, interim teftæ os multipili membranâ, tenui, pellucidà obturatur; atg; una Cochlea alteri racematim adglutinatur. Olera depafcunt \& omnigenam herbam; neq; ipfa Poma intacta relinquurt.

Ad finiftram partem cervicis, foramen tum maxims patet, dum repit animal; ex co vero excrementa ejicit.

Ei excrementa figurata \& dura. Si in liyeme incidan- 
unr, ubi ex toto victu abfinent, etiam tùm inteftina infima five colon \& rectum excrementis replentur; an famem ideò meliùs \& diutiùs fuftineant ?

$\operatorname{sistin}$

Spicis?

Maio exeunte aut Junio tardius, fi fortè tìm pluvia incidat, primìmcoëunt : adeóq; Veneri intentæ funt, ut de loco in locum transferri polfunt, Copulâ ufq; fervata.

Illud addam, me, dum in coitu con, ungebantur, fingula spicula in utriufq; cervice penitùs infixa, non femel obfervâffe. Ea autem fubftantiầ teltaceâ friabili, \& eleganter figuratâ conftabant.

Qu:

Harum Cochlearum ova diu fruftrà quxfivi tàm extra, quàm intra corpus ad coitûs tempus. Tandem ea in horto fub herbam circa menfen Julium copiosè inveni: alba crant, majufcula, leviter interfe cohærentia, cortice membraneo, mollíq;

Appetente Autumno harum pulli nucis è corylo magaitudinem ferè implent; adeò celeriter crefcunt. Notandum eft, in his juvenibus tefta tenera admodum ef, \& circa aperturam minimè reflexa.

Ex his unam vitro inclufi, eíq; Limacem atrum, infra defcribendum fuppofui: poftridie autem limacis cutem miferè corrofím, dilaceratan, eúmq; planè confectum animadverti: tantus aninus eft ctiam pigerrimis animalibus. Eft aliquid inter Vifcera, quod pinguedini maximè aflimilatur : in ignen vcrò impolitum, flammam non concipit, nec liquefcit, fed induratur.

saliv6. Hæ Cochlex falivam ab ore copiosè eructant ; qui tamen alius humor, \& longè diverfus effe videtur $a b$ eo, qui emittitur à corporis puncturâ, aut incifione in cute factâ. Etenim hic pofterior, fubcæruleus, multóc; dilutior eft. Ille autem alter fponte cructatus, \& craffior, magifif; tenax, item paulo coloratior ad flavedinem accedens, fortè $a b$ herbis pramanfis in ventriculo, unde provenit, infectus.

Illa unfiper de utrufg; differentia expertus fum.

Utriufg? 


\section{De Cocbleis Terveftribirs.}

UTtriufq; humoris copiam vitreâ ampullâ primùm mifcui. At hi benè conquaffati in unam maffam inftar gelatinæ flavæ coaluêre. Tùm in aliam ampullam fubcærulei humoris copiam per fe fepofui, qui tamen diu \& multùm fimiliter conquaflatus, neutiquam concrefceret.

Alterum experimentum erat hujufmodi. Ex his Cochleis aliquammultas linteo inclufi, tantillum falis is aliquoties infpergendo, neq; tamen alium humorem, quàm falivam fubflavam tenacémq; ejecerunt : è linteo verò exemtos falpcllo incidi, quibus vulneribus fubcærulei humoris copia emiffa eft.

Hinc autem liquet, humorem coccineum quarundam Cochlearum Fluviatilium infrà defcribendarum fponte eructatum, effe de falivæ, non fanguinis naturâ; at de purpurâ aliter perhibuerunt Antiqui.

Subcæruleum humorem ab incisâ cute emiffum, cochlearíq; injectum finas tantifper leniter evaporare fuper prunas; momento ferè temporis fit Gelatina alba, inftar fanguinis feri; cum quo, ut opinor, magnam affinitatem habet.

In his autem animalibus diffectis innumeras venas lacteas circum inteftina difcurrentes, non aliter quàm in fanguineis animalibus notare licet: hunc verò chylum in corporis habitu difperfum, in cæruleum iftum humorem aliquando concoqui verifimillimum eft; utpote cùm in alterius generis vafa feratur, \& lactei humoris effervefcentia paululùm conquiefcat.

Præterea idem humor, ipféve animalia nonnullis apud artifices ufibus non tacendis inferviunt.

Primus is eft, quem in cerâ dealbandâ Monfpelii ipfî vidimus. Modulos ligneos contufis Cochleis illinunt, ing; ceram liquefactam eos demittunt; ita Cochlearum fanies ceræ adhæfionem nimiam prohibct, ut leviter concuffis modulis, ceræ tenuem membranam accipiant; reliquum ve- 


\section{6 \\ De Cocbleis Terrefribias.}

rò ejus reỉ diuturnâ infolatione \& affliduâ irrigatione perficitur in areis.

Alter ufus eft in re ftatuaria in hunc modum; accipe calcis vivæ, q. v. albuminis ovi, humoris cochlearum per puncturam cmiffi, fingulorum partes æquales; mifce \& in marmore conterantlir. Preftantiffimum ........ perhibetur ad lapides fractos inter fe conglutinandos; fiquidem. in inftanti ferc \& admodum firniter induratur.

Dintis.

De Cochlearum dentibus, optimo Microfcopio in auMicrograpis. Ob). 40 . xilium adhibito, ita perhibet Cl. Hookius nofter. E fuperiore, inquit ille, oris parte Cochlcæ cujufdam Teftâ contectx (fi rectè intelligo) officulum durum recurvúmq; exemi ; id mihi vifum eft figurari in modum dentium, gingivis ordine fuo difpofitorum, inq; plures minores majoréfqi dentes nigros dividi : verùm unum folidúmq; officulum erat, quo eam rofx foliis vefci ipfe obfervavi; atq; ex iis lunatas exiguas partes mordiffe in modum literæ majufculie C. Hujus autem oficuli pars fuperior ejus inferiore \& nigriore parte multo albidior eft \& minùs finuata, $\varepsilon r$ ad oras paulatim extenuatur in aciem; huic infuper velut novem dentes five partes eminentes, omnes, ipfo officulo medio, inter fe conjunctre. Totum illuftratur admodum eleganti figurâ, quam vide apud Authorem.

\section{TIT ULUS III.}

Cocblea citrina aut leucopbas non rarò unicolor, inter. dum tamen unica, interdum etiam duabus, ant tribus, aut quatuor, plermngì verò quinis $F$ afciis pullis diftincta.

Difcrititio. A mediocribus annumeranda eft.

Coloris varictate mire ludit; ut verò de hac realiquid certò fćrem, harum ingentem copiam colligendant

curavis 


\section{De Cocbleis Terreftribus.}

curavi, è quibus, coloris differentias quod attinet, rem ita fe habere didici.

I. Teftam ex toto citrinam, fi aperturæ oras excipias, quæ vel candidæ, vel pullæ; harum verò numerus ingens.

2. Teftam ex toto leucophaam, ipfis aperturæ oris pullis; hæe non nimiùm raræ.

3. Teftam citrinam unicâ fafciâ pullâ per medium anfractûs circundatâ.

4. Eandem fingularem fafciam in teftâ lcucophrê̂.

5. Teftam leucophram duabus latifimis fafciis pullis cinctam, ferè totum anfractum inter fe occupantibus.

6. Idem dictum puta de teftâ citrinâ. N. B. Hre pofteriores quatuor teftæ admodum raræ funt.

7. Teftam leucophæam, cujus anfractus primus quing; Fafciis pullis cingitur; ex quibus tres fuperiores duabus inferioribus paulo latiores funt.

8. Idem Fafciarum \& numerus \& modus \& color in Teftâ citrinâ : atq̧; hæ duæ ultimæ teftæx omnium longè frequentes funt.

9. Quatuor Fafcias pullas in teftâ citrinâ; è quibus dưe fuperiores totidem inferioribus latiores funt. $\mathrm{Hæ}$ auten rariores multó.

Ex Teftis citrinis aliquot eatenus pellucidas obfervavimus, ut ipfius animalis Venula \& motus nobis evidente: apparerent: jucundum fanè fpectaculum!

Ipfi animali Teftæ inhabitanti color interdum cinereus, interdum fufcior.

Ubiq; per Angliam in fepibus \& dumetis frequens be- Locm: ftiola.

Hæ omnium primæ à Brumâ prorepunt.

Mienfe Maio coëunt ; ídq; diebus tantùm tepidioribus coiths \& ferè horâ antemeridianâ. Adulti, qui fc. ad juftam magnitudinem perverierunt, foli coëunt. 
De horum animalium coitu ita doctifinnus mihíq; amiciflmus Johannes Rayus in Catalogo Plantarum circa Cantabrigiam nafcentium, ante annos fedecem edito, ad Solanum. 'De animalculis hifce monere liceat, quòd eo'rum fingula de utroq, fexu æquè participant, \& funt an${ }^{\circ}$ drogyna ; viciffim enim agunt \& patiuntur, immittunt fi: mul \& recipiunt, ut cuilibet fatis conftabit, qui Vere 'coëuntes feparaverit; etfi nec Ariftoteles nec alii, quod 'fcimus, rei naturalis fcriptores ejus rei meminerint. Hæc ille.

Aliquis fortè opinetur, in colorum varietatc fexûs differentiam difcerni poffe; at diligentia noftra in hâc re fruftrà fuit ; fiquidem inter eas promifcua Venus eft; citrinas fc. \& inter fe \& cum leucophæis, \& utrafq; cum fafciis infignitis indifcriminatim conjunctas fuiffe obfervavimus.

Si totam cervicem teftâ exertam fcalpello præcidas, in hâc præter Gulæ initium \& genitalia membra \& ipfum inteftinum rectum habebis. Atq; illud in causâ fuit, cur apud Romanos olim Cochlearum cervices in rebusVenerem magnoperè excitantibus numeratæ funt; ut ex Petronio Arbitro patet.

Harum Cochlearum cute incisâ humor pallidè cyaneus emittitur; at qui è vini firitu dicto coagulatur \& indurefcit.

Tempeitate pluviosâ, humore abundanter haufto, madefcunt : neq; alio tempore facilè aut libenter prorepunt: surfus ficcitate reftitant \& ferè loco permanent; adećq; carum ingreflus eft quædam velut natatio in proprio huInore.

Turdis in deliciis funt; hi quippe Cochleam imam roftro perfringunt, beftiolámg̨; eximunt. 


\section{TITULUS IV.}

Cocblea masulatu, unicâ $F$ a criâ pullà, anguftioréq; per medium anfractis ins ingrita.

F A proximè fuperiori magnitudine par eft, aut paulò Decripsiso

H. minor. At eadem planè figurâ, admodum fc. compactili, intráq; quintum anfractum finitur Tefta.

Ei color ex flavo pullóg; variatus in modum marmo: ris, five maculofus.

Item per medium anfractum circumducitur unica fafcia pulla, anguftior.

Ex dcf riptione, \&x loco, \& quòd non coëant cum proximè $\mathrm{f}$ perioribus, abundè conftat has effe fpeciem diftin. ctam.

In fepibus umbrofis non nimiùm rara : at in juncetis $\& z_{\text {Locks. }}$ pratis, udis adnodum frequens.

\section{CA P. III.}

De Cocbleis breviore figurâ, quibus Operculum tefacenm datur.

\section{TITULUS V:}

Cochlea cinerea, interdum leviter rufefcens, ftriata, $0_{0}$ perculo teftaceo cocbleato donata.

Cocblea terreftis turbinata er friata Fabii Columne, De purpura cap. 9.p. 18. ubi etiam delineatur fub hoo. Titulo, Cocblea turbinats.

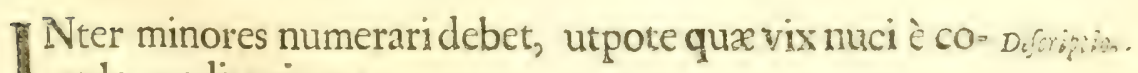
rylo mediocri par. 
Ei color cinereus, interdum leviter rufefcens, aut flavicans.

Omnium noftrarum terreftrium longè elegantiffima Cochlea eft.

Intra quinq; anfractus tefta finitur, at fuperioribus paulò productior eft, ur Fab. Col. ideò Turben dictus fit ; mihi autem aliter vifum eft eam difponere, quòd Cochleis breviore figurâ magis quidem accedat.

Teftæ apertura ferè circinata; ejúfq; oræ rectx.

Admodum densè ftriatur fecundum anfractus; non picturâ quidem, fed ftriis canaliculatis teftæxe incifis.

Os obturatur Operculo craffo fic ut non pelluccat, teftaceo, cochleato ; ídq; imo animalis limbo adhæret, dum prorepit; atq; ita ultimò introducitur, Teftæ aperturam exactè claudendo.

Lecuser Ubiq; per Galliam frequens: at rarior apud nos; in agro tamen Cantiano,\& Lincolnienfi eam aliquoties inveni : etiam Eboracenfis ager eâ non carct.

I have found them plentifully in a Woody bigh cliff upon the River Wharfe near Oglethorp; alfo at Burwell moods in Lincolnfhire. 
- De Cocbleis Terreftribus.

MEMBRUM II.

De Cocbleis tcrreftribus longiore frgurâ, five de Buccints.

He. funt Buccinorum terreftrium not $\mathbb{E}$ comm unes. I. Teftâ longâ five productiori dari. 2. Tenui admodum. 3. Minimùm quinq; at plerunq; pluribws anfractibus circumvolvi. 4. Anfractuum latera efe planior a. os minùs in modum circuli eminere, ut in cunctis fuperioribus. 5. Tefte aperturam oblongam, compref. fam, \&u anguftiorem babere.

\section{A P. I.}

De Buccinis quorum Orbes in finiftram partem convolvuntur.

\section{TITULUS VI.}

Buccinum exignum fubflavum, mucrone obtufo, five cylindraceum.

I I C omnium minima Cochlea; vix enim hordei Defriptice dimidium granum implet.

Ei color fubflavus, aut qualis in olivâ viridi conđitâ.

Teftæ apertura paululùm compreffa \& anguftior.

Senis orbibus finitur : quorum quinq, fupcriores ferè $x$ quales inter fe funt; fextus verò fubitò minuitur in nucronem obtufum; hinc tefta cylindracea.

In veteribus Hortorum parietibus, mufco obductis CO- Iocses, piosè reperiuntur vico Eftrope dicto agri Lincolnienfis. 


\section{TITULUS VII.}

Bucinum cxiguun, quing; anfractum, mucrore acuto.

Defcriptio.

Lociss.

\section{T I T ULUS VIII.}

Buccinum rupium, majufculum, circiter Jenis orbibus circumvolutum.

Drfriptio. TD Aulo major eft grano triticeo, pelíucida.

Ei color caftaneus; circiter fenis anfractibus producitur, xqualiter diminutis.

Iocis.

In rupibus ad Torrentes in regiuncula montosâ Craves dictâ, \&x alibi cam Cochleam copiosè invcii. 


\section{De Cocbleis Terreftribus.}

\section{A P. II.}

De Cocbleâ anomalâ.

\section{TITULUS IX.}

Buccinum paroum five Trocbilus fylvaticus agri Lincolmien:is.

T I X piperis grani dimidium implet.

Ei color fubflavus, pellucidus.

Ejus bafis planior, fenis aut feptem orbibus in modum Trochili finitur.

In mufco ad grandium arborum radices in fylvis Bur- Locxso wellenfibus agri Lincolnienfis non femel eam inveni: eft tamen admodum rara beftiola.

\section{CA P. III.}

De Buccinis, quorum orbes ex dextrâ in finiftrams conn volvuntur.

\section{TITULUS X.}

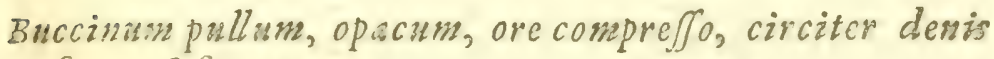
Jpiris fuftigiatum.

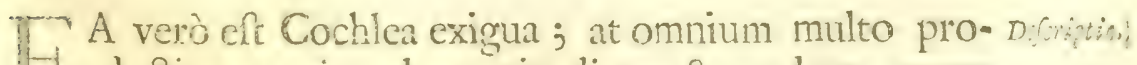

H. ductior, tenuis, ad magnitudinem \& modum avenx

grani facta; unciam dimidiam longitudine implet.

Ei color pullus \& opacus. 
Denis fpiris è dextrâ in finiftram convolvitur.

Ejus bafis paulo anguftior eft, velut alter mucro, mediáq; pars leviter intumefcit.

Teftx apertura compreffa, angufta, \& ad imam ejus partem finuofa : item ejus oræ leviter reflectuntur.

Iocuso

Hæc in fiffuris \& cavitatibus annofarum arborum frequentes; item in parietibus circa hortos.

In Literis ad me olim datis ita de hầc Cochlea $\mathrm{Cl}$. Johannes Rayus. 'Rem fanè curiofiffimam te nuper obfervâffe ' narras, nimirum Cochleam,cujus fpiræ in diverfam partem 'flectant; cùm inter doctos conftans opinio fit, à feptentri' onali Ëquatoris parte Cochleas omnes (motum fc. folis 'obfervando) à finiftra dextram verfus torqueri. Nec ego ' anquam inveni, qualem tu defcribis; five ergo aliæ funt ' hujus generis, five hæc fola exceptio fit, \& diligenter fer' vari \& exactè defcribi depingíq; meretur. Hæc ille.

\section{TI TULUS XI.}

$\circ$

Buccinum alterum pellucidum fubflavum, intra fenas sirciter Jpiras mucronatum.

afcriptio. T A Cochlea proximè fuperiore paulo brevior eft; at T- intra feptem plurimùn fpiras finitur; è dextrâ in finiftram procedentes.

Ejus bafis multo plenior eft quàm in fuperiore, \& in de minuitur ad juftam proportionem.

In media primæ fpiræ circumducitur velut acies quedam acuta eminénfq;.

Ei color pallidus ad flavedinem accedens, pellucidus; eft tenuis \& valde tenera tefta.

cosus.

In agro Cantabrigienfi has fxpiùs inveni ad truncos annofarum Fraxinîm. 


\section{De Cocbleis Terreftribuis.}

Martio exeunte ex his plurimas notavi Venere con- Coithn junctas; illud autem perpetuum ex duabus ita copulatis $s_{\text {}}$ una alteri multo major erat; non leve fanè argumentum fexs difcriminis etiam in hifce animalibus.

\section{MEMBR.UM III:}

De Cocbleis Terreftribus figurâ compre Jja.

He Sunt earum Note characteriftice. I. Habere in Tefte centro ex alterâ parte finum cavum velut Umbilicum. 2. Intra quinq; Jpiras finiri.

\section{A P. I.}

De Cochleis Terreftribas fiğurâ compre Jầ in Jpecie.

\section{TIT ULUS XIF。}

cocblea dilutè rufefcens, aut fubalbida, finu ad unbili. cum exiguo, circinato.

T $3 \mathrm{~T}$ autem mediocris Cochlea; inlatitudine verò di- Defriptis . 1 , midiam unciam rarò fuperat.

Ei color pallidè admodum rufefcens, aut fubalbidus:

Figura compreffa; at paulò minùs quàm reliquis duobus infrà defcribendis.

Ad umbilicum, ubi aperturæ limbus finifterior reliquæ teftx adnectitur, eft finus quidam rotundus, imò circinatus exiguus.

Ipfe animal ferè nigricat : in rependo teftæ umbonem furfum gerit.

$$
\text { R. 3: }
$$


In fylvis \& ad fepium aggeres udos \& umbrofos circa Tadcajer; item in iifem locis agri montofi Craven dicti copiosè reperiuntur.

Hace ctiam Cochlea à Turdis conqueritur, iifq; victui eft; ex his enim quamplurimas teftas invenire licet, quanim due trefve ad apicem fpiræ prefractex funt; qui mos quidem eft huic avi, beftiolam, cujufcunig; fpeciei fit, è teftâ eximendi.

N. B. Eft etiam vel varietas vel alia fpecies huic non ita difímilis in agro Cantiano, paulò major, \& minùs coioratus; item cui cavitas ad umbilicum multò minor.

\section{TITULUS XIII.}

Cachlea cinerca albidíve, fafciata, Ericetorum.

Defcriptitio.

Jus latitudo in majufulis aliquando tres partesuncix
implet; at id raro.

Ei color cinerens aut fubalbidus, fafciis pallidè flavefcentibus: in fafciarum ordine \& magnitudine, \& numero mirus naturxe lufus. Ferè delentur affiduis pluviis, in vacuis precipuè teftis, quibus fc. animalia emortua funt.

Intra quinq; orbes, unus alteri ferè dircete fuperinjeEuir, terminatur; alterâ parte apex frèe mucro parùm aut nihl eninet; alterî confpicuus \& amplus finus.

In Ericetis \& plinis campis montolis agri Eboracenlis, \& Iimlibus locis per totam Angliam frequens.

\section{TITULUS XIV。}

cocblea pulla, Jjivatica, fpiris in acrena deprefjes.

Fl latitudo, quanta uncin tres partes ant prope implet. H. Color fufcus aut pullus. 


\section{De Cocbleis Terrefiribus.}

Oris apertura candida ex parte internâ; inferior apertura pars paulo magis producitur, quàm fuperior.

Intra quinq; foiras terminatur; at ullà è fuperioribus multo compreffior eff; adeo orbium extrema pars deprimitur in limbum acutum.

Sinusautem five foramem rotundum in orbium medio, non nimiùm grande.

Eft clegans \& rara Tefta ; at in fylvis agri Lincoinienfis eam multoties inveni; per hyemem fubter corticem annofarum arborum ; per xftatem in herbâ.

\section{SECTIO II.}

De Cocbleis tcrrefiribus, Nudis, Limaces quibufals dictis.

Atq; bactenus de Cocbleis terreftribus, Teftis contectis egimus; aliud earum genus Nudum proximè defcri. pturi fumus. Ii autem quibufdame antiquis Limaces appellantur.

Harum note Characteriftice funt. I. Nuditas. 2. 206i Tefta in fuperioribus, ibi cucullus ant palliolum five fcutum cuticulare, craJum, \&u validum.

\section{A P. I. \\ De Limacibus in specie.}

\section{TITULUS XV.}

Iimax cinereus, maximus, friatus dir marulasus.

I. I C omnium facilè maxinus, pendet.

Ei color cinereus, aliquando fufcior, \& crebris ma- $D$, niftic

culis: 
culis nigris, \& virgulis fufcis diftinguitur; de maculis verò ita curiofì̀s obfervavi, quas fc. in Cucullo habet, effe majufculas \& fine ordine hic \& illic difperfas: ad alvi vero latera funt virgulæ fufcæ velut undatim pictæ, fi non dum conquiefcit animal, certè dum ingreditur ita fe habere videntur; at fupra ipfam alvum maculæ nigræ in duplici ferie difponuntur.

Ipfe venter albefcit.

Super humeros five in medio dorfo, craffo cucullo, teftæloco, contegitur; in hoc fanè magnum præfidium, adeóq; fubter hunc \& caput \& cervicem \& ipfam alvum aliquoufq; fi moleftetur recondit. Item ad majorem fui defenfionem ibidem fubeft Oficulum latum, leviter convexum.

Iocus.

Iapilliks.

In fylvis opacis \& ad fundamenta parietum uda, \& aliis fubterrareis uliginosifq; ædium locis frequentes.

Menfe Martio Lapillum exemi, atq; alterum Augufto, ejufdem formæ \& magnitudinis utrumq; medio fc. animalis cucullo leviter incifo.

Malè autem dicitur is lapis cerebro calvariæ loco fuperimponis capite tamen reducto intra corpus ei propugnaculi vicem preftare poffit.

Hujus lapidis five officuli in nudis quibuldam Limacibus inventi meminit Plinius, lib. 30. cap. 15. lib. 29. cap. 6 .

Lapillum quemego (inquit Aldrovandus) propriis manibus exemi ê capite nudæ Cochlex, poftquam in multis Eruftra quæfiviflem, albidus erat, tabæ ferè magnitudine, multò tamen humilior, compreffúfq; magis, modicè tranfparcns, inæqualis, admodum glaber, parte alterâ planior, alterá veluti in oculum protuberans, fed dentibus friabilis, ta ut in arenulas atteratur.

De hoc lapillo fic Wormius : Lapis limacis ex iis limacibus petitur, qui fine teftis in campis \& locis fubterraneis ragantur, colore fufco. Hi in capite Lapillum habent candidum, 


\section{De Cocbleis Terreftribus.}

candidum, ovalis figure, tenuem, planum, aliquantulum convexum, pondere adeò exili, ut tres quos ego poffideo, fcrupulum non æquent.

Quibus Wormii verbis addo, tres maximos è noftris non quatuor grana pependiffe; item partem earum convexam fuiffe teftaceam; concavam verò veluti cretaceam.

Quòd eidem ufui in Medicinâ adhiberi poffint, cui Uniones aut lapides Cancrorum dicti, etiam cum æquè bono effectu, nihil dubii eft.

His Limacibus victui eft non herba tantùm, fed etiam vicuss. papyrus è lino contrito adeóq; exfucco confecta.

Horum Limacum coitus in hune modum peragitur. In. Coitts. cunte Augufto ad meridiem, die admodùm ferenâ, ex his duos maximos Venere conjunctos vidi; at nec magnitudine æquales, \& cutis variâ picturâ præcipuè inter fe diffe. rebant ; fiquidem alter altero paulo major; illi majoriad caudam virgulæ undatæ fufcx, huic color paulo albidior, crebrif́; maculis fufcis fupra cucullum maximè infigniebatur. Ii autem in aëre liberè dependebant, capitibus deorfum inclinatis, de nodo faligno, è veteris cujufdam arboris trunco extante, demiffi ; corporum verò pondus fuftinuit funis craffus, fefquipedalis, è propria faliva confectus, íf; eorum caudis interplicatis affixus eft. His ita difpofitis, uterq; ingentem Penem exerebat, è dextra cervicis parte prope cornicula. $\mathrm{Hi}$ autem primùm pifcium veficulis fimiles fuêre; deinde eofdem, non aliter quàm caudas interplicabant. Mirum quantum hi intumuêre, pinnif́; quibufdam elegantiffimè ftriatis exornati funt. Iis color pallidè cyaneus, at altera eorum extremitas nervora nulto albidior; ifq; membrorum genitalium plexus, velut mediocre pyrum è duplici petiolo dependens mihi vifus eft. Tandem à me divulfi funt, atq; omnino nullam differentiam in membris corumgenitalibus difcernere licuit ; etiamfi, ut fuprà pofitum eft, fatis erat in formâ externâ, quo diftinguerentur. 


\section{De Cocbleis Terreftribus.}

Eordem limaces alio tempore circa menfem Junium in? fylvis opacis obfervavi ex arborum ramis demiffos, fingulos fingulis funibus bipedalibus, craftis \& validis fatìs; at è propriâ falivâ confectis. Eft fanè magna affinitas inter humoremi illum è quo Araneorum Erucarúmq; fila fiunt, atq; horum animalium falivam.

(2) $\therefore$

Circa initium Aprilis aliud mihi obfervare contigit, horum animalium generationem quod fpectat. Siquidem prægrandi aliquo lapide in horto in alterum latus inclinato, aliquot centena Ova fubter invenimus: ea autem fuerunt fphærica, unius cuncta magnitudinis, ad piperis $f$. albi grana accedentia: iis color albidus; at inter hæc multi tantùm vacui cortices fuêre, ipfis fc. animalibus nuper exclufis; at qux adhue integra, paululùm flavefccbant. Ex his aliquammulta fcalpelli mucrone fúpensâ admodum manu aperui ; è quibus fingulis finguli hujus fpeciei Limaces exiêre, albidi aut pallidè flavefcentes, iidem autem protinus proreperunt, etiam corniculis exertis, acfi fponte nafcerentur: adeo in iplo exclufionis momento obvenimus.

Illud præcipuè notandum, coitum Augufto menfe perfici, Limacéfg; ad Aprilem ufq; menfem in ovo permanfiffe.

\section{TITULUS XVI.}

Limax cinercus, parvus, immaculatus, pratenfiss,

2. $\cdots, \ldots$ I S parsa Cochlea eft; minimi digiti articuli primi craf5icie; neqi in juftâ extenfone ultra fefquiunciam longuls.

Ei color cincreus, immaculatus; nonnulli tamen in his lunt, qui flavent.

Item huic ad polteriorem partem pallioli fubter latet exigum officulum, ovale, pellucidum. 


\section{De Cocbleis Terreftribus.}

in herba pratenfi \& alibi paffim reperitur.

lis pleræq; herbæ victui funt; at Fungi, etiam piperatus, victus. in deliciis funt.

Poft afliduas pluvias circa exitum Junii ex his plurimos coittuss Vencre copulatos ad fepium aggeres vidi ; è dextrâ verò cervicis parte utriufq; per omnia fimile, quantum obfervare liceret, genitale nembrum emiffum. Atq; id quoq; argumento cft, has fpeciem à proximè fuperioribus effe diitinctan! ; quod in fingulis fpeciebus, ex adultis funt qui coëunt, \& ad juftam magnitudinem quàm proximè pervenerunt.

Ab hoc Limace in manibus recepto, emittitur quidam Hixor late eiss. humor lacti fimilis, velut à pifcibus mafculis $\&$ in oftreis aliquando obfervare licet. An femen genitale?

lllud infuper de hâc beftiolâ notavi ; quòd fc. occiderat, aut fortè occifum invenerat, fcarabæum quendam majufculum; ejúfq; pectori capite tenusfefe intruffifet, ut ejus vifcera depafceretur.

\section{TITULUS XVII.}

Limax ater.

Gefneri de Aquatil. lib. 4. pag. 254. Cocblea nude tertia tota nigra Aldrov. de infectis lib. 6. cap. 10.

I $\mathrm{S}$ maximus limax eft: pendet. In fuperiore corporis Difcriptitis

1 parte totusaterrimus.

Venter ei albefcit, aliquantulum ad cæruleum vergens.

Cervix \& cauda rugis profundis \& inæqualibus velut exafperatur : at Palliolum five fcutum lævius.

Ex his nonnullos ex atro rufefcentes aliquoties obfervavi; at id per accidens fuiffe exiftimo. 
Lociss.

ViEtus,

Qบกิอ

In pratis udis, \& locis umbrofis, etiam fupra celffifimos montes frequens. Menfe Februario prorepunt, quo tempore ob diutinam inediam valdè extenuantur.

Iis promifcuus victus eft è qualibet herba ; corum excrementa, cùm virides herbas depafcunt, viridia; cùm verò folia marcida \& rufefcentia, fimiliter colorata : fungi etiam piperati is in deliciis funt.

Sub initium Maii ad radices Lapathi, paululùm fub terram eorum Ova velut in maffam conglomerata invenimus; his autem color pallidè cærulea, fingula ad magnitudinem piperis grani, fphærica, cortice molli contecta.

Verne lasthe. In hujus abdomine diffecto ingentem venarum lacteaxum copiam; circa inteftina difcurrentium advertere licet; \& numero \& magnitudine fanè animalis modum multùm excedentium. In eo autem à lacteis in animalibus fanguineis differunt, quòd hæ noftræ lacteo liquore perpetuò turgefcunt, aut certè tantum ejus humoris in fe contineant, quòd femper difcerni poffint; illæ verò, nifi certis à paftu horis, prorlus vacuæ funt, \& ex toto deplentur. An ideo nobis conjecturam facere liceat, has chyli etian conceptaculo \& promocondo effe, unde iis fufficiat, quo famem diutiùs perferant?

Pailiolum five fcutum in multis centenis hujus fpecie: animalibus incîdi : at nunquan lapidem, qualem in primo hujus Sectionis defcripfimus, inverii : in aliquibus verò velut cretam albam in arenulas friabilem.

Hujufmodi Animalia in fole ficcari poffint integra; guod, ad eorum prefervationem ipfe expertus fum.

Horum fumma Cutis ob intenfam nigredinem maximì notabilis, ut nihil fupró. An adeo aliquomodo illa adhiberi poffit in pictura aut aliàs, vide. 


\section{LIBRY}

\section{COCHLEARUM ANGLI不 P A RS IIL。}

De Cocbleis Fluviatzlibus.

\section{S E C T I O I.}

De Cocbleis Fluviatilibus Turbinatis in genere.

Cocblearum Fluviatilium Turbinatarum be funt note characteriftice. 1. Ip a a animalia Corniculis donari aut tenuibus aut ramofis, aut capillaceis; eorum verà univerfis ea extrema in apicen wacronatum terminario 2. Bina tantùm Corracula babere. 3. TE ftarum aperturas parùm aut nibil reflecti.

\section{ME MBR U.M I.}

De Cosbleis Fluviatilibus turbinatis; quibus validior \&o craffior Tefta; atq; ea operculo Teftaceo claufa.

\section{C.A P: I:}

De Cocbleis, quarum calices fuis operculis teftaceis claudantur.

\section{TIT ULUS XVIII.}

Cocblea maxima, fufca five nigricans, fafciata.

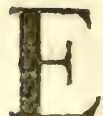

A autem ad vulgarem hortenfem terreftrem fecur- Dir option di Tituli magnitudine quàm proximè accedit ; imò aliquando fuperat; etenim ex his vidi, cui erat fefquiuncialis longitudo à fummo vertice ald extreman bafin. 
Ei color fufcus five niger; ita ut, ubi viva teftis infuns aninalia, teftarum fafciæ vix notari poffint: fiquidem duabus aut tribus non nimiùm latis fafciis fufcis circumdatur.

Paulo productior eft, quàm terreftres primorum Titulorum.

Ei craffior \& validior Tefta, quàm ulli è reliquis fluviatilibus Turbinatis Cochleis infrà defcribendis, unâ Neritâ exceptâ.

Orbes five anfractus rotundi; numero quinq; ; quorum unus ab altcro minùs occultatur, mag̀̀s tamen propendent : definit Tefta, etfi compactili admodum figurâ, in mucronem valdè acutum tenuémg; at brevem.

Orbium apertura ferè circinata; ad cujus finiftram partem, ubi anfractui infedit, eft quidam finus profundus, anguftior.

Huic Operculum teftaceum, tenuè admodum, pellucidum, rufercens, ftriis circularibus diftinctum; quà verò animali adnectitur exiguum Tuberculum paululùm eminet, cui cx alterâ parte cavum refpondet. Operculum Plantex parti exteriori, five ad ejus calcem, ut ita dicam, adnectitur.

Ipfius animalis caput velut bovinum; illud verò \& cornicula, plantæq; pars exterior interiórg; admodum eleganter colorantur; Havo fc. crebris minutiffimifq; maculis fufcis interftincto.

Huic cornicula craffa, at mucronata.

zochs. In Fluvio $\mathrm{Cam}$, infra vicum Chefterton dictum, agri Cantabrigienfis copiosè inveniuntur; alibi etiam frequentes in Paludibus, qualis ceft Pottery Carr dicta juxta Doncafter. Item in Foflis ad fluvium Darwent juxta Bubwith octavo ab Eboraco milliari magnâ copiâ reperiuntur.

$V$ efeitur foliis potamogeiton, aut aliis herbis fluviatilibus: 


\section{De Cucbleis Fluviatilibus.}

Illud fingulare, ei effe excrementa figurata, exigua ad modum \& figuram hyperici feminis, etiamfi fit beftiola $x$ què magna ac quævis Cochlea terreftris. Plura excrementa fimul ejicit, velut oves aut cuniculi.

Has Cochleas viviparas effe, primùm didici à Clarmo viro $D^{\text {mn }}$ Plot noftro. Vide Hift. Naturalem agri Oxonienfis nuperrimè editam.

\section{T ITULUS XIX.}

Cocblea parva, fubflava, intra quinq; jpiras fonita.

F ST parva Cochlea ad magnitudinem fabx equinx; Drfus H. ejus longitudo trientalis.

Ei color fubflavus, qualis in cornu pellucido, aut olivâ viridi conditâ; at paulo fưfcior.

Teftæ apertura ovalis; operculo pellucido teftaceo, cochleatóq; clauditur.

Intra quinq; anfractus finitur; hujus orbes proportionem inter fe obfervant.

Ipfius animalis cornicula numero bina funt, capillacea, aut certè valdè tenuia.

Copiosè reperitur in multis fluvies; maximè in aquis too h. ftagnantibus. 
De Nerita Fluviatili.

\section{TITULUS XX.}

Nerita fluviatilis, ̀̀ ceruleo virefcens, maculatus, operculo jubrufo lunato do aculeato datus.

Defriaptio. $\quad F$ I longitudo paululùm fupra uncix quartam partem; A. latitudo ferè intra eandem menfuram.

Tefta etiamfi exigua fit, tamen valida eft, craffáq; fanè longè fupra modum cæterarum quarumcunq; teftarum fluviatilium.

Ferè intra alterum orbem finitur, vix ad tertiam producitur ; vertex parùm aut nihil eminet.

Teftæ apertura eft figurâ lunatâ, five ad dimidium circulum per centrum diffectum.

Teftæ color è cæruleo virefcit, maximè fi aquâ illam intuearis; item ea maculis fufcis in modum operis cujufdam reticulati pulchrè diftinguitur.

Ipfe animal albefcit, duobus corniculis capillaceis datur, juxta quæ oculi, tanquam exigua punctula nigra planè confpiciuntur.

Hujus exteriori limbo adnectitur velut unguiculus five operculum lunatum, fubrufum, tenue, teftaceum: huic adeft quidam velut aculeus, in coctis animalibus facilè difcernendus.

In vadis lapidofis huvii Oufe juxta Fooforth \& Clifton copiosè inveniuntur; item in fluvio Wharfe: item in Fluvio $L$ une agri Lancaftrienfis fupra pontem juxta KerbyLasnfdale. 


\section{De Cocbleis Eluviatilibus.}

\section{MEMBRUM II.}

De Cocbleis Fluviatilibus admodum tenui tefta datis longioréq; figurâs, five de Buccinis fuviatilibres: quorum aperturce amplifsima Jemper patent.

\section{A P. I.}

De Buccinis fluviatilibus, à dextrâ finiftram ver fus convolutis.

\section{TITULUS XXI.}

Buccinum longum 6 spirarsm, omnium \&u maximum \&o productius, fubflavum, pellucidum, in tense acusern. ex ampliffimà bafi mucronatum.

Turbo lavis in ftagnis degens Aldrov. De Teftaceis lib. 3.pag. 359.n.3. ubi ejus figura habetur.

7 A omnium congenerum \& productior \& facilè maxi- befriptist - ma Cochlea. Ejus longitudo fefquiuncialis; bafin verò, quâ plenior eft, linea ferè binuncialis comprehendit. Ei color fubflavus; éftq; tefta valdè tenuis \& pellucida.

Ingens Teftx apertura, ovalis; adeóq; ipfa prima fpira amplifíma eft; reliquæ verò quinq; admodum tenues, ínq; mucronem acutum producuntur.

Ipfe animal Teftæ inhabitans binis corniculis latis, tenuibus, mucronatis infignitur: ex his verò nonnullas vidi, 
quibus cornicula in exiguos ramos more cervorum didua cebantur.

Binos ejus oculos aliquis facilè difcernere poffit, velut punctula nigra ad corniculorum radices. Sunt etiam juxta oculos ferè conjunctim cumiis, at paulo anteriùs, meatus quidam exigui an auriculares, aut bronchiales?

Ipfius animalis labrum fuperius anplum eft, latéq; explicatur, ut ei velut alteræ pinnæ fint.

Cùm ejusPlanta plenè explicatur, \& verfus cœlum fpe. atat, natat beftiola: eâ verò replicatâ, totóq; corpore intra teftam reducto, illicò fubfidit animal.

Huic Cochleæ excrementa longa, inftar vermiculorum figurata.

7oction In Meridionalibus Anglix partibus admodum frequentes; nec nimiùm raræ circa nos, præcipuè in paludibus. In foffis Pottery Carr dictis plurimas ibidem obfer. vavi ingenti magnitudine.

Herbas fluviatiles ut Potamogeiton \&c. depafcunt.

toittiso

Medio Septembri eas in Coitu deprehendi; ex his aliquot in vafe vitreo capaci fervavi, quæ tum per aquam nando, membra genitalia alba exerebant è dextrâ cervicis parte.

Dvis Item Vere coeunt, quod ipfi repiùs vidimus. Maio ineunte in quibufdam Pícinis, ubi hæ Cochleæ abundârunt, \& paucæ aliæ repertæ funt, harum femen genitale magnâ copiâ obfervavimus; herbis autem quibullibet aquaticis adhærebat, erátq; hujufmodi : longitudinem unius knciæ aut duarum aliquando, craffitudinem pennæ anferinæ majufcule implebat; teres admodum; utrâq; extremitate paulò tenuius \& obtufum; inftar cryftalli pellucidum; tactu fatis firmum; fi illud luci oculífq; interponas, innumeræ exigux Cicatriculæ figurâ ovali tibi fient manifette; ordinatim difpofitx; quibus omnibus juxta cicatricula limbun fingula fira punctula flavicantia. 


\section{De Cochleis Fluviatilibres.}

$\mathrm{H} x$ Cochlex acu aut falpello incifæ, aquam tingentem humorem nullum emittunt.

\section{TITULUS XXII.}

Buccinum minùs fufcum, fex Jpirarum, ore anguftiorc.

DRoximè fuperiori in plerifq; notis valdè fimilis eft te- Befroptrita

Ita : at multo minor; item fi magnitudine æquales ex illis una, ex his altera, inter fe conferantur, hujus os five Teftæ apertura dimidio anguftior eft quàm illius.

Ei color fufcus \& minimè pellucidus, fi id in vivis animalibus \& ubi teftæ recentes \& integræ funt, advertatur.

Item hujus tefta multo validior, nec adeò tenuis. In cæteris probè conveniunt.

Hre admodum frequens in ftagnis circa Eboracum, ut Locks. in eo quod appellatur Hodman-Hoe-Pitt juxta Acomse.

Ipfum animal ab incifione nullum emittit liquorem celoratum.

\section{TITULUS XXIII.}

Buccinum pellucidum, fubflavmm, quatuor fpirarsms,

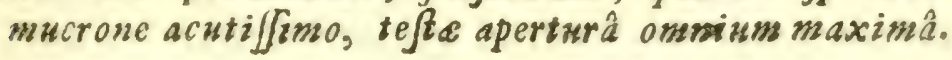

L $S T$ tenerrima \& tenuis admodum tefta, fubflava, Defcrigsin H. pellucida.

Rictus five teftæ apertura ingens, omniúmq; facilè maxima, fiquidem ei longitudo ferè uncialis, latitudo verò paululùm fupra dimidiam unciam.

At totius teftæ longitudo vix uncialis fupra quadrantem: adcò ex quatuor fpiris quibus conftat, tres ima exigua

$$
T_{2}
$$


funt, unius fuperioris refpectu: ipfa tamen infima admodum acuta \& tenuis licèt exigua fit.

In maximis ex his teltis, quales jam defrgnavimus, ad exteriorem partem aperturæ funt quædam rugæ five plicæ radiat $x$; at in mediocribus nullx.

Ipfe animal flavefcit; duobus latifimis corniculis, tenuibus, mucronatis infignitur; quæ in his pinnarum locum \& effectum præftare videntur.

Utrinq; ad corniculorum radices juxta caput funt finguli Ocelli, velut nigra punctula calami fcriptorii mucrone depicta.

toous: In Fluviis \& aquis ftagnantibus ubiq; per Angliam frequens; in his verò maximæ inveniuntur.

Ejus humor, puncturâ emiffus, aquam minimè colorat.

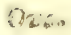

Ineunte Aprili ingentem vim feminis cujufdam genitalis cuilibet herbæ fluviatili adhærentis obfervavi. Id autem diftinguebatur innumeris exiguis granulis fubfufcis more fpermatis ranarum dicti. Illam vero hujus Cochlex freturam effe hac ratione didici. Ex his aliquot diu apud me in aquâ fervavi, donec plurimæe exinde nafcerentur hæe ipfre Cochlex.

Medio Maio harum fperma diligenter obfervavi; erat antem craffum, paulo longius fupra unciam dimidiam; inftar cryftalli pellucidum. In cujus medio (adhuc enin non refolvebatur), inerant plurimæ exigux Cochlex ad maģnitudinem feminum papaveris; ipsâ tamen teftæ figurâ maximè notabiles \& facilè cognofcibiles.

TIT ULUS XXIV.

Buccinan fubflavum, pellacidam, triwn fpirarum:

wowifin. Gupra modum tenuis \& tenera eft hæc Cochlea ; adeóq; $\$$ admodum pellucida \& levis eft, de vacuá teftâ lo gharo: 


\section{De Cocbleis Fluviatilibus.}

Ei color fubflavus, aut albidus.

Longitudine multùm fuperat umciam dimidiam.

Ei ingens teftx apertura, ovalis, qualis in plerifg; hujus capitis.

Intra tres fpiras finitur; quarum dux inferiores ad mucronem admodum exigux; ipie mucro obtufior.

Ipfus animalis cornicula bina aurium inftar aut pinnarum, tenuia, lata, mucronata.

In Fluviis optimæ \& faluberrimæ aqux admodum fre- zous. quentes; \& alibi etiam in aquis ftagnantibus non rare.

Eit autem animal Amphibium; fiquidem xtate fluvio: libenter deferit; herbam depafcit, falicúmqg; fumma vo mina fcandit.

Hac Cochlea, averfam five pronam Faciem quod Spcctat, optimè depingitur apud doctifimum Tulpi-

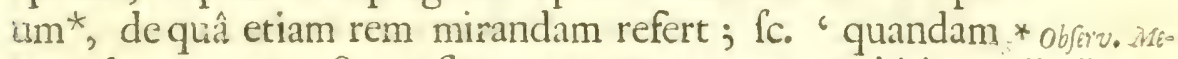

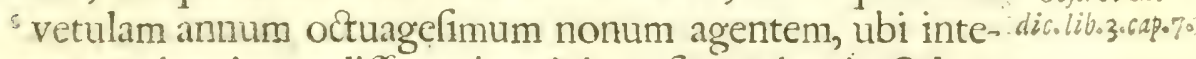

'grum triennium tuliffet animosè in vefica urinaria Calcu'lumponderantem tres uncias cum duabus driacinits, eni' xam fuiffe tandem felicifimè lapideum hunc fxtum, cum 'duobus N. B. Cochyliis, foris itidem lapideâ cruftâ ob'ductis.

Profectò, quantùm judicare licet de picurâ, ea Cochylia ab eo dicta ex his noftris Cochicis piane fierunt. 


\section{CA P. II.}

De Buccino fluviatili, cujus fpire à finiftrâ in dextrasn convoleuntur.

\section{TITULUS XXV.}

Buccinum exiguum, trium fpirarum à finiftâ in dexw tram convolutarum.

sefriptio. TS T Cochlea vix trientalis; nec magnitudine vulgaI- ri piro par.

Ingens apertura, ovalis more cæterorum fui generis. Anfractus tantùm tres; quorum duo infimi exigui admodùm, fi unum fuperiorem refpicias. A finiftrâ verfus dextram convolvuntur.

Eft tefta tenerrima, tenuis admodum, pellucida, lævis. Ipfius animalis cornicula capillacea.

26:5. Hæ Cuchleæ copiosè inveniuntur in quodam rivulo ad meridiem vici Heyworth dicti juxta Eboracum; \& alibi in aquis ftagnantibus frequentes. 


\section{De Cocbleis Fluviatilibus.}

\section{MEMBRUM III.}

De Cocbleis fuviatilibus, turbinatis, fiğurâ deprefsà

Harum Cochlearum not e characteriftice Junt. I. Habere cornicula rubra capillacea. 2. Ip fa aninzalia colore pullo e efe. 3. Coccum fundere.

\section{C.A P. I. \\ De Cochleis Suprà diftinct is in Jpecie.}

\section{TI T UL US XXVI.}

Cochlea pulla, ex utraq; parte circa umbilicum cava.

H Ujus latitudo ferè uncialis; craffities quadrantalis. Diferitgrios I Ei color pullus.

Anfractus circiter quatuor, pleni,', quorum unus alteri rectè fuperinjicitur.

Aperturæ margo ad inferiorem partem paululùm extenditur velut labrum.

Eft etiam utring; cavum ad centrum five umbilicum anfractuum; quod tamen minus eft in parte fuperiore, quàm in inferiore.

Ex his minores videntur canaliculati; at id admodùns leviter denfis \& minutiffimis ftriis ; in ficcâ verò teftâ ex vix apparent.

Ipfe animal in aquam injectum feipfum exerit oftendítq; ; ex nigro rufefcit; duobus comiculis rubris \& capillaceis infignitur. 
Ex his Cochleis magna copia habetur in Fluvio Cam \& in rivulo $\mathrm{Fofse}$ dicto juxta Eboracum: \& alibi per Angliam frequentes admodum; maximè in paludibus \& aquis ftagnantibus.

Humorem coccineum expuit Cochlea, fi Teftæ aperturæ injiciatur vel falis mica, cujufcunq; generis, aut piperis gingiberífve paululum. An verò ifte humor ex corporis habitu proveniat, ut fanguis ab incifione, dubitatur; tamen à corniculo juxta caput præcifo is mihi vifus eft emitti, item levi corporis puncturâ profluere; at id genus experimentum difficulter tentatur, ut certò ftatuamus, an ex iplo vulnere erumpat nec ne. Verifimilius eft, eam vel falivam effe circa fauces \& ventriculum, aut peculiarem humorem proprio vafe contentum.

Eundem humorem coccineum toto anno, Aprili certè \& Septembri laceffita exhibet.

Ifte humor fic expeditè haberi poteft in magnâ quantitate: harum Cochlearum copiam in linteum facculum conjice; deinde iis infperge falis paululum; illicò copiosè diftillabit humor coccineus.

Humori autem fic emiffo fi aluminis pollinem infpergas, protinus fubfidit pars ejus colorata, reliquúfq; humor inftar aquæ limpidus fit. Si ad eundem modum cum fale \& alumine experimentum facias de humore fubcæruleo $a b$ incifione emiffo in terreftribus nonnullis Cochleis, nihil colorati dejicies, at totus in quoddam gluten fubceruleum indurabitur.

Infuper pars cjus colorata chartá bibulâ feparari potent ; at Ferit quicem coloris venuftas \& in pullum fordidum utatur.

Sin autem accto mifceatur, aut vini fpiritu dicto, aut falis deliquio è plantis uftis purgati, aut falis communis diJuto, non aliter quoq; quàm cum alumine perit ejus humoris coccinea clegantia. 


\section{De Cocbleis Fluviatilibus.}

Per fe quoq; emiffus, difficulter admodum fervatur; il lud certè fruftra experti fumus in angufti oris ampullis bene claufis, etiam oleo fuperinjecto, melléve circumfufo.

\section{TI T ULUS XXVII.}

Cochlea fufca, alterâ parte planior, du limbo inflgnita, quatuor Spirarum.

TH Jus latitudo paulo fupra dimidiam unciam; craflitu- Dferiptsteo 1 do verò uncix octavam partem vix implet.

Ei color fufcus.

Intra quatuor fpiras terminantur orbes; quorum unus alteri directè fuperinjicitur.

E medio orbe limbus notabilis extat, quâ f́c. parte planior videtur; at eft leviter cava ad umbilicum utring;

Ipfe animal nigricat; bináqj cornicula rubra exerit capillacea.

Eundem coccineum humorem cum fuperiore effundit.

Übiq; admodum frequens $\&$ in Fluviis $\&$ in aquis $\mathrm{ftag}=2, \cdots$ nantibus.

Has in coitu obfervavimus circa medium Maium.

coirtas

\section{TITULUS XXVIII.}

Cochlea exigua fubfufca, alterâ parte planior, fine livin bo, quinq; fpirarum.

- Ujus latitudo vix uncix tertiam partem, at craftitu- Deforption do vix decimam fextam uncix partem implet; ut dimidio tenuior fit quàm ulla è proximè fuperior jufdem latitudinis. 
Ei color fubfufcus ant nigricans.

Hü-teeft limbus; at parte alterâ fc. fuperiore planior bus in proximè fuperiore, ibi velut acies.

Dentor grod meximè notabile eft, huic fpiras quinq;

Oeas beracum in nquis itagnantibus aliquoties eam invare. in forli vor Paludis Pottery Carr dicte fatis fregurement, is folis ad Fluvium Darment juxta Bubwith*ury magná copiâ habentur.

\section{SECTIO II.}

De Cochleis bivalvibus, five de Mufculis aque dulcis.

In hoc conveniunt, utramq; valvam aquè cavam effs.

$$
\begin{gathered}
\text { C A P. I. } \\
\text { De Musculis Aque dulcis. }
\end{gathered}
$$

\section{TIT ULUS XXIX.}

Mufculus latus, teftâ admodum tenui, ex fufco viri. defcens, interdum rufefcens.

Chama-glycymeridi fimilis, fed majoris mytali fpecies, Aldrov. de Tefaceis lib. 3. pag. 472 . Wbi etian fio guram videbis.

An Chana glycymeris Margaritifera Velfciz. Ephemerid. German. Anni 3. Obfervat. 36.

Discriptioe $I$ latitudo ad duas uncins; longitudo ad tres uncias H, \& dimidium: at hic omnium maximus fuit, quem. ego unquam inveni in noftris fluviis; nam pleriq; paulo ninores funt.

Ex: 


\section{De Cocbleis Fluviatilubirs.}

Ex his verò ipfis Mufculis plurimos invenimus in follis Paludis Pottery Carr dictx juxta Doncafter, quibus longitudo ferè quinqj-uncialis, latitudo paululum fupra duas uncias \& dimidium. Horum tamen tefta \& tenuis \& $l \mathfrak{l}$ vis; fiquidem ambæ valvæab omni carne purgatæ alicujus Teftx menfura fuprà pofitx pendebant tantùm fcrupulum unum fupra quinq; drachmas. Item in rivulis paludofis juxta sawterforth agri Cravenenfis, ut mihi relatum eft à fide dignis authoribus, fimiles ingentes mufculi reperiuntur.

Tefta quodammodo pellucida eft; cui color ex fufco rufefcens, interdun (idq; perpetuò in maximis \& minimis) leviter virefcit.

Valvarum internus color $\mathrm{cx}$ argenteo cxruleus, mirè refplendens.

Ümbones, ubi valvæ conjunguntur,parùm aut nihil eminent, fed æqualiter rotundi funt: neq; ulla inæqualitas in valvarum cardinibus difcernenda eft ; atq; intùs etiam ad cavitates umbonum fumma æqualitas.

Ipfius pifcis caro fubrufa.

Hos mufculos copiosè invenimus in Fluviis Air, \& Ri. Locusa ble dictis agri Cravenenfis; item in Fluvio rure juxta Rippan; \&alibi locis fuprà nominatis.

In limo arenofo ita fefe collocant. Valvarum cardines furfumfpectant, earúmq; oræ tenuiores intra limum profundè demittuntur, \& ferè ex toto conduntur, exceptâ altera cxtremitatis obtufioris exiguâ parte; at in eâ caput animalis, adeóq; ea, valvis fc. modicè diductis, ferè fentper quafi rimulam facit, quâ notâ eos expiccari expeditum eft.

Hi mufculi Cornici victui funt, qui ut pifcem eximat, roltro valvas confringit; idcóq; hæ aves aquas frequen tant ; \& ̀̀ reliquis id genus avibus propterea ab ag̣uâ Cog. nomen Anglicè accipiunt. 
In vetuftioribus pleriff; valvarum interna pars alicubi afpera $\&$ inæqualis eft, velut verruculis diftineta ad mag. nitudinem papaveris feminum. Harum autem nonnullæ vel leviter tactæ decidunt; at pleræq; valvis nimiùm firmiter adhærent. Hæc fanè valvarum vitia, an verò illæmargar ritæ habendæ, alii judicent.

*.2ib.9. cap.35. Illud à Plinio * proditum eft, Uniones reperiri folere rufos \& parves in Conchis quas Myas appellant; recentioréfq; multi idem confirmant. Ita Veifcius, loco fuprà cìr tato, de quibufdam Mufculis lacuftribus, quos ex figurâ depictâ noftros effe conjicio.

In lacu, inquit ille, non longè à Viennâ Auftrix Mufculi pictorii funt, è quibus diffectis Margaritas non paucas ipfi exemimus; quarum pars Valvarum interiori fuperficiei ob id afperæ, fixa eft, pars fponte exciderat \& in carne latebat; coloris tamen non albi, fed fubflivi \& fubobfcuri, quem fplendor quidam argenteus illuftrabat.

E noftris etiam feriptoribus olim fic quidam Anonynus:

* See the ad: ditional notes of D. B. to Sir Hueb Platts ieviltouic. * Hi aliis mufculis Fluviatilibus paulò minores funt, \& magis nigricant. (An intelligendum eft de proximè fequentibus.) Ex iis in agro Buckengamienfi aliquot vidi; at in Fluvio clun dicto agri Salopienfis precipuè abundant. Ex iis a.ipfe Margaritas exeni ; illúdq; perpetuum cfle didici, fc. cos tantüm Mufculos Margaritas in fe continere, qui extrà inæquales \& afperi velut nodis interftinati; laves rurfus illis omnino vacuos fuiffe. 


\section{TITULUS XXX.}

Mufculus angufior, ex flavo viride foens, ralidas, Onn. bonibus acutis, valvarum sardinibus zelut pintsis donatis, fincuglis.

D UIC longitudo circiter uncias tres \& dimidium, Dafcibgesen. latitudo ad unciam unam \& dimidium; hujus menfuræ duæ Valvæ drachmas feptem \& triginta quinq; grana.

Valvæ craffx, validx, \& ponderofx.

Color ex flavo viridefcens, interdum ex fumma viriditate infufcatur.

Ejus sitera extremitas multùm $a b$ umbonibus producitur. Unimbo uterg; ac cardines acuti, \&r paululüm eminent. Ipfi Cardines finciofi. \& velut pinnis donati. Etiam cavitas interna ad cardines imuofa \& inæqualis.

Valvis internis color in mediocribus ex argenteo cæruleus, in vetuftionibus ir maximis ex argenteo rubefcens.

Ipfrus animalis caro paulò albidior eft quàm in fupesiore.

Hi in Fluvio Oufe \& Fofse juxta Eboracum copiosè in- Lochs . veniuntur; item in Fluvio Nid ad pontem skip. brig dictum.

In his, ficut in proximè defcriptis, duo funt craffa $\&$ \& valida ligamenta nervofa, unẫ atq̣; alterâ concharum extremitate difpofita, per quæ animal valvis fuis adhæret, quibúfq; mediantibus eas aperit claudítq;

Horum autem ipforum ligamentorum Capitibus, quà Mangarises. rc. valvis adhærent, circiter 16 margaritas in uno mufculo inveni, à magnitudine papaveris ad piperis grana: ex minutis verò aliquot fuêre admodum rotundæ, cætcræe autem majufculæ afperæ \& inæquales. Hæc fanè fenefcen- 
tium Mufculorum vitia funt: nam in mediocribus multis diffectis non unam quidem inveni : adde quòd in imis ligamentis hæ Margaritæ velut thecis difpofitæ fuerunt; non aliter quàm Calculi in renibus, aut aliàs in animalium fanguineorum carne nati. In reliquo autem pifce nihil. Illud tibi manifertius patebit, fi parùm coquantur mufculi \&: non crudi diffecantur.

Horum Mufculorum aliarúmve Cochlearum teftæe fi in acri lixivio coquantur, carum exteriores \& decolores membranæ feparari poffint : primo fc. mollis \& colorata membranula abftergitur, deinde alius ex media materia velut cretacea cortex abradendus eft, fub quo Margaritarum fplendor totam utring; teftam occupat. Concharum fic purgatarum pulvis in ufu medico margaritarum ufum optime, ut opinor, fupplere poffit ; fanè accommodatiffimus eft ad medicamenta quævis, in quibus requiruntur vel ipfe margaritæ, vel Oculi cancrorum dicti, vel corallium.

\section{TITULUS XXXI.}

Rinfculus exiguus, pifi magnitudine, rotundus, fubfla. vus, ip fis valvarum oris albidis.

Syefciptite.

T. J U S magnitudo ad modum pifi vulgaris, aliquando I- xquat nucem mediocrem è corylo.

Tefta utraq; intùs for̀̀s lævis, tenuis, pellucida.

Ei color fubflavus five corneus, exceptis ejus extremis oris, qux albefcunt.

Ejus figura fubrotunda eft; nam fingulx valvæ admodum cavæ funt, \& in dorfum multùm clatæ, \& æqualiter ab utraq; cardinum parte extcnduntur, qui ferè in mediis valvis funt; ut ad rotundam figuram proximi accedat. 


\section{De Cocbleis Fluviatilibus.}

In aquis ftagnantibus circa Eboracum copiosè inveni- zooss.

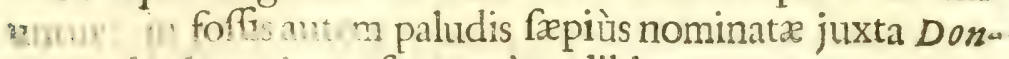
aster duplo miajores funt quàm alibi.

\section{SECTIO III.}

De Cocblea fluviatili Univalvi, five de Parill

\section{TITULUS XXXiI.}

Patella firviatilis, fufca, vertice mucronato, inflexois.

- I Ujus bafi latitudo paululùm fupra tertiam uncix par- Digrapios

11 tem (de majufculis, quas unquam inveni, loquor; nam pleræq; dimidio minores funt) à vertice verò ad ba fim vix quartam uncix partem implet.

Ejus vertex mucronatus; at qui veluti in hamum inflectitur.

Ei vivæ, \& faxis adhærenti color fufcus.

Tefta autem vacua, tenuis $\&$ fragilis $\&$ pellucida ett.

Ipfius animalis Planta, qux pedum vicem fupplet, nams de loco in locum, victins ratione, fe movere folet, rotunda eft, adhærioníg; aptior.

Ex his majufculas in Fluvio Air multis in locis inveni; Loc... multo minores funt qui in vadis lapidofis Fluvii onfe \& Wharfe reperimntur.

Exeunte Septembri ejus fperma faxis adhærens copiosè obfervavi: erat autem in minutis globulis gelatinæ inftas difperfum: jam verò in fingulis globulis plures exiguas patellas vel ipfâ figarâ difcernere \& cognofcere potui. In Coitu verò altera alterius verticem fcandit, infeditq; pluréfqj; fic copulatas tunc temporis notavi. 


\section{COCHLEARUM MARINARUM A N G L I 正 LI B ER.}

Roximè fuperiore Tractatu Cochleas tùm terreftres tùm fluviatiles diligenter expofui; jam verò ad 1 Cochleas marinas noftræ Infulæ venio : atq; illa noinde cùm opus alterum de Lapidibus, in Cochlearum modum figuratis, jam olim meditatus fueram, ídq; penè ad umbilicum perduxeram, hoc eo curiofiùs explicuiffe volui, quo inter alia ea mihi indè nafci vifa eft utilitas, ut, rebus utriufq; generis inter fe collatis, certum aliquid judicent viri, rerum naturalium ftudiofi, an iftæ Figuræ è teftis marinis verè oriantur. quod pleriq; volunt; aưt fui generis lapides perpetuò extiterint, \& cum ipfis montibus nati.

Ut autern harum Cochlearum marinarum copia nobis daretur, ipfi litus Orientale, quod Danemarchiam fpectat, \& Occidentale, quod adverfus Hyberniam pofitum eft, pluribus in locis vifitavimus: aliáfg; nonnullas ab aliis Angilix partibus per amicos fide dignos invertigavimus. Adeò illud veriffimum eft, quod præcipuè nobis propofuimus, omnes has f́pecies à me defcriptas in noftro mari inventas efle. Quot verò defint, alii, quibus \& loci opportunitas \& otium eft, diligenter inquirant : \& nobifcum, fi ita videbitur, pergratum enim facient, cas communicent.

Hæc a. omnia cum Rondeletii, Gefneri, Aldrovandi dercriptionibus fedulò contulimus. At, ne mireris, tam pau- 


\section{De Cocbleis Fluviarilibus.}

ex noftris iis fuiffe cognita, fcire licet, illos aut alterius Orbis rariora Conchylia, aut fola mediterranea edidiffe; nonnulla tamen, ab iis defcripta invenio, quæ nobis fortè cum mediterranei maris Conchis communia funt.

Sed hæc quidem mediocria funt; ex iis tamen multa ad vitæ ufum hodiernum; alia olim ad luxuriem \& pompam; omnia fanè ad Hiftoriæ rerum naturalium confummationem, adeóq; ad Philofophiæ profectum conferunt. 


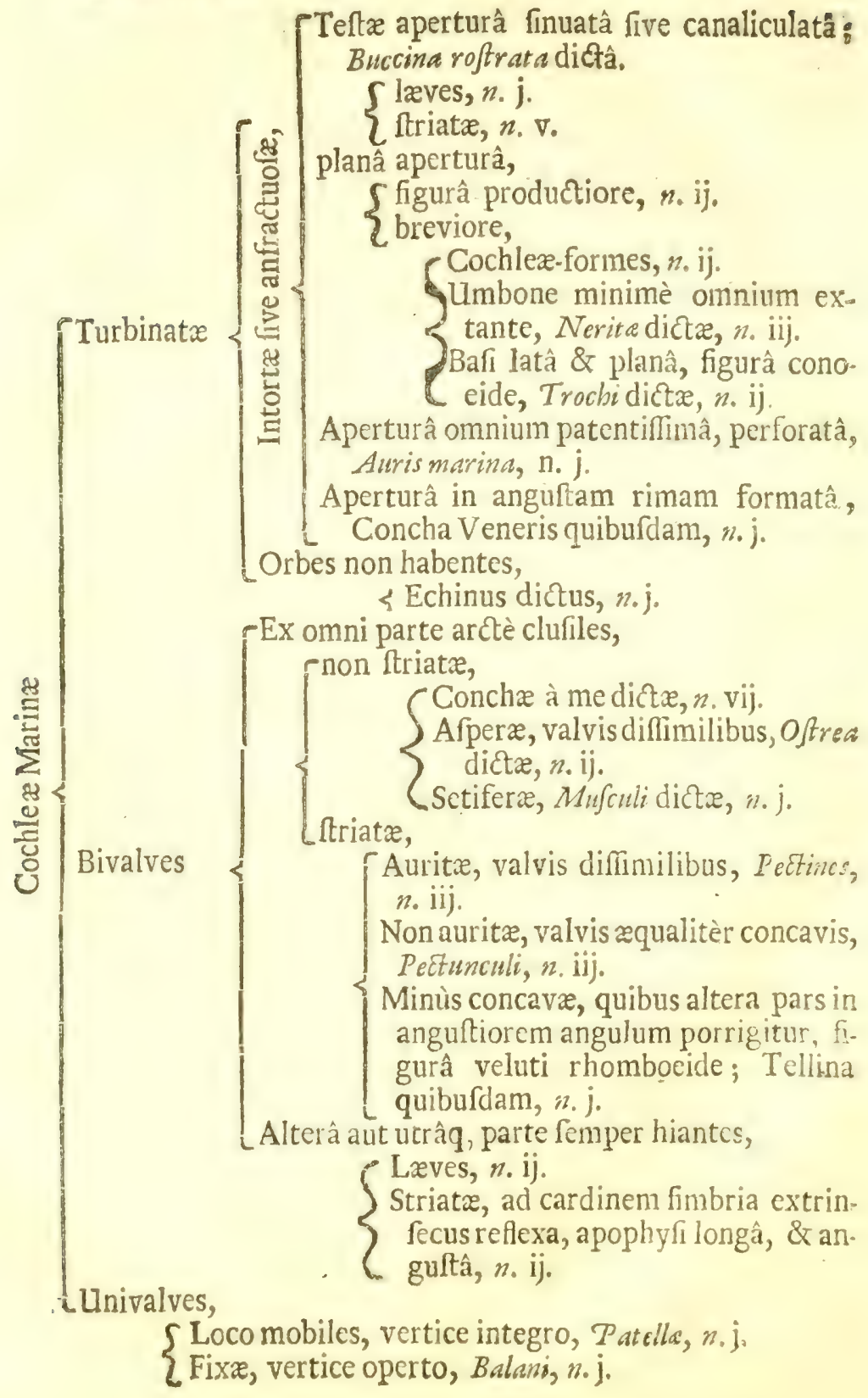





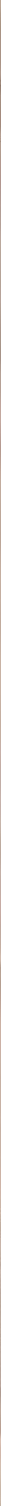






\title{
COCHLEARUM MARINARUM
}

\author{
A N G L I E \\ SECTIOI. \\ De Cochleis Turbinatis.
}

\section{ME MBR UM I.}

De Cochleis turbinatis, intortis five anfractuofis.

\section{ARTICULUS I.}

De Cocbleis turbinatis, intortis; quibus apertura fo. nuata five canaliculata; Buccina roltrata ideo à me dictis.

\section{C.A P. I. \\ De Buccino roftrato lavi.}

\section{TITULUS I.}

Buccinum albume leve, maximum, 7 minimitm Jpirarum: a tabelke.

H

IEC Tefta admodun crafta \& ponderofa eft.

Huic color albidus externè ; intùs verò flavefcir; id quod intelligi debet de vivorum animalium. teftis, \& quæ noviffimè ex mari expifcatæ funt.

Ejus longitudo minimùm quinq; uncias implet; Hinea verò feptem uncias longa hanc quâ plenior eft, vix circuindat. Intra $>$ ferè fpiras finitur.

$$
\text { X } 2
$$


Aperturæ longitudo ad tres uncias accedit, quà verò maximè pates, unciam paululùm excedit: in furmmaaper. turæ parte, quidam Canaliculus five finus in modum roftri producitur.

Teftæ pars exterior ex toto lævis eft,i. e. fine ftriis, quamvis frepiùs vel rugis quibufdam vel aliis rebus extrinfecus adnatis exafperetur.

Hanc vivam Operculum tenue, colore pullo, etiam teftaceum claudit.

Roc4s.

Illam pifcantur in alto mari apud scarborough, ubi primùm ex his vivas vidimus.

\section{CA P. II.}

De: Buccinis roftratis firiatis.

\section{TITULUS II.}

Buccinum crafsun rufefcens, friatum ou undatum.

Defreiption.

I E $\mathrm{C}$ tefta craffa admodum \& ponderofa eft ; extrà ex fufco rufefcit, item intus ex albo leviter purpurafcit; de maximè recentibus teltis loquor.

Septem minimùm fpiras in integrâ teftâ numerare licet.

Teftæ longitudo fupra tres uncias extenditur; ejus ambitum quà maximè patet, vix quinuncialis linea colligit.

Apertura qualis in fuperiore, \& fimile roftrum canairculatum. At fi tefta integra eft, in medio labro aperturæ eft etiam alius finus ex undatis ftriis paululùm reductiss Hụic crebræ \& minutiffimæ ftriæ fecundùm fpiras circuminjiciuntur; item alix ftriæ craffx ductu undato \& tranls verfo eminent. 
Ex his aliquot in Litore, juxta Scarborowgh, Hartle- Lochso pool, \& ad Oftium fluminis Tees, at rariùs invenimus.

\section{TITULUS III.}

Buccinum texne, leve, friatum din andarum.

H $\mathbb{E C}$ telta à fuperiore, quam maximè refert, in his Diferizticos differt; I. Quòd hæc tenuis admodum \& levis,cum illa valida \& ponderofa fit 2. Quòd huic amplior apertura。 3. Quòd huic ferè defunt friæ undatæ in fummo \& maximo orbe.

In reliquis a. conveniunt.

Ex his aliquammultas invenimus in æeftuario maris Hy- Lockss. bernici in alterâ ripâ adverfus $\mathrm{L}$ ancafter.

\section{T I T U L US IV.}

Buccinum anguftius, tenuiter admodum friatum, octo minimsum $\int p i r a r u s$.

L \&C tefta craffiufcula eft \& valida; quas vacuas Defreziptios.

1 \& fortè vetuftas in litore invenimus albid $x$ funt. Ad octavam minimùm fpiram producitur; ejus \& mucro tenuior \& bafis etiam anguftior eft.

Maxima ejus longitudo paulùm fupra duas uncias extenditur; ejúfq; craffitudinem, quà ventricofior eft, eadern ferè linea comprehendit.

Propiùs confideranti hæc crebris ftriis, fecundùm fpiras circumductis, at minùs profundè fulcatis leviter exafperatur:

Huic roftrum productius velut alter mucro, canalicula-tum. Has: 
158

Lestuse

Has teftas in litore Scarborgenfi collegimus; at ibidem rariores funt.

\section{TITULUS V.}

Buccinum minus, albidum, a pperum, intra quinas Jpiras finitum.

Dsfrivintio. Ujus animalis tefta omnium, pro magnitudine, longè I. craffifima \& ponderofifima eft.

Color albidus, intìs, forás.

Longitudo ad fefquiunciam; at, quà craffior, linea duas uncias longa vix eam ambit.

Pendet.....

Intra quing; fpiras finitur; at ex non ita facilè numerantur, quod ftrix crebriores paululum emineant, \& fpirarum intercapedinem non parùm confundant.

Ipre mucro acutiss, \& parùm producitur.

Itcm ob ftrias quafdam tranfverfas magis inæqualis \& tactu afperior fit.

Tcitx apertura anguftior eft ; ejúfq; ipfius oræ ex infigni craffitic fubito fintint acutx, \& in modum ferra leviter exafperantur.

Ipfum rotrum brevius, at canaliculatum.

$20 \%$

coitus.

Hac \& fequentia Buccina litoralia dici pofint; cuòd in litore certè feopulofo ingenti copiâ ubiqj reperintur.

Hixc buccina, Jinio ineunte, poft xeft s receffum in ficco foopulo, tempore matutino, in Coitu frequenter obfervavimus. 


\section{De Cocbleis Marinis.}

\section{TITULUS VI.}

Buccinum minus, ex albo fubviride, ore dentato, cöqj ex flavo leviter rufe fcente.

Doximè fuperiori par tefta, an paulo minor; figura, fpirarum numero, afperitate, ftriis, roftro, omnibúfq; ferè reliquis admodum fimilis.

Huic a.color ex albo fubviridis.

Item aperturæ oræ obtufiores. Ipfa apertura paulo anguftior ; cujus interior pars ad finiftram, quinis velut den tibus obtufis \& parum eminentibus infignitur; parti aperturæ interiori color ex Alavo rufefcens.

Item huic, ut fuperioribus fingulis, Operculum tenue, rufefcens, quo fe inclufum tenet animal.

Hæc quoq; buccina in iifdem fcopulis litoralibus copi- Locuss. osè inveniuntur juxta Scarborough \& Hartlepool. 


\section{ARTICULUS II.}

De Cocbleis turbinatis, intortis, tefta aperturå planå.

$$
\text { C A P. I. }
$$

De Cochleis turbinatis cic. ore tlano, figurâ produ ctiore.

\section{TIT ULUS VII.}

Euccinum crafum, 2 acutis at inequaliter altis forios in fingulis 12 minimium fpiris donatum.

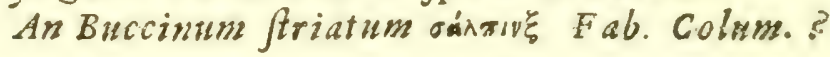

Deforipptito

TUIC Cochlex longitudo paulum fupra tres uncias, 1. craffiorem verò partem linea binuncialis vix comprehendit.

Admodum craffa, \& ponderofa tefta eft.

Huic color albus; at vivam nondum vidi.

Noltrx erat mucro prefractus; ut certum aliquid de fpirarum numero finire non potui; at in eâ 12 fpiras numeravi.

Spirarum interftitia notabilia $8 z$ admodum finuofa. Spiræ ex proportione paulatim adeò minuuntur, ut elegansem admodum figuran pyramidalem efficerent.

In fingulis mediis fpiris, duæ, at altitudine inæquales, acutx fpirze eminent; certè in tribus fuperioribus fpiris maxime confpicuæ; at inferiores etiam fpiræ velut alis crebris fulcis excavatæ vif funt.

Os five teftxe apertura velut circinata; at rarò integra, ut nec ipfe mucroinvenitur.

Rarifima 
Rariffima Tefta; at aliquoties illam redemi à pifcato- xosus. ribus litoris Scarborgenfis; adeóq; in alto mari nafci videtur.

\section{TIT ULUS VIII.}

Buccinum tenue, densè friatum, 12 minimùne Jpiris donatum.

LL A Cochlea eft longitudinis fefquiuncialis; quà ven- Defriviption

1 tricofior, linea uncialis comprehendit.

Levis \& tenuis tefta eft.

Huic color albidus ex leviter rufefcente.

Os five apertura ferè circinata; at rarò eâ parte integræ inveniuntur.

12 Spiras numerare licet: eæ minùs eminent; fed planiores funt; ex æquâ ratione minuuntur, \& in longum \& elegantem mucronem porriguntur.

$\mathrm{H} x$ Cochlex poft tempeftates hybernas in litus $S$ car- Lochso borgen $\int e$ ejiciuntur; item ex litore occidentali agri Lancaftrienfis eafdem habui. 


\section{AP. II.}

De Cocbleis turbinatis, ore plano, figurâ breviore five compactili, Cochlea-formibas.

\section{TITULUS IX。}

Cocblea fufca, fafciis crebris anguftifg; pradiła. Cous bing à pifcatoribus Scarborgenfibus Anglicè dicta.

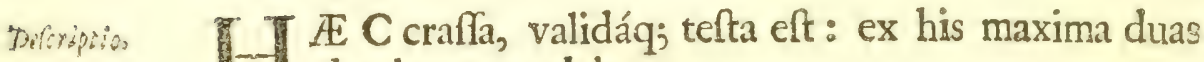
drachmas pendebat.

Ejus longitudo paululùm fupra unciam; linea verò duas uncias longa ejus bafin, quà craflior eft, vix comprehendit.

Creberrimæ fafcix anguftx fecundùm fpirarum ductus circuminjiciuntur: hæ verò ipfæ fafciæ in junioribus \& minimis in ftrias eminent; adeóq; cochlea iis quodammodo afperantur. Iplex a. ftrix coloris fufci funt, ad nigredinem accedentis, cùm earum interftitia, qux tamen valdè angufta funt, albicent.

Intra quinas fpiras finitur: at eas numerare difficile eft \& propter ftrias frequentes, \& quòd ipfer fpiræ planiores fint; ipfe a. ejus mucro acutior eft.

Illud in hâc teftâ fingulare eft; aperturæ imas oras paululùm per latus dimitti; aliter quàm in aliis plerifq; fieri folet, ubi ex ad angulos ferè rectos committuntur.

2.0.38,

Hæc Cochlea è litoralibus noftris frequentifima eft, maximè locis fcopulofis.

Junio coëunt in ficco,quod ipfe vidi : coeuntium alteri santùm, ni fallor, infignis penis.

Huic ipfi animali reticulata cutis ex nigris lineolis. Item operculum tenue pullum. 
De Cocbleis Marinis.

Has guftavi ; nec mihi infuavis vifa eft: à Belgis eas plurimum appeti audio.

\section{TITULUS X.}

Cocblea rufefcens, fafciis maculatis, maximè ad imos orbes diffinita.

[ T E lævis \& modicè craffa Tefta eft.

Huic longitudo vix uncialis; at lineola duas uncias longa illam, quà ventricofior eft, vix comprehendit; fc. figurâ admodum compactili.

Intra quintum orbem finitur; quorum primus ventricofus, reliqui exigui \& parùm producti, ipféq; mucro obtufior, velut in Cochlea vulgari hortenfi.

Hæc ex albido rufefcit; at ad imam maximè partem primi \& fecundi orbis velut fafcia rufa è quibufdam maculis rufis, obliquè ductis compofita, \& plures ejufmodì effe poffint per totum orbem fuperiorem: fed de colore in vivis animalibus nihil certum affirmare polfum, quòd teftas vetuftas tantùm $\&$ maris agitatione multùm detritas adhuc vidi.

Ipfa apertura velut ovalis eft; item ad ejus alteram partem eft quoddam foramen aut cavum, anguftum, profundum; id vero ipfi teftæ extrinfecùs eft.

Ex his aliquot non femel invenimus in litore arenofo a- Loce $^{2}$ gri Lincolnienfis, ac etiam ad oftium Fluminis Humber: at utrobiq; quidem cochlea rariffima eft. 
Dë Neritis, i. e. de Cochleis turbinatis plano ore five aperturâ non rofrat $\hat{\text {, quibus }}$ đo pauce Jpire, di qui. bus umbones five mucrones parù aut nibil eminent.

\section{TITULUS XI.}

Nerita ex fufco viridefcens, aut ex toto flavefcens, wodò palliciè, mod'o intersè ad colorem mali aurantio maturi.

Defriptio.

T I C tefta valida $\&$ craffa eft: nucem è corylo me. 1 diocrem æquat; $\mathrm{fc}$. paulo dimidiam unciam excedit longitudine; nec multo minor latitudine.

Intra tertiam fpiram finitur, ejus mucro quaf occuls tatur, certè parùm aut nihil eminet aut extat.

His color non idem, modò ex toto flavent, modò intenfiùs rufefcunt; interdum ex fufco virefcunt.

Zochso

Hæ funt ex litoralibus noftris Cochleis; \& in fcopulofo litore ubiq; abundant.

Junio ineunte in Coïtu has Cochleas vidimus; modò duas flavas, modò flavam \& fufcam copulatam; idq; in ficco, cùm fc. maris æftus recefferat, quod tùm fortè matutino tempore incidit. 


\section{De Cocbleis Marinis.}

\section{T IT ULUS. XII.}

Nerita fafciatus, unicâ latâ fafciâ infignîus, ceterùre jubfuecus exviridi.

L I IC a. proximè fuperiori fimilis eft, magnitudine, Defcriptio I figurâ, fpirarum numero, \&x. unicâ fafciâ latâ per medium ductâ diftinguitur.

An verò hæc diverfa fpecies fit, non admodum contendo; at quòd ex his nullas in coitu obfervare potui, nec per fe, nec cum aliis fuperioris gener is copulatas, alias effe fufpicor $\mathrm{ab}$ illis.

Ibidem quoq; non minùs frequenter habentur.

Iocits.

\section{TIT ULUS XIII.}

\section{Nerita reticulatus.}

CI \& Cochlea fuperioribus fui generis paulo mitor Fl eft; at figurâ per omnia fimilis: in eo different. quòd huic color fufcus ex viridi, modò flavefcens, at qui reticulato quodam opere eleganter diftinguitur.

Ex his vivas in litore fcopulofo juxtas Scarborough ri peri, \& ad Hartlepool: at rariffimæ funt. 


\section{CAP. IV.}

De Trocbis, i.e. quibus figura conoz̈des, ex bafi lat éplanâ : ip farum etiam Jpirarum latera admodum plana, er minimè extantia unume fuper alterum.

\section{TITULUS XIV.}

Trocbus albidus, macnlis rubentibus diffinctus, 6 mi. zinùm Spirarum.

Prigite

I I C tenuis \& pellucida terta eft; item lævis, nifi 1 vetuftas id efficiat; ctenim vivas adhuc non vidi.

Ei color albidus; in parte verò maximè eminente, five in mediâ quâq; fpira eft quidam macularum rubentium ordo.

Huic minimùm fenæ fpiræ, paulatim ad elegantiffimum \& acutum mucronem faftigiatæ: fpiræ etiam leviter ftriantur, at neq; crebris neq; admodum eminentibus ftriis.

Huic longitudo paululum fupra dimidiam unciam; filum a. duos digitos longum ejus bafin vix circuit.

ris.

Juxta scarborough at rariùs; ad oftium verò Humber \& oram maritimam agri Lincolnienfis fat copiofé.

\section{TITULUS XV.}

Thocbus crebris ftriis fufcis, \&u tranfversè \&undatim difpofitis, donatus.

Difriprio. It Itm brevior \& craffior eft. 
Intra quinas finitur firas: ipfre etiam fpiræ leviter extant, earúmq; latera paulo rotundiora funt : huic quoq; ftriæ exiguæ, at crebriores \& leviter eminentes, ut afperula fit.

Porrò huic ftriæ, in quo fumma elegantia, fufcæ \& 8 uranfversè \& undatim difpofitæ.

Ad litus Orientale copiosè habentur plerifq; locis.

\section{ARTICULUS III.}

De Cocbleầ turbinatâ, Aperturầ omnium longè pazentifysmâ, perforatấ.

\section{TITULUS XVI.}

Auris marina quibufdam: Patella fera Rondeletio.

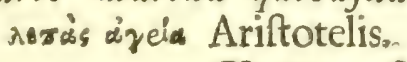
giborber of poedr, Anglicé.

H E C Cochlea Auris marina appellatur, ob quandam Dafrippio. 1 fimilitudinem cum aure noftrâ. Longitudo uncias quatuor, latitudo ferè tres uncias implet.

In cava Tefræ parte unionum fplendor infignis. Ex parte a. convexa fordidè rufécit.

Turbinatorum more claviculatim torquetur; adeò ur ab aliquibus Univalvibus malè annumerata eft. At intros alteram ferè piram finitur.

Item ex parte convexâ afpera eft $\&$ inæqualis ob quafdam ftrias, fecundùm fpirarum ductum delineatas; quarum etiam maximæ profundiùs fulcantur; item quòd hâc etiam parte foramina paululim emineanto 
In aliquíibus verò $\mathrm{fex}$, in aliis majoribus feptem fora mina perpetuò patent; reliqua a. quæ ampliùs triginta numerare licet, nè aperiuntur quidem, quum non perforantur, ut diligentiùs internam \& concavam Teftæ partem inutenti palàm fit. Ea a. incipiunt à fpirarum mucrone, ubi perexigua; deinceps incrementum paulatim fumunt.

Eocess

Ultimum a. \& prægrande foramen excipit velut labrum quoddam five roftrum canaliculatum, ut fuperioribus primi membri non minùs rectè annumerentur.

In infulis prope Garufey copiosè reperiuntur; eafdem etiam in litore Italico juxta Putcolum collectas habui.

\section{ARTICULUS IV.}

De Cocbleâ Turbinatâa, aperturâ in rimam formatâ; i ipe fis Spiris intìs latentibus.

\section{TITULUS XVII.}

Concha Veneris exigua alba, friata. JRung.

Defrizptio. $1 \mathrm{C}$ perexigua tefta eft; vix enim fabam equinane æquat.

Color ei albus, aut ex albido fubrufefcens.

Huic ftriæ tranfverfæ crebræ eminentes.

Eocuss.

Juxta Hartlepool agri Dunelmenfis fat copiosè reperiuntur; ubi J

N. B. Valdè fímilem vidi ab infulâ Jamaicâ : at in co difcrimen, quòd illi in fumma parte convexâ eft unicus profundior fulcus, qui in noftrâ deeft. 


\section{De Cocbleis Marinis.}

\section{MEMBRUM Ir.}

De Cocbleis iurbinatis, orbes non habentibus. Echini inter teftacea ab Arifíot.numerantur. Et quid idem omnia Turbinata Elicem non babere innuit, ideo Aldrovandus alterum Turbinatorum genus Echinos fecit; quem or nos quidem bâc in re fequimur. Aldr. de Teftac. p.256.

\section{TITULUS XVIII.}

Echinus marinus, aculeorum veftigiis parùm aut nibil eminentibus.

T I U I C Teftx figura globofa five fphærica; at ex al= Dertits terâ parte paulò planior eft. Creberrimis aculeis undiq; contegitur: in vivo pifce $\&$ intra aquam natante erecti $;$ at mortuo aut extra aquam: pofito iidem defidunt. Ipfi a. aculei exigui \& tenues, vix dimidium digitum fuperant. Qui ex his majufculi, omnes obtufiore mucrone definunt: iifdem etiam color albidus.

Detritis a. aculeis, eorum veltigia parùm aut nihil e. minent.

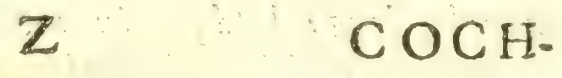




\title{
COCHLEARUM MARINARUM
}

$A N G \perp \mathbb{A}$

\author{
SE C T IO II.
}

De Cocbleis Bivalvibus.

\section{ME MBRUM I.}

De Cochleis Bivalvibus que ex omni parte ardè inter Se conjungi polfint.

\section{ARTICULUS I.}

De Cocbleis Bivalvibus, ex omni parte cluflibus, now friatis.

\section{CAP. I. \\ De Conchis non ftriatis.}

Harum a. note characteriftice frunt. I. Vtramg; valvis effe equè cavam. 2. Duobus prester cardines validis ligamentis, mufculifve, binc indè in mediâ Teftâ difpogetis, ipfis teftis adnecti. 3. EfJe leves aut leviter asperas.

\section{TIT UL US XIX.}

Concha longa latáq;, in mediis cardinibus cavitate quadam pyriformi infignita. An Chama-glycymeris Rondeletii?

Discriptic. gilis eft. 



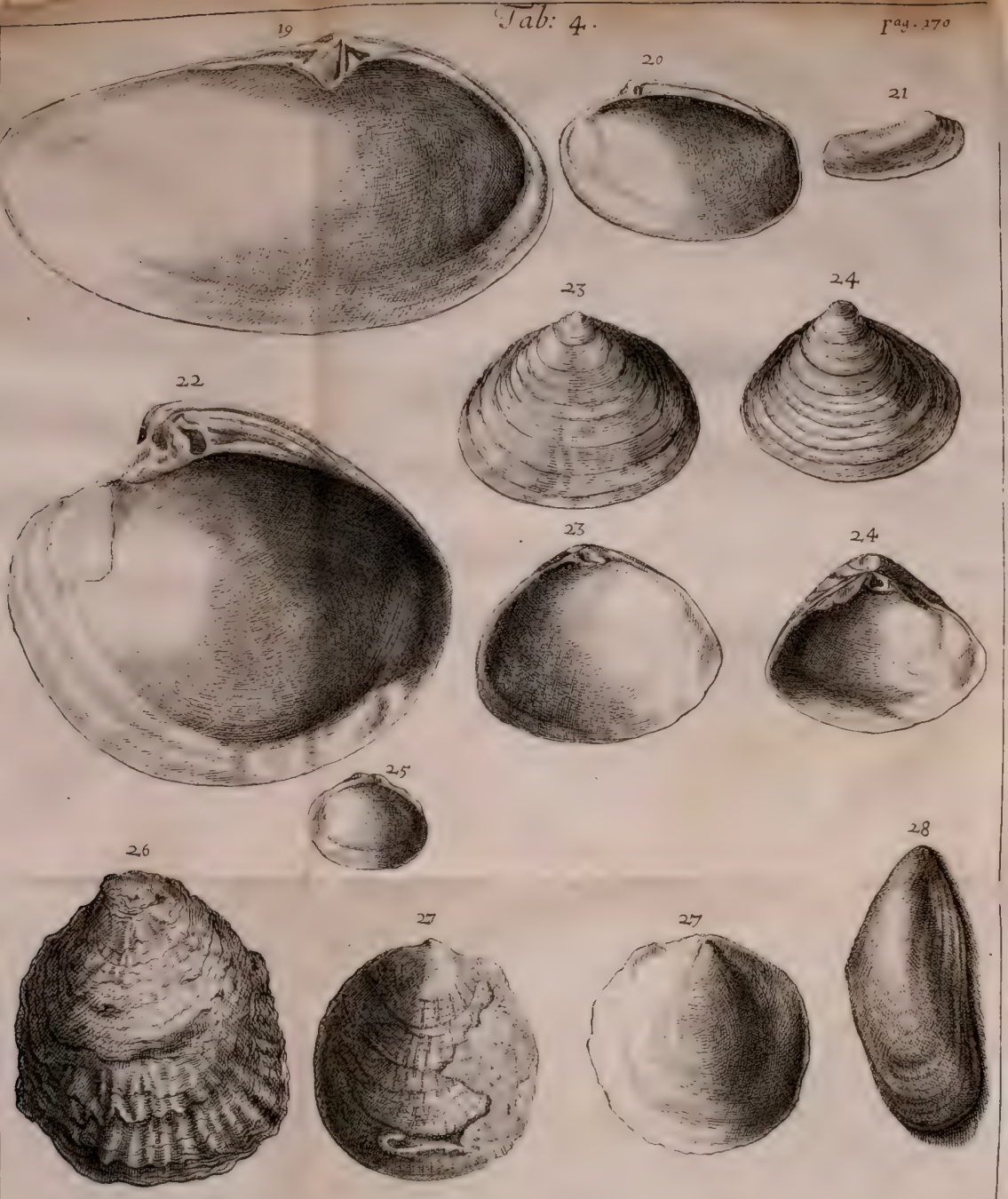


$-$ 


\section{De Cocbleis Marinis.}

Longitudine quatuor minimùm digitos cum dimidio implet; latitudine paulò fupra duos habet.

Minùs profundè excavatur; intùs lævis, item extrà haudquaquam afpera eft.

Intùs albent, extrà flavefcunt: at cujus naturaliter co. loris fit, minùs conftat; quippe omnibus à me obfervatis fumma cuticula deerat; nifi quòd in aliquibus cutis five membranæ fufcioris exigux particulæ adhærerent.

Ex altera parte cardinis paulò magis producitur; at utraq; pars extrema \& ferè æqualiter lata \& fubrotunda.

Ad medium verò cardinem in utrifq; valvis, præter alios finus anguftiores, eft quædam infignis cavitas pyriformis.

Huic animali, preter nexus ad cardinem, duo ligamenta funt, quorum veftigia in utrifq; valvis fatis notabilia.

In litore arenofo juxta Pbilo; item ad oftium fluminis sockse Tees copiofiffimè reperiuntur.

\section{TITULUS XX.}

Concha quafe rhomboides, in medio cardine utrinq; cira citer tribus exiguis denticulis donata.

L I C tefta modicx craffitudinis eft, \& inter firmi- Defcriptiso. ores numeranda eft.

A latere ad latus duos digitos patet; à cardine verò ad imam oram paulo fupra unum digitum ; figurâ quodammodo rhomboide.

Extrà rugis afperatur, in aliquibus creberrimis minutiffimíf; quafi ftriis tranfverfis.

Ipfe umbo exiguus acutúfq; eft : proximè verò fub um-bone cardo conftat è duobus exiguis finubus, $\& x$ totidem 
aut trinis denticulis: at etiam alii finus funt, in longam procedentes, maximè ex alterâ parte.

Huic color extrinfecus albus; at non nifi teftas fuis animalibus vacuas \& fortè vetuftas adhuc vidimus: intùs verò ad alteram à cardine magis remotam partem colore violaceo infigniuntur; reliqua interna tefta albet. An quibus hæc etiam nota, è recentioribus fint?

Zocuss

Ad oftium fluminis Tees ripâ Eboracenfi, fatis frequenter reperiuntur.

Cùm in hâc Conchâ \& infrà defcribendâ Tellinâ illuftres notæ purpura-violacei coloris infunt; an Conchylium antiquortum à Bivalvibus, ut Purpura à Turbinatis ortum fit, meritò quæro.

\section{TITULUS XXI.}

rholas nofter, five Concha intra lapiden quendam cretaceum degens.

Dofrriptico $\quad \mathbb{J} \mathbb{C}$ admodum tenuis \& fragilis Tefta eft. Nullam vidi quæ digitum longitudine implevit; at latitudine vix mediam partem digiti attingunt.

Modicè caver fint valve; ex unâ parte rotundantur: ex alterầ verò admodum obtufx ac fí præcifx forent.

Extrà rugofx, intus læves.

Mortux \& vetufta teftx, nam alias nondum vidi, albent.

2osks. Hx conche juxta Hartlepool frequenter reperiuntur, \&e in lapidis cujufdam cretacei foraminibus latitant ab info carmo ortu: nam ex his eximi non polfunt, nili prius lapis frangatur.

De ipfis a. foraminibus hre obfervavi, I. Ea ficri in lapide molli, \& quæ facile forari pollit. 2. Alterâ parte 
patent,alterâ claufa funt. 3. His fingulis figura una \& eadem eft, eáq; veluti ovalis ; fc. ipfum os anguitius, media pars paulò ventricofior, rurfus anguftior ima pars, quæq; rotundatur. 4. Pro ratione animalis majora minoráve funt ; ut parvo animali exiguum foramen, \& adulto majufculum; at omnium foraminum cava duplo aut triplo majora funt, quàm Conchx requirant, fc. ut liberè valvas aperire pof. fint. 5. Majorum foraminum longitudo ad 2 uncias ; latitudo, quà ventricofius, paulo fupra dimidiam unciara eft.

\section{TITULUS XXII.}

Concha èmaximis, admodum crafsa, roiunda, ex niz. gro rufefcens.

I I E $\mathrm{C}$ tefta admodum craffia \& valida cft.

E maximis eft : requaliter ferè lata eft, fc. ad digitos tres utrinq; patens; adeò ei figura fubrotunda eft.

Cava, \& in dorfum multùm elata eft.

Huic color, cùm fumma cuticula adet, ex fufco rufefcens, ant caftaneus: intus albet.

Ferè lavis eft; at cute detractề, ex parte gibbâ leviter rugofa eft; \& in aliquibus minutioribus fun adnodum minutx itrix tranfverfe, fc. à latere ad latus deducte.

Ipfe a. umbo angurtior, acutus \& leviter roftratus eft.

In ipfo verò cardine funt plures finus profindiores, dentéfqs sive apophyfes eminentes.

Copiofifime reperiuntur in litore arenofo ad oftium some Fluminis Tees, \& alibi juxta Pbilo. 


\section{De Cocbleis Marinis.}

\section{TIT ULUS XXIII.}

Conchatenuis, fubrotunda, onz nimm minimè cava, cardizis medio finu du amplo do pyriformi.

E:miptic. 1 \& $\mathrm{C}$ tefta admodum tenuis \& fragilis eft.

Latitudine fefquidigitum patet, longitudine ferè ad duos digitos producitur; ita ut fubrotunda fit.

Huic color albicans, qualis in omnibus vetuftis teftis; nam vivos id genus pifces nondum vidimus.

Valvæ minimè omnium profundè excavantur, ipfí umbones perexigui, \& ad cardinem acuti funt. Ipfe a.cardo ex pluribus finubus conftat; at medius reliquis amplior $\&$ quodammodo pyriformis.

Lockso Copiosè habentur ad oftium fluminis Tees juxta Redcar ripâ Eboracenfi.

\section{TITULUS XXIV.}

Concha cra $\int a$, ex alterâ parte compre $\int \mathbb{a}$, ex alterâ $\int u b-$ rotunda.

D.jwizitio. $\quad 7$ E $\mathrm{C}$ tefta pro magnitudine craffa \& valida eft. Modicè excavatur.

Huic color albidus; at vivos pifces nondum vidimus.

Figura fubrotunda; à cardine ad imam oram líguidigitum longa; à latere ad latus paulò fupra eandem menfuram patet.

Ipfe umbo acutus \& leviter roftratus.

Intus levis; ex parte verò gibbâ aliquot rugx tranfverfe five ftrix, at fine ordine.

Ex alterâ verò parte $a b$ umbone ad rećam lineam pro- 
cedit, ex alterâ \& adverfâ eâ, rotundior eft ; quâ folâ notâ abundè diftinguitur à proximè fuperioribus.

Ad oftium Fluminis Tees, \& in litore arenofo juxta zochso.

Pbilo; at rariores funt.

\section{T ITULUS XXV.}

Concha paroa fubrotunda, ex parte internâ rubens.

T IEC tefta modicè craffa eft; five ad tenuiores po- Defcriptrio,

O tiùs accedens.

Huic latitudo digitalis; longitudo digiti quartâ parte minor.

Extrà albefcit cum quodam rubore; intùs verò præcipuâ quâdam rubedine per totam internam faciem illuftratur.

E lateribus verò alterum ferè circinatum, alterum à cardine in obtufum quendam angulum rectà procedit : at paulo antè quàm ad iftum angulum veneris, quidam finus leviter deprimitur; id tamen, nifi admodum diligenter attendas, haud tibi ita facilè occurret; at ea præcipuas diftinctionis nota eft.

E millenis fortè unam inveni fuprafcriptis triplo majorem.

In Brevibus Lancaftrienfibus, juxta Philo \& alibi fre- Lockus. quentiffima concha; \&è litoralibus eft; nam ex his vivos pifces captos vidi. 


\section{CA P. II.}

De Concbis a peris, valvis diffimilibus, znico ligamers. to interno donatis, Oftrea dictis.

\section{TITULUS XXVI.}

oftreum vulgare maximum, intìs argenteo quodam fplendore albefcens.

W. $\mathbb{E} \mathrm{C}$ tefta fatis nota eft, admodum craffa, valida \& ponderofa, ingenti magnitudine, maximè quæ inter rupes Scoticas expifcantur.

Huic figura fubrotunda, at inæqualis feré. Item valvæ inæquales \& diffimiles; fc. quarum una plana, altera cava; utraq; verò extrinfecus rugofa $\&$ afpera admodum; at non frriata. Intùs a. Lævis \& albefcens cum argenteo quodam fplendore, foris color ferè fufcus.

Huic pifci unicum tantùm ligamentum internum in mediis valvis affixum.

In his interdum fuæ Margaritæ inveniuntur. Plurimis in locis in noftro mari pifcantur.

Ofrei anatome è clarifsno Willifro noftro de Anime Bruti cap. 3.

Teftx in Oftreis ab ovo connatx; \& prino molles, prout mole accrefcunt, fenfim indurantur.

Mrifouli vedit

Utriq; Teftre Mufculus robufzus, in medio oftrei conTeftas acclitdentes ten athfitus per tendines fuos adnafcitur. Hujus fibre motrices (qux velut chordarum fafciculus videntur) rectà afcendentes, dum contrabuntur, Teftas arot̀ occiudunt, re- 
laxatæe verò eas aperiri \& attolli finunt: quod munus ape. riendi teftas, Mufculus alter huic ad junctus exequitur.

Preter hos mufculos rectos, \& ad Teftarum plana per- Muctenli circupendiculares, funt bini alii circulares, per utriufq; teitæ margines expanfi; qui ibidem inter fe Branchias comprehendentes, earum motibus potifimùm inferviunt, uti mox oftendemus.

In fummitate Oftrei, mufculi circulares uniti, quoddam quafi velum, pro tegendo capite conftituunt: deinde paulo inferiùs divifi, quatuor branchias fuperiores includunt; in quarum medio rima dehifens, proceffu aliquo ad Oftrei $O$ s ducit. laves Brancluas moventes.

Ab Ore tranfitus brevis \& rectus ad ventriculum eft. ventriculus. Hujus cavitas fatis ampla foraminulis, in corpora fuf $\mathrm{Ca}$, ei utrinq; affixa, ducentibus, prædita eft. Corpora iftæc, \& Mefenterii \&.Hepatisloco effe, eorúmq; muniis defun- Hep ar, 48 efenter gi videntur; quatenus nempe puriorem chyli partem, mox è ventriculo fufcipiunt, ipfámq; defxcatam humori vitali tradunt.

In Oftreo, inteftinum ex imo Ventriculo incipiens, In:fin:m. cum tubo plano \& æquali, verfus mufculi recti angulum dextrum defcendit, ubi in fe convolutum \& retortum, rurfus fupra ventriculum \& hepar afcendit; inde demerfum ac in finiftrum latusreflexum, juxta mufculi rectilimbum incedit, donec in Anum definit. Ad hunc modum Anus. in Oftreo, inteftinum fimplex \& unicum, longiffimo gyro, plufquam in aliis quibufcunq; animalibus, circumducitur; quo quidem frercora diutius retinere queat; $f$. ne cùm in ficco degit, ea importuniùs depofita, lymphas, ob vitæ pabulum, teftis inclufas, (dum is mifcentur) polluant.

Inteftino hoc in longum diffecto \& aperto, in fundo cjus corpus fubdurum \& ferè rotundum eminet, quod ab ano ad ventriculum alcendens, ibidem emergit, \& fub cefoplago verfus caput protenditur: frinali mednlle non 
abfimile videtur: ductus a. chyliferos, corpora fubfufca, ventriculo appenfa, fupplere oftendimus.

Pericardium cum cords or valis.

Ersinctis.

Infra ventriculum, Pericardinm, cor albicans cum auricula ampla \& nigricante includens, locatur: quo aperto illud pulfare confpicitur, \& quây; diaftole, humorem vitalem è venâ cavâ in auriculam admittere; deinde quâq; fyftole eundem in aortam, è regione confitam, propellere; deinde juxta vafis hujus ramos tripartitos, iftius humoris pars quædam fuperiùs tendit verfus caput, hepar, \& ftomachum; item portio quædam in mufculum rectum reflectitur; interim pars ejus maxima magno arterix trun$\mathrm{sO}_{2}$ ad branchias delata, ibidem intra ductus minutiffimos, \& valdè numerofos, velut exiles rivulos explicatur, ht fecundùm omnes fuas partescorpufculis nitrofis ab aquấ infpirandis, frui poffit. Et hoc quo uberius fiat, advertimus, aquam, non modo extimas Branchiarum fuperficies, prout in pifcibus fanguineis, alluere; verùm ubiq; penitiores earum ductus, \& intimos quolq; receffus fubire.

Quinimò ipfx Branchice per oftrei hemifphærium, \& ampliùs expanfxe, cuncta alia vifcera, ferc̀ item partes mole ruperant. Adeò pifcibus, quoniam in aquâ parciùs refpirant, ita provifum eft, ut fimul pluribus in locis refpirationis pabulum iis fuggeratur. Branchiarum cirri quatuor, \& cujufq; illorum bini veluti lobi funt; nempe fuperior, latior, \& craffior; ac inferior, qui tenuior \& paulo contractior exiftit. In totis earum ductibus, unaquæq; duplicata eft, atq; binas pinnarum feries coalefcere vifas continet: ad fingulas Branchias duo vafa, fc. Arteria \& Vena fpedant; qux in cirrorum aggeribus difpofita, propagines exiles utriuff; generis per univerfas fimbrias difponunt. Cæterìm præter hos quatuor vaforum ordines, tot infuper foraminum vafa ifthæc interjacentium, feries reperiuntur; qua item ductibus manifertis in pinnarum interftitia aperiunt ; \& illic aquas mufculorum circularium commiffurầ inferiori abforptas deducunt.

Quoad 
Quoad Branchiarum motus dulo ti patet, mufculos circulares, qui eas includentes utriq; teftæ innituntur, modò relaxatos ad extremas teftarum margines pertingere; quo inftanti etiam Branchiæ relaxatæ, aquas imbibunt, fimúlq; ex iis pabulum nitrofum hauriunt ; modò contractos introrfum diduci, fimúlq; branchias ad exprimendum aquas recèns admiffas cogere.

Si ratio inquiratur, cur pilces teftacei prater vafa humorem vitalem circumducentia, etiam ductus five canales apertos, quibus lymphie ad intimos eorum receffus convehuntur, habeant; ea videtur, quòd fubfidente $x$ quore, fxpiùs aliquandiu in ficco manent; idcirco ut reípirare poffint, aquas copiofas, intra proprias iftorum compages, velut utribus repofitas continent. Itaq; hi diutiùs, quàm alii extra undas vitam agunt. Satis notum eft, Oftrea, quando undis eximuntur, magnam aquæe quantitatem intra teftas fuas occludere. Atq; hæc hactenus Clar. Willifius nofter.

Vide Figmias, earúnq; expli. cationes bicira. ferendas.

De oftreomm generatione \&u quomodo viridia fant*.

Menfe Maio fæturam ejiciunt Oftrea, id quod à noftris pifcatoribus patt vocatur. Id a. figurâ lenticulari eft, at ipfis lenticulis paulo majus. Saxis verò veteribúfq; Oftreorum teftis rebúfq; fimilibus, quæ omnia Clutrb vocantur, per maris fundum difperfis, adhæret.

Non fine ratione conjiciunt, recenter edita ova intra 24 horas Teftis contegi.

Menfe Maio, legibus maritimis, Pifcatoribus permiffum eft, omnigena oftrea, cujufcunq; ea magnitudinis fint, expifcari.

Quibus captis, fxturam à re cui adhæret leniter cuftello feparant ; eâ re mari rurfus commilfà, ut loci fxcunditas in pofterum præfervetur; nifí ubi adeò recenter edita - 
fit proles, ut tutò dividi non poffit; quo cafu iis conceffum eft lapidem aut Teftam, \&cc. auferre, cui adhæret fætura : cùm fuper unicam Teftam viginti tenella oftrea $\mathfrak{x}$ piùs numerentur.

Poft menfem verò Maium id auferre quod ciuteb vocatur, furtum eft; nec, nifi ea Oftrea, quæ juftæ magnitudinis funt, impunè capere licet.

Hanc verò prolem aliáq; oftrea ad quofdam maris finus devehunt; ubi ea alveis quibufdam maritimis demittunt, quos lectos five Atrata vocant : ibi adolefcunt, \& pinguefcunt; duobus certè aut tribus annis minutifluma proles ad juftam magnitudinem perveniunt.

Ea a. oftrea, quæ viridia fieri cupiunt, foffis quibufdam, in brevibus maritimis tres pedes altis demittunt; has a. inundant altiores tantùm æeftus ad plenilunium \& novilunium. Ipfis verò foffis aptantur quædam Emiffaria, per quæ aqua marina eatenus refluit, donec ad dimidiam altitudinem fubfiderit.

Hæ verò Foffæx, à quâdam loci proprietate, fole adjuvante, virides fiunt; fuúmq; colorem tridui aut quatridui fpatio oftreis conmunicant; quamvis ea ibi manere fex feptimanas aut duos menfes finunt, quo tempore intensè viridia fiunt.

Solis a. operationem in hâc viriditate inducendâ illud probat, fc. foffas Talesburienses tantùm æettate id præftare; at ipfam terram vehementiùs id efficere teftatur, quòd foffre Bricklefeaen Jes \& xtate \& hyeme id perficiant. Item illud accedit, Foffam unam ab alterâ pede diftantem id non præftare; eáfg; quæ olim id optimè fecêre, jam proprietatem fuam amififfe.

Oftreorum a. è valvis illa quæ concava eft, cùm æftus. influit, terram fpectat; cùm verò refluit, fe invertunt.

E loco a. non fe movent, nifi tempeftate frigidâ, ut luto fe obruant. 
Is verò pifcis, qui à ftellâ nomen habet, cùm oftrea fe aperiunt, ea ingreditur, depafcitúrq;

Demptâ a. eầ materiâ, quæ $\mathfrak{C l u t c h ~ v o c a t u r , ~ \& ~ f u p r a ̀ ~}$ expofita eft, Lutum augetur, in quo tùm maximè generantur pectunculi \& mufculi, oftreáq; deftruunt; cùm iis non fit, ubi frturam deponant.

Oftrea verò à fæxtura ægrotant. Junio a. \& Julio menfibus meliùs fe habere incipiunt, \& Augufto penitùs fanefcunt. Mafculi a. æegritudo cognofcitur à quâdam nigră materiâ in branchiis difcernendâ; Fœminæa a. ea materia ibidem tìm alba eft.

Oftrea in Folfis quidem falfa funt; at illud magis in. ftratis; maximè verò in alta mari. Hac hactenusille.

\section{TITULUS XXVII.}

of țresm parvwn veluti ftriatum, teftâ intùs virefcente, cardine utrinq; canaliculato.

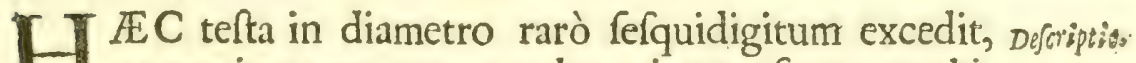
II at maxima eorum pars multo minores funt; ex his a. ipfi vidimus aliquot centena.

In his verò teftis extrinfecus eadem ferè afperitas, qualisin fuperiore oftreo; eadémq; \& ma;or varietas in figura. Nam ex his alia admodum concava; alia minimè profunda ; alia diverfimodè finuofa; alia ad amuffim ferè rotundatur.

Extrinfecùs etiam in multis ftriarum quarundam, pectinum ritu, non levia veftigia.

In ipfo verò cardine fingulis Teftis finguli finus five cana* liculi funt.

Unicus a. in mediâ cavitate Mufculus, cujus impreffumr veftigium albefcit, at circà cum argenteo quodam fplendo. re virefcit. 
Ad̆ oftium fluminis Tees ripâ Eboracenfi copiosè habentur. Hæc a. me primùm guftâffe memini Burdigalæ Galliæ Aquitanix, ubi in deliciis funt; ibíq; Oftrea saxatilic appellantur, fiquidem inter fcopulos inveniuntur.

\section{A P. III.}

De Conchis Mufculi dictis, fetiferis, anico ligamento donatis, figurâ ferè rhomboide.

Eiscriptic. Tujus Conchæ utraq; Tefta admodum tenuis; parte 1. verò acutiore paulo craffior \& fpiffior eft. Reliquo ambitu rotundo multo tenuior \& fragilis.

Foris ex cæruleo nigricat; intùs ex cæruleo albefcit : utring; verò lævis admodum.

Lumini objecta, à fummo cardine ad imam oram, ad modum radiorum venæ exiguæ cæruleæ eleganter procedunt ; idq; in nonnullis nudè confpicitur.

Ferè ita menfurantur; longitudine duos digitos \& dimidium explent; latitudine paulò fupra unum. At in aliquibus locis ad mirandam magnitudinem perveniunt.

Setam exerunt è finu magis reducto, adverfus quen angulus acutus eminet. Ipfe a. cardo acuminatior; ima ora rotunda.

Admodum capax concha : figurâ rhomboide.

Huic unicum ligamentum, ex adverfo cardini ad oram rc. rotundiorem collocatum.

Caro intùs pallefcit cruda; cocia vitellis ovorum fimiin: eft; in ambitu fimbriata.

Murculi 


\section{Me Cocbleis Marinis:}

Mufculi fuum Byffum gignunt, pinnarum more: fed tam differt, inquit Rondeletius, à pinnarum byffo, quàm ftuppa canabina à tenuiffimo \& delicatifimo ferico.

Mufculi fedem non mutant; fiquidem villis five fetis, quafifcopulis adnafcuntur.

Magnnâ copiâ ubiq; per oram maritimam \& in flumini- Locko bus quog; aquæ dulcis reperiuntur.

Edules funt apud nos; item eorum precipuus ufus a. pud Lancaftrienfes quofdam ad agros ftercorandos; ubi carris vehuntur à fcopulis in vicinos agros. Item ex his. efca plurima ad pifces capiendos. 


\section{ARTICULUS II.}

De Cochleis bivalvibus, ex omni parte cluflibus, friatis.

\section{A P. I.}

De Pectinibus.

Pectinume verè be note charaderiftice funt. 1. EfJe friatas. 2. Veluti auritas. 3. Alterầ è teftis cavâ, alterâ planâ. 4. Unico Mufculo donari. 5. Nullis cpophy fibus five tuberculis teftaceis; fed in mediontriuf $q ;$ tefa cardine fimilem cavitatem fire canalicklum babere, nervo obfirmatum.

\section{TITULUS XXIX.}

pecten maximus, circiter I 4 friis admodum crafjis, or eminentibus, or iifdem ipfis friatis infignitus. \& Stallop.

Defriptiz.

Eftx, quam defcripfi, longitudo, i. e. à fummo car. dine ad imam oram, .... uncias \& dimidiam implevit; latitudo ad uncias quatuor porrecta eft.

Intùs albet, extrà ex albido rufefcit.

E teftis altera modicè cava, altera plana eft, alterius veluti operculum.

Modicè craffa eft.

Utræq; teftæ, quâ parte auritæ, frrictiores funt ; dcinceps vero paulatim amplificantur, \& funt rotund'x.

Utræ; teftæ fimiliter ftriatæ; ipfx a. ftriæ à cardine incipiunt, \& ad imam oram rectè procedunt. In fingulis 
De Cocbleis Marinis.

reitis circiter i 4 ftrix funt, admodum craffex \& eminentes: ipłx a. eædem majores ftriæ aliis quoq; ftriis minutis exornantur; quas etiam minutas in ipfis auriculis \& in canaliculis obfervamus.

In utraq; Tefta ad medium cardinem fimilis finus amplus, pyriformis eft; ibi niger quidam nervus finus occupat, ipfúmq; cardinem maximè obfirmat.

In Freto juxta peninfulam Portland \& alibi in illo ma- Locusse ri expifcantur.

Hi pifces ex teftaceis poft Oftrea maximè in deliciis funt.

\section{T ITULU S XXX.}

pecten tenuis, fubrufus, maculofus, circiter 20 ftrizis majoribus, at levibus, donatus.

HUjus Teftæ longitudo rarò, quantum adhuc vidi- Defripttio. 11 mus, binos digitos excedit; at ejus latitudo paulo minor eft.

Tenuis \& levis eft.

Circiter 20 ftrias majufculas \& eminentes numeravi: ipfe a. non, ut in proximè fuperiore, ftriantur, fed læves funt : ipfi verò canaliculi five ftriarum interftitia minutiffimis adeóq; creberrimis ftriis undatim \& tranfversè donantur.

Item auriculæ utriufq; generis ftriis ad eundem modum ftriantur.

Huic color rufus, five rubeus, maculis five nubeculis albidis variè interftinctus, in modum cujufdam marmoris.

Sinus, ubi cardo, anguftus, \& pyriformis.

In litore juxta Scarborough \& ad Hartlepool fatis fre- Locsso quentes funt, maximè poft procellam.
$\mathrm{B}$ b
TIT U- 


\section{TIT ULUS XXXI.}

Pecten minimus anguftior, incqualis ferè \&u a per, finss ad cardinem cylindraceo, creberrimis minutiffimífg? friis donatus.

Defriptice. TH $\mathbb{E} C$ tefta admodum inæqualis eft, \& finuofa; in17. terdum afpera fcabráq;: interdum modicè craffa ; interdum è validiffimis.

Hujus longitudo ferè ad duos digitos eft, latitudo ad unum; ut fui generis fuperioribus anguftiores fint.

Hujus item ambitus admodum inæqualis, vix unam figuram obfervans. Item ex his aliz admodum concave, alix minùs, alix minimè, perinde ut in oftreis videmus.

In medio cardine, ubi vinculum nerveum inferitur, fisaus quidam five canaliculus anguftus eft figurâ cylindracêิ.

Huic auriculæ vel una vel amba ferè deteruntur; ubi a. ambæ adfunt, mediocres funt.

Huic ftrix creberrimx, pertenues, \& minimè eminentes, ut difficile fit eas numerare.

Huic color fufcus, interdum albidus, interdum fubcroceus: at qui fit in vivis, nefcio.

zistiss.

Ex his plurimas habui ab oftio fluminis Tees ad litue Eboracenfe. Item fuxta $S c a r b o r o u g h$ leguntur. 
CAP. II:

\section{De Pectunculis.}

Hâc a. appellatione eas conchas intelligi volumus,

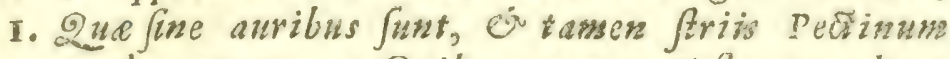
more donantur. 2. Quibus utrag; Tefta equalitep cava eft. 3. Que unico mufculo five ligamento do. nantur.

\section{TITULUS XXXI.}

Pedunculus maximus, at minus concavns; plurinio minutioribus \& parim eminentibus frits donat we, roftro acuto, minúfq; incurvato.

T I IC omnium facilè maximus Pectunculus eft; $f c$ à roftro ad imam oram duos digitos \& dimidium explet; neq; latitudine multo minor eft.

Tefta valida, ponderofa \& craffa eft; at paulo minùs concava eft quàm proximè duo inferiores.

Ipfe umbo five roftrum ad cardinem acutius \& minus incurvatum eft.

Huic funt apophy fes aliquot eminentes ad cardinem in trinis articulis; at finus quidam in medio articulo, proximè fub roftrum, minutus \& pyriformis ent, qui in duabus fequentibus non confpicitur.

Huic color albicus; at ex his vivos pifes nondum vidi.

Ad oftium fluminis Tees reperiuntur; at ibi quog; è rar noms. riffimis funt. 


\section{T IT UL US XXXIII.}

Pedunculus echinatus. Concha esbinata Rondeletii. Gefneri, Aldrovandi.

Dienciatio.

I I C tefta à latere ad latus duos digitos implet, à 1 fummo ad imum paulo minus; at ex his multo majores vidimus.

Utraq; tefta æqualis, \& admodum concava eft; modicè craffa; at majores craffæx admodum \& validæ funt.

Circiter viginti ftriæ majufculæ eminent; in quibus mediis exeruntur aculei quidam curvi, finguli certis intervallis inter fe diftantes; in canaliculis vero nulli dantur aculei.

Ad imas valvarum oras ftriæ \& canaliculi fibi mutuò committuntur, \& refpondent.

Iplæ teftæ ad cardinem tribus articulis conjunguntur pet modum ginglymi ; ita ut eminentes utring; mucrones mutuâ infertione, uterq; in oppofitæ teftæ acetabula cohæreant.

Ei color albidus, etiam cùm adeft fumma cuticula : in. tus candidus.

Ambitus ad amuflim ferè rotundus, ut in neutrum la. tus magis procedat.

rocrsis

Ad oftium fluminis Tees \& in litore juxta scarborough. poft magnas procellas hæ teftæ inveniuntur. 


\section{T I T ULUS XXXIV.}

Pectunculws vulgaris, albidus, rotsandws, circiter 26 ftrits majufculis, at planioribus donarus. The Tuthle.

L- E $C$ tefta à fummo ad imam oram rarò cligitum fu- Difariptio,

- I perat. Ejus verò latitudo paulo major eft. At ex his altero tanto majores \& amplius vidi.

Huic color albidus extrà, intus candidus. Tribus articulis per modum ginglymi ad cardinem connectuntur teftx; \& in his apophyles mucronatæ.

Ütraq; tefta æqualis, \& admodum concava, præ cæteris fuperioribus fui generis.

Ex altero latere tefta in angulum procedit; ex altero rotundatur.

In his circiter 26 ftrias numerare licet, at non mulitim eminent, fed planiores funt; canaliculi inter ftrias exigui fünt.

Paffim in litore arenofo magnâ copiâ reperiuntur; \& à Locuso nottris ad victum colliguntur $\mathrm{ab}$ autumno adultimum uf $\mathrm{f}$ ? ver.

Gratiffmi faporis funt, \& tam crudi quàm cocti eduitur, perinde ut oftrea. 


\section{A P. III. \\ De Tellinis.}

A Pedumculis differunt. T. Quid biso mufulis dow nantur. 2. Figurâ rbomiboide.

\section{TITULUS XXXV.}

Tellina intìs ex violapurparafcens, in arabiu ferratia.

Defciptio. H. 1 E C pulchra tefta eft: à cardine ad bafin digiti tres T partes non excedit: à latere verò ad latus ferè fer quidigitum implet.

Extrinfecus albet; intus ex violâ purpurácit.

Modicè craffa eft. Ipfe umbo exiguus \& acutus. UItraq; tefta parilis, \& minùs concavæ.

Ex alterầ parte in angulum procedit; ex alterâ magis in longitudinem diffunditur, at ambitu rotundo \& obtulo.

Minutifimis \& creberrinis ftris \& nihil eminentibus fulcatur: iten cjus ore ime crenulis minutifimis in mo. dum ferræ denticulantur.

Lec... Ad oftium fluminis Tees \& in litore juxta Scarborough inveniuntur; at è rarioribus conchyliis funt, 


\section{De Cocbleis Marinis.}

\section{MEMBRUMII.}

De Cocbleis bivalvibus, alterâ parte ant utråq; naiuraliter Semper apertis ant biantibus.

\section{CA P. I.}

De Conchis incluflibus frve bianiabus, levibus.

\section{TITULUS XXXVI.}

Concha levis, alterâ tant ìm parte clufilis, apophyfe admodum prominente latâg; predita.

T Æ $C$ tefta modicè craffa eft.

FV Vetufta \& detrita teftx albidx; vivos pifces non- Décriprios dum vidi.

A latere ad latus paululùm duos digitos excedit, à caro dine ad imam oram vix fefquidigitum lata.

Quâ parte clufilis, magis concava eft, \& in ambitu obzufo rotundatur; alterâ vero parte adversâ \& \& femper hiante; minùs clata \& veluti prærupta eft.

In exteriore fuperficie leviter rugofa, intìs levis eft.

Ipfe umbo, pro teftre modulo, exiguus eft. Ei verò unicus in cardine articulus; ubi in alterề è reftis acetabulum five finus infignis eft; in alterâ apophyfis admodum prominens \& lata, \& infar cochlearis cujufdam linuata eit.

Ad oftium fluminis Tees non rare. 


\section{TITULUS XXXVII.}

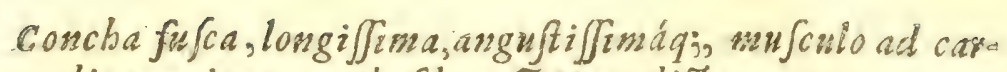

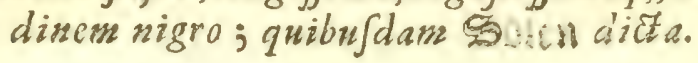

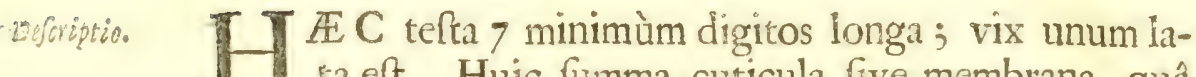
1 ta eft. Huic fumma cuticula five membrana, quâ tegitur, fubfufca eft; intus albet.

Eft etiam têta tenuis, lævis, modicè concava.

Utraq; tefta æqualis; mufculo nigro conjunguntur; ipfe a. cardo prope alteram partem; in altera è teftis ảuæ exiguæ apophyfes dentiformes, in alterâ tenuis velut lamella in binos alterius dentes excepta.

Utraq; pars extrema retufa, \& quafi prærupta; utraq; femper aperta \& naturaliter hians.

Loctis. Polt magnas procellas hybernas copiosè in litore juxta scarborough, \& alibi colliguntur.

\section{CA P. II.}

De Conchis nathraliter biantibes, friatis.

\section{TIT ULUS XXXVII.}

Concha altera parte dimidia friis undatim crifpatis donata, alterâ levisis; apophyy $\mathfrak{\imath}$ longâa, anguftâ, recurviu, dentiformi. An è Peloridibus antiquorum?

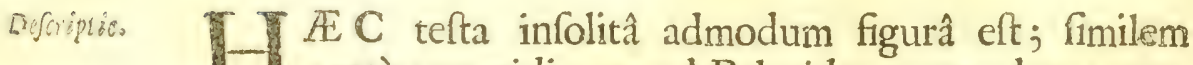
I certè non vidi : an ad Peloridas quorundam accenfenda, \& quòd prodigiofa fit, \& quòd utrinq; femper naturaliter 
turaliter pateat? Hæc a. requirunt authores ex vocis variâ interpretatione.

Modicè craffa eft; à latere ad latus paulo fupra duos digitos lata, à cardine ad imam oram digitum non multùm excedit.

Pars gibba per medium diftinguitur unico latiufculo fulco, rugis tranfverfis ftriato; altera medietas lævis aut certè leviter rugofa, altera denfis ftriis undatim crifpis, \& à latere ad latus procedentibus donatur ; ipfæetiam eædem ftrix verfus extimam oram quibufdam aculeis eminentibus exafperantur : illa a. medietas, quæ lævis eft, in ambitu rotundatur, atq; in aciem quandam finitur; hæc verò quæe crifpa, in acutum mucronem procedit; ab ipfo a. cardine ad iftum mucronem quafi quædam fimbria tenuis reflectitur.

Pars concava Lævis; at è regione fulci paululùm elata. In utrâq; teftâ mira apophyfis, dentiformis, dimidium digitum longa, angufta, leviter curva, mucronata, $\&$ in ipfo mucrone modicè cava.

$\mathrm{H} x$ admodum frequentes ad oftium fluminis Tees ripâ Loenso Eboracenfi.

\section{IITULUS XXXIX.}

Concha candida, dupliciter friata, éveluti aculealso

Llud fatendum eft, me dubitâffe an hæc tefta proximè $D$. friptis:

fuperiori conchx fubjici \& adnecti deberet, quod fortè hæc utrinq; clufilis fit : tamen quòd hæc tam multis notis cum illa conveniret, eas disjungere nolui. In hac ad cardinem datur fimilis fimbria reflexa. 2. Afperitate \& undatis ftriis. 3. Apophyfi longâ \& anguftâ.

E conchis longis Aldrovandi effe video.

$$
\text { C c }
$$


Tenuis \& fragilis admodum tefta eft. Colore candidiffimo; at qualis is fit in vivis, nefcio. Sefquidigitum longa, dimidium lata. Admodum concava, \& angufta; \& ad modum cylindri rotundatur: hinc eam ex antiquorum dactyli s effe exittimo.

Striæ crebræ à latere ad latus procurrunt, aliæq; tranfwerfe, at paulo rariores eminent, maximè verfus illam partem, quæ cardini vicinior; ubi ftriæ etiam undantur, ut in proximè fuperiore dictum eft, \& velut aculeis quibufdam exafperantur.

Item in alterâ parte rotundatur, in alterâ in mucronem. procedit, velut in pyloride.

a.:. Ad oftium fluminis Tees, at rariores funt. 


\section{COCHLEARUM MARINARUM \\ A N G L I $巴$ SE C T I O III.}

De Cocbleis Univalvibus.

\section{A P. I.}

De Cochleis univalvibus, loco mobilibus, vertice integro.

\section{TIT ULUS XL.}

Patella ex livido cinerea, friata. G Stither, 且im-

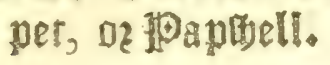

प $\mathrm{X}$ his maxima tefta à vertice ad imam marginem Defcriftico

- paulo fupra digitum exceffit ; ejus a. aperturæ diametrus duos digitos patuit.

Ipfa verò apertura five bafís non ad amuffim rotundatur, fed paulo longiùs ex alterâ parte ferè procedit : at femrer xqualis eft ipfa bafis, unde conftat ipfum animal fe de loco in locum movere poffe.

Teftre extima pars ferè ftriis, iifg; interdum multùm eminentibus, diffinguitur; at fine certo numero aut ordine: at in multis eædem ftriæ minùs notabiles.

Hæc tefta craffa \& valida eft; intùs lævis \& minimè frriata.

Huic color ex livido cinereus five maculofus \& varius.

Ipfum animal, inquit Bellonius, cornua, ut Limax, excrit ; \& os \& caput habet huic perfimile.

Scopulis iitoralibus per omnia maria noftra magnâ copiâ Lo ases. adhærent.

$$
\text { C c 2 ... Lepades }
$$


Lepades i piffortoribus crudxe eduntur, tefte Rondeletio apud Aldrovandum.

Harum a. 1" rripurus ufus apud noftros pifcatores eft, ut è teftis exemtæ hamíf ; injectæ, ad cæteros pifces capiendos efcæ fint.

\section{A P. II.}

De Cochleis univalvibus, loco fixis, vertice aperto.

\section{TIT UL U S XLI.}

Balanus cinereus, velut è fenis laminis ftriatis compofitris, ipfo vertice alterâ teftâ, bifidà, rbomboide occlase.

Balani parva Jpecies, Rond. apud Aldrovandum, p. 523. ejus verò figura ad imam paginam 522 . babetur.

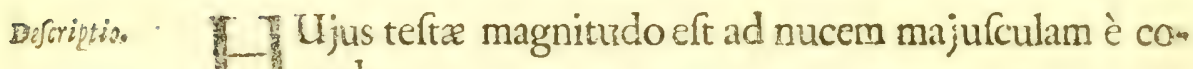
II rylo.

Color cinereus, albidúfve.

Patellx quodammodo fimilis figura.

Scopulis verè adfigitur, non pro arbitrio adhæret, un. de per verticem victum fumit. Illud a. inde fit manifeftum; quòd fi oftreis aut lapidi adhæreat, ejus bafis, foft feparationem à re, cui adhæfit, veftigia rei repræfentat eíg; aptatur.

Ipfa a. tefta ex fex laminis ftriatis conftat; fc. tribus majoribus, totidémq; minoribus. Ipfe a. vertex alterâ quafi bifidâ clauditur, ut hujus operculi figura guadrata five. rhomboides fit.

4cous. Paffim in fcopulis, item navium carinis, mufculis, oftreis, \&c. adhæret.

Harum carnem coctam animi causâ liberalììs guftavi ; mihíq; primo grata vifa eft; poftea quovis pipere amarior. linguámg̨; mcam diu pupugit.

C.OCH- 

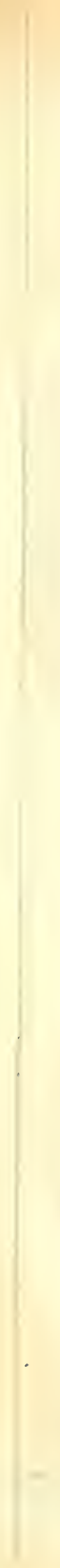



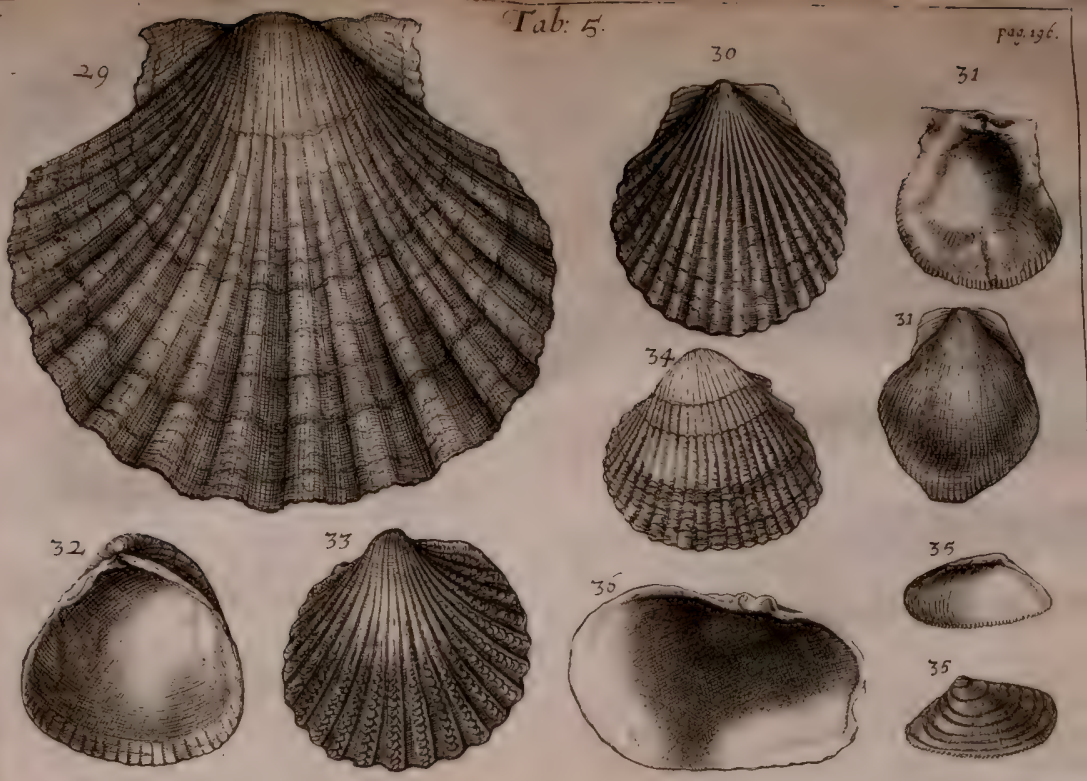

37
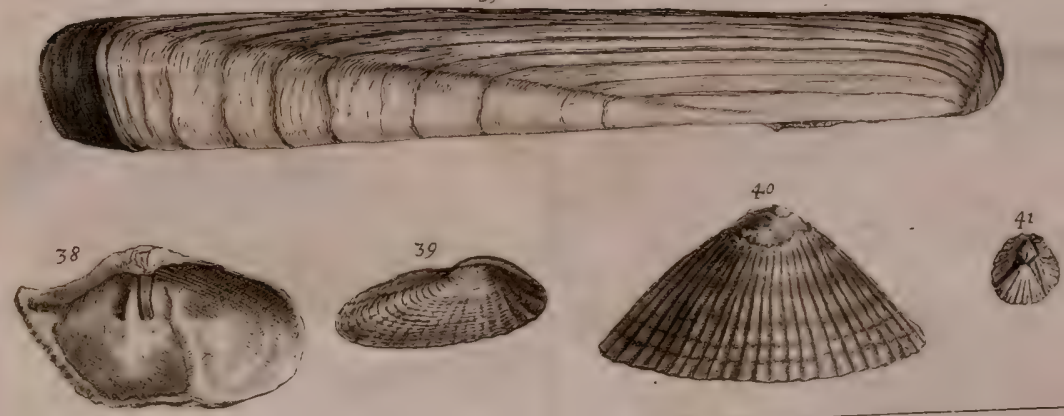

C O CH L I T A R.UI M

A N G L I AE

$S I V E$

Lapidum ad Cocblearum quandam imagi-

nem figuratorum

L I B E R. 


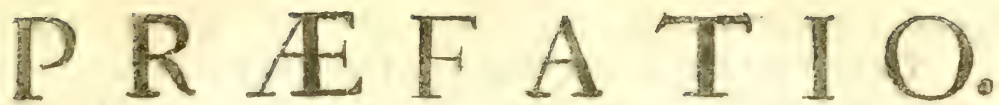

T Arinam fupellectilem noftre Infula proximo libro diligenter expofui ; boc verò fubterraneos ejufdem loci Cochlitas, five Lapides ad cochlearum quandam imaginem figura. los indicare aggrediar. Non autem ignoro, bas rerum viventium imagines multorum ingenia fati. gâjJe. At corum fentenitias non utiq; examinandas putavi, cism id ab amiciflimo viro D. J. Ray, pro fut

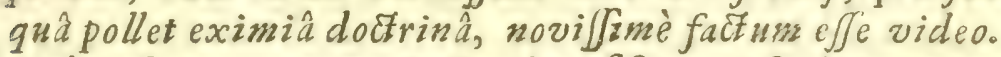
sed ipfas res coram Lectoribus fifto; ipfe loquaniur. si tamen eorum Sententic qui hos lapides terrigenos effe judicârunt, favere videar, non temerè id facio. Nam ex his noftris, ut opinor, obfervationibus mani. feftum fiet, aut ita eos ortos effe, out ip fa animzalia, que verè $\&$ ex toto referant, in rerum natura defeiffe generari; fiquidem univerfis Cochleis alia figure, atq; cocblitis aliz.

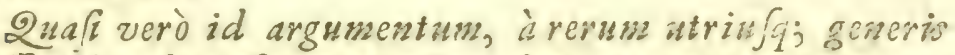
diffimilitudine fumptum (quod tamen unicum in animo penitìs difcutiendum babwi) ad remprorfus conficiendam non fat is effet; finguli feres tituli alna quog, ex abundanti fuppetunt. Quorum sonnulla, als alibs fortè omi $\iint_{a}$, paucis prafabor.

Quorundam Cocblitcrun, etian Bivalvium, enom mem magnitudinem, quim maximè fupra modw $\mathrm{Coch}$ learum in noftro mari ob fervatarum.

In ipfis fubmarinis rupibus aque frequenter ac in mediterraneis inveniri: adè ut ipfa que referant oni- 


\section{Præfatio.}

malia, ibidem expeczare debeams, quid ab ip is lociss, abi aliquando in vivis fuersnt, mare nondan receffit.

Univerfos Cocklitas tarn folidos quar crufaceos ex

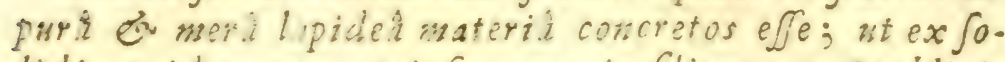
lidis quidariz ux utriug geseris flice: ex Cocblitis verò cruflaceis, qui fui parte coclileas naximè repre. fentant plerofgi e felenite, aut alio quodara frnili fluore refplendente confare. Huc facit memúranaceos quofdan Fofiritas ex mero pyrite relut foluto conflatos.

Iteme Cochlitarum quorundam velut rudimenta o rnaximè imperfictas figuras palsm in rupibus objervare licet: Squidem ex ipfis iifdem Cochlitis funt, qui na. iuraliter bifores, qui univalves, qui ex utraq; altera, aut alias quaf unầ tertiâ aut quazis minope parte mutilati d defectivi inveniantur. At bac omnia it a evenire credibile ejt, vel propter loci anguftiam, in quo primitis concrevere, vel ob materice penuriam. Iden cryftalin variorum generum aliifq; lapidibus fi* Dentylits. guratis, quales funt * Trochite, contigit. Quemadmo. dem vero in cryftallis defectivis Jua note funt; ita e in Cochlitis quomodocunq; imperfectis, quedam camen non obfcura, certè barnm rerum peritis, indicia difcretiva infunt.

Illud, quanvis minimè contra nos facit, non pre-

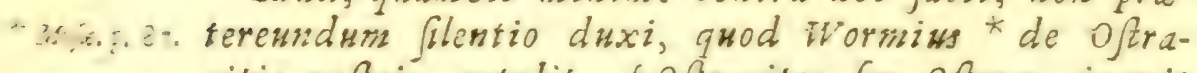
citis noftris retulit. 'Oftracites feu oftrea, inquit 'ille, in lapidem calcantinum conver $\int e$, omni fri parte

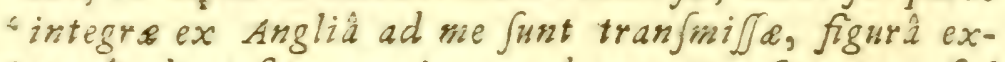
'terni $\dot{a}$ teftis, omnino quod erant, referentes; Jed - duplo an triplo ponderofiores, colore nigricante, odore " Julphureo, vel pulveris pyriz, ex illarum corpore vitrioli ' O. Julphuris quajl flos quidam exfudavit, imo ip $\int_{2}$ - met in humido fucilè difjolvebantur, etiam aëri bu"midiori faltern expoite. Ad Littus fepicntrionale Infule 


\section{Præfatio.}

'Sheppey in Cantio Anglie reperiuntur. Hec ille. Irs. primis notandum eft, effe littus marinum, ubi bac inventa funt, proprio fcilicet oftreorum loco: deinde idem de aliis quibufcung; Conchylizs marinis ibidem repertis obfervari poffe credibile eft; imò ipfos Concbitas, fi quos Terre natura ibidem gignat, ita penitus poffe imbui, nibildubito, cùm idem alibi frequenter occurrit. Inter omnes fanè fuccos lapidefcentes, (è quibus tamen non nifi unum ed alterum novi) ille qui è pyrite five vitriolicus, \&u cocbleas o univer $\sqrt{a}$ tanquam in fuam naturam convertere potes eft. De altero verò fucco Calcario, illud tcftor, me poft indefesfam diligentiam tandem in. cidiffe in quafdam Cochlearum terreftrium teftas, co fucco or intis refertas, ox extrì contectas, at ip as tefas omnino nullam mutationem inde fubiiffe, vel materiâ, vel crafsitie, vel pondere; fed facile agnofci potwêre, pro eo quod unquam fuerunt, $\int c$. pro exuvi is $C$ ochlearum terreftrium. Sed de his fuccis alibi fufius tractare meditor.

At quomodocunq; Se res babeat, opere pretium me facturum puto, cùm, fi non utiq; perdita (nam aliidi. cunt, animalia in nefcio quâ profundiori marinâ aby Jo latére poffe) at bactenus recondita, adeóq; prorfus no. va in lucem proferam.

Illud unum de Figuris, Lector, te fcire volo, tuitfig; idcirco gratias expecto, eas me fummâ diligentian ad ipfos lapides depingendas curâfe, cùm res ip fas verbis fotis exprinere baud potui. Figurce autern de fcriptionibus magno adjumento funt; fequidem bac ratione ip $\int_{\varepsilon}$ res velut in confpectum quendam adducte, memorie of intelligentice magnopere fubveniunt.

Cùn verò bunc librum ad finems perduxeram eccepro. ditt in lucone Hiftoria Naluralis agri Oxonienfis, omni literarma genere referta, ab eruditifis 


\section{Prefatio.}

Anglicè foripta. Inter alia verò boc ip fun argumenturn. de Cocblitarum origine fusè $\mathcal{E}$ doctiffime tractavit. 2uoniam autem inibi multe Lapidum figure exbiben. tur, quas adhuc mibi videre non contigit, illas buic noftra metbodo accommodandas din inerendas putavi, ze quid fciens omitterem, quod nofira tell us upiam ferat. Ac, fi idem diligentiflomus Author inceptum opus ufq; promoveat, nullus dubito, quin, tantam. In fulams jenitus rimando, multo plures bujus generis lapides fisuratos quam vel ip se, aut ego adhuc defcripferimus, a. pud nos reperiet. Mibimetipfe etiam reftant, non pawca aliorum Cochlitarum fragmenta, quorum quia notas sharacterifticas non adbuc rectè effequutus fum, in prefenti non libenter edo; quod entium multiplicationem jupervacaneam, bujufmodi Hiftoric commune vitium, maximè vito \&u abhorreo. Adeóg; illos in aliud tem. pas deferendos effe cenfeo.

Lapidusa. 


\section{Lapidum Anglixe ad Cocblearsm quendon modums fuguratorisin Tabula.}

Turbinati, h.c. unâ velut Teltâ, in conum procedente donati :

Intorti, five anfractuofi,

Quorum Orbes in fe convolvuntur, quibufdam Ammo. nis cornua dieti.

Cutrinque ad Umbilicum aqualiter concavi:

$\{$ Striati.

$\{$ Lxves.

Ex alterâ tantùm parte.

Cumbilico utrinque prominule.

Bivalves:

Buccinorum in modum produci :

$\left\{\begin{array}{l}\text { Striati. } \\ \text { Læves. }\end{array}\right.$

S Productiores.

¿ Figurâ compactili five Cochlex-formes

Qui Helicem, five volutam non habent:

Striati fubrotundi, ut Echinitæ.

Striis in omnes lapidis partes xqualiter proce-

$\{$ dentibus.

Striis inæqualiter procedentibus.

Læves in longum acumen faftigiati, ut Beiemnit o

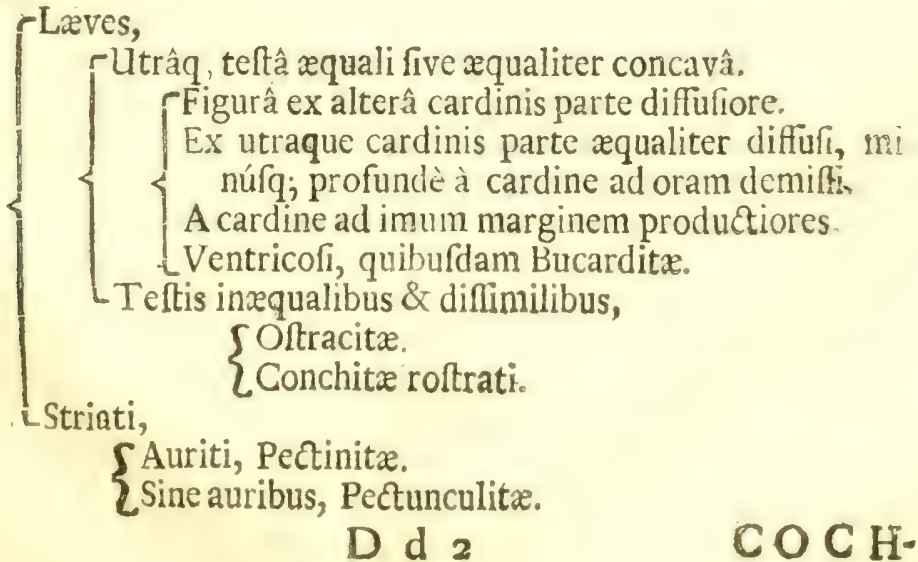





\section{COCHLITARUM A NGLIH}

\section{P A R S 1 .}

De Lapidibas Turbinatis.

SECTIO I.

De Lapidibus turbinatis, Intortis.

MEMBRUMI.

De Lapidibus Turbinatis, Intortis, quorum Orbes, ferpentum in modum in fe convolvuntur, quibufdam Ammonis Cornua dicta.

\section{ARTICULUS I.}

De Ammonis Cornubus, utring; ad umbilicume aqualio ter concavis.

\section{A P. I.}

De Ammonis cornubus friatis.

\section{T I TULUS I.}

Ammonis cornu maximum, ftriis crebris in ip $\int_{0}$ ambitw parum eminentibw, aliefq; utring; ad latera raris, crafjis, elatis.

An 15. Tab. 5. D. Plott ? in 20 tantime à noftro differre videtur, quod ejus lapidi dorfum leve eft.

T I C nofter lapis 13 digitos in diametro colligit; at Defcripsio 3. tres tantùm in ambitu craffus eft. Ad umbilicum u-trinq; æquè concavus eft, \& ibidem idcirco multo minùs saffus eft.

Quatuor 
Quatuor tantùm orbes numerare licet.

Eius extimus ambitus, five fpina planior eft; at ftiiis tranfiverfis crebris, exiguis, parùm eminentibus diftinctus eit. Item ex utrầq; parte extimi or bis aliæ quoq; tranfverfa ftriæ; quæut craflæ\& €latæ, ita raræ, vix ampliùs I 2 funt. In fecmdo vero Orbe, ut ille minor eft, ita ipfex ftrix \& multo crebriores minorefq; funt; atq; eâdem ra tione in reliquis intimioribus orbibus ad centrum ufq; teriæ \& numero augeri \& minui videntur.

Huic color albidus eft; afrum verò hu jus generis lapidem fublividum, æneóq; quodam fplendore relucentem, fabam magnitudine tir excedentem, vidi.

Maximum è Lapidicinấ calcariá juxta Nunnington op: pidulum agri Eboracenfis habui: at alterum minimum in fubmarinis rupibus, maris receflu nudatis, juxta spiton ejufdem agri inveni.

\section{TITULUS II.}

Aramoris Cornu, fpina in ambitu eminente, ftrits lateralibus paulo ultra mediam tantum partem Orbis ex. timi pertingentibus.

E. 5 ma IC IC Iapis quatuor digitos in diametro implet; at I- paululum uno digito craffior eft.

in extimo ambitu velut fpinam, hoc eft, unam frriam acutam cminentémq; inter duos profundiore: fulcos mediam habet: hujus autem fpinæ unitas nufquan interrumpitur.

Strix veró laterales curvæ procedunt; at orbis non multo amplitus quam tres partes occupant; in que magmum hujus fpeciei difcrimen.

Neg; in hoc lapide amplius quatuor orbes numerare potui. 


\section{De Lapidibus Turbinatio.}

potui. Huic lapidi color ferè lividus, certè fi ex rupibus aluminofis exemti fint : alios autem ex his \& fufcos \& ferrugineos vidimus.

Maximè in fractis articulos quofdam obfervare licet; at in nonnullis iidem ipfi etiam extrinfecùs apparent, fc. quodam opere foliaceo fingulos articulos diftinguente. In: tùs ferè materiâ quâddam cryftallinâ fuffarcinantur. Cæaterùm pars cruftacea interdum ex ferri glebâ conftat.

Horum a. lapidum magnam copiam vidi in rupe alu- tess. minofà juxta Wbitby agri Eboracenfis.

\section{TI T ULUS II!}

Ammonis cornw, Jpinâ in ambitu emineste, ftriis la teralibus ex toto Orben extimum trajicientibus. 10. I4. Tab. 5. D. Plott, attende deforiptiones.

T Orum lapidum innumeros vidimus medix magnitu- Ds saimoro 1 dinis; at aliorum fragmenta ingentia alicubi à me inventa funt.

Quem verò defcribo, duos tantùm digitos in diametro colligit ; idem vix dimidium craffus eft.

Orbium numerus circiter quaternus. In ejus ambitu velut acuta fpina inter duosfulcos media eminet : tamen id non ift perpetuum; nam in multis fulci vel utiq; defunt, vel leviter admodum infculpti funt.

Striæ laterales orbem ex toto trajiciunt; iffe ferè \& crebræ \& eminentes: at nec in his ftriis idem numerus \& elevatio eft. Alia etiam occurrunt fingularia, ut aliqui bus quidem quafi aculei in fummis ad fpinam ftriis.

Item in nonnullis articuli foliaceâ quadam picturâ facilè dircernendi. Articulorum autera apophyfes, five tubercula, circiter fenæ funt. 


\section{De Lapidibus Turbinatis.}

Huic color ferrugineus; nec dubito, quin ex iis fint, qui ex merâ ferri glebâ conftent.

Losus.

Hos lapides in rivulo juxta Eugthorp agri Eboracenfis oppidulum copiosè invenimus. Item indefcenfu colli fupria Monafterium Byland dictum, in lapide velut arenaceo cinerećq; inclufos. Item in Lapidicinis juxta Hinderskelfe \& Nunnington; ubi horum lapidum ingentia fragmenta habentur.

N. B. In Conchitæ roftrati, infrà deferibendi, Titulo 45. externâ parte, huius cornu Ammonis orbes ftriatos profundè velut infollptos vidimus, eúmg; apuid nos fervamus; fanè ac fi cjus matricis fuforize altera pars dimidia ellet. Id quod, ex mente Stenonis, Dani, iftius Conchitæ mollitiom arguere videtur. Contra verò illud facit ; quodd fi quando animal fuit, Teftam ex naturæ lege indies ab exiguo ovo increfcere, proximéq; à parvo indurefere necefle fit: at conchites in jufta ejus magnitudine cornu Ammonis impreflionem recepit, foilicet dum durus erat; quod abfurdum \& à rei natura maximè alienum eft.

\section{TITULUS IV.}

Anmonis cornu friis lateralibus in sedio ambitu ad acutos angulos concurrentibus.

Defreptrio. TIC lapis è majoribus eft, quantam è quibufdam If fragmentis coniicere licet ; fiquidem nihi efe unius orbis fragmentum, fefquidigitum latum; at id minuscraffum, quàm reliqui mediocres.

In plerifq; ftrix latcriles $\&$ crcbræ \& eminentes: in nonnullis vero multo elatiores: $\& 2$ in alis cadem admodum rarx \& ex longis intervallis: intérq; ftrias unius \& ejuf- 


\section{De Lapidibus Turbinatis.}

dem lapidis interdum aliæ alias altitudine \& tenuitate muttùm excedunt. Item ftriæ laterales in majoribus paulùm undantur ; \& univerfis, pro perpetuâ diffinctione, in medio lapidis ambitu ad angulos acutos coëunt \& committuntur. Angulorum autem apices craffius lapidis caput fpectant.

In his quoq; lapidibus articulos animadverti.

Item ex his, qui hoplitæ funt, id êt, qui armaturâ quâdam æneâ lucente donantur ; adeóq; de pyritarum natura eatenus participant. Præterea fupra ipfam quoq; armaturam, nefcio quam materiam tenuem, \& margaritarum fplendoris æmulam inductam notavi: ac fi cujufdam Teftæ marinæ quædam reliquiæ effent. Ut rectè ante me Clariffimus Hookius nofter obfervavit.

In rivulo, fxpiùs memorando, juxta Bugthorp; item in Locuso ipfo maris Litore prope $S$ carborough agri Eboracenfis, \& alibi ejufdem oræ maritimæ, nempe non longè à spiton in rupibus fubmarinis hi lapides à me reperti funt.

\section{TITULUSV.}

Ammonis Cornu 5 anfractumm, fingulis friis ip fom Jpimam trajicientibus, fibiq; invicem ad alterms lat abi terminantur, adplicitis.

Hujus figuram, rudem licèt, nobis primùn exbibuit 7. Baubinus, H. Font. Boll. pagg. $6,7,8,10$. item 2. Tab. 5. D. Plott.

W IC lapis modicæ magnitudinis eft; ejus diameter descriptio I tres digitos rarò explet.

In illo quing; circumvolutiones numerare licet; iden. earum numerus \& $\mathrm{in}$ maximis $\&$ in minimis eft, quos fabas equinas vix excedentes vidi. 
Strix huic crebræ, ad ambitum quafi multiplicatæ \& implexæ: fed fi rem paulo curiofiùs confideres, nihil etiam ibidem illis ordinatius eft; nimirum fingulæ fpinam trajiciunt, \& ad invicem altera alteræ adplicita, ex altero, circiter medio an paulo minùs, latere finiuntur. Atq; hæc nota characteriftica longè infignis eft: at plurimæ varietates funt in craffitudine, raritate \& denfitate ftriarum; item aliis font quidam Aculei è ftriis lateralibuseminentes; aliis extrmus ambitus latiflimus præ cæteris \& in aciem depreflus eit, \&c.

In his quoq; lapidibus \& articulos foliaceâ quâdam pi¿́turâ confpicuos, \& alios plurimos Hoplitas, h. e. velut nrmaturâ coloris auricalcei ornatos, fc. eatenus pyritæ parricipantes.

In rupibus aluminofis juxta $W$ bitby admodum frequenles funt, \& paffim in litore marino ab oftio fluminis Tees, ad albos ufq; fcopulos à spiton denominatos. Item in vicinia $W$ ansford agri Huntingtonien/s.

Ferè autem medio quodam lapide fphærico, aut paulo depreffiore inclufif funt; cujus latera difrupta, exemto Ammonis cornu, matricis cujufdam fuforiæ duo dimidia reprefentant. Atq; hæ ipfex pilæ non rarò, maximâ fui parte, è pyrita funt.

\section{TIT ULUS VI.}

Ammonis Cornuftrios lateralibus aer fus ambitun furcatic Ex D. Plott 11.Tab. 5.

S lapis medix magnitudinis eft: fubflavefcit: ftriæ laterales ex ejus media parte ferè fingulares procedunt, at pleræg; cædem antequam ad ipfum ambitum pertingant, bifurcantur ; dorfum multum protuberat; tamen id quogs ftriatur.

Juxta. 
De Lapidabas Turbinatis.

Juxta Cleydon oppidulum agri Oxonienfis reperime $1 \cdots \cdots$ tur.

\section{TITULUS VII.}

Ammonis cornu friis lateralibus verfos Jpiname concur. rentibus, \& in Tubercula quedam unitis, aliifg; minus eminentibus dorfum trajicientibus.

Ex D. Plott 13.Tab.5.

- Ujus lapidis ftriæ pleræq; juxta ambitum in quædanæ - Tubercula coëunt: ipfum verò dorfum latiufcılum \& eminens aliis ftriis trajicitur.

Ex his alii molles, alii duri lapides funt.

In argillâ fubcæruleâ juxta Great-Rolworight, ejufdem to:\%. agri, à Templo verfus orientem reperiuntur.

\section{CA P. II.}

De Ammonis Cornubus, utring; ad umbilicum æquè cac vis, levibus.

\section{TITULUS VIII.}

Ammonis cornu, leve, pellucidum, crebris articulis, fl lumini objiciatur, velut undatis diftinctum.

IIC lapis exiguus eft; neq̧; cnim in diametro dimi- Difcippice. diam unciam implet.

Lævis, \& pellucidus eft; ti tamen inter lumen \& oculum ponatur, crebros eju articulos, yelut friis undatis

$$
\mathrm{E} \mathrm{C}_{2} \text { diftinctos, }
$$


difinctos, obfervare facile eft. Figura autem depreffa eft, aliquantóq; magisad ambitum.

Medius vero lapis haud parvo foramine pertunditur; at id fracti lapidis vitium videtur: cúmq; adeò is integer fuit, ibidem mediis aliquot fpiris impletum fuiffe, credibile eft.

Lockss.

Ex hâc fpecie hunc unum in rivulo juxta Bugtborp inveni.

\section{ARTICULUS II.}

De Ammonis cornúbus, ex alterả tantùm parte ad ums bilicum cawis.

\section{TITULUS IX.}

Ammonis cornu lave ex alterâ tantùm parte ad umbilicum cavum, Jpiris ferè teretibus.

An I 2. Tab. 6. D. Plott.?

Defciptio. IC lapis levis eft, nec ullis omnino ftriis donatur. minimos habui lenticulares; aliófq; in diametro ad fefquidigitum patentes vidi.

His verò omnibus orbes fubteretes: ita in circumvolutione ordinantur, ut qui umbilico propiores, paưulùm Cochlearum more extra planum egrediantur.

Quatuor tantùm fpiras numerare potui.

Ipfius autem lapidis color fublividus, qualis eft rupes calcaria plumbifera, è qua exemtus eft.

Lochs.

In quibufdam Lapidicinis inter montes Cravenenfes agri

Eboracenfis 


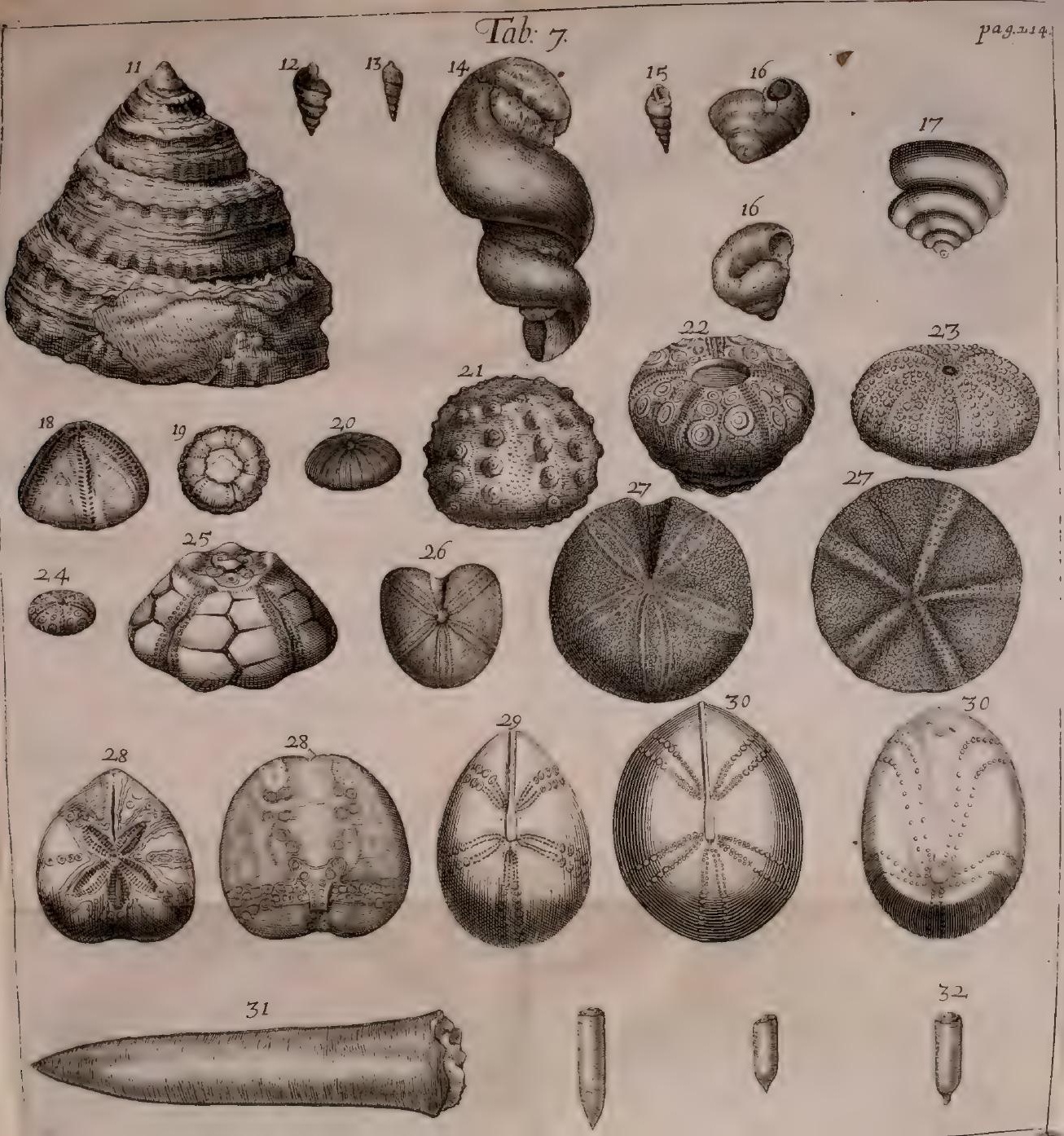





\section{De Lapidibus Turbinatis.}

Eboracenfis inventi funt; privatim in a stone 2uarrie betwixt Afhton-Tarne and Frier-head.

\section{ARTICULUS III。}

De Ammonis cornu, ex utrâq’ parte ad umbilicum $\mathfrak{e}^{\circ}$ què prominulo.

\section{T I T ULUS X.}

Ammonis cornu vix duorum orbium, ferè reticulato quodam opere depictum, unbilico utrinq; leviter pro.. minulo.

I IC lapis perpufillus eft, quantum hacterius obfer- Defripizics 1 vavi, ex is autem aliquot centenos vidi. Lenticulam rarò excedunt; alii in diametro quartam digiti partem implent:

Prima fpira five orbis latiffimus eft, \& planior, quàm in ullo lapide fupradefcripto : verfus caput autem is adeò extenuatur in aciem, ut penè acutus fit, cùm univerfi fuperiores velut præruptis capitibus fint.

Ultra fecundam verò fpiram vix continuatur ejus circumvolutio. Huic apex five umbilicus ex utraq; parte leviter prominulus.

Hic quog; fæe hoplites \& armaturâ velut æneâ nitet: ferè verò albidum colorem habet opere quodam reticula. to eleganter depictum, five ad imaginem quandam Litera. rum Sinenfium, nigris lineis.

In profundis cuniculis, unde Carbones foffiles, juxta Loost. $\operatorname{coln}$ in agro Lancaftrienfi, copiosè inveniuntur.

Eorum autem Matrices funt quidam lapides five duri Nodi: 
Nodi lapidei ferè rotundi; at ut omnium magnitudinum, ita \& penè figurarum. Horum quidem Nodorum figuræe adeò variæ funt, ut omnigenos ferè fructus aliáfq; nefcio quas res \& naturæ \& artis, quales multæ apud Aldrovandum habentur, haud malè repræefentent; ut funt Diorchitæ, Triorchitæ, Bolctitæ, Cucurbitæ, Phialitæ \& id genus infinita alia.

Hi autem Nodi plerunq; copiofiùs inveniuntur, in eo rupis ftrato, quod noftri soap-Scale appellant, idq; ferè proximè fuper ipfos carbones incumbit, unde ipfos Nodos Gandully nominant. Alibi verò in viciniâ Halifax eofdem nodos Tbeaumespottg vocari audio.

In mediis verò hujufmodi pilis horum figuratorum lapidum plurimos unà nidulantes invenies. Jucundum fpeEtaculum!

\section{MEMBRUM II.}

De Lapidibus Turbinatis, quorum Orbes Buccinomum ine modum producuntur.

$\sim$

\section{A R T ICULUS I. \\ De Buccinss lapideis, friatis.}

\section{TITULUS XI.}

Enctinites magnus, veniricofus, of frits of rugis quibufdam inordinatis donatus.

D. Prio. TI IC inter majores numerandus eft; Buccinis quibuf1. dam marinis par \& grodammodo fimilis, at mini- 


\section{De Lapidibus Turbinatis.}

mè idem. $\quad A$ bafi ad mucronem duos digitos $\&$ dimidium implet ; in ipfius verò bafis diametro paulo minor eft, adeóq; linea octuncialis ejus bafin vix circumambit : ipfáq; ejus bafis planior eft, itaq; non malè Trochites appellari poffit.

Eadem bafis ftriis crebris \& minutis, tamen fatis eminentibus diftinguitur; eædémq; ftriæ fecundùm onnes fpiras ad ipfum ufg; mucronem procedunt.

Sex minimùm anfractus, unum altero minutiorem nแผาe. rare licet.

Item in fingulis orbibus præter ftrias funt ctiam quædam rugæ tranfverfæe ipfis ftriis paulo emincntiores, afperiores, inordinatx.

Hunc lapidem in Rivulo juxta Bugthorp inveni.

\section{TITULUS XII.}

Buccinites exigurs, ftriatus, frià media fingulorum op. bium paulo eminentiore.

TI IC lapis in minimis numerandus eft $;$ inter fenos fe difup : rè orbes finitur.

Ejus bafis paulo magis eminet, quàm in proximè fuperiore; atq; huic etiam fimiles ftrix, ex fpirarun ductibus procedentes; media autem ftria in fingulis orbibus maximè fuper creteras eminet. Item è ftriis quadam ex innumeris quafi punctulis eminentibus five exiguis Tuberculis conftare videntur.

Hic paulo productior \& $x$ anguftior eft pro magnitudinis ratione, quàm proximè fuperior ; at totầ longitudine vis dimidiam unciam explet. Ei color fubfufcus eft.

Hunc quoq; in eodem Rivulo juxta Bugthorp inveni. Locuse 
216 6 De Lapidibus Turbinatis.

\section{TITULUS XTH.}

strowbitis eleganter ftriatus dimidinm digitum lono gitudine vix expleass.

Ex D. Platt Fig. 2. Tab.4.

Justa Heddington agri Oxonienfis repertus eft.

\section{ARTICULUS II.}

De Buccinis lapideis, levibus.

$$
\begin{aligned}
& \text { CAP. I. } \\
& \text { De Eaccinitis Levibus, figurâ productiore. }
\end{aligned}
$$

\section{TITULUS XIV.}

Baccinites lavis, albidus, fpiris nusperofis, inter fo haud contiguis.

$$
\text { An I. Tab. 4. D. Plott? }
$$

H U N C lapidem ex toto integrum adhuc non vidi: at illum ad plures digitos produci ex fragmentis credibile eft. Ejus alterum caput craffus linea triuncialis vix circumambit: paulatim in mucronem tenuem acutúmq; ex numerofis fpiris definit.

Ipia autem foiræ laves planioréf́p; funt,aut certè mediis earum partibus leviter rotundatx. Item altera alteræ haud ullatenus fuperinjicitur, neq: inter fe quidem contingunt, 


\section{De Lapidibus Turbinatis.}

ut in univerfis animalium cochleis, quantìm hactenus vid'. Ipfa autem intervalla, quæ fpiris interfunt, materiâ quh dam cryftallinâ ferè replentur.

Huic color albidus, \& matcria calcaria, qualis rupes eft, unde excifa eft.

Ex his aliquot è Lapidicinis, quæe funt juxta Frinder. skelfe \& Newton truncatos habui ; aliófí ipfo itinere quod ad Whitby ducit, 3 circiter milliaribus ultra Pickering oppidum agri Eboracenfis.

\section{TITULUS XV.}

Buccinites lavis, Jublividus, Jpiris octonis arde inter fe conjunctis.

I I I lapis lævis eft, longitudine digitum rarò im- Dgrapiets

- I plet ; frpiùs dimidio minor eft. Eadémq; ferè menfura bafin circumambit, à bafî in tenuem acutúmq; mucronem paulatim minuitur.

In integro lapide circiter 8 fpiras numerare licet; ha verò arctiffimè inter fe conjunguntur; parùm aut niîit eminent, fed extimo ambitu velut planx funt. Ei color fúblividus, \& è materiâ calcariâ eft, quale eft faxum, in quo inventus eft.

Ex his aliquot invenimus in Lapidicinis faxi plumbifer: Lexs. regionis montofx Craven dictæ. 


\section{A P. II.}

De Buccinitis levibus, figurâ compactili, quos privatim Cocblitas vocari malumus.

\section{TITULUS XVI.}

Cocblites levis, ore ad amuJfim rotundo exiguo.

Defcriptio.

Lockss.

I. I I lapis in bafi vix tres partes digiti implet; \& paulo minùs altus eft. Primus ejus Orbis ore rotundo aperitur; certè circulus magis exactè defribi non poteft.

Item in primo orbe extrinfecus unica lacuna, five fulcus leniter impreffus eft; à quo aliquot obfura lineamenta hinc \& illinc obliquè procedunt; aliàs lævis eft.

Non ampliùs quatuor Orbes numerare licet, qui breviorem etiam, altero alteri fuperinjecto, figuram efficiunt.

Prxterea in mediâ bafi eft quoddam foramen five finus, in quem fpecillum fatis profundè demitti poteft; atq; id more quarundam Cochlearum ex animalibus.

Huic color albidus, c̀ faxo calcario albido in Lapidicinis juxta Whitwell agri Eboracenfis exemtus eft.

\section{TITULUS XVII:}

Cocbleomorphites fex fpirarum.
Ex D. Plott Fig. II.Tab. 6.

Tlixta Tegnon \& Sbollozer bill agri Oxonienfis in. $\int$ ventus. 


\section{SECTIO II:}

De lapidibus Turbinatis, belicem non habentibus.

\section{ARTICULUSI.}

De Lapidibus fine ullà volutà Turbinatis, friatis, fubrotundis, plerifg; Echinite dicti.

\section{A P. I.}

De Echinitis friis in omnes lapidis partes aqualite: procedentibus.

\section{TIT ULUS XVIII.}

Echinites filiceus, vertice faftigiato.

I3. Tab. 2. D. Plott.

17 Ujus generis lapides plurimos habeo $;$ at magnitudi- Dejom

1 ne difcrepant; ex iis illum, quem depingi feci, defcribam: à vertice ad bafin fefquidigitum altus eft; ad eandémq; ferè meniuram ejus diameter patet.

A vertice ad bafin quinæ ftriæ duplicatæ procedunt, in mediâ bafi rurfus coëuntes, lapidémq; in totidem æquales partes fecant.

Ipfæ autem ftriæ è multis exiguis lineolis tranfverfis confant; atq; hæe lincole in aliis multo crebriores, in aliis longiores, in aliis ex binis rotundioribus foraminibus? in aliis ex iifdem fimplicibus funt.

$$
\mathrm{F} f 2
$$


Infa verò bafis plana, nifi in ejus medio, ubi leviter cavus rotundúfq; finus eft : horum itidem lapidum vertices variant, at in plerifq; magis faftigiati funt.

Ejus materia è filice propriè fic dicto eft.

Alii extrinfecis læves \& perpoliti ; alii fabri \& inæguales funt.

Color varius, interdum albidus, fubfúfus, pellucidus, Iffi è medio nigro filice ex his aliquot exemimus.

200\%s,

Hi lapides in partibus Anglix Auftralibus, ubi nigri Trlices abundant, copiosè habentur.

\section{TIT ULUS XIX.}

Ecininites orionlatus, deprefus, folicous ; quibufdam Umbria. Cejn. de figuris Lapiai.p. 61. Aldrow. Muf. Mett.p.6I'.

Defriptio. IC lapis exiguus eft, vixs tres digiti partes latitudi1 ne; craflitie verò non ultra quartam partem implet.

Ex utraqj parte, etiam ubi in proxime fuperiore vertex eminet, \& plantis \& x 2 quali ferè cavitate donatus.

Quinæ duplicatæ ftriæ ejus latera ex æquis intervallis diftinguunt; $\epsilon \mathfrak{X}$ autem ex exiguis Tuberculis conftant.

Item hic lapis ex vero flice eft.

20ons. Ex his aliquot in agro Norfolcienfi collectos habemus.

\section{T. IT ULUS XX.}

Fabinites parvulus ftriis capillaceis undiq; infegnitus. Ex D. Plott Fig. 9. Tab.8.

Juxta Teynton agri Oxonienfis inventus eft. 


\section{De Lapidubus Turbinatis.}

\section{TITULUS XXI.}

Echinites vericice planiose, firiis è 'Tuberibus quibufdans grandioribus conflatis clonatus; $e x$ ovis anguinis quorundam.

1. IC lapis Ovi dimidi gallnacei magnitudinen im. $D$, whti: plet; digitum altus, fefquidigitum in diametro ad bafin colligit. Ipfa bafis plana, vertice paulo anguftiore; at eodem deprefliore \& minùs faftigiato.

A Vertice quinæ duplicatæ ftriæ æqualiter procedunt, \& mediâ bafi concurrunt. Hæ autem ftriæ è Tuberculis majufculis multúmq; cminentibus conftant, eadémq; certis nec brevibus intcivallis à fe invicem diftant; præter quæ funt etiam frequentes quædam verruculæ undiq; difperfa.

Ipfe lapis albus ex faxo calcis eft.

Hunc lapidem è Lapidicinâ juxta Hinderskelfe habui. Lovis.

\section{TITULUS XXII。}

Echinites albido-cinereus extrà, exparte internâ fili. ceus, nigricans.

$$
\text { Ex D. Plott.Fig. 4. Tab. 5. }
$$

If X toto tenuifimis laminis micantibus, ex adverfo la. H. pidis difpofitis, contegitur: ex quibus etiam Tuber. cula \& finus conftant.

Juxta stonor-hon e agri Oxonicnils inventus eft. 


\section{TITULUS XXIII.}

Echinites Ovarius.

Ex D. Plott Fig. 5. Tab. 5.

Juxta Teynton agri Oxonienfis inventus eft.

\section{TITULUS XXIV.}

Echinites ovarius parvus. Ex D. Plott Fig. 6. Tab. 5.

Proximè fuperiore differt, quòd huic exiguo æquè A magna Tubercula, at multo pauciora. Ibidem ubi proximè fuperior repertus eft.

\section{TITULUS XXV.}

Ecbinites velut laminis quinangularibus diftinctus. Ex D. Plott Fig. 3.Tab.5. An echinus lapis Aldrovandi de Teftaceís lib.3. cap. 40?

I U I C durities velut filicea: color fubflavus : primùm quinis modicè rectis lineis divifus ex utraq; parte duplici punctorum ferie exornatis, ab umbilico protuberante in lapidis bafi afcendentibus ad alterum fimilem in ejus vertice; fed rofe in modum foliaceo. Deinde rurfus alis quinis ferratis lineis fubdivifus, antequam ad umbilicum pertingant, finitis: quo fit, ut univerfa fpatia lipeis interjectil quinguangula fint; ad fimilitudinem fquamarum cujufdam Teftudinis.

i. in: $i 5$.

Juxta Stonor-boufe agri Oxonienfis inventus cit. 


\section{CA P. II.}

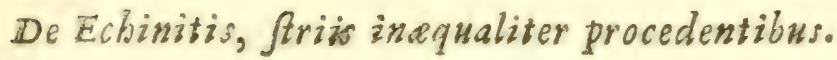

\section{TITULUS XXVI.}

Ecloinites è lapicie Selenite, quinis radio $\dot{e} d u p l i c i$ ferie tranfuerfarum lineolarum conflatis.

$$
\text { An 12. Tab.2. D. Plott? }
$$

1. I I mediocris lapis eft; ex alterâ parte panlulùm nuncurtion gibbus; ex alter Deinde hand æqualiter rotundatur; fed ex alterâ ambitis parte paulo anguntior $\mathrm{eft}$, ex adversâ parte finu quodam velut inter binas nates diducitur. Ifti verò finus modioli \& umbilici à quibufdam appellantur.

Item huic quinæ velut fafcix, inæqualiter procedentes, è cuplici ferie lineolarum tranfver farum conflatx. Et ut circa medium verticem incipiunt, ita ad mediam bafin rurfus concurrunt; fc. utrobiq; finu quodam cavo excipiuntur.

Ipfe autcm lapis quafi Selenites eft; adeo ex vario fitu radios inftar Lunæ micantes fpargit : at eum è laminis adversìm pofitis, extrinfecus certe, conftare videtur; an verò alia quædam materia his fubfit, aut eædem laminæe ex toto lapidem conficiant, periculium facere nolui, quod hic mihi folus lapis hujus generis fit.

In faxo albido calcario inventus eft in quâdam Lapidicinâ juxta Newton-Grange agri Ebcracenfis: illúmqg ab amiciffino viro $\mathrm{D}^{\text {to }}$ Cumber acceptim furo. 


\section{TITULUS XXVII.}

Echinites prater quinas frias, annwits cxiguis innume. ris infignitus.

$$
\text { Ex D. Plott Fig. 9, 10. Tab. } 2 .
$$

I. I I C lapis materiâ quâdam c̀ laminis conflatâ contegi1 - tur ; ipłæ a. laminæ obliquè pofitæ funt.

Figura depreffior eft : fubflavus. Ejus radii ex duplici ferie tranfrerfarum lineolarum conftant: ex omni parte exiguis annulis elegantiffimè delineatis exornatur.

Louss. Hi lapides juxta Tangley, Fulbrook, \& Burford agri Oxonienfis oppidula quèm copiofifimè reperti funt.

\section{TITULUS XXVIII.}

Esinites proter radios es annulis duplicat is infignitus. Ex D. Plott II. Tab.2. item 9. Tab.7.

H Nigro filice; radii aıtem è duplici punctorum ferie, 1 quibus fingulis fingulx tranfverfx lineolæ funt; item huic alia puncta in mediis annulis duplicatis; quorum mediis fpatiis fimplex, à finitis verò radiis duplex ordo procedit.

Puncta vero ita in mediis annulis pofita, leviter tantìm excavantur, at radii, ut ad medium lapidem extenduntur, ita profundè infidunt.

Juxta Afuton Rowant agri Oxonienfis inventus eft. 


\section{TITULUS XXIX.}

Echinites, radiorum punctis verfus margine annulis ovalibus inclufis.

Ex D. Plott Fig. 14. Tab.2。

H Ü C lapidi Modiolus non intra radios, velut in fuperioribus conclufus eft, fed ad marginem ufq; extenfus eminet; à quo centro velut duplices radii procedunt, è duplicatâ punctorum ferie conftantes, quæ verfus marginem expanfa annulis fimplicibus includuntur. Ipfi autem annuli, finguli bina puncta circumambiunt, figurâ ovali funt.

Extrinfecùs cinereus; at intùs è nigro filice conftat.

Inter Exolm \& Brightwell agri Oxonienfis inventus eft.

\section{T IT ULUS XXX.}

Echinites pundtis prominentibus. Ex D. Plott Fig. I, 2. Tab.3.

1. I C lapis extrinfecùs cinereus; intùs è filice nigro. 1- Huic umbilicus fuperiori fimilis eft; radii autem $a b$ co defcendentes ex toto differunt; horum autem univerfa puncta prominent, cùm illorum cava fint : \& cùm illi in duplicatis virgulis punctífq; procefferint, qux prope marginem in ovalibus annulis inclufa funt; horum duplicia puncta protuberantia, medio ad marginem itinere, in fimplicia verfa funt, quamvis multo ampliora. Deinde cùm jam radii fimplicibus punctis procedentes \& in umbilico, ex altera parte non međiâ bafi pofito, concurrentes G $g$ 
\& diverfimodè bafin trajicientes, radiorum virgulis aliis brevioribus aliis longioribus, iridis florem quodammodo repræentant.

Hijus verì lapidis partes protuberantes univerfa cavæ funt, lit ex carum fricturâa apparet: unde fufpicari fas ent, aliortm lapidum puncta profundiora olim elata fuifie, perinde ut in hoc; at temporum injuriâ præfracta \& detrita fuiffe.

Juxta Pyrion agri Oxonienfis inventus eft.

\section{ARTICULUS II.}

De Eapidibus fine ullà volutâ Turbinatis, lavibus, in longum acumeen fuftigiatis; plerifg; Belemnitæ didti.

\section{TITULUS XXXI.}

Belemnites niger, maximus, bafe forat $a$.

Defrititio.

T. IC pragrandis lapis eft; at quamvis ex iis fere innumcros vidi, tamen paucos maximos integros. Unins fragmentum apud me fervo quatuor digitos longum, \& quod triunciall's linea vis circumambit.

Omnium, ccrtè integrorum bafis aliquouff; forata cit ; reliquus verò lapis verfus mucronem ex toto folidus eft.

Partem vero cavam modo hæe, modo illa matcria opplet: at quòd fit etiam naturaliter in aliquibus materia quædam, tanguam propria lapidis medulla, ex ejus concrematione didici. Etenim Sclenitæ inftar in albiffimam valentifimámq; calcem, medullâ exceptâ, uftulatur; quæ tamen, etiam poftquam ignem experta eft, nigricat; efiq; ex annulis quibufdam, Entrochorum more difpolitis, conitat. 


\section{De Lapidabus Turbinatis.}

In ipfo verò lapide materia ftriis ad medullam tendentibus diftinguitur. olet.

Perfricatus cornu combuftum aut quoddam bitumen.

Hi ctiam interdum armaturâ ænei coloris micant ; \& tùm catenus pyritæe naturam induunt.

Huic color niger; interdùm pellucidus.

In tota illa agri Eboracenfis regione montofâ, qui Locise. Blackmore appellatur,præcipuc̀ abundant: item in Riṿulo juxta Bugtborp \& alibi reperti funt.

N. B. Diu dubitavi, illáne folida horum lapidam fragmenta, quæ apud me funt, \& de quibus apud plerofq; hujufmodi Hiftoriæ authores lego, alteram fpeciem conftituant: ipfi necum diligentiùs videant; cgo admodum incertus fum, quo ea à fuperioribus diftinguam.

\section{TITULUS XXXII.}

Belemnites minimus, ferè cujufdam fuccini inftar \&. pellucidus ei coloratus; quibufdam Lapis Lyncurius dictus.

1. I C lapis rarò duos digitos longitudine cxplet; craf- Defriptitu fitic pennam anferinam haud fuperat.

Huic color fuccini æmulus; pellucidus.

Bafis in hoc quoq; interdum leviter forata, fepiùs folida cft : ferè in acumen longum, velut ille alter maximus, faftigiatur: tamen variè ctiam ex fuâ naturâ definit; $\mathrm{fl}_{\mathrm{i}}$ quidem illud acumen modò tenue, modò ventricofius, modò obtufius eft.

Præterea eft ferc̀ quædam fiffura uma aut plures tam in hoc, quàm in illo fuperiore lapide ; eft tamen ubi in utroq; defiderantur. 
In hoc quoq; quædam inordinatæ ftriæ ad centrum procedunt.

avi.:. Hunc lapidem plurimis in locis apud nos quàm copiofifímè inveni : at perpetuò in terrầ rubrâ ferreâ, five ea mollior gleba, five faxea fit.

In all the cliffs, as you afcend the Yorkhire and Lincolnhire Wooldes for above 100 miles in compafs; as at Spiton, Lawnsborough, Caftour, Tedford, Cawkwell.

N. Ad calculum, morbum regium, ventris tormina prodeffe dicitur. 


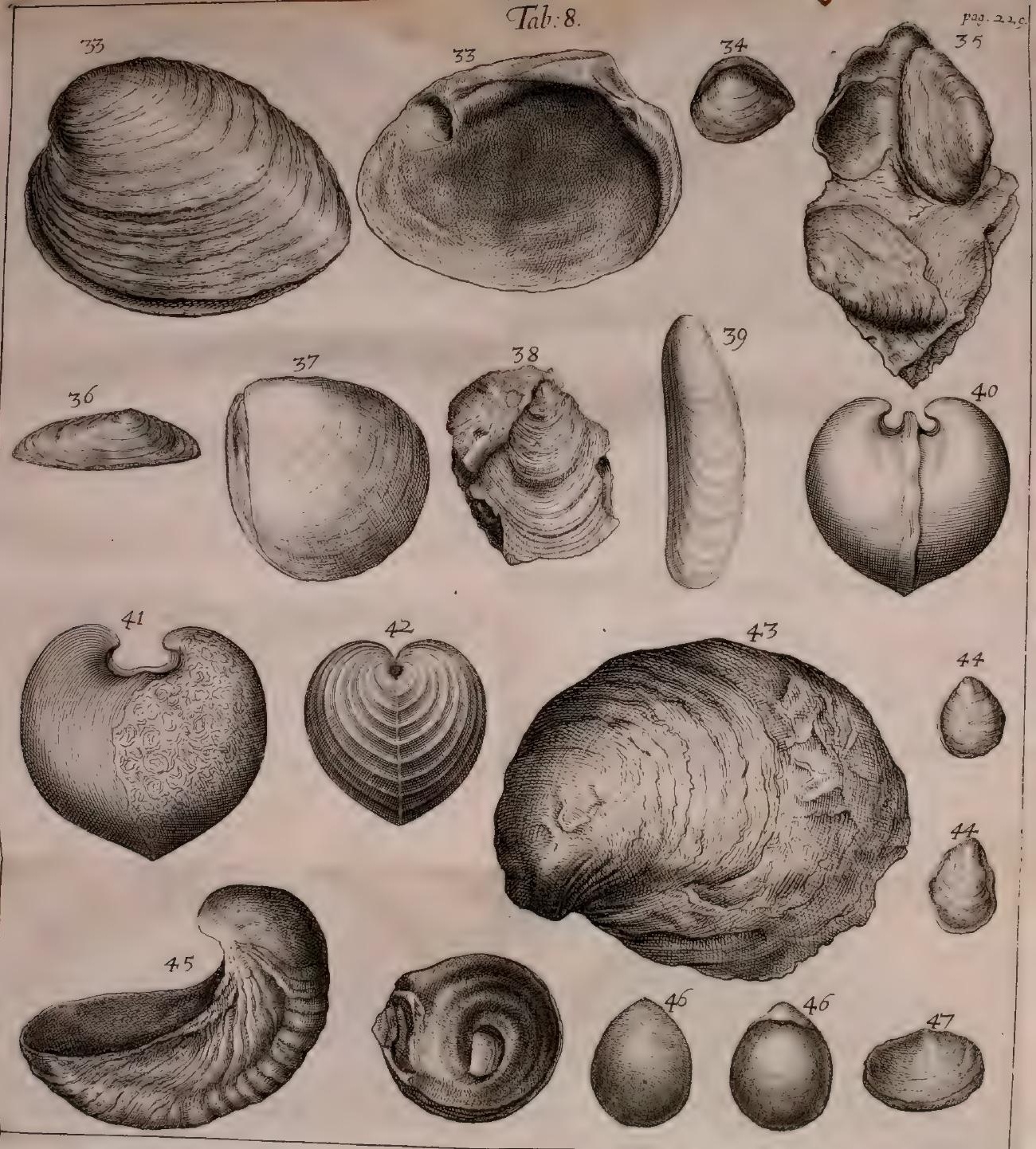





\section{COCHLITARUM ANGLIA P A R S II.}

De Lapidibws Bivalvibws.

ME MBRUM I.

De Lapidibus bivalvibus, levibus.

ARTICULUS I.

De Lapidibus bivaluibus, levibus, "riâg; zalvâ equć cavâ.

\section{CA P. I.}

De Consbitis, figura ex altera cardinis parte diffufrores

\section{TI T ULUS XXXIII.}

Conchites major, rugofus, ad figuram triquetram acce= dens.

$\mathrm{H}$

I C lapis ad maximos accedit; fcilicet à latere ad la- Difriztrion...

tus tres circitèr digitos, à cardine ad imam oram duos tantùm patet.

Ipfe cardo ad alteram partem rotundam magis inclinatur; altera verò \& adverfa pars in acutiorem angulum longilìs procedit; adeò ut ad figuram velut triquetram acsedit.

Sub ipfo cardine ad rotundum anguhum cft quidam finus, in plerilq; altiùs foratus, cui fimilem in ullis anima lium Conchis non animadyerti. 
Utraq; valva fimilis \& æqualis cit; minùs in dorfumelata gibbáve; extrinfecus grandibus rugis tranfverfis \& inordinatis diftincta.

Valvæ admodum craffæ \& validæ funt ; è materiâ quâdam fplendente, Selenite inftar, conftant, ídq; in noviffime fractis luculenter obfervare licet. Huic lapidi color albidus, \& interdum fublividus eft.

Ex his multos bifores \& integros invenio; at ex is etiam funt, quos disjunctos \& naturaliter figillatim concretos reperies.

Quemadmodum veró externâ facie, ita \& internâ \& concavâ fui parte fatis benè animalium Conchas referunt; adeò ut fummum naturex artificium nunquam fatis admirari foffumus; feilicet quàm nihil ibidem defideretur, quod ufpiam in viventium Teftis obfervamus: nimirùm exdem hic ad cardinem apophyfes, etian vinculorum five Mufculorum veftigia infignia, ut illìc, funt.

rocuss. Ex his multos è ripis rivuli juxta Bugthorp effodimus; alióf; in arena maritimâ juxta scarborougb invenimus.

\section{TITULUS XXXIV.}

Concbites fublividus, ex alterâ parie velut mucronatus, ex alterà fubrotundus, è rupibus aluminofis.

Difcriptio. T. II IC lapis rarò nuccm majufculam ex avellanâ cxcedit; quanıvis id genus decuplo majores vidi. At hic, quem è multis centenis maximum elegi, à latere ad latus digitum tantùm implet; à cardine vero ad imum marginem digiti quartâ parte minor eft.

Extrinfecus admodum gibbus, \& ventricofus ent.

Ex aiterâ parte fubrotundus, in quam cardo pofitus eft; ex alterầ adversầ in acutum mucronem producitur; $a b$ eâ 


\section{De Lapidiuns Bivaloibus.}

quoq; parte finus eft, in quo medio quafi quædam acies eminet : quâ folâ notâ, ab omnibus Animalium Conchis, quantum notavi, difcernendus $\in \mathbb{f}$.

Huic color fublividus eft, perinde ut tọta rupes unde exemptus eft.

Ex toto lævis eft: materia, quâ conftat, Sclenitæ inftar micat ; admodum craffa eft.

Hos bifores integrófq; femper inveni.

Horum lapidum ingens copia in rupe aluminof Whitby, reperitur.

\section{TITULUS XXXV.}

Conchites leviter rugofus, deprefsior, figurâa quodammo. do Mufculorum è fuviatilibws, è Ferri fodinis.

I I IC lapis inter mediocres numerandus eft: fefqui- Dfrriptico digitum latus; à cardine verò ad imum marginem vix digitum attingit.

Ipfe cardo ad alteram partem, qux ctiam rotundatur, magis fpectat; ex adverfa verò parte in acutiorem angulum procurrit; depreffior eft: atg; hæc omnia ad modum quorundam Vufculorum Fluviatilium.

Leviter rugofus eft: huic color interdum fubniger; ferè cinereus: pars cruftacea, animalium teftis refpondens modicè crafla eft ; ac noviffimè fracta, Sclenitze inftar refplender.

Innumeros unà concretos vidimus in quodam lapide Lc:ass. nigro, ad carbonum foffilitum naturan accedente; iifdemq; fodinis non longè à celebri oppido Halli fax effollo.

Item in finilibus fodinis prope Leedes ejufdem agri.

Idem Conchites in Ferri fodinis juxta Adderton, \& in vicinia Bently: ubi ingentia faxa ex hoc sonchita cum ferri: 
ferri metallo commifta habentur; adeóq; iidem conchitex, quatenus cavi funt, ferri glebam in fe continent.

Hæc autem faxa noftri homines in laminas fecant, \& in pulcherrimum marmor levigant: ex his Menfas in Villa Whitley $\circ$ hall dictâ admodum venuftas vidimus.

\section{A P. II.}

De Conchitis ex utraq; parte aqualiter diffufes; at ab ipfo cardine ad oram anguftioribus.

\section{T ITULUS XXXVI.}

Conchites albidus, oblongus di anguftus.

Discriptio. II $1 \mathrm{C}$ lapis duos circiter digitos longus eft; at admo1 dum anguftus, inftar filiquæ fabæ equinæ. Utraq; valva fimilis \& modicè elata eft in dorfum; item utraq; pars in acutiorem angulum fimiliter procedit.

Ipfe verò cardo longior \& planior eft; ex adverfo oræ fúbitò extenuantur.

Materia, è qua conftat, cuidam micanti fluori fimilis eft; lapidémq; in fe calcarium albidum complexus eft. Pholades apud Aldrovandum depictos multùm refert.

Hos in Lapidicina juxta Nemton in vicinia Hemfley agri F.boracenfis, ferè in fummis faxi ftratis invenimus. 


\title{
De Lapidibus Bivaloibus.
}

\author{
C. A P. III.
}

De conchisis à cardine ad imum narginene demilfs. oribus.

\section{TIT ULUS XXXVII.}

Concbites maximus, margine lato, eir ad alteram ejus partem finu amplo donatus.

II IC lapis inter maximos numerari debet. In dia- Difcriptico metro duos digitos \& dimidium implet; at ex his duplo minimùm majores \& ingentes lapides vidimus; at truncatos.

Ejus margo five ima ora latiffima rotundatur, ipfius cardinis umbonés exigui, utrinq; æquales, \& modicè roftrati : ad alteram cardinis partem amplus finus, ex introrfum depreffis teftis eft; ex adversâ verò parte potiùs leviter eminet.

Modicè gibbus eft : huic color cinereus, albidus; lxvis eft; fi ftriæ quidem fint, vifum ferè effugiunt.

Quod in hoc lapide Teftæ refpondet, admodum tenue \& tenerrimum e:t. Interdum argillam induratam, interdum faxum calcis, interdum metallum ferri in $\mathbb{f e}$ continent.

Ex his aliquot bifores, alios verò plurimos univalve: five fingulares invenimus.

Hos lapides in rivulo juxta Bugliorpo item in Lapidi- Louss. cinâ juxta Lavnsborough, maximos verò juxta Bruffe agri Eboracenfis oppidula \& alibi in ferri fodinis invenimus.

Item alicubi eft in vicinia Crake, ubi iidem marmor clegans quoddam cinereum conftituunt. 


\section{TIT ULUS XXXVIII.}

Concbites rugofus, ad figuram quodammodo Mufuli marini $;$ è flice proprie fic dicto.

Defriptio. I IC lapis admodum imperfectus eft: tamen, quòd illum fic tantùm frè invenimuıs, utiq; defcribendas effe videtur.

Inter majores ponendus eft. In diametro paulo ampliùs duos digitos colligit. Ejus margo rotundari videtur : ad cardinem verò paulatim anguftior eft \& quodammodo roftratus ad modum Mufculi marini.

Admodum rugofus eft ; eíq; color ferrugineus aut fubflavus, qualis extimus ferè lapis eft.

Biforem illum, imò ne alteram quidem è valvis ex toto perfectam, nufquam inveni.

Illud maximè notandum eft in hoc lapide, nihil effe, quod $\mathrm{T}$ eftx fimile fit, preter ipram figuram; cum ex toto folidus is fit, \&x filiceus, \& fine omni cruftâ ; adeóğ pura puta figura eft, à vi lapidis infita effigiata.

Loisis

Plurimas velut pilas, aut lapides quàm proximè fphæricos juxta Bugthorp, \& alibi in vicinis agris collegi : hi verò meri filices albidi funt.

Ac in his mediis de induftria fractis jam defcriptorum Conchitarum figuras fxpins obfervavimus. 


\section{De Lapidibus Bivaluibus.}

\section{TITULUS XXXIX.}

Concbites Mytuloides.

Ex D. Plott Fig. 1. Tab.5.an 2. ejufdeme Tabulde?

TI lapides cavi non funt; fed terrẫ quadam lapidosâ I flavefcente referti : extrinfecus armaturâ quâdam albầ refplendente contecti ; longífq; lineamentis ex lapidis figura donati.

In effodiendo puteo juxta Cleydon agri Oxonienfis inventi funt.

\section{CA P. IV.}

De Conchitis infigniter Ventricofes; quibufdam Bucarditæ dicti.

\section{TIT UL US XI. \\ Bucardites ex abbido flave fcens, levis. Ex D. Plott Fig. 2. Tab.7.}

N lapidicinis juxta Heddington agri Oxonienfis copiosè repertí.

\section{TTTULUS XLI.}

Bucardites coftis donatus. Ex D. Plott Fig. 3. Tab.7.

F. X his aliquor habuit Author, 2. libras pendentes, deD. cémq digitos in ambitu. 
Juxta Brife Norton \& Witney, \& North-Leigh agri. Oxonienfis inventi.

\section{TITULUS XLIT. \\ Bucardites reticulatus. \\ Ex D. Ploti Fig. 4. Tab. 7 .}

\section{ARTICULUS II.}

De Conchitis levibus, anomits, i. e. valvis magnitus. dine es figurâ, aut utroq; modo incqualibus, di]familibrifq;

\section{CA.P. I.}

De Lapidibus oftreorum in modum figuratis.

Defcipiptio.

\section{TITULUS XLIII.}

oftracites maximus, rugofus or apper.

$$
\text { 19. Tab. 4. D. Plott. }
$$




\section{De Lapidibus Bivalvibus.}

Haud primâ facie Oftreo vulgari adeò diffimilis, quin minùs diligentes, harúmq; rerum imperitos decipere poffit.

Figurâ fubrotundâ eft, quaquaverfus menfuratus în diametro ad tres, aliquando ad 5. digitos patet: fefquidigitum craftus; de aliquibus, quos apud me fervo, loquor; nam ex his etiam minutulos vidi.

Ex his alii valdè cavi funt; adeóq; in dorfum gibbi; aili \& omnium longè maximi parùm cavi. Intus verò læves; in quâ parte etiam quædam non obfcura velut vinculorum vertigia.

Extrinfecùs autem admodum rugofi, pleriq; \& afperi: modò fublividi : modò albidi.

Neq; illud tacendum duxi, ibidem velut quoddan vermiculatum opus aliquando adhærere; perinde ut in Teftis. quibufdam marinis obfervamus.

Materia, quæ Teftis reffondet, verè ex naturâ Selenitæ eft.

Bifores integros adhuc non vidimus; ut de alterâ è teftis, an fit inæqualis, nihil certum ftatuere poffumus; tamen quia Oftrea quàm proximè referant, illos fe Oftreorum more habere, fi quando ufpiam integri reperiantur, nihil dubito.

Item his umbo ad cardinem leviter roftratus eft, qui tamen in oftreis paulùm aliter eft.

Hi lapides juxta oppidum celebre Huntington copiosè t.os:as. reperiuntur; qui ferè fublividi funt, \& cavi.

Item in Lapidicinâ juxta Hinder skelfe agri Eboracenfis, ex iis, magnitudine \& pondere \& craffitie præ cæteris infignesipfe exemi : at hi albidi \& parùm cavi fuerunt; \& qui ad oftrea vulgaria multo magis accederent. 


\section{TITULUS XLIV.}

Ofracites minor, cardine anguftiore, es ad imus paulo miniuslatus, quàm ip âparte medià; mufculi marini inftar.

Defraiptio. T.1 IG quog; lapis anomius eft, sx uncialis, pro magniII tudine validus, modicè in dorfum elatus.

Ipfe cardo anguftior $\mathrm{eft}$, à quo paulatim latefcit; at ipfo ambicu rurfus paulo ftrictior eft, ad modum mufculi marini.

Leviter rugofus \& albidus eft.

Utraq; valva paultilum gibba eft.

Losus. Biforem illum femper inveni, $\mathrm{fc}_{\mathrm{c}}$ in rivulo juxta Bug. thorp agri Eboracenfis.

\section{CA P. II.}

De Conchitis levibus, valuis difparibus, roftratis.

\section{TITULUS XLV.}

Conchites anomius rugofus, roftro fubteretio infigniter adunco donatus.

$$
\text { 18. Tab. 4. D. Plott. }
$$

Defriptio. II IC lapis maximis annumerandus eft; utpote qui I- tres digitos minimùm longus ent, validus, admodum craffus.

Huic figura fubteres \& anguftior eft ; à roftro paulatim latefit, ambitu rotundo finitur.

Rugofus; 


\section{De Lapidibus Biva!vibus.}

Rugofus; eft etiam quædam fingularis lacuna five fulcus, ad alteram tantùm partem leviter impreffus, à cardine ad imam oram procedens.

E valvis altera infigni roftro adunco donatur; altera planior, \& figurâ \& magnitudine ita diffimili, ut potiùs alteræ operculum quoddam effe videatur, pernde ut in quiburdam Turbinibus marinis obfervamus; illud tamen obftat, ut cum ea opercula ipfis animalibus non conchis jungantur, hae noftra alteræ per ginglymon connexa fit.

Huic color ferè albidus, interdum fublividus; materia ex fluorum natura.

In utraq; valva mufculi quædam veftigia \& lata \& $x$ ad. modùm profundè infculpta, adeóq maximè confpictia funt.

Ex his fortè paucos bifores \& integros inveni, quos apud me fervo; at multo fxpiùs fingulares occurrunt. Imò Opercula (ita ea nobis diftinctionis causâ, appellare liceat) in aliquibus locis fola reperiuntur, ut in Lapidicina juxta Yinderskelfe \& alibi in vicinia: ubi ex his phrima, at fine wllo conchite adunco, quantun obfervare licuit. Itaq; cave fis opercula alteram lapidis fpeciem facias; aut ullos Conchitas fingulares reputes, quòd intcgri \& bifores nondum tibi occurrerunt. Mihi quidem illud crodibile eft, Cuchlitas, ut aliquando, temporis \& loci injuris, mutilari poffint, ita colden modo integros, modò ex dimidiâ, aut minore fui parte etiam naturaliter concretos effe. At quomodocunq; $a b$ intcgritate deficiant, fulim tamen perpetuò characterem, fi benè intelligatur \& attendatur, exprimunt.

Hi lapides plurimis in locis agri Eboracenfis longè om- $L, \ldots$. nium copiofifimè habentur. Ut in rivulo juxta B ugtborp \& in vicinia in Lapidicinis juxta Lawnsborough \& c. Item juxta Burton Stather agri Lincolnienfis \& in vicinia ejus oppiduli, \&c. 


\section{TITULUS XLVI.}

Conchites anomius, roftroprominulo, \& veluti pertufo donatus.

Dipartara, Conche anomia, $i$. Vertice roftrato Fab. Columne. * p. 22 . Fig. 8. Tab. 4. D. Plott.

Defripitio.

IIC lapis è minoribus eft, à vertice ad imum marginem 1 circiter digitum explet; at latitudine ex tertiâ parte minor cft. A vertice paulatim latefeit; inus ambitus rotundatur. Plerique comprefirores funt; at ex his aliquot ventricofiores vidimus. Utraq; valva in dorfum modicè clata eft ; ca verò media, quæ vertice roftrato donatur, propius roftrum, in quoddam faftigium leniter eminet. E valvis altera vertice prominulo donatur, roftríve alicujus adunci in modum; is verò veluti pertufus \& fubteres eft.

Ferè a, in hoc lapide, ea pars, quæ teftam refert, adnodum tenuis \& albida eft, fluorif́; cujufdam micantis xmula. At in iis funt, qui $\mathrm{ex}$ toto folidi \& pellucidifunt, id genus filicum inftar, quos noftri foldeg appellant.

Alii vcre, qui cavi fint, interdun ferri glebam, interdum cryitallos quofdam continent.

Ex his nullum nifi biforem adhuc inveri.

Horum lanidum ingentem copiam in quâdam folfầ fabulosâ juxta Gunnerby, uno circiter nilliario ab oppido celebri Grantiane invenimus.

Nini? ufpiam inter marinas Conchas fuic fimile inventum eft. Ita Fibrus Columna è Nobilum Italorum furpe; Mirum quidem, inquit ille, huje:fmodi Teftus recentes \& vivas hodic non reperiri; quamobrem è longa maris alluvione profectals \&e advectas cenfenis potius, quàm natuzon defirle fimiles parere. 


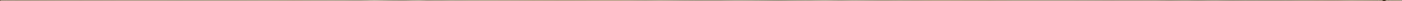





\section{De Lapidibus Bivalvibus.}

\section{TITULUS XLVII.}

conchites anomius tensis of compreffior, latiufculo of rotundo ambitu.

H I C lapis inter minores ponendus eft; circiter digi- Defrriptio.

- I tum latus, à cardine verò ad imum ambitum paulo minor eft. Ipfe cardo in medio lapide ponitur, ut neutram partem magis fpectet; latera latiufcula, utrinq; $x$ què rotundantur.

Huic præterea figura tenuis \& compreffa eft.

In anomiis roftratis numerari debet; quòd in alterâ valvâ huic vertex leviter propendens; \& cui fubmiffior vertex eft, ejus media pars paulo minùs in dorfum elata eft.

Lævis eft \& colore fublivido.

Hos Lapides in faxo plumbifero regionis montofre $\mathrm{Cra}^{\circ}$ rochs: verz dictex, juxta Stock \& Branghton inveni. 


\section{MEMBRUM II. \\ De Lapidibus bivalvibus, friatis.}

\section{CAP. I.}

De Lapidibus bivalvibus, firiatis, awritis, quibufdans Pectinitæ didi.

\section{TITULUS XLVII:}

Bifription IC lapis, quem defcribo, exiguus eft, vix Uncialis;

Pectinites rarioribus:friis. An 10. 1 2.13. Tab. 4. D. Plott?

1. It ex his aliquot vidi, qui duos digitos à vertice ad imum ambitum implerent.

Huic auriculæ ftriatæ; at in hoc ftrix \& raræ \& eminentes; item illas aliæ lineolæ exiguæ \& capillares trajiciunt.

Pectinum more paulatim à cardine latefcit \& imo ambitu rotundatur; admodum leviter gibbus eft.

Hunc lapidem nufquam biforem adhuc inveni; at $\mathfrak{x}$ piùs defectivum, vel auriculis, vel majore etiam fui parte; quíq; fic quidem confideranti facilè agnofcendus effet.

Huic valdè tenuis materia cruftacea; at ex natura Selenitæ cujufdam.

Huic color fublividus, fxpì̀s ferrugineus, \& albidus.

Zocis.

In Lapidicinis faxi albidi calcarii, quæ juxta Hinder. skelfe \& Thornton in vicinia Pickering agri Eboracenfis, copiosè habentur. 


\section{TITULUS XLIX.}

Pectinites membranaceus, densè friatus, è pyrite in lan pide nigrofifsili.

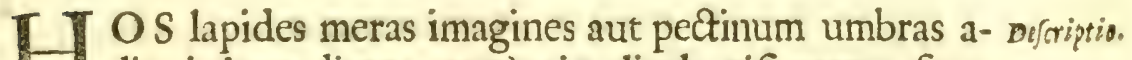

1. liquis jure dicat; certè vix aliud, nifi eorum figuræ in Pyrite membranaceo funt.

Ipre autem lapis, in quo delineati funt, niger \& fiffilis eft; fcilicet è multis tenuifímis laminis, altera alteræ fuperinjecta, fingulæq; ad craffitudinem pergameni, conftant. In fingulis autem laminis horum Pectinitarum plures Figuræ eleganter admodum effigiantur; aliæ minutæ; aliæ majufculx; alix integræ; aliæ ex parte tantùm; at univerfx fibi fimiles funt.

Ex his majores in diametro duos digitos implent; in quibus ftriæ admodum crebræ \& minutæ; etiam eædem in auriculis fimiliter. $\mathrm{H} x$ autem minimè eninent, ut nec ipfí Pectinitæ ullâ ex parte; ita prorfus Tabulam pictanı aut figuram chartæ impreffam repræfentant.

Multi velut ex auro refplendent; adeổ ut in iis certè, fi qux materia fubfit, ea ex pyrite eft.

Ex fodinis carbonum Foffilium juxta Hallifax.

\section{TITULUS L.}

Pectinites minor, friis capillaribus donatus; $\dot{e} \int a x 0$ calcario plumbifero.

- IC omnium longè elegans lapis eft propter ftrias ca- Defriptico

I pillares. In minoribus numerandus eft; fc. dimi-

$$
\text { I i } 2
$$


dium digitum à vertice ad imum ambitum implet; à lascre vero ad latus paulo amplior eft.

In dorfum modicè elatus : in quo medio in quibufdam quædam Lacuna à vertice ad imum ambitum procedit.

Strias \& aures itidem ftriatas, pectinum more, habet at hæ ftriæ adeò minutæ \& creberrimæ funt, ut vifur, minùs certè curiofum penè effugiant; fingulæ ad capillorum minutiem.

Huic aures pro lapidis modo amplæ; is valdè tenuis \& fragilis eft; fublividus, \& inftar Selenitæ ncviter fractus renitet.

Plurimos hujus generis lapides in ripa Lapidofa Rivuli per oppidulum stock regionis montofx Craven dictx tranfcurrentis inveni. Item à Beresford agri Staffordienfis alios habui.

Hunc biforem nondum vidi.

\section{TITULUS LI.}

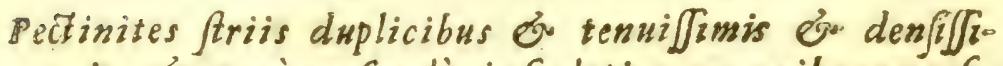
mis, \&u aquè profundè infculptis; ex quibus que $\int_{\varepsilon}-$ cundù lapidis longitudimem prosedunt, ad cardinem, ut in aliis pectinitis fit, non concurrant $; B$ : lice verò tranfver fe fingule ad cardinem Spedtanto. Huic color Jubrufus; fucq; auricule funt. Ex D. Plott Fig. II.Tab. 4 .

N lapidicinis appiduli Heddington agri Oxonienfis repertus eft. 


\section{De Lapidions Bivalvibus:}

C A P. II.

De Lapidibus bivalvibus, friatis, non amritis ; a mes Pectunculitx nominati.

\section{TITULUS LII.}

Pedunculites, denfilsmis \& minùs profundè infculptis farits donatus. An Fig. 3. Tab'4. D. Plott?

I I'C lapis inter mediocres numerandus eft; ei colos fubrufus. Cætera in Titulo expreffi.

Hunc biforem, \& vix integrum hactenus vidi.

In Rivulo juxta Bugthorp inventus eft.

\section{T. IT UL US LIII.}

Pedunculizes cinereus, ftriis ferè ad alteram ?o wertice partem inclinatis.

$$
\text { An Fig. 14, I5, 17. D. Plott? }
$$

L IC lapis mediocribus annumerandus eft ; rard fef11 quiuncialis; paulo magis tamen in longitudinem. patet, qux à vertice ad imum ambitum reputanda eft; ex alterâ ferè parte paulo productior eft, \& in hanc \& ftriæ \& vertex inclinari videntur.

Ipłæ verò ftriæ diftinctè eminent $\&$ modicè denfántur.

Leniter gibbus eft: colore albido: ex tenui materiâ. Selenitæ æxula.

Biforem adhuc nullum vidimus, at biforem effe credi- 
bile eft ex parte productâ; quæ ex parte diverfâ in aliis atq; aliis producitur.

Lochs.

In Lapidicinis è faxo calcario albido juxta Lamonsborough \& Whit woll agri Eboracenfis fat copiosè reperitur.

\section{T IT ULUS LIV.}

Pectunculites albidus, friis admodìm diftinctis \&o elatis, ex uirâas parte gibbus, at cx alterâ paulo planior: è collibus cretaceis.

Discriptio. II I C integer \& admodum elegans lapis eft; modica magnitudinis; fcilicet à vertice ad imum marginem circiter duos digitos colligit; à latere ad latus paulo minor eft.

Ab ipfo vertice paulatim latefcit; ambitu rotundo definit; qui à frequentibus etiam ftriis ibi finitis denticulatur.

Ipfæ ftrix \& crebræ \& multùm eminentes, diftinctiffimæq; ad fummam elegantiam funt. Item funt quædam tranfverfe velut Fafciarum imagines. Ex utraq; parte modicè gibbus eft, at ex alterâ parte paulo depreffior; in quâ parte ipfx etiam ftrix hîc \& illîc rarioribus quibufdam Tuberculis exafperantur.

Ea materia, qux teftam refert, \& tenuis \& albida eft, \& fluoris cujufdam inftar lucida.

In fe complectitur cretam albam.

zocho. In collibus cretaceis juxta Royfton agri Cantabrigienfis inventus elt. 


\section{De Lapidibus Bivalvibus.}

\section{T ITULUS LV.}

pecturculites SubJphericus, è Saxo calcis plambifero.

$F^{X}$ his lapidibus unum, nec illum biforem, ingentis Dfcriptite

1 magnitudinis apud me fervo: at reliqui onnes, quos vidi, mediocribus annumeraridebent; quorum minorum unus in Tabula depictus eft.

Hic verò, qui omnium \& fui \& aliorum generum Cochlitarum bivalvium facilè maximus eft, infantis caput $x$ quat; nimirum à vertice ad imum marginem fenos minimùm digitos implet; à latere verò ad latus, propter figuram rotundam, vix deni digiti circunambiunt. In dorfum maximè eminet, \& in modum orbicularem gibbus eft. Item in illo prægrandi Cochlite, de quo jam loquimur, fingulæ etiam ftriæ, pro lapidis magnitudine, minimum ferè digitum craffitie implerent. At in modicæ magnitudinis lapidibus ftriæ \& minutiores \& minùs eminent.

Ipfe quoq; vertex admodum incurvatur. His color fub. lividus eft.

Ex his maximus juxta Keighley inventus eft : alii aliis in Locis. locis regionis montof Craven dictx in. faxo calcis fublivido plumbiferóq; reperti funt. Item alios habui ex agro Staffordienfi in faxo calcis cinereo,eóq; tamen etiam plum: bifero.

\section{T I T ULUS LVI.}

Pectunculites anomius, cui infignis quedam Lacusa per medium dor fum rect à procedit.

$$
\text { 13. Tab. 3. 6. Tab. 4. D. Plott. }
$$

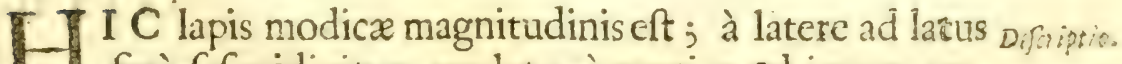

1 ferè fefquidigitum explet; à vertice ad imum am- 
bitum uncialis eft. In dorfum modicè elatus. Medium dorfum profundior quædam lacuna rectà dividit; item ad imam illam lacunam ipfe margo labri cujufdam inftar paulo productior eft. Reliquæe etiam ftriæ ample \& torefe.

Iple vertex ex altera parte paulo anguftior \& aliquanculum roftratus eft; adeóq; inter anomios ponendus eft.

Juxta cervices quafi humeri acuti eminent, ut in pectinitis, fir aures iis demptx effent.

Infignem craffitudinem horum lapidum, quấ parte teftas referunt, fatis mirari nequeo; certè multùm fupra modum omnium viventium Concharum. At his eadem ferè materia, quæ reliquis plerifq; figuratis corporibus, in * Philiofoph. iifdem rupibus inventis, ut Trochitis,de quibus alibi * fusè Tranfact. dict.

D. Oldenburgh tractavi, $f c$. è cujufdam fluoris natura.

4.500. p.618ז.

Ex his innumeros in faxo calcario fublivido, plumbiferóq; quodam oppidulo regionis Craven, stock dicto inveni. Ubi omnes, quantum vidi, fingulares fuerunt.

At ex agro Staffordienfi bifores cinereos habemus; \& ex ipfis liubmarinis rupibus juxta scarborough bifores folidos, pellucidos, \& quafi filiceos ipfe exemi.

Imò unum apud me fervo ex filice propriè fic dicto albo \& non pellucido, quod experimentum de chalybe captım abundè teftatur.

N. B. Reliquis omnibus, exceptis iis, qui jufta stock inventi funt, ifti humeri angulofi deeffe videntur; imò aliquibus \& labrum \& lacuna haud ita confpicua funt; cafdem varietates plurimas in cryftallis quibufcung; obferware licet. 


\section{De Lapidibus Bivalvibns.}

\section{TITULUS LVII.}

Pecunculites anomius trilobus. Concha altera anomita friata tginoBos rarior. I. Fab. Col. * * Depturpisa.
p. 22 .

- U IC lapidi rara admodum Figura eft, \& cui fimilis Dforpiptin. nufquam, quod novi, inter conchas viventes, reperitur; ut autem rara, ita haud inelegans forma eft.

Huic modica magnitudo eft; maximam è multis defcribam; à vertice ad imum ambitum digitalis, at paulo latior eft.

Utraq; valva quafi triloba eft; at inter fe diffimiles; fiquidem è valvis illa, quæ ventricofior, minor eft, eadémq; fub alterius vertice leviter roftrato inferitur : hujus verò minoris media pars multùm protuberat, verfúfq; imum ejus marginem duæ hinc inde lacunæ, in plerifq; $\mathrm{fa}-$ tis depreffex, illam quafi in tres lobos diducere videntur; at ea tamen una eft, quamvìs, ut rectè Fabius Columna, c̀ tribus teftis frmul junctis conftare videtur.

Altera è valvis, cujus vertex roftratus eft, medium lobum in finum amplum depreffum \& paulo productiorem habet : duo autem ejus reliqui lobi \& paulo breviores funt \& admodum eminent. Hâc parte, inquit Fab. Columna hic conchites Aviculam alis expanfis incurvam repræfentare videtur.

Striarum \& modus \& numerus minùs certus eft; fiquidem in aliis pauciores, in aliis crebriores \& minus elatie videntur : in plerifq; margines denticulantur ob ftrias eò ufq; productas \& ibidem profundiùs fulcatas: è contrà verfus verticem eædem ftriæ leviter infculptæ, \& penè ob. literantur.

Ex his alii cruftis Selenitæ cujufdam æmulis conteguntur, glebam aluminofam, aut ferream, aut alterius nefcic 
cujus naturæ terram complexi: alii ex toto folidi, pellucidi, quafi filicei.

Hos lapides bifores integrófq; femper \& ubiq; invenimus. At ex his tamen alii multi ferè plani $\&$ fine lobis funt; alii vix ftriis donati.

Zotis.

Hic lapis in multis Angliæ locis frequens eft : ut in Foffis fabulofis juxta Gunnerby agri Lincolnienfis. Item in faxo plumbifero agri Derbienfis. Item in fubmarinis rupibus aluminofis ad spiton agri Eboracenfis.

\section{T I T ULUS LVIII.}

Pectunculites frivis latiufculis undatis, concham Triodacnam Aldrovandi quodammodo referens. Ex D.Plott Fig. 4 . Tab. 4.

T U N C juxta Grcat Rolwright agri Oxonienfis in argillâ fublividâ; ’̀ quâ conftare videtur: materiâ zamen xneâ refplendente ex parte contegitur.

\section{TIT ULUS LIX.}

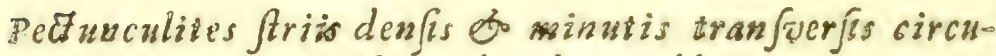
laribus, utraq; valva admodum gibba.

E folido lapide cinereo, quale eft ipfum faxum, è quo exemptus eft.

$$
\text { Ex D. Plott Fig. 5.Tab. 4. }
$$

I IC lapis in Lapidicinis juxta Heddington agri Ox1 onienfis inventus eft. 


\section{Typographorum lapfus fic corige.}

Ag. 8. lin. 9. lage cos,p.25. l. I. adde folii cujufdam, p. 28. l.25. dele verò, p. 29. 6.23 . leg. minimè, tantùm juxtà ovorum, p. $33 . l \cdot 4$. dele quòd, leg. ut, p. 39. l. 9. leg. nimirum; ibid. l. 30. leg. viridia, p. 41. l. 15. leg. tranfverfx, p. 42. l. 6. leg. ipfius, p. 48. l. 3. leg. nudari; ibid. l. 4 . leg. qui, p. I I 2 . leg. ipfum, idem ad p. 136, 137. 125 . 140. p. I1 3. 1. 25 . leg. multiplici, p. 124. 1. 6. leg. hx, p. 132. l. 10. leg. cæruleus, p. 133. 6. 16. leg. clauduntur, p. 141. l. 2 r. leg. conchyliis; 60 . penalt. conchylia, p.155.l. 10. leg. dicta, p. 181. l. 4. leg. expofitum; ibid. l.12. leg.alto, p.194.l.12. leg. pyloride. Pirefat. in Cochlitis ultim. pag. l. 13. leg. affequutus, p. 205. k. ult. leg. craflus.

Et fi quxalia Errata funt, candido Lectori emendanda. permittuntur. 



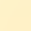






